Florida International University

FIU Digital Commons

FIU Electronic Theses and Dissertations

University Graduate School

$12-3-2018$

\title{
The Effects of Copper Exposure on Fish Locomotion and Predator-Prey Interactions
}

Tiffany N. Yanez

Florida international University, tyane001@fiu.edu

Follow this and additional works at: https://digitalcommons.fiu.edu/etd

Part of the Behavior and Ethology Commons, Laboratory and Basic Science Research Commons, Marine Biology Commons, Other Animal Sciences Commons, and the Toxicology Commons

\section{Recommended Citation}

Yanez, Tiffany N., "The Effects of Copper Exposure on Fish Locomotion and Predator-Prey Interactions" (2018). FIU Electronic Theses and Dissertations. 4065.

https://digitalcommons.fiu.edu/etd/4065

This work is brought to you for free and open access by the University Graduate School at FIU Digital Commons. It has been accepted for inclusion in FIU Electronic Theses and Dissertations by an authorized administrator of FIU Digital Commons. For more information, please contact dcc@fiu.edu. 


\section{FLORIDA INTERNATIONAL UNIVERSITY}

Miami, Florida

THE EFFECTS OF COPPER EXPOSURE ON FISH LOCOMOTION AND

PREDATOR-PREY INTERACTIONS

A thesis submitted in partial fulfillment of the

requirements for the degree of

MASTER OF SCIENCE

in

BIOLOGY

by

Tiffany Yanez Zapata 
To: Dean Michael R. Heithaus

College of Arts, Sciences and Education

This thesis, written by Tiffany Yanez Zapata, and entitled The Effects of Copper Exposure on Fish Locomotion and Predator-Prey Interactions, having been approved in respect to style and intellectual content, is referred to you for judgment.

We have read this thesis and recommend that it be approved.

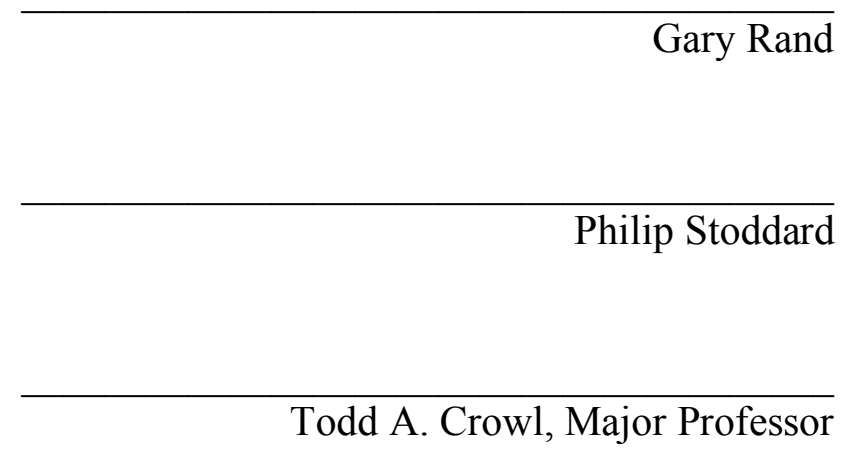

Date of Defense: December 3, 2018

The thesis of Tiffany Yanez Zapata is approved.

Dean Michael R. Heithaus College of Arts, Sciences and Education

Andrés G. Gil Vice President for Research and Economic Development and Dean of the University Graduate School

Florida International University, 2019 


\section{ACKNOWLEDGMENTS}

This research was funded by an NSF Center of Research Excellence in Science and Technology (CREST) award (EH1547798). I would want to thank Dr. Natalia Soares Quinete and Ingrid Ley for their support during this project. I want to give recognition to my advisors Dr. Philip Stoddard, Dr. Gary Rand, and special thanks to Dr. Todd A. Crowl and Dr. Jone Corrales for their patience, support, and guidance. I want to thank my undergraduate research technician Rose Santana and my best friends Robb Evancoe and Claudia Vela for encouraging me every day and believing in me. Finally, I want to dedicate my thesis to my family, especially to James, Tabatha, Iris, Jordan, and Gisella. Because of you, I am where I am today. Gracias por todo familia, esto es por y para ustedes. 


\title{
ABSTRACT OF THE THESIS \\ THE EFFECTS OF COPPER EXPOSURE ON FISH LOCOMOTION AND \\ PREDATOR-PREY INTERACTIONS
}

\author{
by \\ Tiffany Yanez Zapata \\ Florida International University, 2019 \\ Miami, Florida

\section{Professor Todd A. Crowl, Major Professor}

This study determined the effects of the copper water quality criterion (WQC) by the EPA on [1] swimming performance and [2] predator-prey interactions of the Sailfin Molly, across a salinity gradient. Fish acclimated to FW (0 ppt) and 8-ppt saltwater were exposed to 11.3 and $8.44 \mu \mathrm{g} / \mathrm{L} \mathrm{Cu}$ for $96 \mathrm{~h}$, respectively. At the end of the exposures, fish swimming performance was determined by using the critical swimming speed, $U_{\text {crit, }}$, the speed at which a fish cannot longer maintain position in the water column. $U_{\text {crit }}$ was then measured again after a 4-week depuration period to determine if the fish were able to perform as well as control fish. Fish tissues were not analyzed for these experiments; therefore, the 4-week depuration period is hypothetical. In a separate study, mollies were presented with a predator model and isolated chemical cues of predation, then tested for predator avoidance behaviors. Copper exposures had opposite effects on visual and chemical cues. It was found that adverse effects of copper have the potential to harm fish populations. 


\section{TABLE OF CONTENTS}

CHAPTER

PAGE

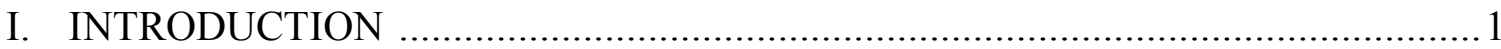

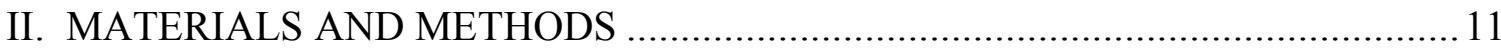

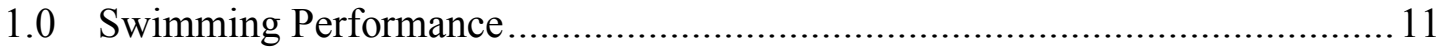

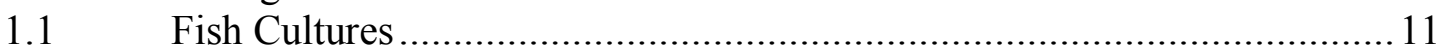

$1.2 \quad$ Experimental Copper Toxicity Studies ...................................................... 13

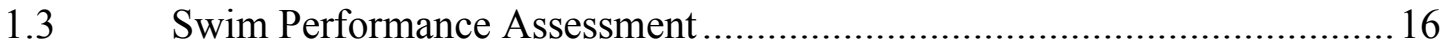

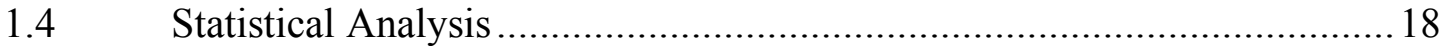

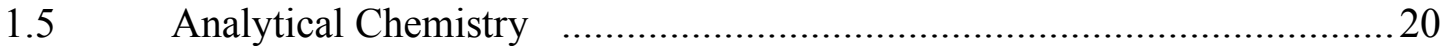



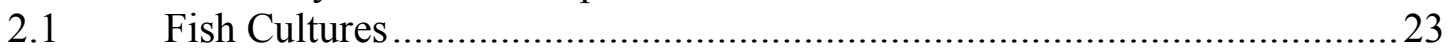

$2.2 \quad$ Experimental Copper Toxicity Studies ……………………………......2

2.3 Predator and Prey Behavior Evaluation ……………………..................26

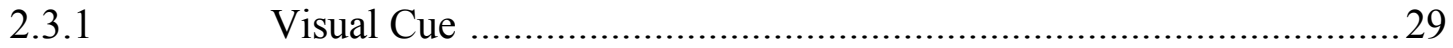

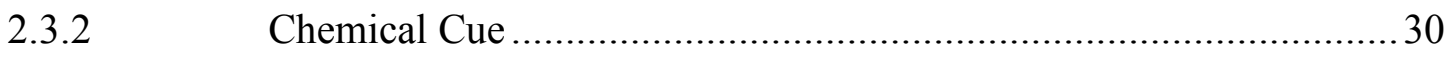

2.3.3 Visual \& Chemical Cues ……………..................................... 31

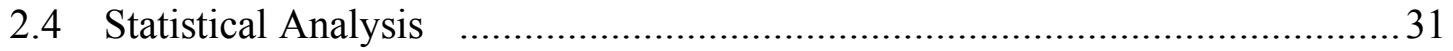

2.5 Analytical Chemistry ............................................................................... 32

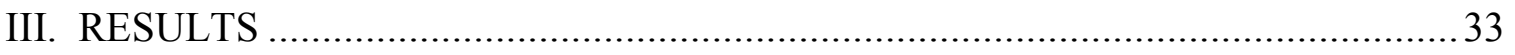

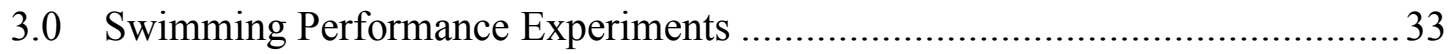

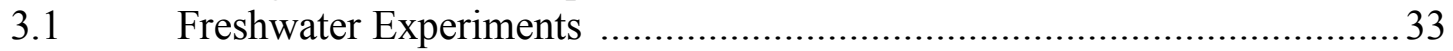

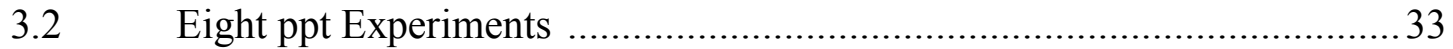

3.3 Swimming Performance: Freshwater VS. 8ppt saline (no-copper) ............34

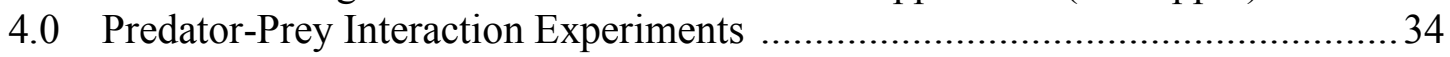

4.1 Response to Predator Exposure ………………….................................35

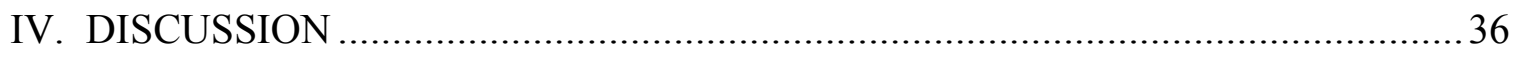

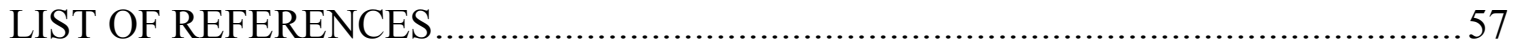




\section{LIST OF TABLES}

TABLE

PAGE

1. Swimming Performance Water Analytical Chemistry ..................................52

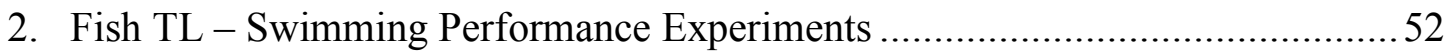

3. Predator-Prey Water Analytical Chemistry................................................53

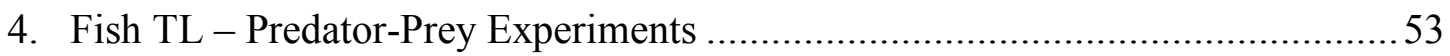

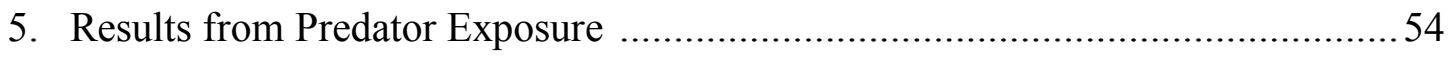

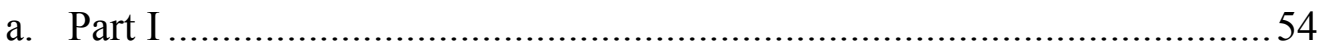

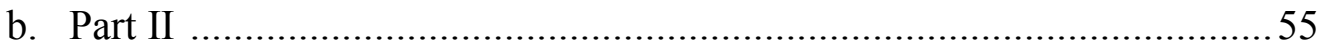

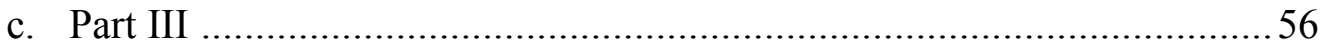

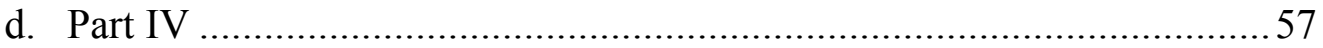




\section{LIST OF FIGURES}

FIGURE

PAGE

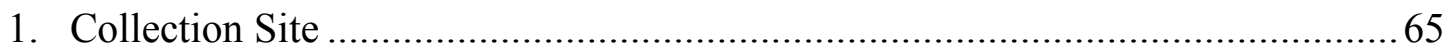

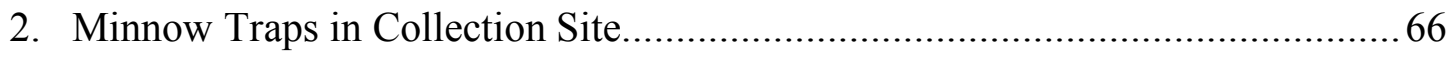

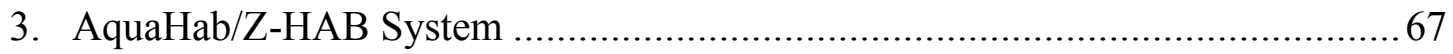

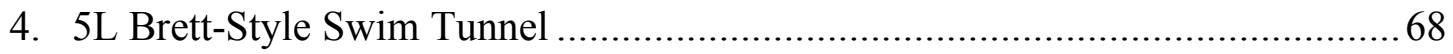

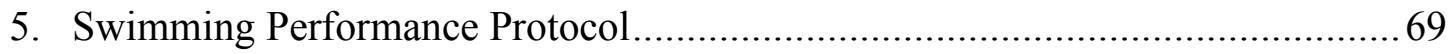

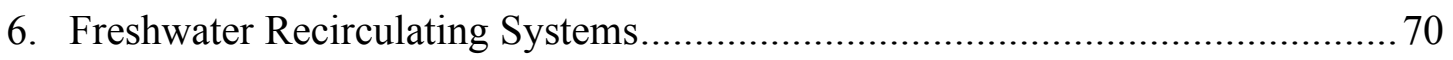

7. Predator-Prey Interaction Experimental Set Up ……........................................ 71

8. Experimental Chamber Covered with a Black-Out Curtain..................................72



10. Visual Cue Experimental Set Up (Trial 2) ..................................................... 74

11. Chemical Cue Experimental Set Up (Trial 2) .................................................. 75

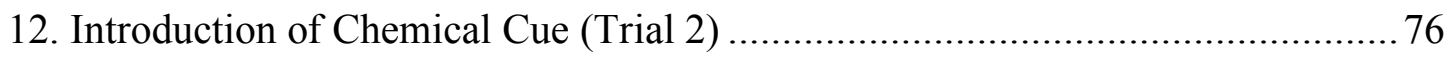

13. Freshwater Swimming Performance Experiment Results.................................... 77

14. 8ppt Salinity Swimming Performance Experiment Results ................................ 78

15. Swimming Performance of Control Fish ......................................................... 79

16. a) Total Distance Travelled (Bl) Before Introduction of Visual Cue ...................8 80

b) Total Distance Travelled (Bl) After Introduction of Visual Cue .....................81

c) Change in Total Distance Travelled (Bl) (Visual Cue) ..................................8 82

17. a) Total Distance Travelled (Bl) Before Introduction of Chemical Cue ...............83 83

b) Total Distance Travelled (Bl) After Introduction of Chemical Cue .................8 84

c) Change in Total Distance Travelled (Bl) (Chemical Cue) ……….................... 85

18. a) Total Distance Travelled (Bl) Before Introduction of Visual \& Chemical Cue

b) Total Distance Travelled (Bl) After Introduction of Visual \& Chemical Cue

c) Change in Total Distance Travelled (Bl) (Visual \& Chemical Cue) ................ 88 
19. a) Mean Velocity (B1/s) Before Introduction of Visual Cue .................................8 89

b) Mean Velocity (Bl/s) After Introduction of Visual Cue ..................................99

c) Change in Mean Velocity (Bl/s) (Visual Cue) .............................................. 91

20. a) Mean Velocity (B1/s) Before Introduction of Chemical Cue ...........................92

b) Mean Velocity (Bl/s) After Introduction of Chemical Cue .............................99

c) Change in Mean Velocity (B1/s) (Chemical Cue) .........................................99

21. a) Mean Velocity (B1/s) Before Introduction of Visual \& Chemical Cue .............95

b) Mean Velocity (Bl/s) After Introduction of Visual \& Chemical Cue ...............96

c) Change in Mean Velocity (Bl/s) (Visual \& Chemical Cue) .............................97

22. a) Time Spent Freezing (sec) Before Introduction of Visual Cue.........................98

b) Time Spent Freezing (sec) After Introduction of Visual Cue ...........................99

c) Change Time Spent Freezing (sec) (Visual Cue) ......................................... 100

23. a) Time Spent Freezing (sec) Before Introduction of Chemical Cue .................. 101

b) Time Spent Freezing (sec) After Introduction of Chemical Cue .................... 102

c) Change Time Spent Freezing (sec) (Chemical Cue) ..................................... 103

24. a) Time Spent Freezing (sec) Before Introduction of Visual \& Chemical Cue .. 104

b) Time Spent Freezing (sec) After Introduction of Visual \& Chemical Cue .... 105

c) Change Time Spent Freezing (sec) (Visual \& Chemical Cue) ....................... 106

25. a) Time Spent Cruising (sec) Before Introduction of Visual Cue ....................... 107

b) Time Spent Cruising (sec) After Introduction of Visual Cue ......................... 108

c) Change Time Spent Cruising (sec) (Visual Cue) .......................................... 109

26. a) Time Spent Cruising (sec) Before Introduction of Chemical Cue ................. 110

b) Time Spent Cruising (sec) After Introduction of Chemical Cue..................... 111

c) Change Time Spent Cruising (sec) (Chemical Cue) .................................... 112

27. a) Time Spent Cruising (sec) Before Introduction of Visual \& Chemical Cue .. 113

b) Time Spent Cruising (sec) After Introduction of Visual \& Chemical Cue..... 114

c) Change Time Spent Cruising (sec) (Visual \& Chemical Cue) ....................... 115

28. a) Time Spent Bursting (sec) Before Introduction of Visual Cue .......................116

b) Time Spent Bursting (sec) After Introduction of Visual Cue ......................... 117

c) Change Time Spent Bursting (sec) (Visual Cue) ......................................... 118

29. a) Time Spent Bursting (sec) Before Introduction of Chemical Cue ................. 119

b) Time Spent Bursting (sec) After Introduction of Chemical Cue...................... 120

c) Change Time Spent Bursting (sec) (Chemical Cue) .................................... 121

30. a) Time Spent Bursting (sec) Before Introduction of Visual \& Chemical Cue .. 122

b) Time Spent Bursting (sec) After Introduction of Visual \& Chemical Cue..... 123

c) Change Time Spent Bursting (sec) (Visual \& Chemical Cue) ....................... 124 
31. a) Number of Times Prey Entered Predator Zone Before Introduction of Visual Cue

b) Number of Times Prey Entered Predator Zone After Introduction of Visual Cue 126

c) Change in Number of Times Prey Entered Predator Zone (Visual Cue) ....... 127

32. a) Number of Times Prey Entered Predator Zone Before Introduction of Chemical Cue 128

b) Number of Times Prey Entered Predator Zone After Introduction of Chemical Cue

c) Change in Number of Times Prey Entered Predator Zone (Chemical Cue) .. 130

33. a) Number of Times Prey Entered Predator Zone Before Introduction of Visual \& Chemical Cue

b) Number of Times Prey Entered Predator Zone After Introduction of Visual \& Chemical Cue

c) Change in Number of Times Prey Entered Predator Zone

(Visual \& Chemical Cue)

34. a) Time Spent (Sec) in Predator Zone Before Introduction of Visual Cue

b) Time Spent (Sec) in Predator Zone After Introduction of Visual Cue 135

c) Change in Time Spent ( $\mathrm{Sec}$ ) in Predator Zone (Visual Cue) 136

35. a) Time Spent (Sec) in Predator Zone Before Introduction of Chemical Cue .... 137

b) Time Spent (Sec) in Predator Zone After Introduction of Chemical Cue ...... 138

c) Change in Time Spent (Sec) in Predator Zone (Chemical Cue) 139

36. a) Time Spent ( $\mathrm{Sec}$ ) in Predator Zone Before Introduction of Visual \& Chemical Cue 140

b) Time Spent ( $\mathrm{Sec}$ ) in Predator Zone After Introduction of Visual \& Chemical Cue 141

c) Change in Time Spent (Sec) in Predator Zone (Visual \& Chemical Cue) ..... 142

37. a) Latency to First (sec) Before Introduction of Visual Cue

b) Latency to First (sec) After Introduction of Visual Cue. 144

c) Latency to First (sec) (Visual Cue) 145

38. a) Latency to First (sec) Before Introduction of Chemical Cue 146

b) Latency to First (sec) After Introduction of Chemical Cue 147

c) Change in Latency to First (sec) (Chemical Cue) 148

39. a) Latency to First ( $\mathrm{sec}$ ) Before Introduction of Visual \& Chemical Cue 149

b) Latency to First (sec) After Introduction of Visual \& Chemical Cue . 150

c) Change in Latency to First (sec) (Visual \& Chemical Cue) 151 
40. a) Max Distance (B1) from Predator Zone Before Introduction of Visual Cue... 152

b) Max Distance (B1) from Predator Zone After Introduction of Visual Cue..... 153

c) Change in Max Distance (Bl) from Predator Zone (Visual Cue).................. 154

41. a) Max Distance (Bl) from Predator Zone Before Introduction of

Chemical Cue

b) Max Distance (B1) from Predator Zone After Introduction of

Chemical Cue

c) Change in Max Distance (Bl) from Predator Zone (Chemical Cue)

42. a) Max Distance (B1) from Predator Zone Before Introduction of Visual

\& Chemical Cue ....

b) Max Distance (Bl) from Predator Zone After Introduction of Visual

\& Chemical Cue

c) Change in Max Distance (B1) from Predator Zone (Visual \& Chemical Cue)

43. a) Mean Distance (Bl) from Predator Zone Before Introduction of

Visual Cue 161

b) Mean Distance (Bl) from Predator Zone After Introduction of Visual Cue ... 162

c) Change in Mean Distance (Bl) from Predator Zone (Visual Cue) 163

44. a) Mean Distance (B1) from Predator Zone Before Introduction of Chemical Cue 164

b) Mean Distance (Bl) from Predator Zone After Introduction of Chemical Cue 165

c) Change in Mean Distance (Bl) from Predator Zone (Chemical Cue). 166

45. a) Mean Distance (Bl) from Predator Zone Before Introduction of Visual \& Chemical Cue 167

b) Mean Distance (Bl) from Predator Zone After Introduction of Visual \& Chemical Cue 168

c) Change in Mean Distance (Bl) from Predator Zone

(Visual \& Chemical Cue) 


\section{INTRODUCTION}

In the last six to seven decades, significant amounts of polycyclic aromatic hydrocarbons, pesticides, fertilizers, and trace metals have been introduced into Florida waters, raising environmental concerns (Li et al., 2015; Yang et al., 2013). Important ecosystems in South Florida such as the Everglades and Florida Bay have been greatly affected by large inputs of these chemicals, especially trace metals (Li et al., 2015; Caccia and Millero, 2003). One of the metals that raises particular concern is copper $(\mathrm{Cu})$, which at typical background concentrations can be beneficial for biochemical and physiological processes, but at high concentrations can be detrimental to organisms (Tchounwou et al., 2008). Copper was first introduced in the 1900s for its algaecide and fungicide properties and has been used over the last 50 years as an essential minor element in citrus agriculture (Hoang et al., 2011; Hoang et al., 2009). In 2005, over 250,000 hectares of grapefruit, orange, tangelo, and tangerine temple crops in Florida were treated with more than 500,000 kg of copper (U.S. DA 2006; Schuler et al., 2008). Moreover, in 2007, copper was ranked as one of the top metals accountable for the decrease in water quality across U.S. water bodies by the U.S. Environmental Protection Agency (USEPA) (Schuler et al., 2008).

As a result of the large use of copper in Florida, and its inability to degrade, copper has accumulated in the soils and water, raising concern for the Florida ecosystem and its biota (Hoang et al., 2011). Numerous research studies have concluded that copper in high concentrations harms aquatic organisms (Ward 2013, Heydarnejad et al., 2013, Vergolyas et al., 2010). For example, exposure to copper has been found to impair neurotransmitter and chemosensory functions of fish as well as their capability to 
counteract and detoxify excessive copper concentrations, lowering survival and fitness (Ward 2013, Vieira et al., 2009). Copper has also been found to increase levels of glucose and cholesterol in the blood due to renal injury and liver damage (Heydarnejad et al., 2013), as well as to cause metal accumulation and abnormalities in fish tissues (Javed, 2012; Sampaio et al., 2010; Vergolyas et al., 2010; Bielmyer et al., 2005). Lastly, copper can impair health and reduce growth by affecting fish appetite, consumption, and assimilation of nutrients (Damasceno et al., 2016; Hassan et al., 2015; Javed, 2015; Heydarnejad et al., 2013; Javed, 2012, Mohseni et al., 2012).

Fish can regulate the amount of copper in their system using the metal-binding protein Metallothionein (Abril et al., 2018). Effectiveness of internal copper regulation mechanisms can determine the amount of time a fish requires to detoxify after copper exposure and whether a fish can ever return to normal performance after acute exposure to copper.

Copper tends to be more toxic to organisms in freshwater than in saltwater because freshwater lacks cations, though not always (Kiaune \& Singhasemanon, 2011). Grosell et al. (2007) studied Killifish (Fundulus heteroclitus) and their response (e.g., mortality) to copper at different salinities and found these species were most tolerant of copper at intermediate salinities. The authors suggested that the results could be explained by changes in fish physiology (Grosell et al., 2007). Blanchard and Grossell (2005) discovered that Killifish accumulated the most copper in the liver and gills when they were exposed to low salinities and in the intestines when they were exposed to high salinities, but overall Killifish accumulated the most whole-body copper at low salinities. 
Copper toxicity varies depending on the ambient chemistry of the water. The free ionic form $\left(\mathrm{Cu}^{2+}\right)$ is what is most bioavailable and the most toxic. The U.S. EPA established the water quality criterion (WQC) for copper using dissolved metal concentrations since it approximates the toxic fraction of the total metal (EPA 2007). The WQC is the maximum dissolved concentration of a metal, in this case, copper, that can be present and bioavailable in water without causing acute and chronic toxicity to aquatic life (EPA, 2007). The U.S. EPA on its last revision of copper toxicity in freshwater systems in 2007 “Aquatic Life Ambient Freshwater Quality Criteria - Copper" suggests using the Biotic Ligand Model (BLM) instead of the Hardness Equation (HE). The difference between the BLM and HE is that the HE uses an empirical relationship between toxicity and water hardness, and does not take into consideration nine individual water parameters that the BLM does: alkalinity, temperature, dissolved organic carbon (DOC), dissolved inorganic carbon (DIC), and other major geochemical anions (chloride, sulfate).

While both the BLM and HE explain how water parameters can modify the bioavailability of the metal, the BLM offers a more precise estimation on the influence of water chemistry. Mortality in fish occurs when the biotic ligand complex achieves unfavorable concentrations of the metal (EPA, 2007). Biotic ligands in fish can be found on the gills and assist in the regulation of ions between the body and surroundings. Two mechanisms determine the amount of $\mathrm{Cu}^{2+}$ that effectively binds to the gills, thus determining copper toxicity to the fish. The first mechanism is the competition between $\mathrm{Cu}^{2+}$ with other cations such as $\mathrm{Mg}^{2+}, \mathrm{Ca}^{2+}, \mathrm{H}^{+}$found in solution. The more competing cations in the water (e.g., the higher the hardness), the less $\mathrm{Cu}^{2+}$ will bind to the biotic 
ligands on the fish, thus, the less toxicity to the fish. The second mechanism refers to the competition between anions $\left(\mathrm{Cl}^{-}, \mathrm{HCO}_{3}{ }^{-} \mathrm{CO}_{3}{ }^{2-}\right)$ and dissolved organic matter (DOM), also found in solution and the biotic ligands found on the gills. The more competing anions and DOC, the less bioavailable $\mathrm{Cu}^{2+}$ in solution that can bind to the biotic ligands (Di Toro 2001).

In 2016, the U.S. EPA decided that many of the concepts and conditions of the freshwater BLM could be applied to estuarine and marine waters, with some exceptions, resulting in the "Draft Aquatic Life Ambient Estuarine/Marine Water Quality Criteria for Copper-2016" (USEPA, 2016). The document divides the WQC into Criterion Maximum Concentration - CMC $(\mu \mathrm{g} / \mathrm{L})$ and Criterion Continuous concentration - CCC $(\mu \mathrm{g} / \mathrm{L})$ depending on the length of the exposure, acute or chronic. The document cites research that supports the U.S. EPA's saltwater BLM, in which polychaete worms and rotifers were more affected by $\mathrm{Cu}$ as salinity decreased.

The U.S. EPA follows a set of calculations to derive the established WQC for both freshwater and saltwater systems. For hardness-dependent metals such as copper, LC50 (the concentration in the water that kills $50 \%$ of the population) at various hardness values (e.g., alkalinity, pH, and dissolved oxygen) are normalized for each species tested. The normalized values for each subject species are averaged to find the Species Mean Acute Values (SMAVs) at the reference hardness. Then, the SMAVs of each genus are averaged to obtain the Genus Mean Acute Values (GMAVs). The U.S. EPA follows a specific guideline procedure to calculate the $5^{\text {th }}$ percentile of the GMAVs, which are then used to obtain the Final Acute Value (FAV) at the reference hardness. Final acute values for other hardness values (not the reference hardness) are then derived by using the 
hardness regression slope. Finally, to calculate CMC, FAV is divided by 2, and to calculate CCC, FAV is divided by the Final Acute - Chronic Ration (FACR).

The U.S. EPA WQC protects aquatic life from concentrations that can cause death, but this criterion does not protect again sublethal effects that may lead indirectly to mortality by hindering locomotion, sensory, or cognitive abilities. Swimming performance is an excellent metric to study sub-lethal effects because changes in locomotion can be affected at low copper concentrations before causing death (Oufiero and Garland, 2009). Locomotion impairment promotes mortality indirectly through increased predation. Critical swimming speed ( $\mathrm{U}_{\text {crit }}$ is the speed at which the fish cannot maintain their position against flowing water. Determination of $U_{\text {crit }}$ is an objective method to evaluate the capability and health of a live fish, a more ecologically sensitive and relevant method than examining the organs of the fish independently (Tierney and Farrel, 2004). Effects of copper on swimming performance are useful to understand because reduction in the ability to conduct essential daily activities such as finding quality mates and food, as well as escaping from predators would lower fitness of existing fish populations and the probability of establishing new populations (Oufiero and Garland, 2009; Vieira et al., 2009).

Understanding copper toxicity at different salinities gains importance in the face of increasing saltwater intrusion from sea level rise. Studies have found that salinity alone can affect swimming performance (Chatelier et al., 2004; Kolok and Sharkey 1997; McKenzie et al., 2001). However, contradictory hypotheses and explanations have been posed regarding the effects of copper on fish at different salinities. Our ability to predict 
how salinity and copper will interact to affect swimming performance will hinge on new research filling this gap in our understanding.

Most of the research related to swimming performance has centered on studying large fish species of commercial importance; however, less attention has been given to small euryhaline species at low trophic levels, i.e., lower on the food chain, that constitute the prey base for larger predatory fish species of commercial and recreational importance. No published research has investigated the effects of copper on the swimming and sensory performance of small poeciliid fish at different salinities.

Locomotion impairment such as changes in swimming performance could promote mortality indirectly through increased predation. Therefore, it is pivotal to know to what extent that copper can affect behavioral and sensory abilities since copper could also inhibit predator avoidance behavior and together have a synergistic effect on fish fitness. Copper has been labeled as an info-disruptor because it alters the sensory inputs that alert and inform an animal about its surroundings (McIntyre et al., 2012). Therefore, copper-exposed fish can respond inaccurately or fail to respond at all to cues provided by close predators, possible mates, or food, hindering survival, reproduction, and growth (McIntyre et al., 2012). There is evidence that suggests that pollutants such as copper weaken the fear experienced by the prey, increasing the consumptive effects of the predator (Kwan, et al., 2015). The reduction in fear could be caused by copper interfering with the olfactory system of fish. Olfactory receptor neurons are always exposed to the water and therefore in proximate contact with dissolved copper. Studies have found that olfactory receptor neurons in the olfactory epithelium and olfactory bulb of Coho Salmon (Oncorhynchus kisutch) exposed to copper at concentrations below $20 \mu \mathrm{g} / \mathrm{L}$, were 
rendered reversibly insensitive to odorants in a concentration-dependent manner (Baldwin et al., 2003). Similar results have been found for the mechanosensory receptor neurons found in the lateral line of fish, which could have an effect on predator avoidance, migration, and schooling of fish (Linbo et al., 2006). As an example, during predation trials, McIntyre et al., (2012) found that the predatory Cutthroat Trout (Oncorhynchus clarkii) were more efficient at hunting copper-exposed juvenile Coho Salmon than unexposed controls.

Prey fish perceive a mix of chemical and visual cues when in close proximity to a predator. Fish predators release chemical cues, such as kairomones which alarm prey fish, altering their physiology and behavior. Alert signals trigger predator avoidance behaviors such as a decrease in activity (e.g., freezing) to avoid being noticed by visual predators such as birds and piscivorous fish that watch for prey movements (Martel and Dill, 1995). A number of studies have shown the importance of chemical alarm-cue responsiveness in prey fish (Beyers and Farmer, 2001) and the direct relationship to survival (Chivers et al., 2002; McIntyre et al., 2012). Even though chemical cues can provide accurate information about the presence of predators, their reliability can be reduced by distortion from water currents, providing inaccurate spatial and temporal information. Water chemistry can also affect chemical cues; for example, $\mathrm{pH}$ influences efficacy of response to visual cues (Elvidge et al. 2013). The spatial and temporal reliability of visual cues comes in handy when chemical cues are disrupted by turbulence, but can often be risky since visual detection in water happens at close proximity (Stephenson, 2016). In the field, fish are often exposed to both cues simultaneously, providing more information than either visual or chemical cues in isolation. While studies 
have investigated the effect of copper on the olfactory system and lateral line mechanoreceptors, no one has investigated the effect of copper exposure on fish visual systems.

For this study, I sought a fish species that was not sensitive to a salinity gradient, to avoid possibly masking the effects of copper in the swimming performance. Therefore, the test organism chosen to study the sublethal effects of copper exposures was the Sailfin Molly, Poecilia latipinna, a euryhaline species. Nordlie et al., (1992) discovered that when these fish were acclimated to freshwater conditions, they were able to tolerate up to $70 \mathrm{ppt}$ salinity without significantly changing their plasma osmotic concentrations.

Sailfin mollies are native to coastal areas of the Gulf of Mexico and Atlantic Ocean including Florida. They are mostly found where green algae grow, such as mangroves, since algae is their primary food (Sanchez and Trexler, 2018). Their algaerich diet also makes this fish a good model organism, since copper is frequently used to kill algae. To study the effects of copper on predator-prey interactions, I chose Largemouth Bass (Micropterus salmoides) as my predator because this species is also a Florida native and it has been found to co-exist with Sailfin Mollies (Fry et al., 1999). Largemouth Bass are also considered natural predator of Sailfin Mollies (Florida Museum website) and have been used together in digestion rate and food consumption studies (Hunt, 1960).

The first objective of this study was to investigate the effects of a 96-hour sublethal copper exposure on the swimming performance of sailfin mollies acclimated to freshwater or to brackish water at 8 ppt salinity. The second objective was to determine whether mollies were able to recover from copper exposure after a depuration period of 
four weeks. On the basis of previously published research and previous screening studies I hypothesized:

$\mathbf{H}_{1}$ : The swimming performance of freshwater acclimated sailfin mollies will be reduced after being exposed to 96 hours of the hardness-based U.S. EPA copper water quality criterion.

$\mathbf{H}_{2}$ : The swimming performance of 8 ppt salinity-acclimated sailfin mollies will not be reduced after being exposed to 96 hours of the BLM-based U.S. EPA copper water quality criterion (i.e., salinity will protect against copper toxicity).

H3: Freshwater-acclimated sailfin mollies exposed to 96 hours of the U.S. EPA copper water quality criterion will be able to recover after a 4-week depuration period.

H4: Sailfin mollies acclimated to 8 ppt salinity will show a higher critical swimming speed than sailfin mollies acclimated to freshwater conditions, in the absence of any copper exposure.

The third objective of this study was to study the effects of a $96 \mathrm{~h}$ sublethal copper exposure on the predator avoidance behavior of sailfin mollies when presented with chemical and visual cues in isolation, and combined chemical and visual cues from Largemouth Bass. All these experiments were performed in freshwater only. In order to examine how copper may affect predator avoidance and increase predation from coppercontaminated fish, I recorded 10 metrics of behavior: Total Distance Travelled (measured in body length (Bl)), Mean Velocity ((B1/s), Time Spent Freezing (sec), Time Spent Cruising (sec), Time Spent Bursting (sec), Times Prey Entered Predator Zone, Time Prey Spent in Predator Zone (sec), Latency to enter Predator Zone, Maximum Distance from 
Predator Zone (Bl), Mean Distance from Predator Zone (BL). On the basis of previously published research and previous screening studies I hypothesized:

H5: $_{5}$ Copper-exposed fish will travel more distance than control fish when exposed to chemical and visual predator cues in isolation or both cues simultaneously.

H6: Copper-exposed fish will swim slower than control fish when exposed to chemical and visual cues in isolation or both cues simultaneously.

$\mathbf{H}_{7}$ : Copper-exposed fish will spend less time freezing than control fish when exposed to chemical and visual cues in isolation or both cues simultaneously.

$\mathbf{H}_{8}$ : Copper-exposed fish will spend more time cruising than control fish when exposed to chemical and visual cues in isolation or both cues simultaneously.

H9: Copper-exposed fish will spend more time in burst swimming than control fish when exposed to chemical and visual cues in isolation or both cues simultaneously.

$\mathbf{H}_{10}$ Copper-exposed fish will enter the predator zone more frequently than control fish when exposed to chemical cues and visual cues in isolation or both cues simultaneously. $\mathbf{H}_{11}$ : Copper-exposed fish will spend more time in the predator zone than control fish when exposed to chemical and visual cues in isolation or both cues simultaneously. $\mathbf{H}_{12}$ : Copper-exposed fish will take less time to enter the predator zone than control fish when exposed to chemical and visual cues in isolation or both cues simultaneously. $\mathbf{H}_{13}$ : The maximum distance between the copper-exposed fish and the predator zone will be less than the maximum distance between the control fish and the predator zone when mollies are exposed to chemical and visual cues in isolation or both cues simultaneously. 
$\mathbf{H}_{14}$ : The mean distance between the copper-exposed fish and the predator zone will be less than the mean distance between the control fish and the predator zone when mollies are exposed to chemical and visual cues in isolation or both cues simultaneously.

\section{MATERIALS AND METHODS}

\section{Swimming Performance}

\subsection{Fish Cultures}

Sailfin mollies ( $P$. latipinna) were collected in culverts under the roads at Matheson Hammock County Park in Coral Gables, FL $\left(25.6792^{\circ} \mathrm{N}, 89.2566^{\circ} \mathrm{W}\right)$ (Fig. 1). The park is characterized by its broad coast filled with mangroves that meet the ocean creating estuarine environments that host life for intertidal species, such as sailfin mollies. Fish were caught using minnow traps baited with commercial cat food (Fig. 2). Minnow traps were left for an average of 3-5 $\mathrm{h}$ underwater and collected on the same day. Before transporting the fish to the Ecotoxicology and Risk Assessment Laboratory at Florida International University, fish were identified and bycatch species were returned to the wild. The dissolved oxygen (DO) in the culverts was always lower than $5 \mathrm{mg} / \mathrm{L}$. Salinity was 3-30 ppt, varying from week to week depending on the intensity of tides and rain. Sailfin mollies were transported in 5 gal buckets filled with water from the site of collection and oxygenated with air stones and a battery-powered air pump. During transport, the water in the buckets was constantly tested to measured water quality parameters with a DO/Salinity/Conductivity/Temperature meter (Pro 2030, YSI, Ohio, USA) to assure optimal water conditions.

Once in the laboratory, air stones were placed in the buckets and the temperature was slowly adjusted until the water reached $25^{\circ} \mathrm{C} \pm 1$. When salinity was high $(>10 \mathrm{ppt}$ 
salinity), droplets of freshwater were added to reduce the salinity by a maximum of $2 \mathrm{ppt}$ to minimize additional stress. Fish were then transferred from the buckets to quarantine tanks for a minimum of a week to ensure they were healthy. Every two days, $50-70 \%$ of the water in each glass tank was removed and replaced with freshly prepared oxygensaturated freshwater to lower the salinity by $2 \mathrm{ppt}$ with every water change. Once the water reached the desired salinity for experiments, fish were allowed to acclimate for two days and then placed in permanent tanks. The final salinity was 0 ppt or 8ppt, depending on the experiment or treatment.

During acclimation, fish were kept at a density of 2 fish (one female, one male) per 2 liters in recirculating AquaHab/Z-HAB systems (Pentair Aquatic Eco-Systems, Inc., Apopka, FL, USA) at $25 \pm 1^{\circ} \mathrm{C}$, in a $16: 8$ light-dark cycle (Fig. 3). Fish were acclimated for a minimum of two months before the start of various experiments. One group of fish was maintained in freshwater (pH: $7.5-8.5, \mathrm{DO}>6.5 \mathrm{mg} / \mathrm{L})$ and the other group was maintained in 8 ppt salinity (pH: $7.5-8.5$; DO $>6.5 \mathrm{mg} / \mathrm{L}$ ), which was prepared by mixing freshwater and saltwater. Freshwater in the laboratory is obtained from municipal water provided by the City of North Miami. City water was passed through mechanical and carbon filtration and finally through UV sterilization (EVOQUA Water Technologies, Georgia, USA). Saltwater (SW) was obtained from an underwater well and went through the same filtration and sterilization processes as the freshwater (FW).

Sailfin mollies were fed ad libitum once daily with Zeigler Aquatox Flakes (Zeigler Bros., Inc. Gardners, PA, USA). Every day, holding water was measured with DO/Salinity/Conductivity/Temperature YSI Pro 2030 meter and Fisher Scientific $\mathrm{pH}$ 
AP125 meter to assure optimal water conditions. Ammonia, nitrite, and nitrates were measured weekly. If parameters were out of range, $50-60 \%$ of the water was changed. All meters were calibrated prior to measuring by following the company's standard calibration protocol. All culture and experimental conditions followed Institutional Animal Care and Use Committee protocols approved at Florida International University (Reference numbers: 200789, 200853, 200858).

\subsection{Experimental Copper Toxicity Studies}

For the experiments containing only fish acclimated to freshwater conditions, moderately hard water was prepared $\left(80-100 \mathrm{CaCO}_{3} \mathrm{mg} / \mathrm{L}\right.$ hardness; $54-62 \mathrm{CaCO}_{3} \mathrm{mg} / \mathrm{L}$ alkalinity) as suggested by the standard testing protocol used by the U.S. EPA for aquatic toxicity testing (EPA-821-R-02-012, 2002). To prepare mod-hard water, 381 deionized (DI) water (EVOQUA Water Technologies, Georgia, USA) were mixed with $3.80 \mathrm{~g}$ $\mathrm{NaHCO}_{3}$ (Fisher Scientific, PA, USA), 2.4g MgSO 4 (Fisher Scientific, NJ, USA), and $0.16 \mathrm{~g} \mathrm{KCl}$ (Fisher Scientific, NJ, USA), and left to aerate for 24 hours. Separately, 21 of DI water were mixed with $2.40 \mathrm{~g}$ of $\mathrm{CaSO}_{4} 2 \mathrm{H}_{2} \mathrm{O}$ (ACROS Organics, NJ, USA) and left on a stirring plate also for $24 \mathrm{~h}$. After $24 \mathrm{~h}$, both the freshwater and DI water were combined and once mixed the following parameters were measured: alkalinity, hardness and $\mathrm{pH}$. For the experiments containing only fish acclimated to eight ppt, synthetic saltwater was prepared also as suggested by the U.S. EPA. Dionized water was mixed with artificial saltwater (Instant Ocean Sea Salt, Virginia, USA) to a salinity of eight ppt and left to aerate for 24 hours. The next day, the water was filtered with a $50 \mu \mathrm{M}$ followed by a 45 $\mu \mathrm{M}$ filter to assure that no large particles were present in the water that could bind to copper. 
A stock solution of copper $(0.5 \mathrm{mg} / \mathrm{L})$ was prepared 1-2 days before the start of the first experiment. The stock solution lasted for 2 weeks and was kept in a dark amber $1 \mathrm{~L}$ bottle at $4{ }^{\circ} \mathrm{C}$. Immediately before the start of each $96 \mathrm{~h}$ acute experiment, the $\mathrm{Cu}$ exposure solution was prepared at 11.3 dissolved $\mathrm{Cu} \mu \mathrm{g} / \mathrm{L}$ for the freshwater experiments and at 8.4 dissolved $\mathrm{Cu} \mu \mathrm{g} / \mathrm{L}$ for the 8 ppt estuarine water experiments. To create the first concentration (Freshwater experiments), $1830 \mu \mathrm{L}$ of the stock solution was added to a $4 \mathrm{~L}$ Type A volumetric flask and filled with the mod-hard water twice. Then, the water was placed in an acid-washed black plastic bucket. For the second concentration (8 ppt experiments), $1360 \mu \mathrm{L}$ of the stock solution was added to a 4L Type A volumetric flask of and filled with prepared synthetic salt water twice. Then, the water was placed in an acid-washed black plastic bucket.

The concentrations selected for these experiments were derived from the latest drafts released by the U.S. EPA (1) Aquatic Life Ambient Freshwater Criteria for Copper - 2007 2) Aquatic Life Ambient Estuarine/Marine Criteria for Copper - 2016. The U.S. EPA bases the WQC for $\mathrm{Cu}$ in freshwater on the Hardness Equation and the BLM. The concentration provided by the Hardness equation instead of the BLM was selected for my work because the latter took into consideration Dissolved Organic Carbon (DOC) and I did not have a way of measuring DOC directly. The hardness equation took into consideration two parameters that I could regulate, $80 \mathrm{CaCO}_{3} \mathrm{mg} / \mathrm{L}$ and a $\mathrm{pH}$ of 7.5. Following Appendix G, the U.S. EPA considers $11.3 \mu \mathrm{g} \mathrm{Cu} / \mathrm{L}$ to be a non-lethal acute concentration for freshwater species (USEPA, 2007). The U.S. EPA bases the WQC for $\mathrm{Cu}$ in estuarine systems on the BLM. Appendix Table I-1 from the "Draft Aquatic Life Ambient Estuarine/Marine Quality Criteria-2016" provided the Criterion Maximum 
Concentration $(\mathrm{CMC} \mu \mathrm{g} / \mathrm{L})$ for a salinity of $5 \mathrm{ppt}$ and a salinity of $10 \mathrm{ppt}$. The concentration provided by the BLM in Appendix Table I-1 took DOC into consideration, and since I did not have this information, I took the median of the $\mathrm{CMC}$ at $5 \mathrm{ppt}$ salinity and the median at $8 \mathrm{ppt}$ salinity which gave me the concentration of $8.4 \mu \mathrm{g} / \mathrm{L}$ dissolved copper.

Before the start of each experiment, all solutions were titrated to $\mathrm{pH} 7.5$ by carefully bubbling carbon dioxide into the water. General water chemistry measurements (e.g., alkalinity, hardness, dissolved oxygen, temperature, conductivity) were monitored at hour 0,48 , and 96 . Before introducing the fish to the eight $\mathrm{L}$ black plastic bucket, fish were fed, and after $2 \mathrm{~h}$ netted and placed in a circular chamber with one $\mathrm{L}$ of holding water and $0.016 \mathrm{~g} \mathrm{MS}-222$ buffered with $0.032 \mathrm{~g} \mathrm{CaCO}_{3}$ to anesthetize the fish. Only males were subjects in the swimming performance experiments since preliminary studies showed that pregnant females introduced considerable variability to the results. Once the fish was slightly sedated, I measured with calipers the total length in $\mathrm{cm}$ (TL), standard length in $\mathrm{cm}(\mathrm{SL})$, width in $\mathrm{cm}(\mathrm{W})$, depth in $\mathrm{cm}(\mathrm{D})$, and used a Mettler Toledo Balance AG135 to weight the fish in grams (We). Fish TL varied from 3-5 cm; if fish were outside of range, they were excluded from the experiment. Once the fish was placed in the bucket, it was not fed until hour 48. The exposure buckets were kept in an incubator for 96 hours under a $16 \mathrm{~h}$ light: $8 \mathrm{~h}$ dark cycle. The temperature was set to $25^{\circ} \mathrm{C} \pm 1$ and all buckets were covered but not sealed with a clear plastic rectangular lid which had smalls holes for efficient air transfer and to avoid the water in the bucket from heating. All lids were labeled either control or copper to avoid cross-contamination. 
Each Sailfin Molly was individually placed in an eight L plastic experimental chamber (black bucket). All buckets were acid-washed between experiments as recommended by the U.S. EPA. A total of 16 fish per treatment (control and copper) were exposed to assess swimming performance. Following a $96 \mathrm{~h}$ exposure, fish were moved to a 5 L Brett-type swimming tunnel (Loligo System, Viborg, Denmark) to assess swimming capacity. Because there was only one swimming performance system, exposures were staggered on different days. On the same day, only control or copperexposed fish were conducted to minimize cross-contamination.

\section{$\underline{1.3 \text { Swim Performance Assessment }}$}

The water prepared for these experiments were based on the standard testing protocol established by the U.S. EPA for aquatic toxicity testing (e.g., 96 h., mod-hard freshwater [or] synthetic saltwater, $\mathrm{pH}: 7.5 ; 25 \pm 1{ }^{\circ} \mathrm{C}$ ). All swimming performance studies were conducted one fish at a time in the same $5 \mathrm{~L}$ Brett-style swim tunnel (Loligo Systems, Tjele, Denmark, www.loligosystems.com) (Fig. 4). Each fish was contained within a portion of the chamber that maintains a laminar flow of water at a desired speed. The temperature of the swimming tunnel was at $25 \pm 1{ }^{\circ} \mathrm{C}$ and maintained using a recirculating water bath connected to a vat with a submersible heater. Every week the water in the sump was fully changed, fully aerated for 24 hours and adjusted to $25 \pm 1{ }^{\circ} \mathrm{C}$. Every 10-14 days, the flow speed was calibrated using a flow meter (Miniair®20). The

speed increments during each assessment was controlled using the Autoresp ${ }^{\mathrm{TM}}$ software (Automated Intermittent Respirometry Software, version 2, Loligo Systems, Tjele, Denmark). The dissolved oxygen sensor was also calibrated to assure fish were not exposed to anoxic conditions; oxygen levels never fell below $4 \mathrm{mg} / \mathrm{L}$ as required by the 
U.S. EPA. To minimize human contact, the entire swim tunnel was covered with a large black fabric and a camera was placed in front of the tunnel, which signal was transmitted to a small screen without audio to keep track of the fish movement.

To determine if copper exposure affected the swimming performance of sailfin mollies, I recorded the critical swimming speed ( $\left.U_{\text {crit }}\right)$. Laboratory and field studies have suggested that changes in fish physiology, as well as infections and exposure to sub-lethal toxicants, affect and decrease the $\mathrm{U}_{\text {crit }}$ (De Boeck et al., 2016; Beaumont et al., 1995). On the test day, fish were removed with a net from the respective bucket and placed in the swim tunnel individually to acclimate for an hour or until they had calmed down. Fish were considered to had calmed down if they were swimming around the tunnel at a normal speed instead of bursting erratically from side to side. During this first acclimation, the swim tunnel was not flowing, and the water in the swim tunnel was kept fully saturated with oxygen and held at $25 \pm 1{ }^{\circ} \mathrm{C}$. After the hour acclimation, fish were exposed to a second acclimation for $10 \mathrm{~min}$ with a flow velocity of $10 \mathrm{~cm} / \mathrm{s}$. This second and last acclimation revealed the direction of water flow in the tunnel. Each critical swimming speed test was initiated at $12 \mathrm{~cm} / \mathrm{s}$ and was performed as a ramp- $\mathrm{U}_{\text {crit }}$ test which allowed for changes in step duration (Jain et al., 1997). Step duration and speed intervals used data from preliminary swim trials. The experiment started with a height (velocity) of $12 \mathrm{~cm} / \mathrm{s}$ at a length of 5 minutes. From step $1(12 \mathrm{~cm} / \mathrm{s})$ to the end of the experiment, the steps constantly increased by $2 \mathrm{~cm} / \mathrm{s}$, but on the $6^{\text {th }}$ step $(22 \mathrm{~cm} / \mathrm{s})$ the step duration increased to $15 \mathrm{~min}$ (Fig. 5). When the fish stopped swimming, the experiment ended and time was recorded. The fish were given 2-3 opportunities to recover from fatigue and were discouraged from resting at the back of the test tunnel using reverse 
water flow, as needed. When the fish seemed unable to recover, the time and velocity at which it exhausted were recorded to find the $U_{\text {crit }}$ as calculated from the formula: $U_{\text {crit }}=$ $\mathrm{U}_{\mathrm{f}}+\mathrm{U}_{\mathrm{s}} \mathrm{x}\left(\mathrm{T}_{\mathrm{f}} / \mathrm{T}_{\mathrm{s}}\right)$ (Equation 1)

where:

$\mathrm{U}_{\mathrm{f}}=$ the water velocity of the last completed step

$\mathrm{U}_{\mathrm{s}}=$ velocity increments at each step

$\mathrm{T}_{\mathrm{f}}=$ duration the fish swam in the final step before fatigue

$\mathrm{T}_{\mathrm{s}}=$ duration of a whole complete step

After the fish swimming performance was measured, the fish was placed back in its holding container and the container was labeled with the date of the experiment. Fish were left to detoxify for a period of 4 weeks. After the detoxification period, fish were directly moved to the $5 \mathrm{~L}$ Brett-type swimming tunnel, where they were assessed one last time. After the final test, fish were euthanized in one litter of freshwater with $0.100 \mathrm{~g}$ MS222 buffered with $0.200 \mathrm{~g} \mathrm{Na}_{2} \mathrm{CO}_{3}$. The same experimental procedure was followed for both freshwater and 8 ppt-exposed fish.

\subsection{Statistical Analyses}

Freshwater Swimming Performance Experiment:

Critical swimming speed data were transformed from $\mathrm{cm} / \mathrm{s}$ to body length/s (BL/S) by dividing the velocity in $\mathrm{cm} / \mathrm{s}$ by the fish TL. Univariate analysis of variance was used to compare treatment groups ( $\mathrm{Cu}$ 96-hour; $\mathrm{Cu} 4$-week period) from the control. Data sets were first tested for outliers by visually inspecting boxplots, if outliers were present, they were removed from the data set; no outliers were present. Data distributions 
were evaluated with the Kolmogorov-Smirnov test to determine normal distribution assumptions; all passed. Homogeneity of covariance was also tested by the Box's M test and Levene's test; all passed. Linearity between the dependent variables was tested visual inspection of bivariate scatter plots. Means were compared with ANOVA, followed by the Tukey HSD post hoc test, alpha $=0.05$, one-tailed.

\section{$\underline{8 p p t \text { Swimming Performance Experiments: }}$}

Critical swimming speed data were transformed from $\mathrm{cm} / \mathrm{s}$ to body length/s (BL/S) by dividing the velocity in $\mathrm{cm} / \mathrm{s}$ by the fish TL. An independent T-test was conducted to compare the treatment group $(\mathrm{Cu}-96 \mathrm{~h})$ from the control. Data sets were first tested for outliers by visually inspecting boxplots, if outliers were present, they were removed from the dataset; one outlier from the $\mathrm{Cu}$-treated group was removed. Normality of the data was determined with the Kolmogorov-Smirnov; all passed. Homogeneity of variance was evaluated with Levene's test; all passed. Means were compared with twosample T-tests, alpha $=0.05$, one-tailed.

Freshwater Swimming Performance Data VS 8ppt Swimming Performance Data:

Critical swimming speed data were transformed from $\mathrm{cm} / \mathrm{s}$ to body length/s (BL/S) by dividing the velocity in $\mathrm{cm} / \mathrm{s}$ by the fish TL. A T-test evaluated mean performance of the control groups from FW and 8 ppt water conditions to determine whether salinity affected swimming performance. Data sets were first tested for outliers by visually inspecting boxplots, if outliers were present, they were removed from the data set; no outliers were present in the dataset. Normality of data was evaluated with the Kolmogorov-Smirnov test; all passed. Homogeneity of variance was tested with Levene's test; all passed. Means were compared with a T-test, alpha $=0.05$, one-tailed. 


\subsection{Analytical Chemistry}

Copper used in experiments was in the form of copper sulfate pentahydrate $\left(\mathrm{CuSO}_{4} 5 \mathrm{H}_{2} 0\right)$, obtained from Fisher Scientific (NJ, USA, CAS \#7758-99-8; purity: 101.4\%). At the beginning of the experiments $(0 \mathrm{~h})$, in between water changes $(48 \mathrm{~h})$, and at the termination of the experiments $(96 \mathrm{~h}), 45 \mathrm{ml}$ of water were taken with a $20 \mathrm{ml}$ syringe and then filtered through $45 \mu \mathrm{M}$ membrane filters (Fisher Scientific, NJ, USA) to obtain the dissolved copper concentration instead of the total amount of copper present in the water. I was interested in knowing the dissolved concentration instead of the total concentration for two reasons. First, dissolved copper is the only bioavailable form that is able to bind to the biotic ligand located on the fish gills and eventually cause adverse effects. Second, the U.S. EPA WQC are given in dissolved $\mathrm{Cu} \mu \mathrm{g} / \mathrm{L}$ instead of total $\mathrm{Cu}$ $\mu \mathrm{g} / \mathrm{L}$ for the same reason. All water samples were acidified with concentrated nitric acid, 1 drop for every $15 \mathrm{ml}$ so that the $\mathrm{pH}$ would be below 2 ; then refrigerated at a temperature of $4^{\circ} \mathrm{C}$ until further analysis. All water samples were analyzed at the Environmental Analysis Research Laboratory (EARL) at Florida International University. Copper (isotope 63) dissolved concentrations were measured with the Agilent HP4500 Inductively Coupled - Plasma Mass Spectrometry (ICP-MS) machine.

Copper concentrations in experimental water were analytically verified by Method 1 (see below) in the case of the freshwater exposures and Method 2 in the case of the 8 ppt exposures. All methods were developed following the U.S. EPA Methods 1669 (July 1996) and 200.8 (Revision 5.4, 1994). A process called "Direct Analysis" was used to analyze both fresh and $8 \mathrm{ppt}$ samples because the water samples had a turbidity of $<1$ NTU (Nephelometric Turbidity Unit) at the time of the analysis. The limit of 
quantification (LOQ) for $\mathrm{Cu}$ was $5 \mu \mathrm{g} / \mathrm{L}$ and the limit of detection was determined to be $2.33 \mu \mathrm{g} / \mathrm{L}$, which represented the lowest concentration that could be detected and quantified for the current study.

\section{Method 1:}

Tuning and calibration of the Agilent HP4500 (ICP-MS) machine were done prior to the start of the recoverable metal analysis. The tuning solution was purchased from High-Purity Standards (Charleston, SC, www.highpuritystandards.com). The calibration consisted of 9 vials that were freshly prepared before each metal analysis. Once the tuning of the ICP-MS machine was successful, the calibration was conducted to determine if the slope of the curve was acceptable to proceed with trace metal analysis. The first 6 vials were specific to the calibration; then 3 vials followed: Initial Calibration Verification (ICVs), a Continuing Calibration Verification (CCV), and a Laboratory Blank (BLK).

\section{--Beginning of calibration--}

- Calibration 0 vial: $0 \mathrm{uL}$ of Solution A, $100 \mathrm{uL}$ of internal standard (ISMix), and 9900 uL of $\mathrm{HNO}_{3}(3 \%)$

- Calibration 1 vial: 2 uL of Solution A, $100 \mathrm{uL}$ of internal standard (ISMix), and 9900 $\mathrm{uL}$ of $\mathrm{HNO}_{3}(3 \%)$

- Calibration 2 vial: $5 \mathrm{uL}$ of Solution A, $100 \mathrm{uL}$ of internal standard (ISMix), and 9895 uL of $\mathrm{HNO}_{3}(3 \%)$;

- Calibration 3 vial: $10 \mathrm{uL}$ of Solution A, $100 \mathrm{uL}$ of internal standard (ISMix), and 9890 uL of $\mathrm{HNO}_{3}(3 \%)$; 
- Calibration 4 vial: $20 \mathrm{uL}$ of Solution A, $100 \mathrm{uL}$ of internal standard (ISMix), and 9880 $\mathrm{uL}$ of $\mathrm{HNO}_{3}(3 \%)$

- Calibration 5 vial: $40 \mathrm{uL}$ of Solution A, $100 \mathrm{uL}$ of internal standard (ISMix), and 9860 $\mathrm{uL}$ of $\mathrm{HNO}_{3}(3 \%)$

- ICVS: $10 \mathrm{uL}$ of Solution G, $100 \mathrm{uL}$ of internal standard (ISMix), and $9890 \mathrm{uL}$ of $\mathrm{HNO}_{3}(3 \%)$;

- CCV: $10 \mathrm{uL}$ of Solution A, $100 \mathrm{uL}$ of internal standard (ISMix), and $9890 \mathrm{uL}$ of $\mathrm{HNO}_{3}(3 \%)$

- Blank: $0 \mathrm{uL}$ of Solution A, $100 \mathrm{uL}$ of internal standard (ISMix), and $9900 \mathrm{uL}$ of $\mathrm{HNO}_{3}(3 \%)$.

\section{--End of calibration--}

- The internal standard (ISMix) contained known amounts of certain elements ([1000 $\mu \mathrm{g} / \mathrm{L}] \mathrm{Y}, \mathrm{In}, \mathrm{Bi}$ and $[10 \mathrm{mg} / \mathrm{L}] \mathrm{Au})$, used to normalize the responses of the analytes. ISMix was added to the samples, quality controls, and calibration solutions.

- Solution A (AccuStandard, New Haven, CT) was a plasma emission standard calibration that contained the following elements: $\mathrm{Al}, \mathrm{Sb}, \mathrm{As}, \mathrm{Be}, \mathrm{Cd}, \mathrm{Cr}, \mathrm{Co}, \mathrm{Cu}$, $\mathrm{Pb}, \mathrm{Mn}, \mathrm{Mo}, \mathrm{Ni}, \mathrm{Se}, \mathrm{Tl}, \mathrm{Th}, \mathrm{U}, \mathrm{V}$, and Zn.

- Solution G (Crescent Chemical Company, Islandia, NY) was a QC Standard 20 (Second Source) that contained the following elements: Ag, Al, As, Ba, Be, Cd, Co, Cr, Cu, Mn, Mo, Ni, Pb, Sb, Se, Th, Tl, U, V, Zn.

- The HNO3 (3\%) was prepared by adding $30 \mathrm{ml}$ of concentrated nitric acid to $1 \mathrm{~L}$ of DI water in a clean Teflon bottle. 
After running the calibration and obtaining an acceptable slope, instrument calibration was monitored over time via analysis of CCV samples, which were run every ten samples, with an acceptability criterion of $\pm 10 \%$. After the CCV, a BLK was also placed to assure that no cross-contamination occurred between samples, the acceptable range was $\pm 1.5 \mu \mathrm{g} \mathrm{Cu} / \mathrm{L}$. Water samples were prepared by adding $100 \mathrm{uL}$ of ISMix to every $9.9 \mathrm{ml}$ of the acidified water sample. Once the vial contained $10 \mathrm{ml}$, the vial was capped, vortexed and ran through the ICP-MS.

\section{Method 2:}

The same procedure was followed for the 8ppt water samples, but instead adding $30 \mathrm{ml}$ of concentrated nitric acid to $1 \mathrm{~L}$ of DI, $30 \mathrm{ml}$ were added to $1 \mathrm{~L}$ of $8 \mathrm{ppt}$ water in a clean Teflon bottle.

\section{Predator-Prey Interaction Experiments}

\section{$\underline{2.1 \text { Fish Cultures }}$}

Capture, transfer, and acclimation procedures were the same as in the previous experiment with one exception: all fish were gradually acclimated to freshwater conditions and no fish were acclimated to $8 \mathrm{ppt}$.

After being acclimated to freshwater, fish were transferred to recirculating glass tanks either $38 \mathrm{~L}(50 \mathrm{~cm} \times 25 \mathrm{~cm} \times 30 \mathrm{~cm})$ or $76 \mathrm{~L}(76 \mathrm{~cm} \times 30 \mathrm{~cm} \times 30 \mathrm{~cm})$, fish were kept at a density of $3.7 \mathrm{~L}$ water per $2.4 \mathrm{~cm}$ length of fish total length (Fig. 6). Sex ratios in each tank were 4 females to 1 male. All fish were kept on a 16:8 light-dark cycle. The water temperature was maintained at $25 \pm 1^{\circ} \mathrm{C}$, by adjusting the water around the tanks to the ambient temperature of the room which was regulated with an $\mathrm{AC} /$ heater unit. Fish were fed ad libitum once daily with Zeigler Aquatox Flakes (Zeigler Bros., Inc. Gardners, 
$\mathrm{Pa}, \mathrm{USA}$ ). Temperature, salinity, conductivity, $\mathrm{DO}$, and $\mathrm{pH}$ was measured daily with YSI and Fisher meters; ammonia, nitrite, and nitrate were measured once a week. If parameters were out of range, $50-60 \%$ of the water was changed. All meters were calibrated prior to measuring by following the company's standard calibration procedure.

Fish were acclimated to freshwater for a minimum of two weeks prior to starting the experiments. All culture and experimental conditions followed Institutional Animal Care and Use Committee protocols approved at Florida International University (Reference numbers: 200789, 200853, 200858).

\section{$\underline{2.2 \text { Experimental Copper Toxicity Studies }}$}

Moderately Hard water was prepared (80-100 $\mathrm{CaCO}_{3} \mathrm{mg} / \mathrm{L}$ hardness; 54-62 $\mathrm{CaCO}_{3} \mathrm{mg} / \mathrm{L}$ alkalinity) as suggested by the standard testing protocol used by the U.S. EPA for aquatic toxicity testing. The same water preparing procedure as the one explained in the previous experiment was followed. The copper stock solution $(0.5 \mathrm{mg} / \mathrm{L})$ was prepared 1-2 days prior to starting the copper exposures, and always kept in a $1 \mathrm{~L}$ dark glass amber bottle at $4{ }^{\circ} \mathrm{C}$. The stock solution was only kept and used for a maximum of 2 weeks, then it was discarded into the sewage sink to then be treated through carbon filtration. Immediately before the start of each $96 \mathrm{~h}$ acute experiment, the $\mathrm{Cu}$ exposure solution was prepared at 11.3 dissolved $\mu \mathrm{g} / \mathrm{L}$ by adding $1830 \mathrm{uL}$ of the stock solution to a 4L Type A volumetric flask and filled with the mod-hard water twice. The exposure water was then placed in a black plastic bucket, where a fish was later introduced. The concentration was chosen following the Hardness Model acquired from the latest draft released by the U.S. EPA, “Aquatic Life Ambient Freshwater Criteria for Copper - 2007" (Appendix G). 
Before the start of each experiment, all solutions were titrated to $\mathrm{pH} 7.5$ by bubbling carbon dioxide into the water. General water chemistry measurements (e.g., alkalinity, hardness, dissolved oxygen, temperature, conductivity) were monitored at 0 , 48, and $96 \mathrm{~h}$ with titration kits and meters. Before the beginning of the experiment, fish were fed early in the morning and eventually netted and placed in a circular chamber with one litter of holding water and $0.016 \mathrm{~g}$ tricane methanesulfonate (MS222) buffered with $0.032 \mathrm{~g} \mathrm{CaCO}_{3}$ to anesthetize the fish. Both females and males were used in the predatorprey interaction experiments. Once the fish was slightly sedated, I measured the TL, SL, $\mathrm{W}, \mathrm{D}$, and We of the fish.

Each Sailfin Molly was individually placed in an 8 L plastic experimental chamber (black buckets) and not fed until hour 48. A total of 10 replicates per treatment [visual cue (control \& $\mathrm{Cu}$ ), chemical cue ( $\operatorname{control} \& \mathrm{Cu}$ ), and visual + chemical cues (control \& $\mathrm{Cu})]$ were exposed to assess predator-prey interactions. Following a $96 \mathrm{~h}$ exposure, fish were moved to a $122 \mathrm{~cm}$ x $53 \mathrm{~cm}$ x $20 \mathrm{~cm} 130 \mathrm{~L}$ experimental chamber; the chamber was subdivided into an observational chamber $(79 \mathrm{~cm} \times 53 \mathrm{~cm} \times 13 \mathrm{~cm})$ where fish movements were recorded (Fig. 7). In the middle of the observational chamber, a predator zone $(20.5 \mathrm{~cm}$ long $\times 7 \mathrm{~cm}$ wide) was established to account for the number of times the prey entered the predator zone where the visual or chemical cue was introduced. The experimental chamber was made of acrylic, painted white to minimize reflection. Because there was only one experimental chamber and one camera to record the behavior of the fish, exposures were staggered on different days. On the same day, four pairs were run (two $\mathrm{Cu} \&$ two control), two in the late morning (10:00-12:00h) and two in the early afternoon (13:00-15:00h). All of the water was changed between 
experiments. The experimental chamber was cleaned with only FW and scrubbed with sponges to eliminate chemical residues from the previous trial.

\section{$\underline{2.3 \text { Predator and Prey Behavior Evaluation }}$}

The FW that was prepared for these experiments followed the standard testing protocol used by the U.S. EPA for aquatic toxicity testing (e.g., 96 h., mod-hard freshwater, $\mathrm{pH}: 7.5 ; 25 \pm 1{ }^{\circ} \mathrm{C}, \mathrm{DO}>4 \mathrm{mg} / \mathrm{L}$ ). A behavior analysis system (Noldus Ethovision) with static freshwater water was used for my study. The experimental chamber was made of white acrylic with a clear bottom. The tank was placed in a recirculating water bath set at $25 \pm 1{ }^{\circ} \mathrm{C}$, which had the bottom removed and replaced with clear acrylic. Both the experimental chamber and the water bath were placed on a wooden frame that elevated the tank to $1 \mathrm{~m}$. A non-reflective 4' long fluorescent light (40 watts), was placed on the floor under the water bath chamber, to project the light upwards. A monochrome video camera was mounted on the ceiling in the middle of the testing chamber to record the prey behavior (Fig. 7). The entire system was covered and enclosed with a heavy black curtain to prevent the fish from seeing people or other distractions that might affect their behavior (Fig. 8). The room was kept completely quiet while the experiments were being conducted.

All experiments, regardless of treatment, consisted of a 10 min acclimation period where no data were recorded. Trial 1 consisted of a $10 \mathrm{~min}$ period where no cue was added and Trial 2 consisted of a 10 min period where either a visual or a chemical cue was introduced. A total of 20 fish were used per experiment, always 10 control and 10 copper-exposed, 5 females and 5 males per exposure treatment. During Trial 1 and Trial 2, data were recorded every 30 seconds, providing a total of 20 points for every endpoint 
recorded. Prior to the experiment, daily calibrations were made with Noldus Ethovision XT Version 9 (Wageningen, The Netherlands). The calibration consisted on establishing the shape and the size of the arena: length $(\mathrm{cm})$ and width $(\mathrm{cm})$. Daily calibration was done so the software could accurately record the movement of the fish in $\mathrm{cm} / \mathrm{s}$.

The behaviors extracted from the videos with Noldus Ethovision XT ${ }^{\mathrm{TM}}$ Version 9 were 1) Total distance travelled (Bl/s) 2) Mean Velocity (Bl/s), 3) Freezing time (sec), 4) Cruising time (sec), 5) Bursting time (s), 6) Predator Zone Frequency, 7) Predator Zone Duration (sec), 8) Predator Zone Latency 9) Predator Zone Maximum Distance (cm \& Bl/s), 10) Predator Zone Mean Distance (cm \& Bl/s).

1) Total Distance Travelled: Distance travelled by the center point of the animal from the previous sample to the current one. The distance moved was calculated from the following formula:

$D M_{n}=\sqrt{\left(X_{n}-X_{n-1}\right)^{2}+\left(Y-Y_{n-1}\right)^{2}} \quad($ Equation 2)

Where, $\mathrm{DM}_{\mathrm{n}}=$ Distance moved from sample n-1 to sample $\mathrm{n}, \mathrm{X}_{\mathrm{n}-1}, \mathrm{Yn}_{-1}=\mathrm{X}, \mathrm{Y}$. The values were given in $\mathrm{cm} / \mathrm{s}$ and then normalized to $\mathrm{Bl} / \mathrm{s}$ by dividing the total distance traveled in $\mathrm{cm} / \mathrm{s}$ over the total length $(\mathrm{cm})$ of the fish.

2) Mean Velocity: Distance moved by the center of the fish per unit time. The software calculated this velocity by diving Equation \#2 by the time difference between a sample and the previous one:

$V_{n}=\frac{D M_{n}}{t_{n}+t_{n-1}} \quad$ (Equation 3)

Where, $\mathrm{Vn}=$ the velocity at sample $\mathrm{n}$. The values were given in $\mathrm{cm} / \mathrm{s}$ and converted to $\mathrm{Bl} / \mathrm{s}$ to normalize the fish movement.

3) Freezing Time: The time the fish spent frozen in seconds (velocity $<0.5 \mathrm{~cm} / \mathrm{s}$ ). 
4) Cruising Time: The time the fish spent cruising/swimming between a speed of 0.5 and $11.9 \mathrm{~cm} / \mathrm{s}$. Cruising speed is the speed that a fish would be able to maintain for a long period of time without getting tired.

5) Bursting Time: The time the fish spent swimming at a high speed $(>12 \mathrm{~cm} / \mathrm{s})$ that would not be able to maintain for a prolonged period of time.

6) Predator Zone Frequency: Number of times the fish entered the predator zone. Even if the fish barely crossed the corner of the predator zone, this was considered an entering of the predator zone.

7) Predator Zone Duration: The amount of time in seconds that the prey spent in the predator zone. Even if the fish was partially inside the predator zone, the time was still recorded.

8) Predator Zone Latency: The amount of time passed before the prey first entered the predator zone for the first time.

9) Predator Zone Maximum Distance: The longest distance between the fish' body center and the predator zone. The calculation of this endpoint is first calculated by looking at the coordinate of the point on the zone border that is closest to the body center of the fish and then by measuring the distance in a straight line between the two coordinates mentioned above. The values provided by the software were given in $\mathrm{cm} / \mathrm{s}$ and then converted to $\mathrm{Bl} / \mathrm{s}$

10) Predator Zone Mean Distance: The mean distance between the fish's body center and the predator zone. The values provided by software were given in $\mathrm{cm} / \mathrm{s}$ and then converted to $\mathrm{Bl} / \mathrm{s}$. 


\subsubsection{Visual Cue}

To keep the focal fish from getting eaten by the predator (which would have precluded analysis of absorbed copper), I used a model Largemouth Bass (Fig. 9) instead of a live one. The model was plastic, free of phthalate and lead, $15.24 \mathrm{~cm}$ long x 3.175 $\mathrm{cm}$ wide x $7.65 \mathrm{~cm}$ high and purchased from Amazon.com (item model number: S265629).

Because the model floated in the water, it was attached with silicone to a rectangular piece of clear acrylic. The model was placed in the predator zone in the middle of the tank. The predator zone consisted of (1) space that the model bass occupied in the experimental chamber and (2) an unmarked rectangular zone, $2.5 \mathrm{~cm}$ around the model (Fig. 10). To assure that the predator model was always placed in the same location, a frame made of acrylic was attached to the bottom of the tank with silicone. The experiments lasted for a period of $30 \mathrm{~min}$ total, $10 \mathrm{~min}$ of non-recorded acclimation, 10 min of Trial 1 (without model predator) and $10 \mathrm{~min}$ of Trial 2 (with model predator).

The model predator was always introduced from the same side of the chamber. I was able to cover my body with the blackout curtain but my arm remained visible to the subjects as I positioned the model. Trial 2 began as soon as the model was introduced. Once the experiment was over, the subject fish was euthanized in one litter of freshwater with $0.100 \mathrm{~g}$ MS222 buffered with $0.200 \mathrm{~g}$ sodium carbonate. All bodies were kept frozen for further analysis at $-20^{\circ} \mathrm{C}$. Between each trial, the experimental chamber was fully drained, rinsed with freshwater, and refilled to the same height every time. Between trials, the water was also fully oxygenated. The behavioral endpoints measured in these experiments were described in section 2.3. 


\subsubsection{Chemical Cue}

Possible chemical cues of predation were extracted from different holding waters where fingerling Largemouth Bass had been present and feeding on molly fry. The chemical cue was a mixture of $2 \mathrm{~L}$ of holding water where fingerling were given Sailfin Molly fry to eat for a period of 5 hours, $8 \mathrm{~L}$ of the holding water where 85 fingerling were kept all together for 2 hours, 2L of holding water where 60 fingerling were kept in $852 \mathrm{~L}$ for 6 days with no water changes, and $2 \mathrm{~L}$ were 30 fingerling were kept in $852 \mathrm{~L}$ for 14 days with no water renewals. A total of $14 \mathrm{~L}$ of the chemical cue water was prepared and then subdivided into $200 \mathrm{ml}$ aliquots (transparent glass containers) that were kept in a closed carton box and held at $4{ }^{\circ} \mathrm{C}$ until the day of the experiment. Early in the morning before starting the experiments two aliquots were removed from the fridge and placed in a water bath at $25^{\circ} \mathrm{C}$ to reach the same temperature as the testing chamber.

On the basis of my own preliminary studies, I concluded that $65 \mathrm{ml}$ of the chemical mixture was the ideal concentration to study the effects of sublethal effects of copper on sailfin mollies. The chemical cue was not present in Trial 1, but was introduced in Trial 2. The $65 \mathrm{ml}$ chemical cue aliquot was always introduced from the same side of the chamber and directed towards the middle of the predator zone. To minimize distractions and human contact, the cue was introduced through a $15 \mathrm{~mm}$ diameter vinyl tubing that placed the chemical cue right in the middle of the predator zone (Fig. $11 \&$ 12). Right after Trial 2 was concluded, the subject fish was euthanized in one litter of freshwater dosed with $0.100 \mathrm{~g} \mathrm{MS} 222$ and buffered with $0.200 \mathrm{~g}$ sodium carbonate. All bodies were kept frozen at $-20{ }^{\circ} \mathrm{C}$ until further analysis. Between each trial, the experimental chamber was fully drained, washed with freshwater and refilled to 
the same height every time. Between trials, the water was fully oxygenated. The behavioral endpoints measured in these experiments were described in section 2.3.

\subsubsection{Visual \& Chemical Cues}

The procedure followed for this treatment was a combination of sections 2.3.1 and 2.3.2. The predator model was introduced first, then followed by the introduction of the chemical cue.

\subsection{Statistical Analysis}

The same behaviors were recorded for all treatments. A few times, the camera stopped tracking the fish because it froze or went very close to the border of the established arena. When the fish froze and position could not be recorded by the software, position data were manually inputted. When the fish went outside of the arena and no data were recorded, the data point was removed and not included in the data set. Endpoints that accounted for movement $(\mathrm{cm})$, distance $(\mathrm{cm})$ or velocity $(\mathrm{cm} / \mathrm{s})$ were all normalized to Bl/s. Endpoints that accounted for time were all recorded in seconds. Each endpoint had a total of 40 data points since data were acquired every $30 \mathrm{sec}$ for a period of $10 \mathrm{~min}$ per trial.

Group differences in rate and mean were analyzed with ANCOVA and ANOVA. Hypothesis 5-14, were evaluated with ANCOVA with the exception of hypothesis 12, which was analyzed with ANOVA. Therefore, the data used for the statistical analysis were the result of the difference between Trial 2 (post-cue) and Trial 1 (pre-cue) (Trial 2 data - Trial 1 data). In my work, I name this difference "the change of every endpoint". The reason I chose to work with the change of every endpoint was because I was interested in looking at how the behavior of copper contaminated fish varied once the 
cues were introduced when compared to control fish. The dependent variables were the change of every endpoint recorded in these studies (e.g., distance travelled, mean velocity, cruising time, freezing time, bursting time, number of times in predator zone, time spent in the predator zone, maximum distance from predator zone, minimum distance from predator zone). The independent ordinal value was the type of treatment (copper exposure or control), and the continuous covariates were the time expressed in minutes, and the data acquired before the introduction of the cue(s). Hypothesis 12, which addressed the time it took for the prey to enter the predator zone for the first time, had to be tested by ANOVA since time was not a covariate. For all statistical analyses, alpha $=0.05$

\subsection{Analytical Chemistry}

Water Samples

Briefly, the source of copper came from copper sulfate pentahydrate $\left(\mathrm{CuSO}_{4} 5 \mathrm{H}_{2} 0\right)$, which was obtained from Fisher Scientific (NJ, USA, CAS \#7758-99-8; purity: 101.4\%). At the beginning of the experiments (hour 0), in between water changes (hour 48), and at termination of the experiments (hour 96), $45 \mathrm{ml}$ of water were taken with a $20 \mathrm{ml}$ syringe and then filtered with $45 \mathrm{uM}$ membrane filters (Fisher Scientific, NJ, USA) to obtain the dissolved copper concentration instead of the total amount of copper present in the water. All the water samples were analyzed in the same laboratory, Environmental Analysis

Research Laboratory (EARL) at Florida International University, as the samples collected from the swimming performance experiments. Direct Analysis was used to analyze freshwater samples with Agilent HP4500 (ICP-MS) machine and followed the same procedure as Section 1.4 Method 1. 


\section{RESULTS}

\subsection{Swimming Performance Experiments}

\subsection{Freshwater Experiments}

The nominal dissolved copper concentration in the freshwater experiments was $11.3 \mu \mathrm{g} / \mathrm{L}$, but the measured concentrations showed that the average concentration from 40 samples and duplicates was slightly lower at $9.29 \mu \mathrm{g} / \mathrm{L}$. The average concentration of the water samples taken at every water change is displayed in Table 1. Total length of the control fish acclimated to freshwater was $3.36-4.46 \mathrm{~cm}$. The TL of the copper exposed fish acclimated to freshwater varied from $3.43-4.78 \mathrm{~cm}$ (Table 2).

Ninety-six hours of copper exposure under fresh water conditions reduced swimming performance measured by $\mathrm{U}_{\text {crit. }}(\mathrm{p}<0.001$; ANOVA; post-hoc Tukey HSD; $\mathrm{SE}=0.27 ; 95 \% \mathrm{CI}: 0.72-2.02$ ). Fish exposed to copper for $96 \mathrm{~h}$ performed significantly better after 4 weeks of detoxification (depuration) ( $p=0.013$, ANOVA, post-hoc Tukey HSD; $\mathrm{SE}=0.27 ; 95 \% \mathrm{CI}=-1.45--0.15)($ Fig. 13). The copper-exposed fish showed no consistent difference from the control fish in swimming performance after the 4-week depuration period ( $p=0.094$, ANOVA post-hoc Tukey HSD; SE=0.27; 95\%CI: -0.078 1.22).

\subsection{Eight ppt Experiments}

The nominal concentration for the 8ppt estuarine experiments was $8.44 \mu \mathrm{g} / \mathrm{L}$ of dissolved $\mathrm{Cu}$ but the measured concentration showed that the average concentration was $9.31 \mu \mathrm{g} / \mathrm{L}$. The average concentration of the water samples taken at every water change is displayed in Table 1. The TL of the control fish acclimated to 8 ppt salinity was 3.31-4.6 
$\mathrm{cm}$. The TL of the copper exposed fish acclimated to $8 \mathrm{ppt}$ salinity varied from $3.30-4.6$ cm (Table 2).

In contrast to the freshwater conditions, in brackish water of $8 \mathrm{ppt}, 96 \mathrm{~h}$ copper exposure did not reduce swimming performance $(\mathrm{p}=0.88$, T-test; $\mathrm{SE}=0.27 ; 95 \% \mathrm{CI}:-0.50$ - 0.58). For this reason, no depuration period was conducted for these fish (Fig. 14).

\section{$\underline{3.3 \text { Swimming Performance: Freshwater vs. } 8 \text { ppt Saline (no-copper) }}$}

Freshwater acclimated control fish $(\mathrm{N}=16)$ and the 8 ppt-acclimated control fish did not differ in their swimming performance ( $p=0.11$, T-test; SE-0.26; 95\%CI: $-0.11-$ 0.97). Results suggests that salinity does not affect the swimming performance of Sailfin Mollies independently of its reduction of copper availability (Fig. 15).

\section{$\underline{4.0 \text { Predator-Prey Interaction Experiments }}$}

The nominal copper concentration for the experiments was $11.3 \mu \mathrm{g} / \mathrm{L}$. For experiments with visual cues, the average concentration from 40 samples throughout the 96-h exposure was $9.35 \mu \mathrm{g} / \mathrm{L}$. The average concentration of the water samples taken at every water change is displayed in Table 3.

The total length of the control fish varied from 3.57 to $6.98 \mathrm{~cm}$. The control females varied from $3.57-6.2 \mathrm{~cm}$, and the control males varied from $4.35-6.98 \mathrm{~cm}$. The total length of the copper exposed fish varied from $3.72-6.785 \mathrm{~cm}$. The copper contaminated females varied from $3.72-6.185 \mathrm{~cm}$, and the copper contaminated males varied from $3.72-6.79 \mathrm{~cm}$ (Table 4).

For experiments with chemical cues, the average concentration from 39 samples throughout the $96-\mathrm{hr}$ exposure was $9.82 \mu \mathrm{g} / \mathrm{L}$ of dissolved copper. The average concentration of the water samples taken at every water change is displayed in Table 3. 
The total length of the control fish varied from $4.55-7.1 \mathrm{~cm}$. The control females varied from $4.55-7.1 \mathrm{~cm}$ and the control males varied from $4.57-6.75 \mathrm{~cm}$. The total length of the copper exposed fish varied from $4.6-7.29 \mathrm{~cm}$. The copper contaminated females varied from $4.6-7.21 \mathrm{~cm}$, and the copper contaminated males varied from $4.46-7.29$ cm (Table 4).

For experiments with both visual and chemical cues, the average concentration from 14 samples throughout the $96-\mathrm{hr}$ exposure was $9.63 \mu \mathrm{g} / \mathrm{L}$ of dissolved copper. The average concentration of the water samples taken at every water change is displayed in Table 3. The total length of the control fish varied from $4.81-7.11 \mathrm{~cm}$. The control females varied from $5.65-7.02 \mathrm{~cm}$ and the control males varied from $4.0-7.06 \mathrm{~cm}$. The total length of the copper exposed fish varied from $3.81-7.11 \mathrm{~cm}$. The copper contaminated females varied from $5.18-7.111 \mathrm{~cm}$, and the copper contaminated males varied from $3.81-7.06 \mathrm{~cm}$ (Table 4).

\subsection{Response to Predator Exposure}

The results of every behavior recorded (Total Distance Travelled in Body Length, Mean Velocity (Body Length/sec), Total Time Spent Freezing (sec), Total Time Spent Cruising (sec), Total Time Spent Bursting (sec), Amount of Times Prey Entered the Predator Zone, Time Spent in the Predator Zone (sec), Latency to First (sec), Maximum Distance from Predator Zone (Body Length), Mean Distance from Predator Zone (Body Length) have been summarized in table 5 . 


\section{DISCUSSION}

Copper has raised much concern in the last decades due to its abundant use in the agricultural fields (e.g., fertilizer and a fungicide), mining activities, residential activities, and boat paint, which are continually contaminating surface waters (Acosta et al., 2016). When copper is sprayed on land, it eventually gets into the water through storm-water runoff. On a hazard assessment performed at the water conservation areas in South Florida, Carriger et al., (2016) found copper to be a chemical of potential ecological concern at three different locations. In northern California, runoff has been found to contain dissolved copper levels that range from $3.4-64.5 \mu \mathrm{g} / \mathrm{L}$ with a mean of $15.8 \mu \mathrm{g} / \mathrm{L}$ which are well above the water quality criteria established by the Environmental Protection Agency (EPA) (Linbo et al., 2006). The most significant concern associated with copper is its inability to degrade, which leads to rapid accumulation, affecting organisms that cannot detoxify faster than the rate of contamination (Hoang et al., 2011). Copper has shown to have dose-specific effects, damaging organs such as gills, kidneys, liver, brain and the lateral line of fish (Thomas et al., 2016). Other toxic effects related to copper are osmoregulatory disturbances, oxidative stress, and inhibition of $\mathrm{Na}^{+} \mathrm{K}^{+}-$

ATPase (Sovova et al., 2014). Lastly, sublethal levels of copper have been found to have detrimental effects on locomotor abilities such as swimming performance of fish (De Boeck et al., 2006) and sensory abilities (Belanger et al., 2006; Tierney, 2011).

Effectiveness in daily activities such as feeding, reproduction and predator avoidance determine if a fish will be able to survive and pass on its genes to the next generations. The importance of these activities has raised concerns regarding the copper water quality criteria (WQC) established by the EPA, and if the suggested concentrations 
have an adverse effect on chemo/mechanosensory responses (Meyer and DeForest, 2018). A meta-analysis published by Meyer and DeForest (2018) addressed these concerns by looking at how protective the Biotic Ligand Model (BLM) WQC vs. the Hardness-based WQC were when analyzing the effects of copper on behavioral and chemo/mechanosensory endpoints of freshwater aquatic species. $26.8 \%$ of the revised cases that looked at behavior were under-protected under the hardness-based acute WQC and $24.4 \%$ of these cases were under-protected under the hardness-based chronic WQC. In contrast, when the WQC was based on the BLM, 7.3\% of the acute behavior experiments and $4.9 \%$ of the chronic behavior experiments were considered underprotected. Some of the reported behavioral endpoints adversely impacted were, swimming performance, predator avoidance techniques, avoidance of copper, success in detecting an odor source, and the speed moving towards the odor source (Meyer and DeForest, 2018).

When investigating chemo/mechanosensory endpoints, $37.9 \%$ of the revised cases were under-protected under the hardness-based acute WQC and 27.3\% under the hardness-based chronic WQC; leading to alterations of electro-olfactogram responses and loss of lateral-line neurons. When looking at the BLM model, $12.1 \%$ of the acute cases were under-protected, and $4.5 \%$ of the chronic cases were under-protected. Meyer and DeForest, (2018) demonstrated with this meta-analysis that WQC based on BLM protects a higher percentage of organisms than hardness-based WQC. Most states still use some version of the hardness equation, which is still being recommended along with the BLM by the EPA, but some are adopting the BLM to site-specific sites and slowly shifting towards setting the BLM WQC as the statewide basis (Meyer and DeForest, 2018). 
The swimming performance data agreed with the three initial hypotheses of this thesis but not with the fourth hypothesis. Data in this project demonstrated that sublethal exposures to copper in FW provide detectable changes in swimming performance in poeciliid fish acclimated to FW conditions (Hypothesis \#1). The freshwater WQC suggested by the EPA (11.3 $\mu \mathrm{g} / \mathrm{l}$ of dissolved copper) at a hardness of $80 \mathrm{CaCO} 3 \mathrm{mg} / \mathrm{L}$ and a $\mathrm{pH}$ of 7.5 caused a statistically significant reduction $(\mathrm{p}$-value $<0.05)$ in the critical swimming speed of Sailfin Mollies acclimated to freshwater conditions after a 96-hour acute exposure. The copper contaminated fish were able to recover and achieve their baseline $\mathrm{U}_{\text {crit }}$ after a theoretical 4-week depuration period (Hypothesis \#3). The results in this thesis showed that after a 4-week depuration period fish had reached their baseline $\mathrm{U}_{\text {crit; }}$ however, future studies should determine the exact number of hours/days fish need to reach their baseline $\mathrm{U}_{\text {crit }}$ following exposure. Swimming performance is an excellent method to study sublethal effects on fish caused by metals and should be incorporated into ecotoxicological studies because the endpoint is very sensitive to low concentrations of copper.

Few studies have recorded the time it took for fish to recover from copper exposure and reach their baseline $\mathrm{U}_{\text {crit }}$ after a depuration period. De Boeck et al., (2006) compared the effects of chronic copper exposure (28-days) on the $\mathrm{U}_{\text {crit }}$ of Rainbow Trout (Oncorhynchus mykiss), Common Carp (Cyprinus carpio), and Gibel Carp (Carassius gibelio). Authors found that the same concentration (1uM) had different effects on these different species; Common and Gibel Carp are considered less sensitive to copper than trout based on different LC50's. During the first 12-24 h of exposure, the $\mathrm{U}_{\text {crit }}$ of all fish significantly decreased; $48 \%$ in Rainbow Trout, $31 \%$ in common carp and 13\% in Gibel 
Carp. All fish started slowly recovering throughout the month; at the end of the exposure period the $\mathrm{U}_{\text {crit }}$ in Rainbow Trout was $19 \%$ lower than its initial $\mathrm{U}_{\text {crit, }}$ but the recovery was not statistically significant. After 28 days, Common Carp showed a total reduction of $12 \%$ which was significantly different from its initial $\mathrm{U}_{\text {crit; }}$ Gibel Carp recovered right after 48 hours and didn't show a further reduction for the rest of the exposure.

Furthermore, Beaumont et al., (1995a) looked at the interaction between copper, two different $\mathrm{pH}$ values $(5 \mathrm{pH}$ and $7 \mathrm{pH})$ and two different temperatures $\left(5^{\circ} \mathrm{C}\right.$ and $\left.15^{\circ} \mathrm{C}\right)$ and how these together synergistically affected the $U_{\text {crit }}$ of adult Rainbow Trout. Fish exposed to acidic conditions and copper had a significant reduction in $\mathrm{U}_{\text {crit }}(25-50 \%)$, the temperature had no effect on this. Rajotte and Couture (2002) captured Wild Yellow Perch (Perca flavescens) from contaminated lakes that contained different levels of metals, including copper, and studied if their $\mathrm{U}_{\text {crit }}$ had an inverse relationship with the accumulation of these metals in the liver and muscle tissues. When looking at copper only, the most contaminated lake was Whitson, followed by Vermilion, Ramsey, and Nelson Lakes. Yellow Perch captured from Whitson Lake and Vermilion Lake showed the lowest $\mathrm{U}_{\text {crit }}$ values. The copper concentration in the muscle tissues was also the highest at those locations. The highest copper concentration in the liver was found in fish native to Whitson Lake, followed by Ramsey, Vermilion and Nelson Lakes. Authors suggested that the decrease in $U_{\text {crit }}$ was due to copper inhibition properties on the mitochondrial aerobic capacities, causing impairment in the aerobic swimming performance of these fish.

In the study presented here, the $\mathrm{U}_{\text {crit }}$ of Sailfin Mollies acclimated to 8ppt salinity (Hypothesis \#2) was not affected by the acute exposure to the BLM-based WQC 
suggested by the U.S. EPA $(8.44 \mu \mathrm{g} / 1$ of dissolved copper). As salinity increases the number of cations and ligands in the water also increase; therefore, the competition for dissolved copper particles increases, making the dissolved particles not bioavailable for the biotic ligands found on the gills of the fish. Additionally, more ions in saltwater also increase the competition between copper and other particles to bind to the ligands located on the gills of fish (USEPA, 2016).

In addition, there was not a significant difference $(\mathrm{P}$-value $>0.05)$ between the $\mathrm{U}_{\text {crit }}$ of freshwater acclimated control fish and 8ppt acclimated control fish (Hypotheses \#4). Interesting enough, the fish acclimated to freshwater conditions seemed to slightly reach a higher critical swimming speed than the $8 \mathrm{ppt}$ acclimated fish. The results observed in this study were surprising since most of these fish were caught at higher salinities ( $>20 \mathrm{ppt})$. Even though the habitat in which these Sailfin Mollies were collected was constantly subject to tidal fluctuations, 9 out of 10 times the salinity in the culverts was higher than 20ppt. Other studies have found similar results when looking at the effects of salinity acclimation on $\mathrm{U}_{\text {crit }}$ in Adriatic Sturgeon (Acipenser naccarii) and European Aeabass (Dicentrarchus labrax). McKenzie et al. (2001) found that Adriatic Sturgeon acclimated to brackish water (BW) and freshwater (FW) showed no significant difference in their maximum sustainable swimming speed. Chatelier et al. (2004) obtained similar results when European Seabass were exposed to acute changes in salinity from saltwater (SW) to 10ppt, 5ppt, and FW. Kolok and Sharkey (1997) found contrary results to my experiment; the swimming speed of the Killifish exposed to FW was significantly lower than those acclimated to BW. 
Laboratory and field studies have suggested different mechanisms that explain how copper may contribute to the negative changes in $U_{\text {crit }}$ of fish (Farrel, 2008). It has been suggested, but mostly refuted, that changes in swimming performance due to exposure to copper are the result of respiratory distress, which causes mucus production, cell swelling and epithelial lifting on gills (De Boeck 2006). Most authors, however, agree that changes in swimming behavior could be a result of ammonia accumulation, as found in a number of salmonid species (McKensie et al., 2003). Beaumont et al., (1995a, b) observed that as brown trout were exposed to copper, ammonia in their bodies increased, and their $\mathrm{U}_{\text {crit }}$ decreased: $70 \%$ of the variation in $\mathrm{U}_{\text {crit }}$ was explained by plasma ammonia. De Boeck et al., (2006) found similar results, copper exposures reduced the swimming capacity of Rainbow Trout and Brown Trout (Salmo trutta), and the results were also justified by ammonia accumulation. Waser et al. (2009) studied the effects of copper on the secondary lamellar epithelium of rainbow trout and whether these were the cause of $U_{\text {crit }}$ reduction: they found no correlation. Again, researchers suggested that increased ammonia production was the most likely explanation. Kolok et al. 2002 found a different explanation for the reduction in $\mathrm{U}_{\text {crit }}$ in small fish species. Fathead Minnows (Pimephales promelas) exposed to a sub-lethal concentration of copper displayed the greatest $\mathrm{U}_{\text {crit }}$ reduction when whole-body $\mathrm{Na}^{+}$was the lowest and surprisingly when the copper concentration in the body was also the lowest. These results suggest two things, (i) that copper may have impaired $\mathrm{Na}^{+} / \mathrm{K}^{+} \mathrm{ATPase}$ pumps, making it difficult for the fish to maintain whole body $\mathrm{Na}$; leading to a reduced $\mathrm{U}_{\text {crit, }}$, and (ii) that copper susceptibility of Fathead Minnows is entirely genetic (Kolok et al., 2002). 
Following the swimming performance assessment effects of sublethal copper concentrations on predator-prey interactions were only determined in of fish acclimated to freshwater and not to 8ppt because copper exposures did not seem to have a significant effect on fish acclimated to 8ppt. The endpoints analyzed in the predator-prey interaction experiments were 1) Total distance travelled (measured in body length (Bl)) 2) Mean Velocity (Bl/s), 3) Freezing time (sec), 4) Cruising time (sec), 5) Bursting time (sec), 6) Predator Zone Frequency, 7) Predator Zone Duration (sec), 8) Predator Zone Latency (sec) 9) Predator Zone Maximum Distance (Bl/s), 10) Predator Zone Mean Distance $(\mathrm{Bl} / \mathrm{s})$. All these endpoints were analyzed in the presence of chemical cues in isolation, visual cues in isolation, and both cues simultaneously. The reason why these three treatments were chosen was that these cues in isolation or simultaneously are very informative for prey that want to reduce predation risk, and any alteration that copper may have on any of these cues could cause population-level consequences.

Out in the field, fish depend on three main olfactory detection methods to minimize the risk of predation. The first one is predator odor, the second one is stress cues released by frightened or attacked prey, and the last one is cue released from the skin of an attacked prey (Thomas et al., 2016). When fish sense any of the three cues mentioned above, they initiate predator avoidance behavior such as reduced foraging, reduced movement, and increased shelter seeking (Thomas et al., 2016). Chemical cues can also be detected from far away when visual cues are not present, alerting animals of potential danger before it gets too close (Stephenson, 2016). The concentration of the chemical cue can also be indicative of how close the prey is from a potential predator, suggesting the prey to change its behavior in a threat-sensitive way (Stephenson, 2016). 
Although chemical cues are very informative, sometimes they can be spatially and temporally unreliable if strong currents are present. Visual cues can be risky since there has to be proximity between the predator and the prey. Some fish more than others have physical and behavioral characteristics that help them to be more efficient at a specific cue. Guppies (Poecilia reticulata), for example, are considered to have excellent vision (Anstis et al., 1998). Minnows are known to leave the shoal to approach and investigate the predator, term known as "predator inspection", and then return to the shoal and share the acquired visual information with the other fish (Pitcher et al., 1986). Other animals decide to pay attention to chemical cues only if they cannot clearly see their surroundings. Hartman and Abrahams (2000) found that Fathead minnows responded differently when exposed to different turbidity levels. When the water was clear, they did not react to chemical cues, but when turbidity was present, their behavior significantly changed. Similar results have been found in diving beetles (Cybister fimbriolatus); during the daytime, beetles did not react to hungry predator cues but the behavior completely changed once night time arrived (Abjornsson et al., 1997). Hall and Suboski (1995) worked with zebra danio fish (Danio rerio) and discovered that after exposing the fish to a red light with chemical cues, fish were able to learn that the red light indicated danger even in the absence of the chemical cue. This last experiment suggests that fish can learn to recognize novel predators just after a few encounters, and permanently modify their avoidance behavior even when chemical cues are not present.

The results in this thesis showed a consistent but opposite story. Copper contaminated fish tended to respond similarly when introduced to visual cues in isolation and visual \& chemical cues simultaneously but responded oppositely when introduced to 
chemical cues in isolation. Contrary to the $5^{\text {th }}$ hypothesis in this thesis, copper contaminated fish that were exposed to visual cues in isolation (Fig. 16c) and visual \& chemical cues simultaneously (Fig. 18c) greater reduced their total distance travelled (Pvalue $<0.05$ ) when compared to their respective controls. Even though not significantly statistically different, fish introduced to chemical cues in isolation (Fig. 17c) showed an opposite trend. Copper contaminated fish seemed to travel more distance than control fish when introduced to chemical cues in isolation ( $\mathrm{P}-\mathrm{value}>0.05)$.

Along with the $6^{\text {th }}$ hypothesis, the mean velocities from copper contaminated fish introduced to visual cues in isolation (Fig. 19c) and visual \& chemical cues (Fig. 21c) were significantly affected and reduced when compared to their respective controls. Even though not significantly statistically different, fish introduced to chemical cues in isolation (Fig. 20c) showed an opposite trend. The mean velocity swam by copper contaminated fish introduced to chemical cues in isolation appeared to be higher than control fish (P-value $>0.05)$.

The results obtained from the first two endpoints (total distance travelled \& mean velocity) indicated that when copper contaminated fish were introduced to visual cues in isolation or along with chemical cues simultaneously, fish reduced their velocity and movement. These results can be attributed to two explanations, the first one is that the swimming performance of the fish was affected as explained by my first experiment, affecting the fish movement and velocity. The second explanation could be a never studied before blinding effect that copper may have on fish eyes. Control fish may be recognizing the predator model as fake, and not behaving as they would behave when 
encountering a real predator. On the other hand, exposure to copper may be inhibiting this same recognition in contaminated fish by affecting the sight of the fish.

To my knowledge, no research has looked into the effects of copper on ocular diseases in fish, but a link has been found between copper and ocular diseases in humans. Ingster-Moati et al., 2007, found that when looking at 34 patients that were affected with Wilson's disease, a disease strongly associated with high amounts of copper, $85 \%$ of the patients had vertical eye pursuit abnormalities. Li et al., (2014) studied another very interesting case, where an 18-year old boy from China affected with Wilson disease suddenly starting losing the sight of his left eye due to secondary glaucoma. When his urine was analyzed, an extremely high concentration of copper was found, $1765.6 \mu \mathrm{g} / \mathrm{L}$. Further investigations concluded that high amounts of copper deposition in the trabecular meshwork, an area around the base of the cornea, may have been the primary cause of severe glaucoma. Narayanan and authors (2016) discovered that patients affected by Eales disease had a higher concentration of copper transporters (CTR1) in all ocular tissues when compared to control patients. Therefore, they concluded that this abnormality is probably the reason why copper and peripheral neovascularization in the eyes have been continuously reported together.

Although not significant, the opposite trend seen in the chemical cue experiments in the total distance travelled and mean velocity could be explained by the well-known effect that copper has on the olfactory receptors of fish. Copper contaminated fish may not be reducing their velocity or movement as much as the control fish because they are not able to recognize and/or well interpret the chemical cue released into the experimental chamber due to damage the copper causes to the olfactory rosettes 
(McIntyre et al., 2008). In an extensive review, Tierney et al., (2010) linked metals to three changes in olfactory function: (1) Anosmia: the total loss of olfaction; (2) Hyposmia, the reduction of olfactory capabilities, and the rarest (3) Dysosmia: the incorrect process of olfactory information. Copper has been extensively analyzed for its info-disrupting capabilities (Baldwin et al., 2003; McIntyre et al., 2008; Sandhal et al., 2006). Baldwin et al., (2003) discovered that copper (1.0 - $20 \mu \mathrm{g} / \mathrm{L})$ inhibited the neurophysiological response to odorants (e.g., (L-arginine, L-aspartic acid, L-leucine, and L-serine) after only a 10-minute exposure in juvenile Coho Salmon (Oncorhynchus kisutch). Authors concluded that copper negative effects could be crucial for the migratory success and survival of Salmonids. McIntyre et al., 2008, also found that copper is neurotoxic in salmonids because it interferes with the peripheral olfactory nervous system. Researchers found that in soft prepared freshwater, fish lost $82 \%$ of their olfactory capabilities to L-serine after a 30-minute exposure to $20 \mu \mathrm{g} / \mathrm{L}$ of dissolved copper. Increasing of hardness barely ameliorated the effects, indicating that based on the water hardness and alkalinity of the western United States, Salmonids could be at risk to the neurotoxic effects of copper. Tierney et al., (2010) believe that copper ions may prevent the transmission of signals between the brain and the olfactory receptors by blocking sodium or calcium channels in the olfactory receptor cells.

I failed to reject my $7^{\text {th }}, 8^{\text {th }}$ and $9^{\text {th }}$ hypotheses when looking at visual cues in isolation (Fig. 22c, 25c, 28c) and visual \& chemical cues simultaneously (Fig. 24c, 27c, 30c). Copper contaminated fish introduced to visual cues in isolation and visual \& chemical cues simultaneously reduced their cruising and bursting time and increased their freezing time; therefore, showing correct predator avoidance behavior. As the sight of 
copper contaminated fish could had possibly been affected by the exposure to copper, it is reasonable for fish to reduce their swimming activity. Immobile fish have a greater chance to not be noticed by a predator than moving contaminated fish that may not have the same ability to escape as a healthy fish.

Copper contaminated fish introduced to chemical cues in isolation behaved as I hypothesized on my $7^{\text {th }}, 8^{\text {th }}$ and $9^{\text {th }}$ hypotheses (Fig. 23c, 26c, 29c). Copper contaminated fish increased their cruising and bursting time and reduced their freezing time when introduced to chemical cues in isolation, resulting in poor predator avoidance behavior. As suggested in previous literature, copper contaminated fish introduced to chemical cues may have not decrease their activity when compared to control fish because of the misinterpretation of chemical cues. McIntyre et al., (2012) discovered that when juvenile Coho Salmon were exposed to 5-20 $\mu \mathrm{g} / \mathrm{L}$ of dissolved copper for 3 hours, they were not able to react against the alarm response produced by conspecific extract and the presence of a predator previously fed with Coho Salmon. In contrast, when control fish were exposed to these alarm cues, fish reduced their swimming activity. Moreover, McIntyre et al., (2012) concluded that copper treated Coho Salmon were less likely to evade and escape from nearby predators, making them less likely to survive a lethal attack.

Similarly, Sovova et al., (2014) found that juvenile rainbow trout when exposed to copper sulfate and nanoparticles decreased and eliminated their response to alarm substances, respectively.

Up to this point, copper exposed fish introduced to visual cues in isolation and visual \& chemical cues simultaneously seemed to initiate correct predator avoidance behavior. Interestingly, copper contaminated fish introduced to the aforementioned 
treatments entered the predator zone more frequently (Fig. 31c, 33c, 34c, 36c) and stayed in the predator zone for a longer period of time than their respective controls as hypothesized on hypothesis \#10 and \#11. The predator model may have been seen and used as a shelter by the copper contaminated fish, which could put these fish at serious predation risk in a real situation. There was not a statistically significant difference between the number of times and the amount of time the control and copper contaminated fish spent in the predator zone when introduced to chemical cues in isolation (Fig. 32c, $35 \mathrm{c})$.

Copper contaminated fish took a shorter period of time to first enter the predator zone than their respective controls when introduced to chemical cues in isolation (pic. 38c) as suggested in hypothesis \#12. The results could be attributed to two factors. First, copper contaminated fish had a higher swimming activity that control fish; therefore, fish could have crossed the predator zone more times than the control fish by default. Second, control fish may have taken longer time in entering the predator zone because they were able to identify the high concentration of alarm cue found in the predator zone, information that copper contaminated fish could not interpret correctly. There was not a statistically significant difference between the fish introduced to visual cues in isolation (Fig. 37c) and visual and chemical cues simultaneously (Fig. 39c).

Lastly, copper contaminated fish introduced to both visual and chemical cues simultaneously were overall at a closer distance to the predator zone than control fish, agreeing with my last two hypotheses \#13 (Fig. 42c) and \#14 (Fig. 45c). There was not a statistically significant difference between the distance from the predator zone by the 
control and contaminated fish introduced to visual (Fig. 40c, 43c) and chemical cues in isolation (Fig. 41c, 44c).

Prey fish must always be ready to escape an attack if found too close from the predator. Entering the predator zone, spending time in it, approaching the predator zone too fast, and/or maintaining a short distance from the predator zone could put contaminated prey at risk of predation. The lateral line is an essential organ found in aquatic vertebrates that inform animals around their surroundings (e.g., movement of predator/prey; vibrations; pressure gradients) (Montgomery et al., 2014). Considerable research has been done regarding the effects of copper on the peripheral nervous system of fish since dose-dependent relationships have been found across many species. Changes in lateral line can interfere with fish behavior, including prey capture, predator avoidance, shoaling or schooling, and rheotaxis among others (Montgomery et al., 2014).

The lateral line develops early in larvae stages and is made of an array of neuromasts that contain mechanosensory cells called hair cells; these are slightly covered by a thin layer of mucus and are in direct contact with the environment (Ghysen and Dambly-Chaudiere, 2004). There are studies that have linked metals such as cadmium and mercury to toxicity in hair cells by blocking and suppressing the ion channels (Liang et al., 2003). Hernandez et al., (2006) found that when zebrafish larvae were exposed for two hours to low copper concentrations $(1 \mu \mathrm{M}$ and $10 \mu \mathrm{M})$ trunk and tail (PLL) neuromasts regenerated in a dose-dependent manner but that at higher concentrations $(>50 \mu \mathrm{M})$ copper would permanently eliminate PLL neuromasts with exception of the terminal neuromasts. Authors proposed that it is possible that high copper concentrations 
do not only destroy hair cells that proliferate but also those cells that have the capacity to create new hair cells. The results also suggested that after copper gains access to the hair cells, cells die after only a few minutes or hours of exposure; the uptake mechanism is still not well understood (Hernandez et al., 2006). Similar results were found by Linbo et al., (2006); zebrafish larvae exposed to concentrations ranging from 0 - $65 \mu \mathrm{g} / \mathrm{L}$ for 5 hours were able to recover in a dose-dependent manner. In contrast, when fish were exposed to $50 \mu \mathrm{g} / \mathrm{L}$ for 3 days, the lateral line did not regenerate. Authors realized that the cell death was as rapid as 1 hour and that fish exposed to $50 \mu \mathrm{g} / \mathrm{L}$ for 5 hours were able to completely recover after 2 days.

There are several factors to bear in mind when reading this thesis. The most important is the high individual-to-individual variability in animal behavior studies (Toms et al., 2010); therefore, different fish behave differently, and this was clearly seen in both swimming performance and predator-prey interaction experiments. In swimming performance experiments, some fish simply desired not to swim and had to be taken out of the testing chamber. Others learned that by placing their tail at the end of the swimming tunnel, they did not have to exert much energy. These fish were encouraged to swim by reversing the flow of the water; if they kept cheating, the experiment was terminated.

In the predator-prey interaction experiments, some fish focused their energy in exploring the tank, and others swam around the walls constantly trying to find an exit. The introduction of visual and chemical cues also magnified the different personalities of fish. Some fish instantly froze and did not move for the rest of the experiment, others swam around the predator zone but never went into the predator zone, and others used the 
predator model as shelter. The very different behavior of the fish caused my data not to be normally distributed. Following the advice of a statistician, ANCOVAs, and not nonparametric tests were conducted to analyze the data from these experiments. To reduce variation between the samples when looking at the change of each endpoint, Trial 1 data was incorporated to the equation as a covariance to account for the fish behavior before the introduction of the respective cue.

In some occasions, Noldus software lost track of the fish or provided the incorrect data. When the fish was immobile for too long, the software lost track of the fish and data had to be inputted manually. The automated tracking software had glitches from time to time if the water had a reflection or movement that was not captured in the calibration of the arena. When the aforementioned happened, data points had to be manually eliminated because the data were not accurately obtained.

Future predator-prey studies should consider copper impact on the predator since if the predator and the prey are native to the same habitat, both of them could be adversely affected by copper exposure. Studies have suggested that chemical pollution have an effect on dietary consumption. Kwan et al., (2015) found that whelks consumed fewer barnacles as they were exposed to higher copper concentrations. Similar results were found in the rotifer Brachionus calyciflorus and the cladoceran Daphnia magna; their rates of filtration and ingestion decreased in a dose-dependent manner, respectively (Ferrando and Andreu, 1993). McWilliam and Barid (2002) discovered that copper besides producing feeding inhibition during direct exposure also produced a delayed recovery in feeding effect on Daphnia magna, which authors categorized as Postexposure Feeding Depression. 
Lastly, I recommend the state representatives to start shifting to the BLM-based WQC due to the great amount of significant research reporting that the hardness-based WQC does not successfully protect aquatic animals from adverse effects. I suggest the U.S. EPA take into consideration sublethal effects parameters rather than lethality (i.e., $\mathrm{LC}_{50}$ ), such as sublethal effects, when considering and establishing WQC. Even if the sublethal concentration does not kill the fish directly, the concentration could affect the fish swimming performance which could eventually alter their daily activities. If locomotion and predator avoidance techniques are affected and altered, as they were in these experiments, daily activities such as finding quality mates and food as well as escaping from predators could be altered; leading to a decrease in fish fitness and the probability of establishing and/or maintaining populations.

\begin{tabular}{|l|l|l|l|l|l|l|}
\hline Experiment & Treatment & $\begin{array}{c}\text { Nominal } \\
\text { [copper] }\end{array}$ & $\begin{array}{c}\text { Mean } \\
\text { [copper] } \\
\text { at hr 0 }\end{array}$ & $\begin{array}{c}\text { Mean } \\
\text { [copper] } \\
\text { at hr 48 } \\
\text { out } \\
\text { water }\end{array}$ & $\begin{array}{c}\text { Mean } \\
\text { [copper] } \\
\text { at hr 48 } \\
\text { in water }\end{array}$ & $\begin{array}{c}\text { Mean } \\
\text { [copper] } \\
\text { at 96 hr }\end{array}$ \\
\hline Freshwater & copper & 11.3 & 9.64 & 8.92 & 9.30 & 9.30 \\
\hline $8 p p t$ & copper & 8.44 & 9.70 & 9.12 & 9.13 & 9.25 \\
\hline
\end{tabular}

Table 1. Swimming Performance Water Analytical Chemistry. All concentrations are expressed in $\mu \mathrm{g} / \mathrm{L}$. Mean concentrations are measured concentrations obtained from analytical chemistry.

\begin{tabular}{|l|l|l|l|l|}
\hline \multicolumn{1}{|c|}{ Treatment } & \multicolumn{1}{c|}{ TL min } & \multicolumn{1}{c|}{ TL max } & \multicolumn{1}{c|}{ TL mean } & \multicolumn{1}{c|}{ TL stdev } \\
\hline $\begin{array}{l}\text { Freshwater } \\
\text { Control }\end{array}$ & 3.36 & 4.46 & 3.79 & 0.34 \\
\hline $\begin{array}{l}\text { Freshwater } \\
\text { copper }\end{array}$ & 3.43 & 4.78 & 3.92 & 0.36 \\
\hline 8ppt Control & 3.31 & 4.60 & 3.90 & 0.43 \\
\hline 8ppt copper & 3.30 & 4.60 & 3.79 & 0.44 \\
\hline
\end{tabular}

Table 2. Fish TL - Swimming Performance Experiments. Total Length (TL) of fish that were part of the swimming performance experiments. 


\begin{tabular}{|l|l|l|l|l|l|l|}
\hline Experiment & Treatment & $\begin{array}{c}\text { Nominal } \\
\text { [copper] }\end{array}$ & $\begin{array}{c}\text { Mean } \\
\text { [copper] } \\
\text { at hr 0 }\end{array}$ & $\begin{array}{c}\text { Mean } \\
\text { [copper] } \\
\text { at hr 48 } \\
\text { out } \\
\text { water }\end{array}$ & $\begin{array}{c}\text { Mean } \\
\text { [copper] } \\
\text { at hr 48 } \\
\text { in water }\end{array}$ & $\begin{array}{c}\text { Mean } \\
\text { [copper] } \\
\text { at 96 hr }\end{array}$ \\
\hline Visual & copper & 11.3 & 10.01 & 9.10 & 10.11 & 8.19 \\
\hline Chemical & copper & 11.3 & 9.95 & 8.98 & 10.51 & 9.86 \\
\hline Visual \& & copper & 11.3 & 9.95 & 9.48 & 9.52 & N/A \\
\hline Chemical & & & & & & \\
\hline
\end{tabular}

Table 3. Predator-Prey Water Analytical Chemistry. All concentrations are expressed in $\mu \mathrm{g} / \mathrm{L}$. Mean concentrations are measured concentrations obtained from analytical chemistry

\begin{tabular}{|l|l|l|l|l|l|}
\hline \multicolumn{1}{|c|}{ Cue } & Treatment & \multicolumn{1}{c|}{ TL min } & \multicolumn{1}{c|}{ TL max } & \multicolumn{1}{c|}{ TL mean } & TL stdev \\
\hline Visual & $\begin{array}{l}\text { Control } \\
\text { Females }\end{array}$ & 3.57 & 6.20 & 5.06 & 1.15 \\
\hline Visual & Control Males & 4.35 & 6.98 & 5.43 & 1.40 \\
\hline Visual & $\begin{array}{l}\text { Copper } \\
\text { Females }\end{array}$ & 3.72 & 6.19 & 5.20 & 1.16 \\
\hline Visual & Copper Males & 3.72 & 6.79 & 5.73 & 0.79 \\
\hline Chemical & $\begin{array}{l}\text { Control } \\
\text { Females }\end{array}$ & 4.55 & 7.10 & 5.64 & 1.12 \\
\hline Chemical & Control Males & 4.57 & 6.75 & 5.99 & 0.95 \\
\hline $\begin{array}{l}\text { Chemical } \\
\text { Copper }\end{array}$ & 4.60 & 7.21 & 6.03 & 1.15 \\
\hline Fememical & Copper Males & 4.46 & 7.29 & 5.93 & 1.16 \\
\hline $\begin{array}{l}\text { Visual }+ \\
\text { Chemical }\end{array}$ & $\begin{array}{l}\text { Control } \\
\text { Females }\end{array}$ & 5.65 & 7.02 & 6.38 & 0.57 \\
\hline $\begin{array}{l}\text { Visual }+ \\
\text { Chemical }\end{array}$ & Control Males & 5 & 7.06 & 5.46 & 1.42 \\
\hline $\begin{array}{l}\text { Visual }+ \\
\text { Chemical }\end{array}$ & $\begin{array}{l}\text { Copper } \\
\text { Females }\end{array}$ & 5.18 & 7.11 & 6.23 & 0.96 \\
\hline $\begin{array}{l}\text { Visual }+ \\
\text { Chemical }\end{array}$ & Copper Males & 3.81 & 7.06 & 5.17 & 1.46 \\
\hline
\end{tabular}

Table 4. Fish TL - Predator-Prey Experiments. Total Length (TL) of fish that were part of PredatorPrey interaction experiments. 


\begin{tabular}{|c|c|c|c|c|c|c|c|c|c|}
\hline \multirow[t]{2}{*}{ Endpoint } & \multirow[t]{2}{*}{ Trial } & \multirow{2}{*}{$\begin{array}{l}\text { Type of } \\
\text { Cue }\end{array}$} & \multicolumn{3}{|c|}{ Treatment } & \multicolumn{3}{|c|}{ Time } & \multirow[b]{2}{*}{ Fig. } \\
\hline & & & $\mathbf{F}$ & DF & $\begin{array}{c}\text { P- } \\
\text { Value }\end{array}$ & $\mathbf{F}$ & DF & $\begin{array}{c}\text { P- } \\
\text { Value }\end{array}$ & \\
\hline \multirow{9}{*}{$\begin{array}{c}\text { Total } \\
\text { Distance } \\
\text { Travelled } \\
\text { In Body } \\
\text { Length }\end{array}$} & \multirow{3}{*}{$\begin{array}{c}\text { Before } \\
\text { Introduction } \\
\text { of Cue } \\
\text { (Trial 1) } \\
\end{array}$} & Visual & 4.45 & 1 & $<0.05$ & 0.46 & 1 & $>0.05$ & $16 \mathrm{a}$ \\
\hline & & Chemical & 30.70 & 1 & $<0.05$ & 0.005 & 1 & $>0.05$ & $17 \mathrm{a}$ \\
\hline & & $\begin{array}{c}\text { Visual + } \\
\text { Chemical }\end{array}$ & 3.52 & 1 & $>0.05$ & 4.50 & 1 & $<0.05$ & $18 \mathrm{a}$ \\
\hline & \multirow{3}{*}{$\begin{array}{c}\text { After } \\
\text { Introduction } \\
\text { of Cue } \\
\text { (Trial 2) }\end{array}$} & Visual & 19.04 & 1 & $<0.05$ & 0.48 & 1 & $>0.05$ & $16 b$ \\
\hline & & Chemical & 0.19 & 1 & $>0.05$ & 5.89 & 1 & $<0.05$ & $17 \mathrm{~b}$ \\
\hline & & $\begin{array}{c}\text { Visual + } \\
\text { Chemical }\end{array}$ & 72.52 & 1 & $<0.05$ & 16.11 & 1 & $<0.05$ & $18 \mathrm{~b}$ \\
\hline & \multirow{3}{*}{$\begin{array}{l}\text { Change in } \\
\text { Endpoint } \\
\text { (Trial 2- } \\
\text { Trial 1) }\end{array}$} & Visual & 14.70 & 1 & $<0.05$ & 1.62 & 1 & $>0.05$ & $16 \mathrm{c}$ \\
\hline & & Chemical & 0.57 & 1 & $>0.05$ & 6.0 & 1 & $<0.05$ & $17 \mathrm{c}$ \\
\hline & & $\begin{array}{c}\text { Visual + } \\
\text { Chemical }\end{array}$ & 68.25 & 1 & $<0.05$ & 12.73 & 1 & $<0.05$ & $18 \mathrm{c}$ \\
\hline \multirow{9}{*}{$\begin{array}{l}\text { Mean } \\
\text { Velocity } \\
\text { (Body } \\
\text { Length/sec) }\end{array}$} & \multirow{3}{*}{$\begin{array}{c}\text { Before } \\
\text { Introduction } \\
\text { of Cue } \\
\text { (Trial 1) } \\
\end{array}$} & Visual & 4.46 & 1 & $<0.05$ & 0.50 & 1 & $>0.05$ & $19 \mathrm{a}$ \\
\hline & & Chemical & 20.63 & 1 & $<0.05$ & 0.003 & 1 & $>0.05$ & $20 \mathrm{a}$ \\
\hline & & $\begin{array}{c}\text { Visual + } \\
\text { Chemical }\end{array}$ & 3.44 & 1 & $>0.05$ & 4.43 & 1 & $<0.05$ & $21 a$ \\
\hline & \multirow{3}{*}{$\begin{array}{c}\text { After } \\
\text { Introduction } \\
\text { of Cue } \\
\text { (Trial 2) } \\
\end{array}$} & Visual & 17.18 & 1 & $<0.05$ & 0.65 & 1 & $>0.05$ & $19 \mathrm{~b}$ \\
\hline & & Chemical & 0.04 & 1 & $>0.05$ & 10.96 & 1 & $<0.05$ & $20 \mathrm{~b}$ \\
\hline & & $\begin{array}{c}\text { Visual + } \\
\text { Chemical }\end{array}$ & 74.02 & 1 & $<0.05$ & 15.74 & 1 & $<0.05$ & $21 b$ \\
\hline & \multirow{3}{*}{$\begin{array}{l}\text { Change in } \\
\text { Endpoint } \\
\text { (Trial 2- } \\
\text { Trial 1) } \\
\end{array}$} & Visual & 12.80 & 1 & $<0.05$ & 1.97 & 1 & $>0.05$ & $19 \mathrm{c}$ \\
\hline & & Chemical & 0.49 & 1 & $>0.05$ & 11.13 & 1 & $<0.05$ & $20 \mathrm{c}$ \\
\hline & & $\begin{array}{c}\text { Visual + } \\
\text { Chemical }\end{array}$ & 70.33 & 1 & $<0.05$ & 12.37 & 1 & $<0.05$ & $21 \mathrm{c}$ \\
\hline \multirow{9}{*}{$\begin{array}{l}\text { Total Time } \\
\text { Spent } \\
\text { Freezing } \\
(\mathrm{sec})\end{array}$} & \multirow{3}{*}{$\begin{array}{c}\text { Before } \\
\text { Introduction } \\
\text { of Cue } \\
\text { (Trial 1) }\end{array}$} & Visual & 8.88 & 1 & $<0.05$ & 1.47 & 1 & $>0.05$ & $22 \mathrm{a}$ \\
\hline & & Chemical & 13.05 & 1 & $<0.05$ & 0.08 & 1 & $>0.05$ & $23 a$ \\
\hline & & $\begin{array}{c}\text { Visual + } \\
\text { Chemical }\end{array}$ & 11.98 & 1 & $<0.05$ & 1.22 & 1 & $>0.05$ & $24 a$ \\
\hline & \multirow{3}{*}{$\begin{array}{c}\text { After } \\
\text { Introduction } \\
\text { of Cue } \\
\text { (Trial 2) }\end{array}$} & Visual & 44.41 & 1 & $<0.05$ & 17.51 & 1 & $<0.05$ & $22 b$ \\
\hline & & Chemical & 2.38 & 1 & $>0.05$ & 30.03 & 1 & $<0.05$ & $23 b$ \\
\hline & & $\begin{array}{l}\text { Visual + } \\
\text { Chemical }\end{array}$ & 85.88 & 1 & $<0.05$ & 25.22 & 1 & $<0.05$ & $24 b$ \\
\hline & \multirow{3}{*}{$\begin{array}{l}\text { Change in } \\
\text { Endpoint } \\
\text { (Trial 2- } \\
\text { Trial 1) } \\
\end{array}$} & Visual & 45.72 & 1 & $<0.05$ & 16.87 & 1 & $<0.05$ & $22 c$ \\
\hline & & Chemical & 4.64 & 1 & $<0.05$ & 30.41 & 1 & $<0.05$ & $23 c$ \\
\hline & & $\begin{array}{c}\text { Visual + } \\
\text { Chemical }\end{array}$ & 71 & 1 & $<0.05$ & 24.42 & 1 & $<0.05$ & $24 c$ \\
\hline
\end{tabular}

Table 5 Part I. Results from Predator Exposure 


\begin{tabular}{|c|c|c|c|c|c|c|c|c|c|}
\hline \multirow[t]{2}{*}{ Endpoint } & \multirow[t]{2}{*}{ Trial } & \multirow{2}{*}{$\begin{array}{l}\text { Type of } \\
\text { Cue }\end{array}$} & \multicolumn{3}{|c|}{ Treatment } & \multicolumn{3}{|c|}{ Time } & \multirow[b]{2}{*}{ Fig. } \\
\hline & & & $\mathbf{F}$ & DF & $\begin{array}{c}\text { P- } \\
\text { Value }\end{array}$ & $\mathbf{F}$ & DF & $\begin{array}{c}\text { P- } \\
\text { Value }\end{array}$ & \\
\hline \multirow{9}{*}{$\begin{array}{l}\text { Total } \\
\text { Time } \\
\text { Spent } \\
\text { Cruising } \\
\text { (sec) }\end{array}$} & \multirow{3}{*}{$\begin{array}{c}\text { Before } \\
\text { Introduction } \\
\text { of Cue } \\
\text { (Trial 1) } \\
\end{array}$} & Visual & 1.27 & 1 & $>0.05$ & 0.68 & 1 & $>0.05$ & $25 a$ \\
\hline & & Chemical & 0.62 & 1 & $>0.05$ & 0.46 & 1 & $>0.05$ & $26 a$ \\
\hline & & $\begin{array}{l}\text { Visual }+ \\
\text { Chemical }\end{array}$ & 8.66 & 1 & $<0.05$ & 0.30 & 1 & $>0.05$ & $27 \mathrm{a}$ \\
\hline & \multirow{3}{*}{$\begin{array}{c}\text { After } \\
\text { Introduction } \\
\text { of Cue } \\
\text { (Trial 2) }\end{array}$} & Visual & 38.58 & 1 & $<0.05$ & 20.01 & 1 & $<0.05$ & $25 b$ \\
\hline & & Chemical & 3.14 & 1 & $>0.05$ & 32.50 & 1 & $<0.05$ & $26 b$ \\
\hline & & $\begin{array}{l}\text { Visual + } \\
\text { Chemical }\end{array}$ & 38.21 & 1 & $<0.05$ & 46.01 & 1 & $<0.05$ & $27 b$ \\
\hline & \multirow{3}{*}{$\begin{array}{l}\text { Change in } \\
\text { Endpoint } \\
\text { (Trial 2- } \\
\text { Trial 1) }\end{array}$} & Visual & 39.62 & 1 & $<0.05$ & 19.50 & 1 & $<0.05$ & $25 \mathrm{c}$ \\
\hline & & Chemical & 5.16 & 1 & $<0.05$ & 34.70 & 1 & $<0.05$ & $26 c$ \\
\hline & & $\begin{array}{l}\text { Visual + } \\
\text { Chemical }\end{array}$ & $\begin{array}{c}125.8 \\
2\end{array}$ & 1 & $<0.05$ & 50.02 & 1 & $<0.05$ & $27 \mathrm{c}$ \\
\hline \multirow{9}{*}{$\begin{array}{c}\text { Total } \\
\text { Time } \\
\text { Spent } \\
\text { Bursting } \\
\text { (sec) }\end{array}$} & \multirow{3}{*}{$\begin{array}{c}\text { Before } \\
\text { Introduction } \\
\text { of Cue } \\
\text { (Trial 1) } \\
\end{array}$} & Visual & 6.91 & 1 & $<0.05$ & 0.41 & 1 & $>0.05$ & $28 \mathrm{a}$ \\
\hline & & Chemical & 2.56 & 1 & $>0.05$ & 0.28 & 1 & $>0.05$ & $29 a$ \\
\hline & & $\begin{array}{c}\text { Visual + } \\
\text { Chemical }\end{array}$ & 1.92 & 1 & $>0.05$ & 18.55 & 1 & $<0.05$ & $30 a$ \\
\hline & \multirow{3}{*}{$\begin{array}{c}\text { After } \\
\text { Introduction } \\
\text { of Cue } \\
\text { (Trial 2) }\end{array}$} & Visual & 8.77 & 1 & $<0.05$ & 0.40 & 1 & $>0.05$ & $28 \mathrm{~b}$ \\
\hline & & Chemical & 8.85 & 1 & $<0.05$ & 0.10 & 1 & $>0.05$ & $29 b$ \\
\hline & & $\begin{array}{c}\text { Visual + } \\
\text { Chemical }\end{array}$ & 41.22 & 1 & $<0.05$ & 3.18 & 1 & $>0.05$ & $30 b$ \\
\hline & \multirow{3}{*}{$\begin{array}{c}\text { Change in } \\
\text { Endpoint } \\
\text { (Trial 2-- } \\
\text { Trial 1) }\end{array}$} & Visual & 6.91 & 1 & $<0.05$ & 0.41 & 1 & $>0.05$ & $28 \mathrm{c}$ \\
\hline & & Chemical & 7.13 & 1 & $<0.05$ & 0.03 & 1 & $>0.05$ & $29 c$ \\
\hline & & $\begin{array}{l}\text { Visual + } \\
\text { Chemical }\end{array}$ & 39.50 & 1 & $<0.05$ & 0.13 & 1 & $>0.05$ & $30 \mathrm{c}$ \\
\hline \multirow{9}{*}{$\begin{array}{l}\text { Amount } \\
\text { of Times } \\
\text { Prey } \\
\text { Entered } \\
\text { the } \\
\text { Predator } \\
\text { Zone }\end{array}$} & \multirow{3}{*}{$\begin{array}{c}\text { Before } \\
\text { Introduction } \\
\text { of Cue } \\
\text { (Trial 1) }\end{array}$} & Visual & 0.23 & 1 & $>0.05$ & 0.03 & 1 & $>0.05$ & $31 \mathrm{a}$ \\
\hline & & Chemical & 12.31 & 1 & $<0.05$ & 0.22 & 1 & $>0.05$ & $32 a$ \\
\hline & & $\begin{array}{l}\text { Visual + } \\
\text { Chemical }\end{array}$ & 0.02 & 1 & $>0.05$ & 2.28 & 1 & $>0.05$ & $33 a$ \\
\hline & \multirow{3}{*}{$\begin{array}{c}\text { After } \\
\text { Introduction } \\
\text { of Cue } \\
\text { (Trial 2) }\end{array}$} & Visual & 4.04 & 1 & 0.05 & 5.89 & 1 & $<0.05$ & $31 b$ \\
\hline & & Chemical & 0.88 & 1 & $<0.05$ & 2.66 & 1 & $>0.05$ & $32 b$ \\
\hline & & $\begin{array}{c}\text { Visual + } \\
\text { Chemical }\end{array}$ & 6.32 & 1 & $<0.05$ & 3.30 & 1 & $>0.05$ & $33 b$ \\
\hline & \multirow{3}{*}{$\begin{array}{l}\text { Change in } \\
\text { Endpoint } \\
\text { (Trial 2- } \\
\text { Trial 1) }\end{array}$} & Visual & 4.13 & 1 & $<0.05$ & 5.93 & 1 & $<0.05$ & $31 \mathrm{c}$ \\
\hline & & Chemical & 0.83 & 1 & $>0.05$ & 2.69 & 1 & $>0.05$ & $32 \mathrm{c}$ \\
\hline & & $\begin{array}{l}\text { Visual }+ \\
\text { Chemical }\end{array}$ & 6.50 & 1 & $<0.05$ & 4.04 & 1 & 0.05 & $33 c$ \\
\hline
\end{tabular}

Table 5 Part II. Results from Predator Exposure 


\begin{tabular}{|c|c|c|c|c|c|c|c|c|c|}
\hline \multirow[t]{2}{*}{ Endpoint } & \multirow[t]{2}{*}{ Trial } & \multirow{2}{*}{$\begin{array}{l}\text { Type of } \\
\text { Cue }\end{array}$} & \multicolumn{3}{|c|}{ Treatment } & \multicolumn{3}{|c|}{ Time } & \multirow[b]{2}{*}{ Fig. } \\
\hline & & & $\mathbf{F}$ & DF & $\begin{array}{c}\text { P- } \\
\text { Value }\end{array}$ & $\mathbf{F}$ & DF & $\begin{array}{c}\text { P- } \\
\text { Value }\end{array}$ & \\
\hline \multirow{9}{*}{$\begin{array}{c}\text { Time } \\
\text { Spent in } \\
\text { the } \\
\text { Predator } \\
\text { Zone (sec) }\end{array}$} & \multirow{3}{*}{$\begin{array}{c}\text { Before } \\
\text { Introduction } \\
\text { of Cue } \\
\text { (Trial 1) }\end{array}$} & Visual & 0.64 & 1 & $>0.05$ & 0.04 & 1 & $>0.05$ & $34 \mathrm{a}$ \\
\hline & & Chemical & 9.55 & 1 & $<0.05$ & 0.45 & 1 & $>0.05$ & $35 a$ \\
\hline & & $\begin{array}{l}\text { Visual }+ \\
\text { Chemical }\end{array}$ & 0.18 & 1 & $>0.05$ & 0.02 & 1 & $>0.05$ & $36 a$ \\
\hline & \multirow{3}{*}{$\begin{array}{c}\text { After } \\
\text { Introduction } \\
\text { of Cue } \\
\text { (Trial 2) }\end{array}$} & Visual & 18.32 & 1 & $<0.05$ & 0.07 & 1 & $>0.05$ & $34 b$ \\
\hline & & Chemical & 0.01 & 1 & $>0.05$ & 0.70 & 1 & $>0.05$ & $35 b$ \\
\hline & & $\begin{array}{l}\text { Visual + } \\
\text { Chemical }\end{array}$ & 45.04 & 1 & $<0.05$ & 0.13 & 1 & $>0.05$ & $36 b$ \\
\hline & \multirow{3}{*}{$\begin{array}{l}\text { Change in } \\
\text { Endpoint } \\
\text { (Trial 2- } \\
\text { Trial 1) }\end{array}$} & Visual & 18.47 & 1 & $<0.05$ & 0.07 & 1 & $>0.05$ & $34 c$ \\
\hline & & Chemical & 0.003 & 1 & $>0.05$ & 0.66 & 1 & $>0.05$ & $35 c$ \\
\hline & & $\begin{array}{l}\text { Visual }+ \\
\text { Chemical }\end{array}$ & 47.37 & 1 & $<0.05$ & 0.15 & 1 & $>0.05$ & $36 \mathrm{c}$ \\
\hline \multirow{9}{*}{$\begin{array}{l}\text { Latency to } \\
\text { First (sec) }\end{array}$} & \multirow{3}{*}{$\begin{array}{c}\text { Before } \\
\text { Introduction } \\
\text { of Cue } \\
\text { (Trial 1) } \\
\end{array}$} & Visual & 0.14 & 1 & $>0.05$ & NA & NA & NA & $37 \mathrm{a}$ \\
\hline & & Chemical & 2.32 & 1 & $>0.05$ & NA & NA & NA & $38 \mathrm{a}$ \\
\hline & & $\begin{array}{l}\text { Visual + } \\
\text { Chemical }\end{array}$ & 0.80 & 1 & $>0.05$ & NA & NA & NA & $39 a$ \\
\hline & \multirow{3}{*}{$\begin{array}{c}\text { After } \\
\text { Introduction } \\
\text { of Cue } \\
\text { (Trial 2) } \\
\end{array}$} & Visual & 0.11 & 1 & $>0.05$ & NA & NA & NA & $37 b$ \\
\hline & & Chemical & 3.15 & 1 & $>0.05$ & NA & NA & NA & $38 b$ \\
\hline & & $\begin{array}{c}\text { Visual }+ \\
\text { Chemical }\end{array}$ & 0.29 & 1 & $>0.05$ & NA & $\mathrm{NA}$ & NA & $39 b$ \\
\hline & \multirow{3}{*}{$\begin{array}{l}\text { Change in } \\
\text { Endpoint } \\
\text { (Trial 2- } \\
\text { Trial 1) } \\
\end{array}$} & Visual & 0.002 & 1 & $>0.05$ & NA & NA & NA & $37 \mathrm{c}$ \\
\hline & & Chemical & 6.03 & 1 & $<0.05$ & NA & NA & NA & $38 \mathrm{c}$ \\
\hline & & $\begin{array}{l}\text { Visual + } \\
\text { Chemical }\end{array}$ & 0.01 & 1 & $>0.05$ & NA & NA & NA & $39 c$ \\
\hline \multirow{9}{*}{$\begin{array}{l}\text { Maximum } \\
\text { Distance } \\
\text { from } \\
\text { Predator } \\
\text { Zone } \\
\text { (Body } \\
\text { Length) }\end{array}$} & \multirow{3}{*}{$\begin{array}{c}\text { Before } \\
\text { Introduction } \\
\text { of Cue } \\
\text { (Trial 1) }\end{array}$} & Visual & 0.02 & 1 & $>0.05$ & 0.92 & 1 & $>0.05$ & $40 \mathrm{a}$ \\
\hline & & Chemical & 47.32 & 1 & $<0.05$ & 1.36 & 1 & $>0.05$ & $41 \mathrm{a}$ \\
\hline & & $\begin{array}{l}\text { Visual + } \\
\text { Chemical }\end{array}$ & 2.58 & 1 & $>0.05$ & 5.81 & 1 & $<0.05$ & $42 a$ \\
\hline & \multirow{3}{*}{$\begin{array}{c}\text { After } \\
\text { Introduction } \\
\text { of Cue } \\
\text { (Trial 2) }\end{array}$} & Visual & 2.14 & 1 & $>0.05$ & 0.83 & 1 & $>0.05$ & $40 \mathrm{~b}$ \\
\hline & & Chemical & 16.22 & 1 & $<0.05$ & 5.93 & 1 & $<0.05$ & $41 \mathrm{~b}$ \\
\hline & & $\begin{array}{l}\text { Visual }+ \\
\text { Chemical }\end{array}$ & 35.84 & 1 & $<0.05$ & 0.10 & 1 & $>0.05$ & $42 b$ \\
\hline & \multirow{3}{*}{$\begin{array}{l}\text { Change in } \\
\text { Endpoint } \\
\text { (Trial 2- } \\
\text { Trial 1) } \\
\end{array}$} & Visual & 2.16 & 1 & $>0.05$ & 1.30 & 1 & $>0.05$ & $40 \mathrm{c}$ \\
\hline & & Chemical & 0.01 & 1 & $>0.05$ & 4.06 & 1 & $<0.05$ & $41 \mathrm{c}$ \\
\hline & & $\begin{array}{c}\text { Visual + } \\
\text { Chemical }\end{array}$ & 33.06 & 1 & $<0.05$ & 0.18 & 1 & $>0.05$ & $42 c$ \\
\hline
\end{tabular}

Table 5 Part III. Results from Predator Exposure 


\begin{tabular}{|c|c|c|c|c|c|c|c|c|c|}
\hline \multirow[t]{2}{*}{ Endpoint } & \multirow[t]{2}{*}{ Trial } & \multirow{2}{*}{$\begin{array}{l}\text { Type of } \\
\text { Cue }\end{array}$} & \multicolumn{3}{|c|}{ Treatment } & \multicolumn{3}{|c|}{ Time } & \multirow[b]{2}{*}{ Fig. } \\
\hline & & & $\mathbf{F}$ & DF & $\begin{array}{c}\text { P- } \\
\text { Value }\end{array}$ & $\mathbf{F}$ & DF & $\begin{array}{c}\text { P- } \\
\text { Value }\end{array}$ & \\
\hline \multirow{9}{*}{$\begin{array}{l}\text { Mean } \\
\text { Distance } \\
\text { from } \\
\text { Predator } \\
\text { Zone } \\
\text { (Body } \\
\text { Length) }\end{array}$} & \multirow{3}{*}{$\begin{array}{c}\text { Before } \\
\text { Introduction } \\
\text { of Cue } \\
\text { (Trial 1) } \\
\end{array}$} & Visual & 0.08 & 1 & $>0.05$ & 3.16 & 1 & $>0.05$ & $43 a$ \\
\hline & & Chemical & 51.64 & 1 & $<0.05$ & 1.38 & 1 & $>0.05$ & $44 a$ \\
\hline & & $\begin{array}{l}\text { Visual }+ \\
\text { Chemical }\end{array}$ & 5.20 & 1 & $<0.05$ & 7.72 & 1 & $<0.05$ & $45 a$ \\
\hline & \multirow{3}{*}{$\begin{array}{c}\text { After } \\
\text { Introduction } \\
\text { of Cue } \\
\text { (Trial 2) }\end{array}$} & Visual & 0.12 & 1 & $>0.05$ & 6.57 & 1 & $<0.05$ & $43 b$ \\
\hline & & Chemical & 15.17 & 1 & $<0.05$ & 0.01 & 1 & $>0.05$ & $44 b$ \\
\hline & & $\begin{array}{l}\text { Visual + } \\
\text { Chemical }\end{array}$ & 8.68 & 1 & $<0.05$ & 3.30 & 1 & $>0.05$ & $45 b$ \\
\hline & \multirow{3}{*}{$\begin{array}{l}\text { Change in } \\
\text { Endpoint } \\
\text { (Trial 2- } \\
\text { Trial 1) }\end{array}$} & Visual & 0.25 & 1 & $>0.05$ & 7.56 & 1 & $<0.05$ & $43 c$ \\
\hline & & Chemical & 0.11 & 1 & $>0.05$ & 0.95 & 1 & $>0.05$ & $44 c$ \\
\hline & & $\begin{array}{c}\text { Visual }+ \\
\text { Chemical }\end{array}$ & 5.21 & 1 & $<0.05$ & 0.97 & 1 & $>0.05$ & $45 c$ \\
\hline
\end{tabular}

Table 5 Part IV. Results from Predator Exposure

\section{REFERENCES}

Abjornsson, K., Wagner, B. M. A., Axelsson, A., Bjerselius, R., \& Olsen, K. H. (1997). Responses of Acilius sulcatus (Coleoptera: Dytiscidae) to chemical cues from perch (Perca fluviatilis). Oecologia, 111(2), 166-171.

Abril, S. I. M., Costa, P. G., \& Bianchini, A. Metal Accumulation and Expression of Genes Encoding for Metallothionein and Copper Transporters in a Chronically Exposed Wild Population of the Fish Hyphessobrycon Luetkenii. (2018). Comparative biochemistry and physiology c-toxicology \& pharmacology, 211, 25-31.

Acosta, D. D., Danielle, N. M., Altenhofen, S., Luzardo, M. D., Costa, P. G., Bianchini, A., Dafre, A. L. (2016). Copper at Low Levels Impairs Memory of Adult Zebrafish (Danio rerio) and Affects Swimming Performance of Larvae. Comparative biochemistry and physiology c-toxicology \& pharmacology, 185, 122-130.

Anstis, S., Hutahajan, P., \& Cavanagh, P. (1998) Optomotor Test for Wavelength Sensitivity in Guppyfish (Poeicilia reticulata). Vision research, 38 (1) 45-53.

Baldwin, D. H., Sandahl, J. F., Labenia, J. S., \& Scholz, N. L. (2003). Sublethal Effects of Copper on Coho Salmon: Impacts on Nonoverlapping Receptor Pathways in the Peripheral Olfactory Nervous System. Environmental toxicology and chemistry, 22(10), 2266-2274. 
Beaumont, M. W., Butler, P. J., \& Taylor, E. W. (1995a). Exposure of Brown Trout, Salmo-Trutta, to Sublethal Copper Concentrations in Soft Acidic water and its Effect Upon Sustained Swimming Performance. Aquatic toxicology, 33(1), 45-63.

Beaumont, M. W., Butler, P. J., \& Taylor, E. W. (1995b). Plasma Ammonia Concentration in Brown Trout in Soft Acidic Water and its Relationship to Decreased Swimming Performance. Journal of experimental biology, 198(10), 2213-2220.

Belanger, R. M., Corkum, L. D., Li, W. M., \& Zielinski, B. S. (2006). Olfactory Sensory Input Increases Gill Ventilation in Male Round Gobies (Neogobius melanostomus) During Exposure to Steroids. Comparative biochemistry and physiology a-molecular \& integrative physiology, 144(2), 196-202.

Beyers, D. W., \& Farmer, M. S. (2001). Effects of Copper on Olfaction of Colorado Pikeminnow. Environmental toxicology chemistry, 20(4), 907-912.

Bielmyer, G. K., Gatlin, D., Isely, J. J., Tomasso, J., \& Klaine, S. J. (2005). Responses of Hybrid Striped Bass to Waterborne and Dietary Copper in Freshwater and Saltwater. Comparative biochemistry and physiology c-toxicology \& pharmacology, 140(1), 131-137.

Blanchard, J., \& Grosell, M. (2005). Effects of Salinity on Copper Accumulation in the Common Killifish (Fundulus heteroclitus). Environmental toxicology chemistry, 24(6), 1403-1413.

Caccia, V. G., \& Millero, F. J. (2003). The Distribution and Seasonal Variation of Dissolved Trace Metals in Florida Bay and Adjacent Waters. Aquatic geochemistry, 9(2), 111-144.

Carriger, J. F., Castro, J., \& Rand, G. M. (2016). Screening Historical Water Quality Monitoring Data for Chemicals of Potential Ecological Concern: Hazard Assessment for Selected Inflow and Outflow Monitoring Stations at the Water Conservation Areas, South Florida. Water, air \& soil polution, 227:27.

Chatelier, A., McKenzie, D. J., \& Claireaux, G. (2004). Effects of Changes in Water Salinity Upon Exercise and Cardiac Performance in the European Seabass (Dicentrarchus labrax). Marine biology, 147: 855-862.

Chivers, D. P., Mirza, R. S., \& Johnston, J. G. (2002). Learned Recognition of Heterospecific Alarm Cues Enhances Survival During Encounters with Predators. Behaviour, 139, 929-938.

Damasceno, F. M., Fleuri, L. F., Sartori, M. M. P., Amorim, R. L., Pezzato, L. E., da Silva, R. L., Barros, M. M. (2016). Effect of Dietary Inorganic Copper on Growth 
Performance and Hematological Profile of Nile Tilapia Subjected to Heat-Induced Stress. Aquaculture, 454, 257-264.

De Boeck, G., van der Ven, K., Hattink, J., \& Blust, R. (2006). Swimming Performance and Energy Metabolism of Rainbow Trout, Common Carp and Gibel Carp Respond Differently to Sublethal Copper Exposure. Aquatic toxicology, 80(1), 92-100.

Di Toro, D. M., Allen H. E., Bergman, H. L., Meyer, J. S., Paquin, P. R., \& Santore R. C. (2001). Biotic Ligand Model of the Acute Toxicity of Metals. 1. Technical Basis. Environmental toxicology chemistry, 20(10): 2382-2396.

Elvidge, C. K., Macnaughton, C. J., \& Brown, G. E. (2013). Sensory Complementation and Antipredator Behavioural Compensation in Acid-Impacted Juvenile Atlantic Salmon. Oecologia, 172(1), 69-78.

Farrell, A. P. (2008). Comparisons of Swimming Performance in Rainbow Trout Using Constant Acceleration and Critical Swimming Speed Tests. Journal of fish biology, 72(3), 693-710.

Ferrando, M. D., \& Andreu, E. (1993). Feeding-Behavior As An Index Of Copper Stress In Daphnia-magna And Brachionus-calyciflorus. Comparative biochemistry and physiology c-pharmacology toxicology \& endocrinology, 106(2), 327-331.

Fry, B., Mumford, P. L., Tam, F., Fox, D. D., Warren, G. L., Havens, K. E., \& Steinman, A. D. (1999). Trophic Position and Individual Feeding Histories of Fish from Lake Okeechobee, Florida. Canada journal of fish aquatic science. 56: 590-600.

Ghysen, A., \& Dambly-Chaudiere, C. (2004). Development of the Zebrafish Lateral Line. Current opinion in neurobiology, 14(1), 67-73.

Grosell, M., Blanchard, J., Brix, K. V., \& Gerdes, R. (2007). Physiology is Pivotal for Interactions Between Salinity and Acute Copper Toxicity to Fish and Invertebrates. Aquatic toxicology, 84(2), 162-172.

Hall, D., \& Suboski, M. D. (1995). Visual And Olfactory Stimuli In Learned Release Of Alarm Reactions By Zebra Danio Fish (Brachydanio-Rerio). Neurobiology of learning and memory, 63(3), 229-240.

Hartman, E. J., \& Abrahams, M. V. (2000). Sensory compensation and the detection of predators: the interaction between chemical and visual information. Proceedings of the royal society b-biological sciences, 267(1443), 571-575.

Hassan, W., Abdullah, S., Abbas, K., Batool, M., \& Yaqub, S. (2015). The Effect of SubLethal Level of Dietary Copper and Cadmium on the Growth Performance and 
Oxidative Stress in Cirrhina mrigala. Pakistan journal of agricultural sciences, 52(3), 789-794.

Hernandez, P. P., Moreno, V., Olivari, F. A., \& Allende, M. L. (2006). Sub-Lethal Concentrations of Waterborne Copper are Toxic to Lateral Line Neuromasts in Zebrafish (Danio rerio). Hearing research, 213(1-2), 1-10.

Heydarnejad, M. S., Khosravian-hemami, M., Nematollahi, A., \& Rahnama, S. (2013). Effects of Copper at Sublethal Concentrations on Growth and Biochemical Parameters in Rainbow Trout (Oncorhynchus mykiss). International review of hydrobiology, 98(2), 71-79.

Hoang, T. C., Pryor, R. L., Rand, G. M., \& Frakes, R. A. (2011). Bioaccumulation and Toxicity of Copper in Outdoor Freshwater Microcosms. Ecotoxicology and environmental safety, 74(4), 1011-1020.

Hoang, T. C., Schuler, L. J., \& Rand, G. M. (2009). Effects of Copper in Flooded Florida Agricultural Soils on Hyalella azteca. Arch environ contam toxicol, 56(3), 459467.

Hunt, B. P. (1960). Digestion Rate and Food Consumption of Florida Gar, Warmouth, and Largemouth Bass. Transactions of the American fisheries society, 89 (2): 206-211.

Ingster-Moati, I., Quoc, E. B., Pless, M., Djomby, R., Orssaud, C., Guichard, J. P., \& Woimant, F. (2007). Ocular Motility and Wilson's Disease: a Study on 34 Patients. Journal of neurology neurosurgery and psychiatry, 78(11), 1199-1201.

Javed, M. (2012a). Growth Responses of Fish under Chronic Exposure of Waterborne and Dietary Metals. International journal of agriculture and biology, 14(2), 281285.

Javed, M. (2012b). Tissue-Specific Bio-Accumulation of Metals in Fish During Chronic Waterborne and Dietary Exposures. Pakistan veterinary journal, 32(4), 567-570.

Javed, M. (2015). Chronic Dual Exposure (Waterborne plus Dietary) Effects of Cadmium, Zinc and Copper on Growth and their Bioaccumulation in Cirrhina mrigala. Pakistan veterinary journal, 35(2), 143-146.

Kiaune, L., \& Singhasemanon, N. (2011). Pesticidal Copper (I) Oxide: Environmental Fate and Aquatic Toxicity. Rev environ contam toxicol, 213, 1-26.

Kolok, A. S., Hartman, M. M., \& Sershan, J. (2002). The physiology of copper tolerance in fathead minnows: Insight from an intraspecific, correlative analysis. Environmental toxicology and chemistry, 21(8), 1730-1735. 
Kolok, A. S., \& Sharkey, D. (1997). Effect of Freshwater Acclimation on the Swimming Performance and Plasma Osmolarity of the Euryhaline Gulf Killifish.

Transactions of the American fisheries society, 126 (5) 866-870

Kwan, C. K., Sanford, E., \& Long, J. (2015). Copper Pollution Increases the Relative Importance of Predation Risk in an Aquatic Food Web. Plos one, 10(7), 13.

Li, X. Y., Ye, T. C., Li, Y. P., \& Zhang, X. L. (2014). Secondary Glaucoma with Copper Deposition in Trabecular Meshwork in Wilson disease. Clinical and experimental ophthalmology, 42(2), 204-205.

Li, Y. B., Duanp, Z. W., Liu, G. L., Kalla, P., Scheidt, D., \& Cai, Y. (2015). Evaluation of the Possible Sources and Controlling Factors of Toxic Metals/Metalloids in the Florida Everglades and Their Potential Risk of Exposure. Environmental science \& technology, 49(16), 9714-9723.

Liang, G. H., Jarlebark, L., Ulfendahl, M., \& Moore, E. J. (2003). Mercury (Hg2+) Suppression of Potassium Currents of Outer Hair Cells. Neurotoxicology and teratology, 25(3), 349-359.

Linbo, T. L., Stehr, C. M., Incardona, J. P., \& Scholz, N. L. (2006). Dissolved Copper Triggers Cell Death in the Peripheral Mechanosensory System of Larval Fish. Environmental toxicology and chemistry, 25(2), 597-603.

Martel, G., \& Dill, L. M. (1995). Influence of Movement by Coho Salmon (Oncorhynchus-kisutch) Parr on Their Detection by Common Mergansers (Mergus merganser). Ethology, 99(2), 139-149.

McIntyre, J. K., Baldwin, D. H., Meador, J.P., \& Scholz, N.L. (2008). Chemosensory Deprivation in Juvenile Coho Salmon Exposed to Dissolved Copper Under Varying Water Chemistry Conditions. Environmental science \& technology, 42 (17), 6774-6775.

McIntyre, J. K., Baldwin, D. H., Beauchamp, D. A., \& Scholz, N. L. (2012). Low-Level Copper Exposures Increase Visibility and Vulnerability of Juvenile Coho Salmon to Cutthroat Trout Predators. Ecological applications, 22(5), 1460-1471.

McKenzie, D. J., Cataldi, E., Romano, P., Owen, S. F., Taylor, E. W., \& Bronzi, P. (2001). Effects of Acclimation to Brackish Water on the Growth, Respiratory Metabolism, and Swimming Performance of Young-of-the-Year Adriatic Sturgeon (Acipenser naccarii). Canada journal fish aquatic science, 58: 11041112 .

McKenzie, D. J., Shingles, A., \& Taylor, E. W. (2003). Sub-Lethal Plasma Ammonia Accumulation and the Exercise Performance of Salmonids. Comparative 
biochemistry and physiology a-molecular \& integrative physiology, 135(4), 515526.

McWilliam, R. A., \& Baird, D. J. (2002). Postexposure Feeding Depression: A Dew toxicity endpoint for use in laboratory studies with Daphnia magna. Environmental toxicology and chemistry, 21(6), 1198-1205.

Meyer, J. S., \& DeForest, D. K. (2018). Protectiveness of Cu Water Quality Criteria Against Impairment of Behavior and Chemo/Mechanosensory Responses: An Update. Environmental toxicology and chemistry, 37(5), 1260-1279.

Mohseni, M., Park, G. H., Lee, J. H., Okorie, O. E., Browdy, C., Bharadwaj, A., \& Bai, S. C. (2012). Evaluation of Toxicity of Dietary Chelated Copper in Juvenile Olive Flounder, Paralichthys olivaceus, Based on Growth and Tissue Copper Concentration. Journal of the world aquaculture society, 43(4), 548-559.

Montgomery, J., Bleckmann, H., \& Coombs, S. (2014). Sensory Ecology and Neuroethology of the Lateral Line. Springer handbook of auditory research, 48: $121-150$.

Narayanan, I. G., Saravanan, R., Bharathselvi, M., Biswas, J., \& Sulochana, K. N. (2016). Localization of Human Copper Transporter 1 in the Eye and its Role in Eales Disease. Ocular immunology and inflammation, 24(6), 678-683.

Nordlie, F. G., Haney, D. C., \& Walsh, S. J. (1992). Comparisons of Salinity Tolerances and Osmotic Regulatory Capabilities in Populations of Sailfin molly (Poecilialatipinna) from Brackish and Fresh Waters. Copeia (3), 741-746.

Oufiero, C. E., \& Garland, T. (2009). Repeatability and Correlation of Swimming Performances and Size Over Varying Time-Scales in the Guppy (Poecilia reticulata). Functional ecology, 23(5), 969-978.

Pitcher, T. J., Green, D. A., \& Magurran, A. E. (1986). Dicing with Death - Predator Inspection Behavior in Minnow Shoals. Journal of fish biology, 28(4), 439-448.

Rajotte, J. W., \& Couture, P. (2002). Effects of Environmental Metal Contamination on the Condition, Swimming Performance, and Tissue Metabolic Capacities of Wild Yellow Perch (Perca flavescens). Canadian journal of fisheries and aquatic sciences, 59(8), 1296-1304.

Sampaio, F. G., Boijink, C. D., dos Santos, L. R. B., Oba, E. T., Kalinin, A. L., \& Rantin, F. T. (2010). The Combined Effect of Copper and Low pH on Antioxidant Defenses and Biochemical Parameters in Neotropical Fish Pacu, Piaractus mesopotamicus. Ecotoxicology, 19(5), 963-976. 
Sanchez, J. L., \& Trexler, J. C. (2018). When is an Herbivore Not an Herbivore? Detritivory Facilitates Herbivory in a Freshwater System. Ecology and evolution, 8(12), 5977-5991.

Schuler, L. J., Hoang, T. C., \& Rand, G. M. (2008). Aquatic Risk Assessment of Copper in Freshwater and Saltwater Ecosystems of South Florida. Ecotoxicology, 17(7), 642-659.

Sovova, T., Boyle, D., Sloman, K. A., Perez, C. V., \& Handy, R. D. (2014). Impaired Behavioural Response to Alarm Substance in Rainbow Trout Exposed to Copper Nanoparticles. Aquatic toxicology, 152, 195-204.

Stephenson, J. F. (2016). Keeping Eyes Peeled: Guppies Exposed to Chemical Alarm Cue are More Responsive to Ambiguous Visual Cues. Behavioral ecology and sociobiology, 70(4), 575-584.

Tchounwou, P. B., Newsome, C., Williams, J., \& Glass, K. (2008). Copper-Induced Cytotoxicity and Transcriptional Activation of Stress Genes in Human Liver Carcinoma (HepG(2)) Cells. Metal ions in biology and medicine, Vol 10, 10, 285290.

Thomas, O. R. B., Barbee, N. C., Hassell, K. L., \& Swearer, S. E. (2016). Smell No Evil: Copper Disrupts the Alarm Chemical Response in a Diadromous Fish, Galaxias maculatus. Environmental toxicology and chemistry, 35(9), 2209-2214.

Tierney, K. B. (2011). Swimming Performance Assessment in Fishes. Jove-journal of visualized experiments(51), 4.

Tierney, K. B., Baldwin, D. H., Hara, T. J., Ross, P. S., Scholz, N. L., \& Kennedy, C. J. (2010). Olfactory toxicity in fishes. Aquatic toxicology, 96 (1), 2-26.

Tierney, K. B., \& Farrell, A. P. (2004). The Relationships Between Fish Health, Metabolic Rate, Swimming Performance and Recovery in Return-Run Sockeye Salmon, Oncorhynchus nerka (Walbaum). Journal of fish diseases, 27(11), 663671.

Toms, C., Echevarria, D., \& Jouandot, D. J. A Methodological Review of PersonalityRelated Studies in Fish: Focus on the Shy-Bold Axis of Behavior. International journal of comparative psychology, 23: 1-25.

United States Department of Agriculture (2006). Florida State and County Data/Census of Agriculture (2002-2004), vol 1. AC-02- A-9. National agricultural statistics service. 
United States Environmental Protection Agency (2007). Aquatic Life Ambient Freshwater Quality Criteria - Copper. EPA-822-R-07-001

United States Environmental Protection Agency (2016). Draft Aquatic Life Ambient Estuarine/Marine Water Quality Criteria For Copper. EPA-822-P-16-001

Vergolyas, M. R., Veyalkina, N. N., \& Goncharuk, V. V. (2010). Effect of Copper Ions on Hematological and Cytogenetic Parameters of Freshwater Fishes Carassius auratus gibelio. Cytology and genetics, 44(2), 124-128.

Vieira, L. R., Gravato, C., Soares, A., Morgado, F., \& Guilhermino, L. (2009). Acute Effects of Copper and Mercury on the Estuarine Fish Pomatoschistus microps: Linking Biomarkers to Behaviour. Chemosphere, 76(10), 1416-1427.

Ward, A. J. W., Thistle, M., Ghandi, K., \& Currie, S. (2013). Copper Interacts with Nonylphenol to Cancel the Effect of Nonylphenol on Fish Chemosensory Behaviour. Aquatic toxicology, 142, 203-209.

Waser, W., O. Bausheva, \& M. Nikinmaa. (2009). The Copper-Induced Reduction of Critical Swimming Speed in Rainbow Trout (Oncorhynchus mykiss) is not Caused by Changes in Gill Structure. Aquatic toxicology, 94 (1): 77-79.

Yang, Y. G., He, Z. L., Wang, Y. B., Fan, J. H., Liang, Z. B., \& Stoffella, P. J. (2013). Dissolved Organic Matter in Relation to Nutrients (N and P) and Heavy Metals in Surface Runoff Water as Affected by Temporal Variation and Land Uses - A Case Study from Indian River Area, South Florida, USA. Agricultural water management, 118, 38-49. 


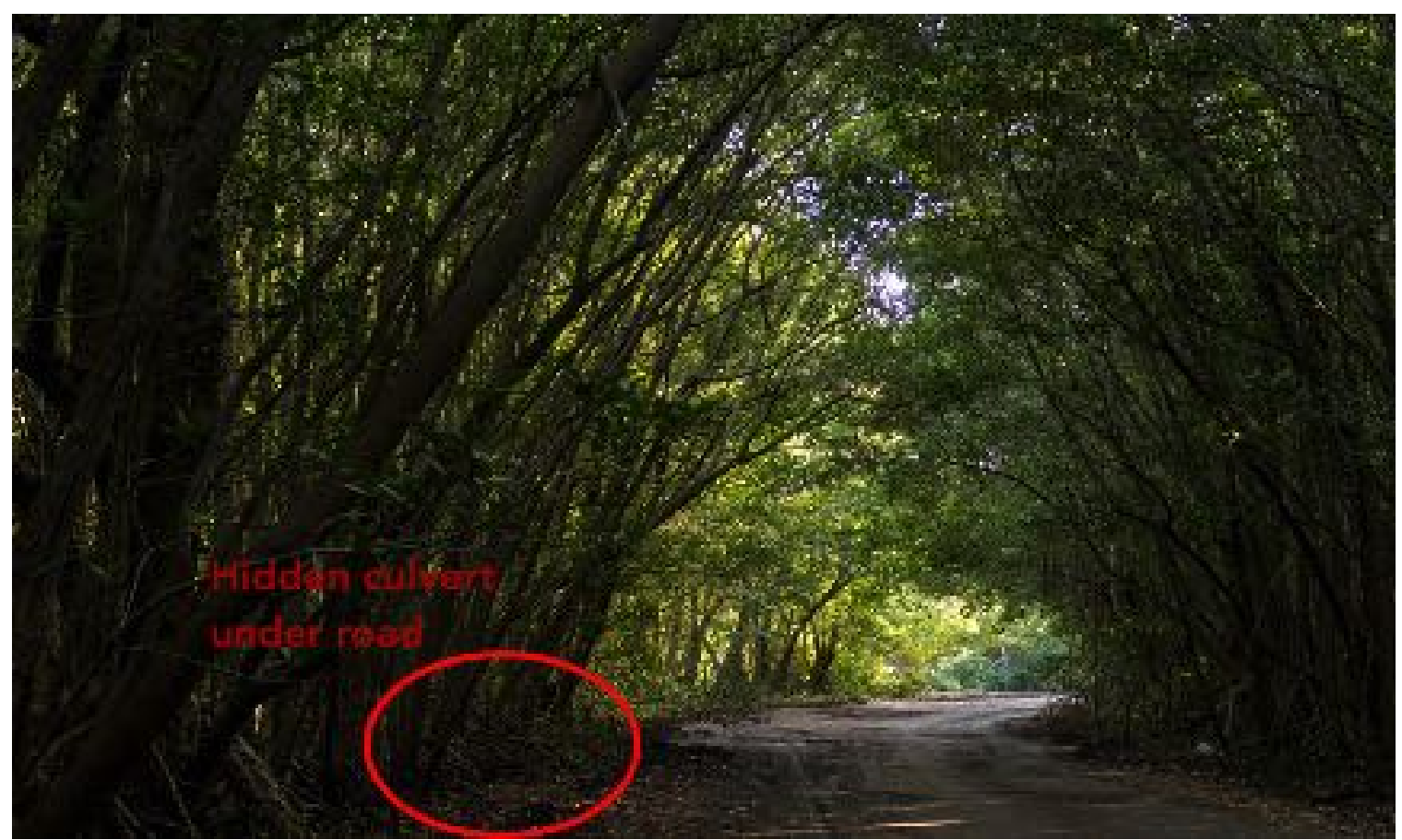

Figure 1. Collection site. Matheson Hammock County Park in Coral Gables, FL. Fish were caught from culverts located under the roads with minnow traps. Traps were left for a period of 3 hours and then collected. By-catch was returned to the wild, only Sailfin Mollies were taken back to the Ecotoxicology and Risk Assessment Laboratory at Florida International University. 


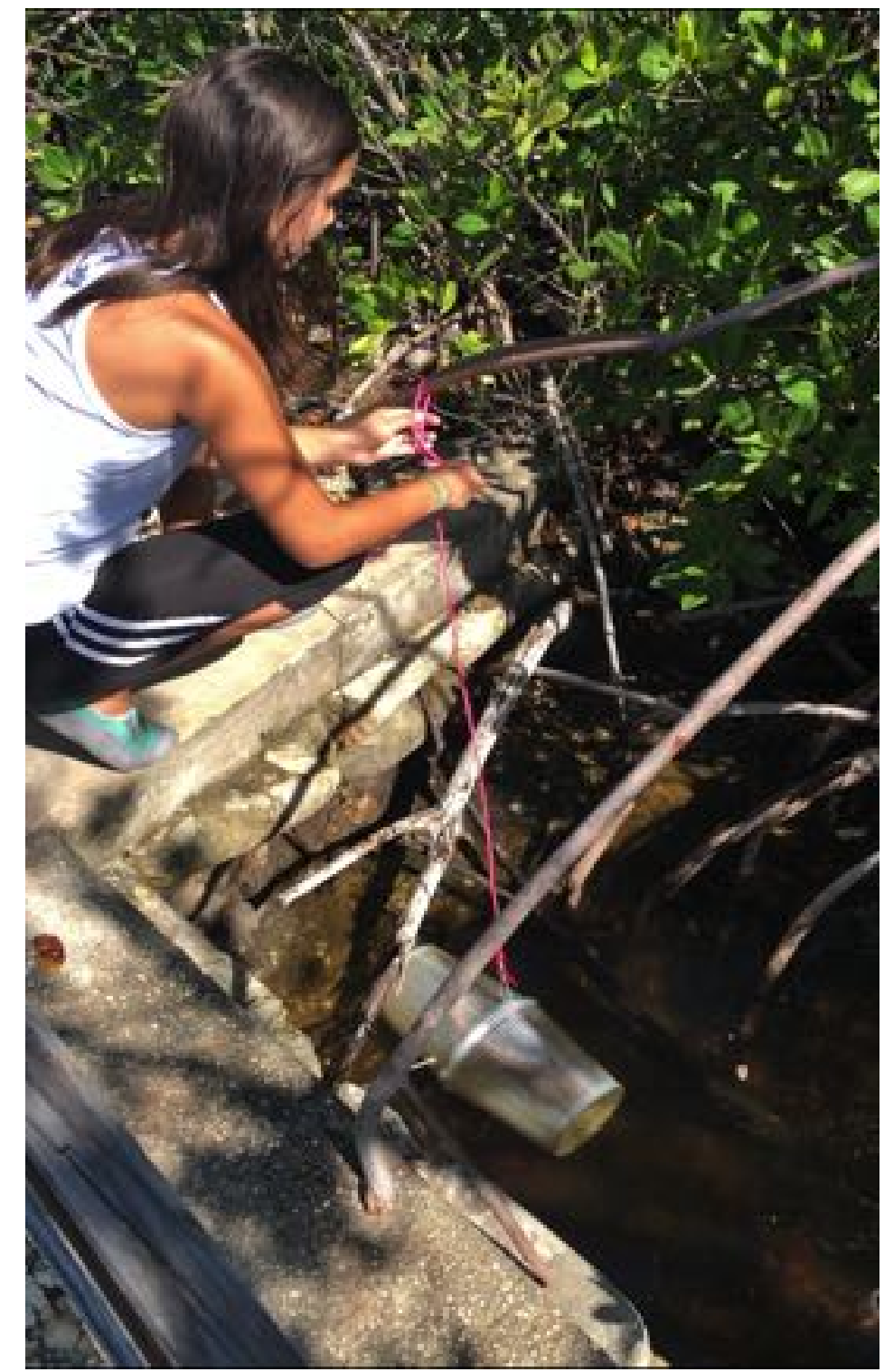

Figure 2. Minnow Traps in Collection Site. Fish were caught with minnow traps filled with commercial cat food. Minnow traps were placed in the culverts of Matheson Hammock County Park and left for 3 to 5 hours. By-catch was returned to the wild, only Sailfin Mollies were taken back to the Ecotoxicology and Risk Assessment Laboratory at Florida International University 


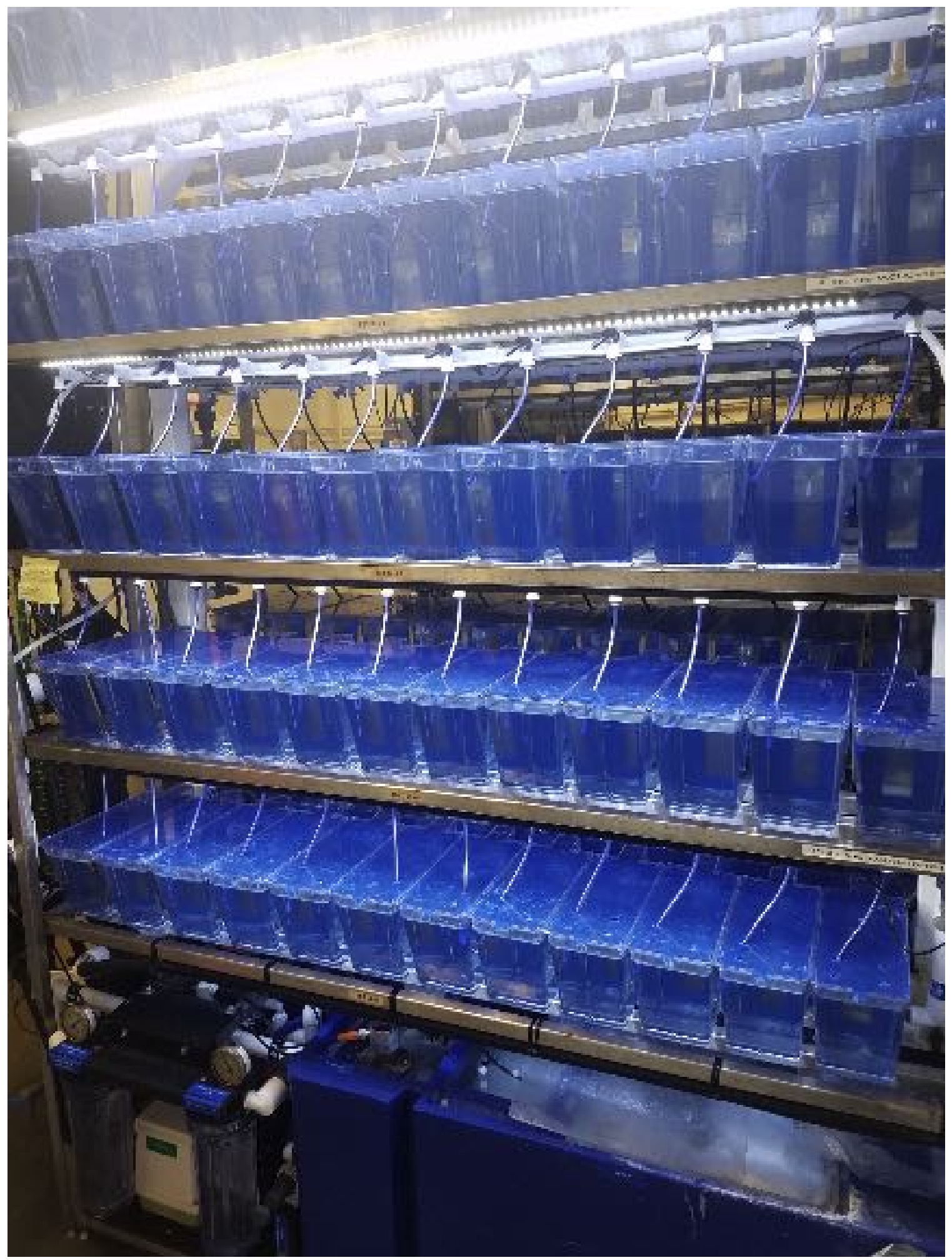

Figure 3. AquaHab/Z-HAB system. These systems were used to hold fish prior to the swimming performance experiments. (Pentair Aquatic Eco-Systems, Inc., Apopka, FL, USA). 


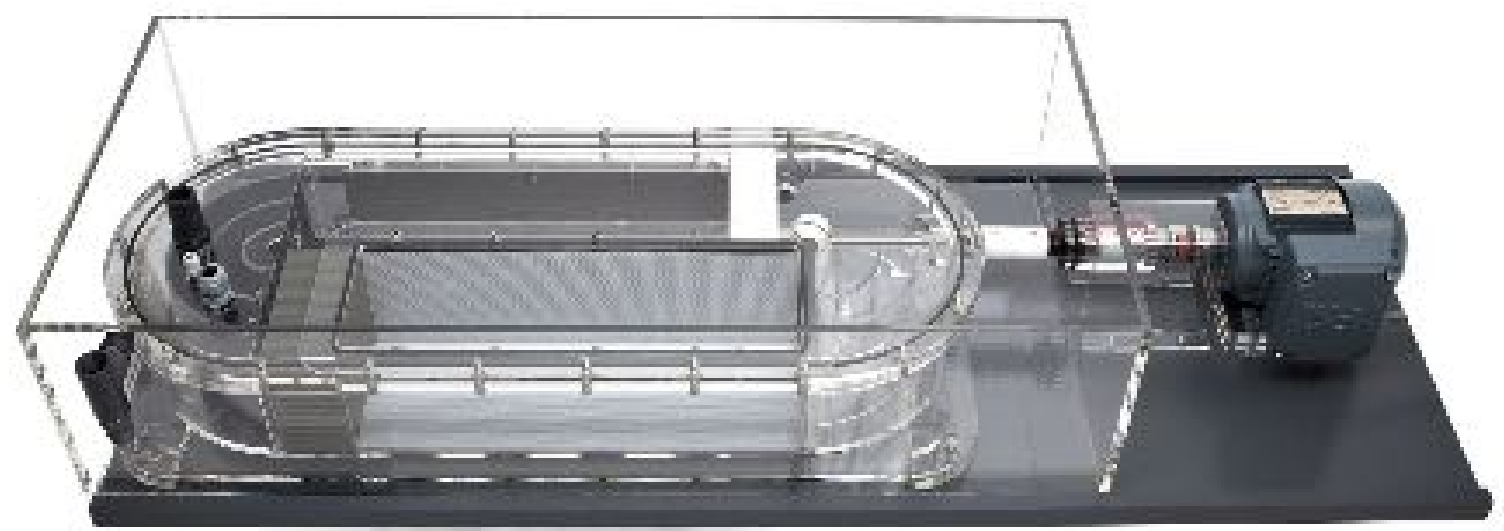

Figure 4. 5-L Brett-Style Swim Tunnel. This was the swimming tunnel used for the swimming performance experiments. (Loligo Systems, Tjele, Denmark, www.loligosystems.com). 


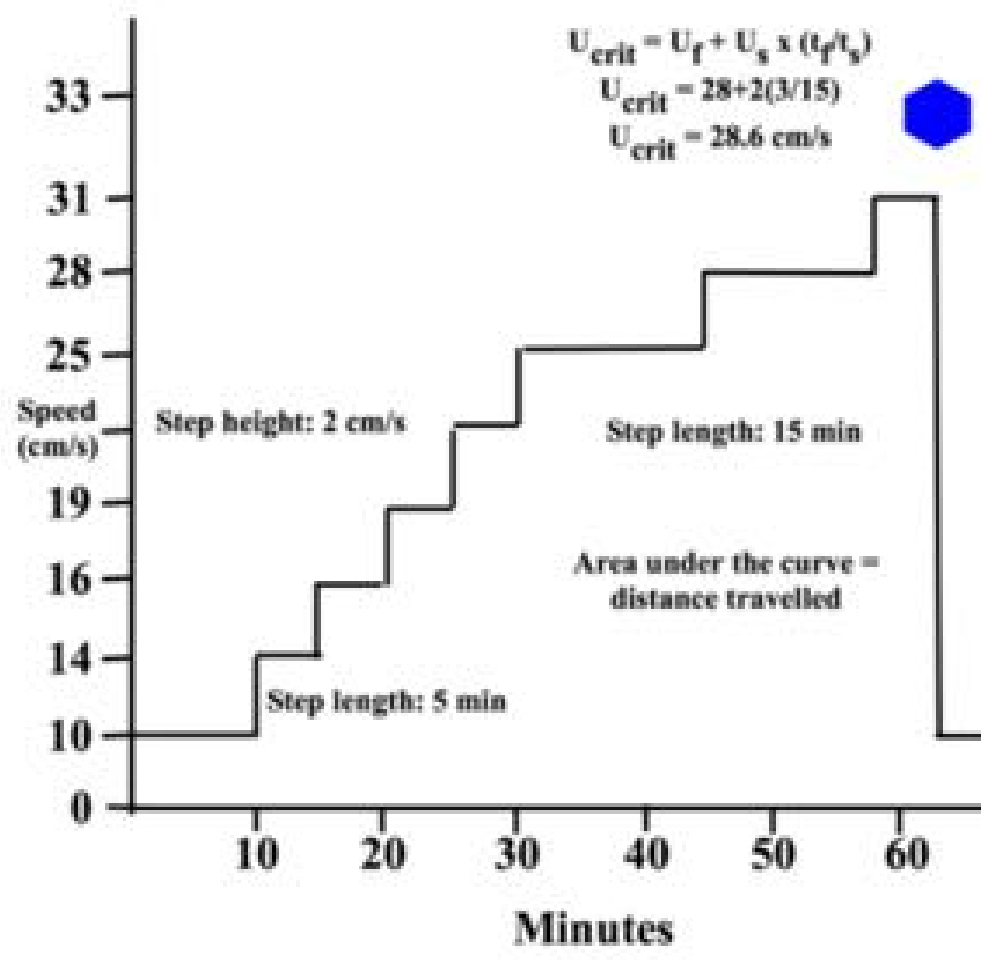


For the first ten minutes of the experiment fish swam at a velocity of $10 \mathrm{~cm} / \mathrm{s}$ for 10 minutes. The velocity was then increased by $2 \mathrm{~cm} / \mathrm{s}$ every 5 minutes until step number 5 . The first 5 steps of the experiments lasted a period of 5 minutes per step. From step 6 onward, the steps were prolonged to 15 minutes each, until the fish could not maintain position in the water column anymore. When the fish seemed unable to recover, the time and velocity at which it exhausted were recorded to find the $\mathrm{U}_{\text {crit }}$ as calculated from equation 1. 


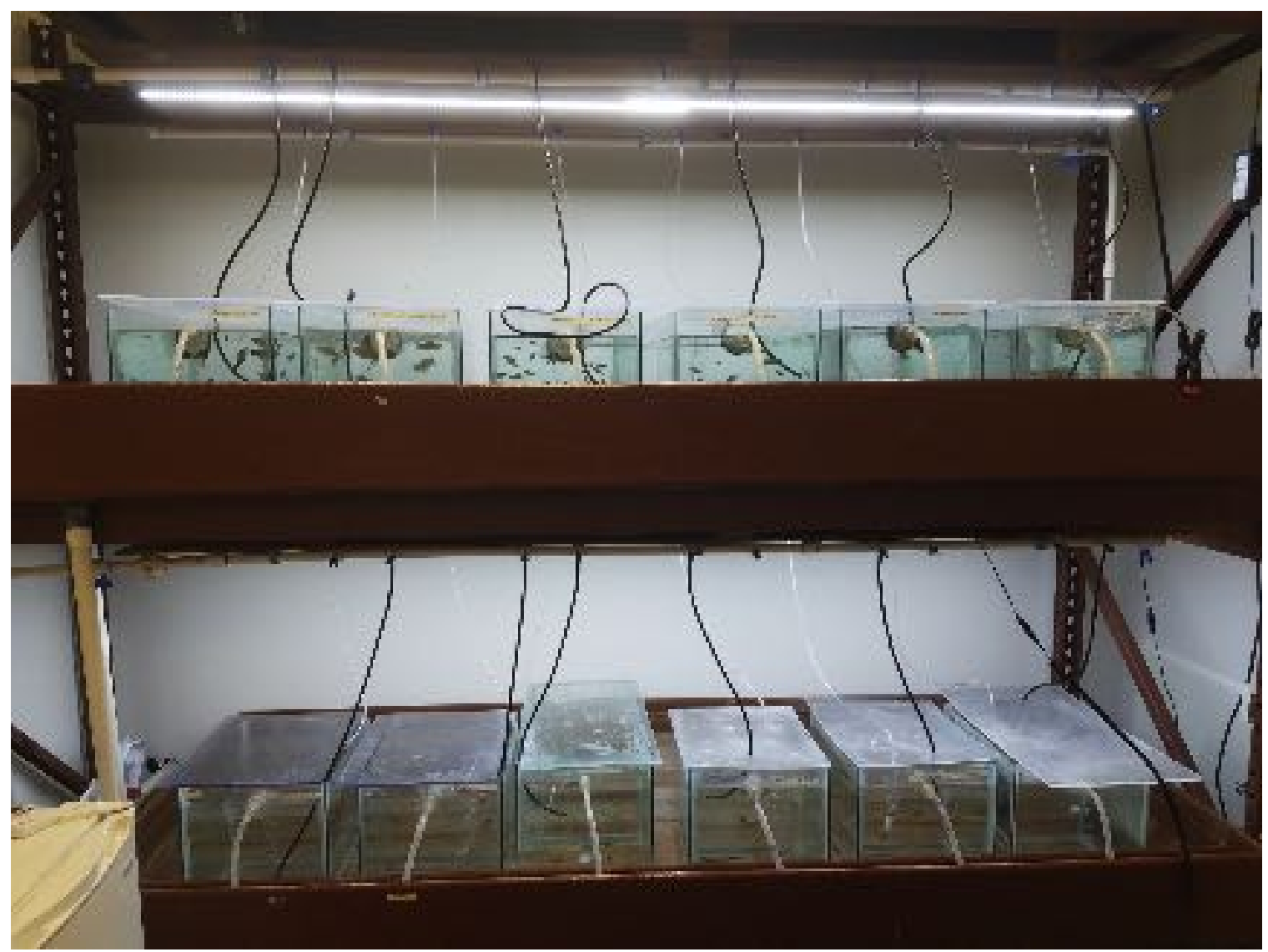

Figure 6. Freshwater Recirculating System. These systems were used to hold fish prior to the PredatorPrey Interaction Experiments. 


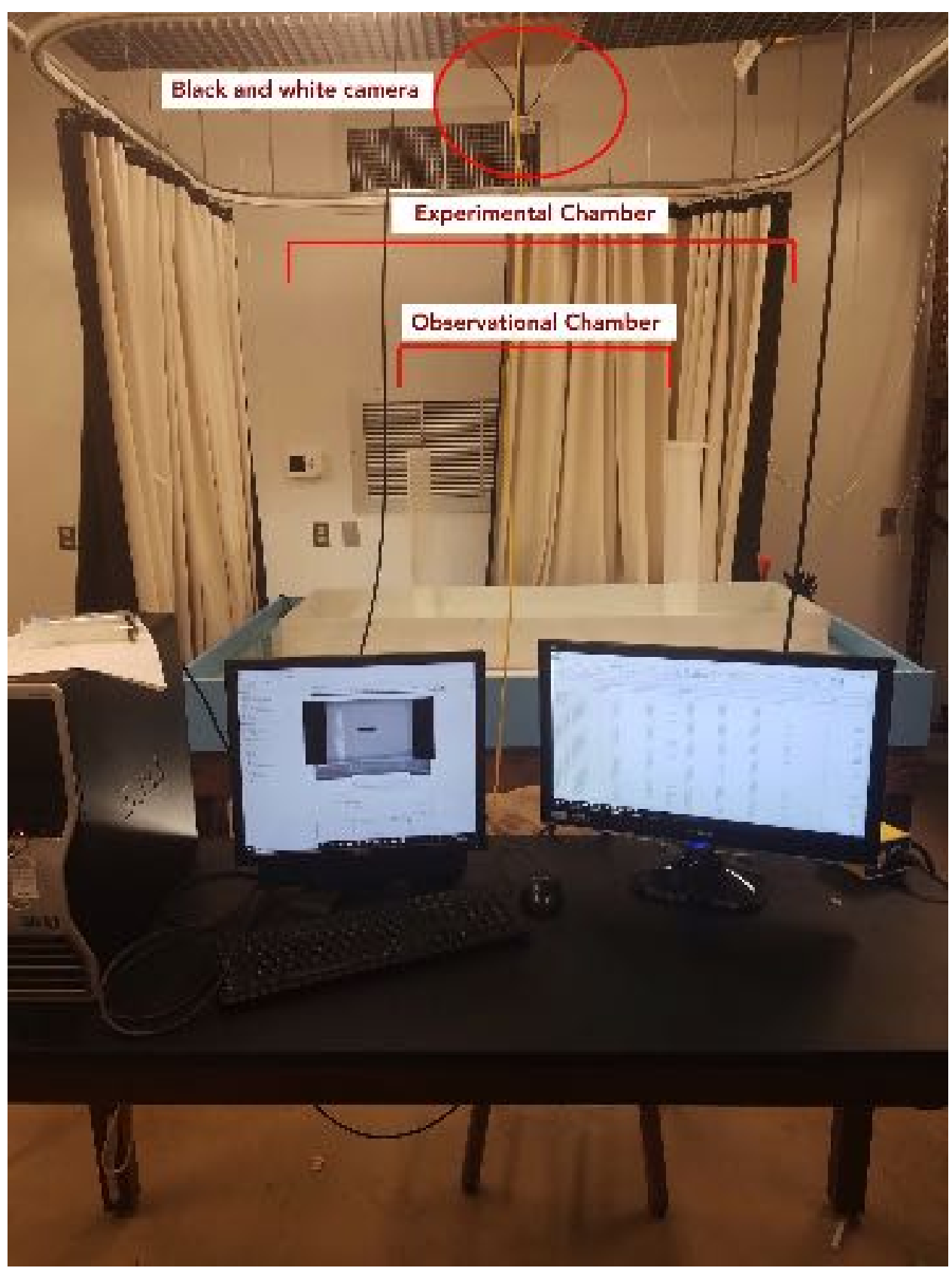

Figure 7. Predator-Prey Interaction Experimental Set Up. The experimental chamber was $122 \mathrm{~cm} \times 53 \mathrm{~cm} \times 20 \mathrm{~cm} 130 \mathrm{~L}$, which was then subdivided into an observational chamber $(79 \mathrm{~cm} \times 53 \mathrm{~cm} \times 13 \mathrm{~cm})$ where fish movements were recorded. The experimental chamber was made of acrylic, painted white to minimize reflection. One camera was position above the observational chamber to record the behavior of the fish. 


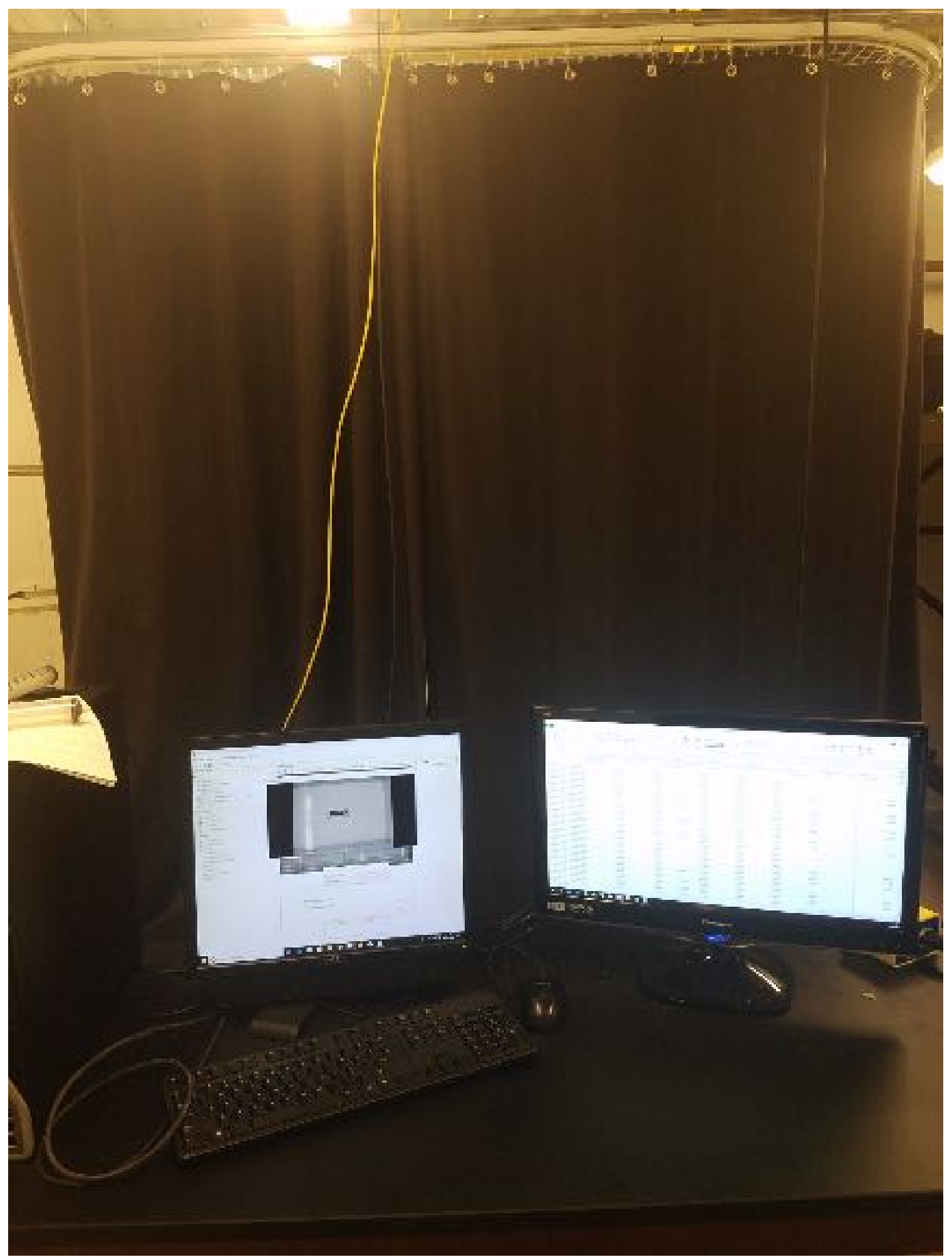

Figure 8. Experimental Chamber Covered with a Black-Out Curtain. A black-out curtain was used to cover the experimental chamber to minimize human contact with the fish. 


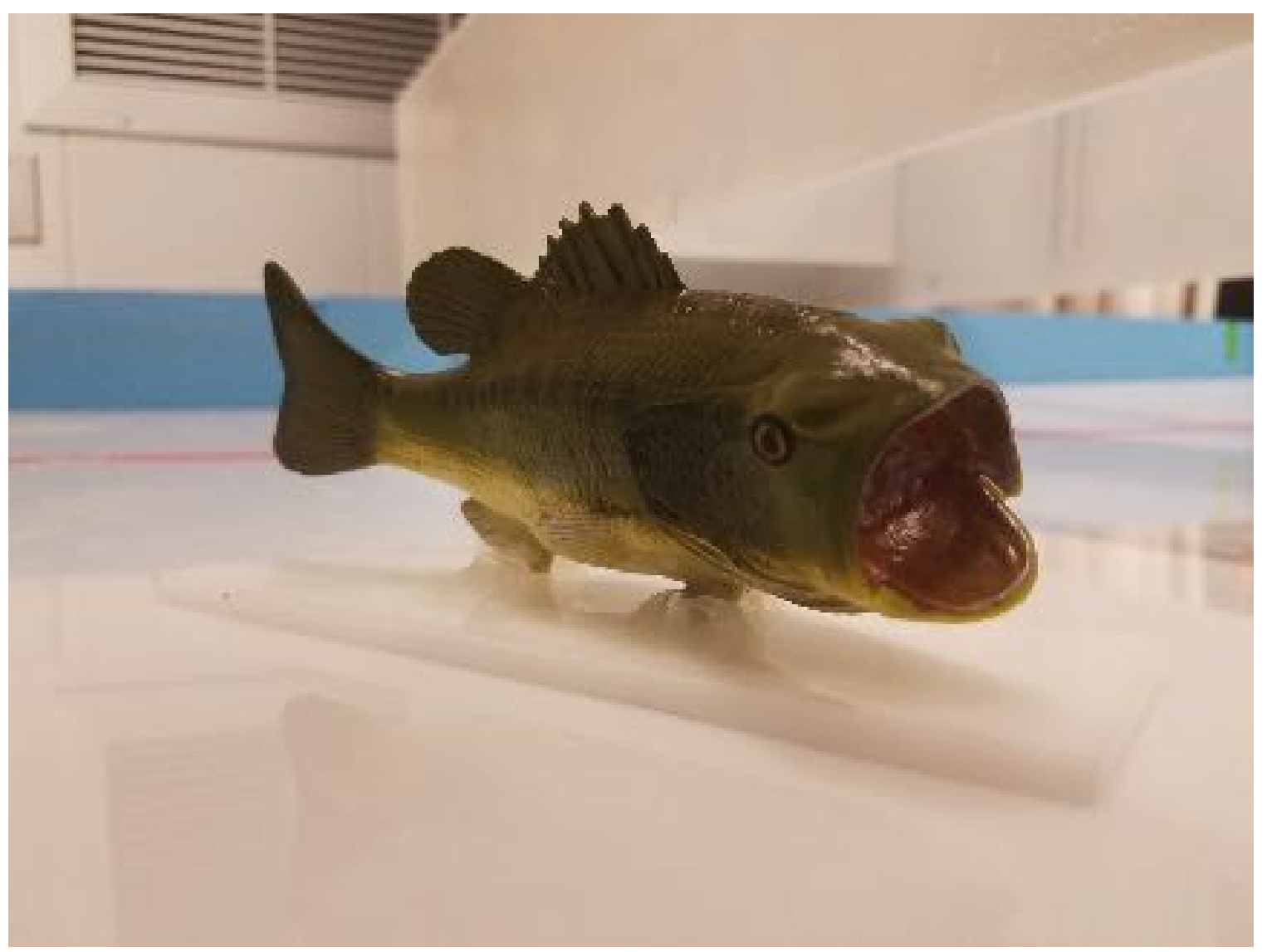

Figure 9. Largemouth Bass Model. This model was used as the visual cue in the predator-prey interaction experiments. The model was plastic, free of phthalate and lead, $15.24 \mathrm{~cm}$ long x $3.175 \mathrm{~cm}$ wide x $7.65 \mathrm{~cm}$ high and purchased from Amazon.com (item model number: S265629). 


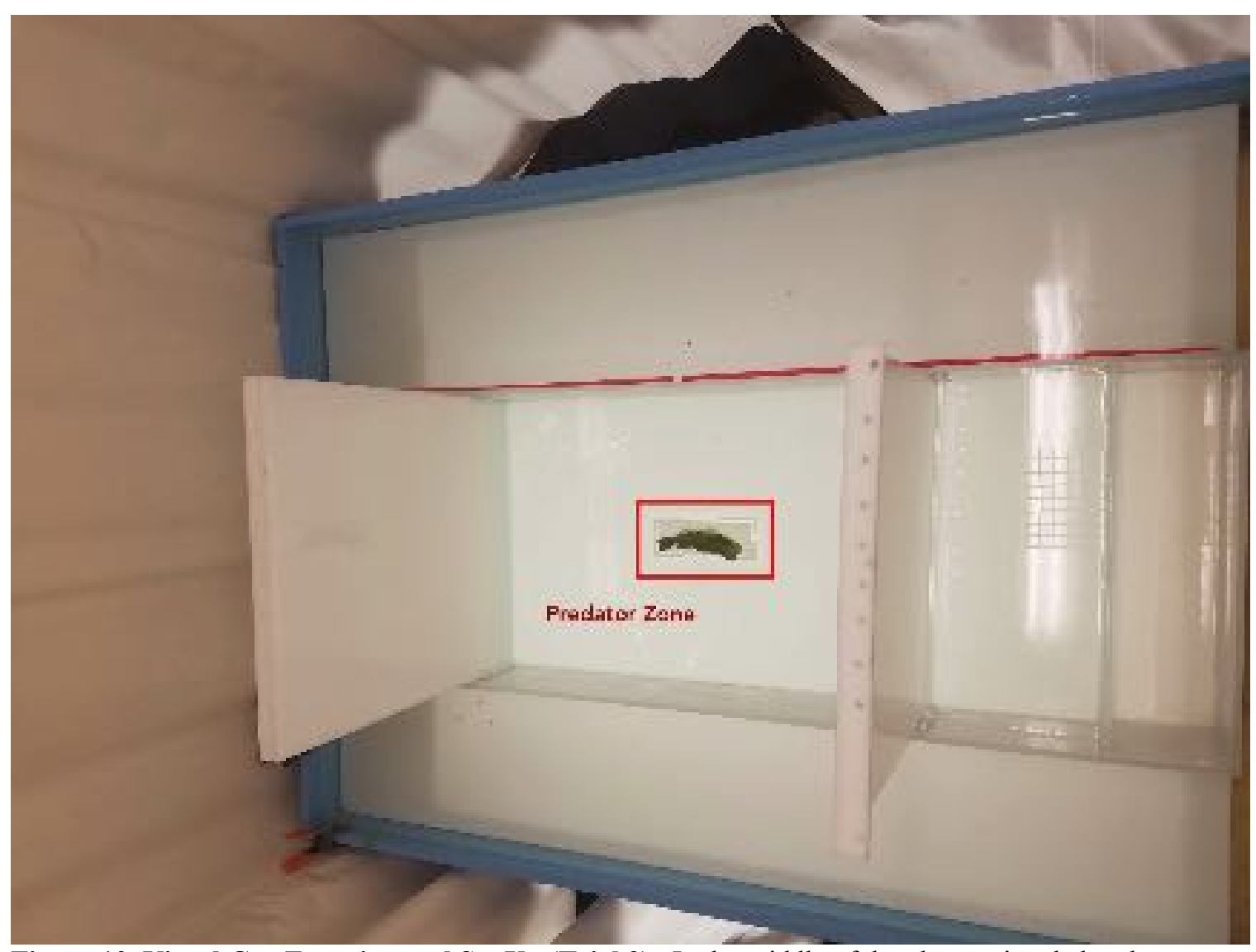

Figure 10. Visual Cue Experimental Set Up (Trial 2). In the middle of the observational chamber, a predator zone ( $20.5 \mathrm{~cm}$ long $\times 7 \mathrm{~cm}$ wide) was established to account for the number of times the prey entered the predator zone where the visual cue was introduced. The predator model was positioned in the middle of the predator zone. 


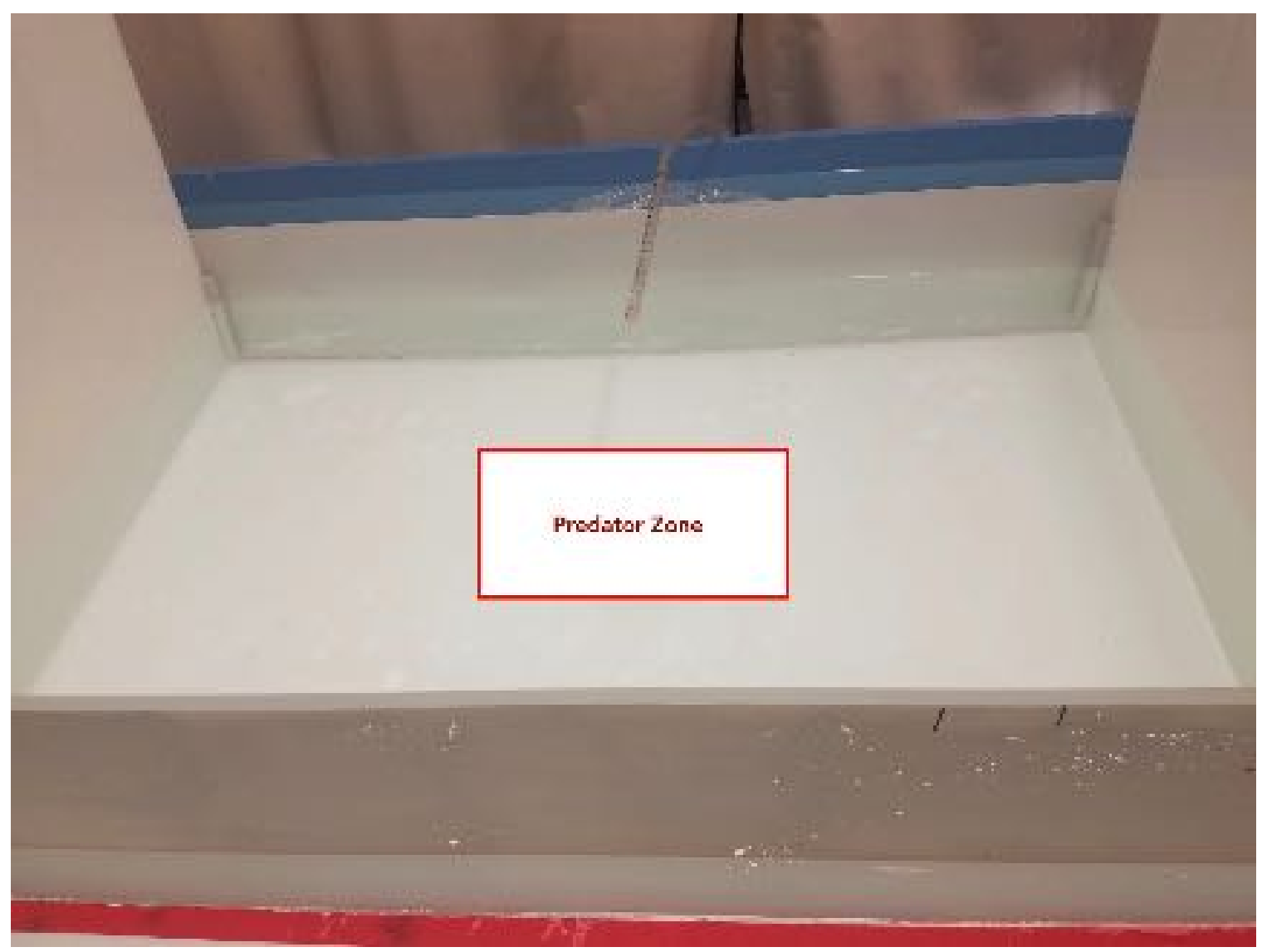

Figure 11. Chemical Cue Experimental Set Up (Trial 2). In the middle of the observational chamber, a predator zone ( $20.5 \mathrm{~cm}$ long $\times 7 \mathrm{~cm}$ wide) was established to account for the number of times the prey entered the predator zone where the chemical cue was introduced. The chemical cue was always introduced in the middle of the predator zone. 


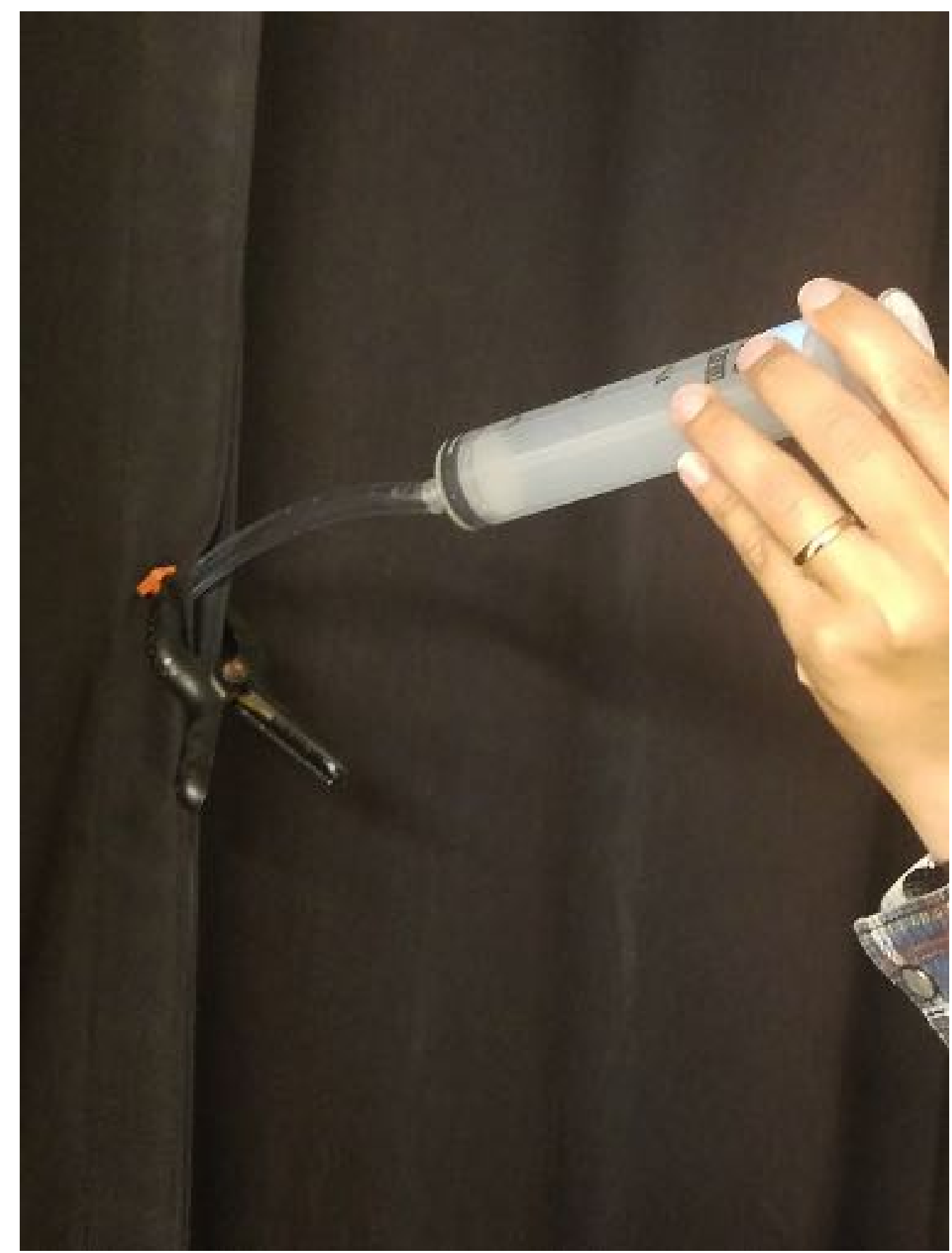

Figure 12. Introduction of Chemical Cue (Trial 2). On the basis of my own preliminary studies, I concluded that $65 \mathrm{ml}$ of the chemical mixture was the ideal concentration to study the effects of sublethal effects of copper on sailfin mollies. The chemical cue was not present in Trial 1, but was introduced in Trial 2. The $65 \mathrm{ml}$ chemical cue aliquot was always introduced from the same side of the chamber and directed towards the middle of the predator zone. To minimize distractions and human contact, the cue was introduced through a $15 \mathrm{~mm}$ diameter vinyl tubing that placed the chemical cue right in the middle of the predator zone. 


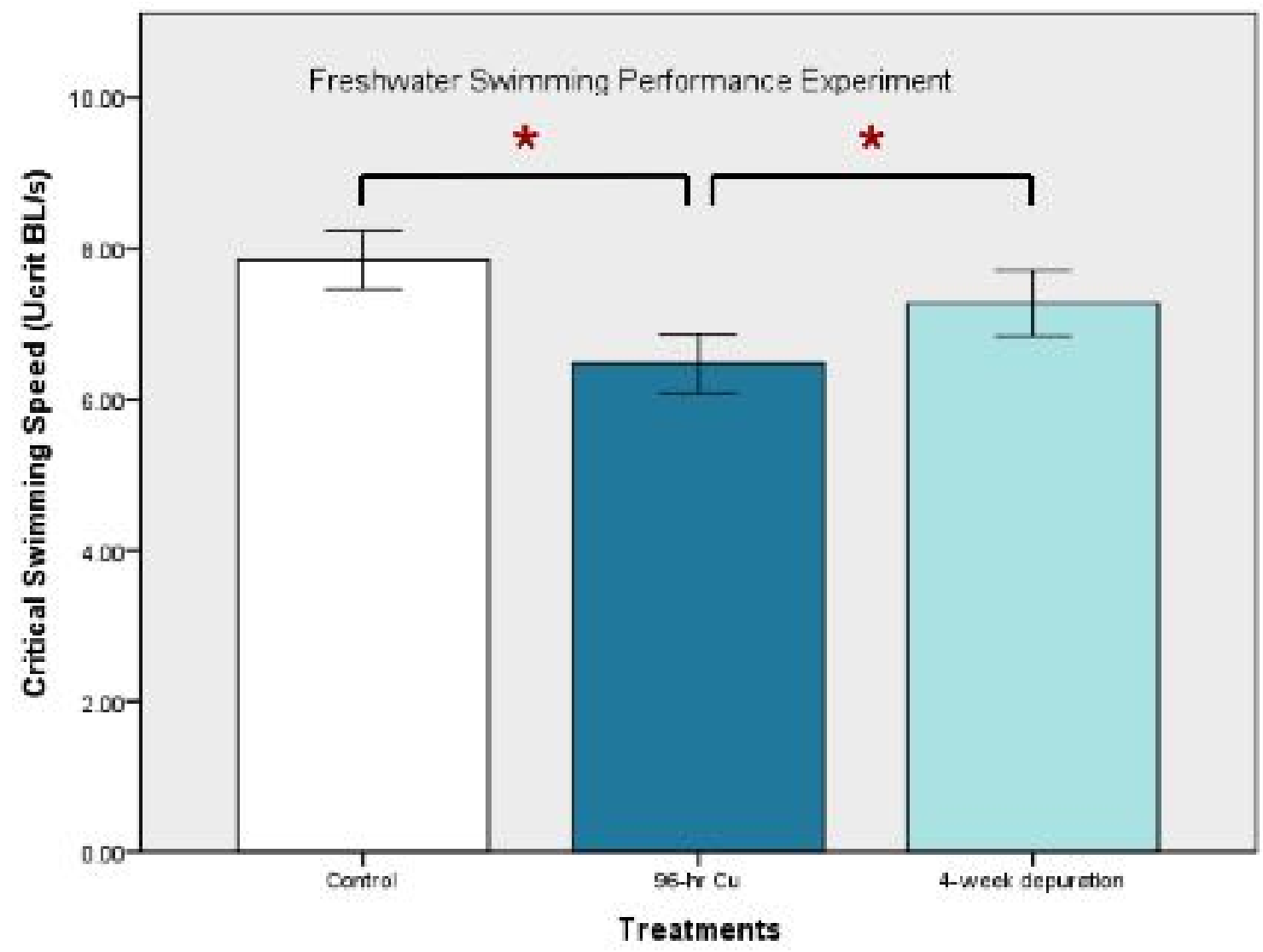

Error Bars: $95 \% \mathrm{Cl}$

Figure 13. Freshwater Swimming Performance Experiment Results. A 96-hour sublethal acute copper exposure (target concentration $11.3 \mu / \mathrm{L}$ ) was enough to affect swimming performance and reduce their critical swimming speed (P-value $<0.05)$, also known as $\mathrm{U}_{\text {crit }}$ in body length per sec $(\mathrm{Bl} / \mathrm{s})$. A 4-week depuration period was enough time for the contaminated fish to recover and perform as well as the control fish that were never exposed to copper (P-value $<0.05$ ). 


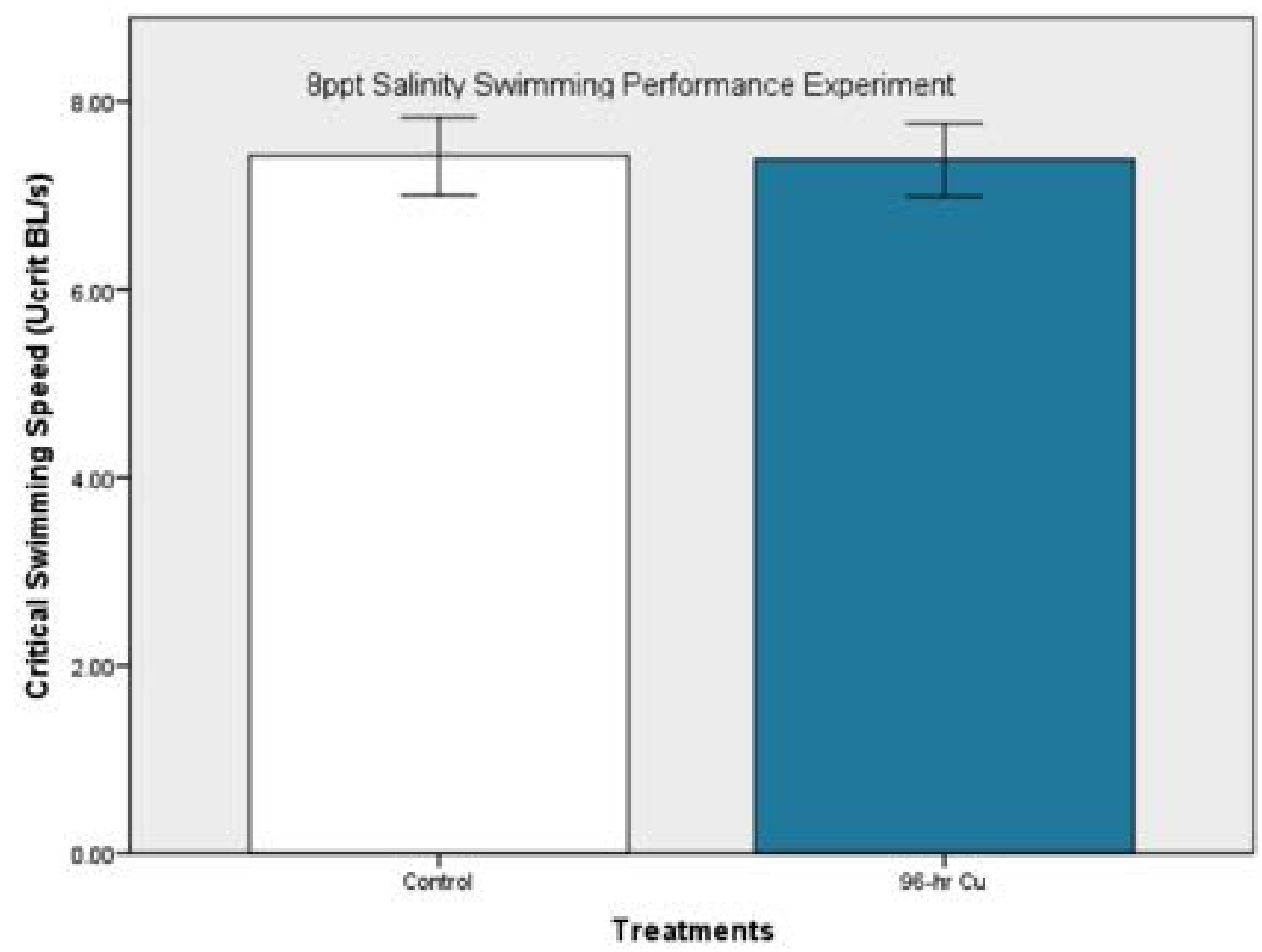

Error Bars: $95 \% \mathrm{Cl}$

Figure 14. 8ppt Salinity Swimming Performance Experiment Results. A 96-hour sublethal acute copper exposure (target concentration $8.44 \mu / \mathrm{L}$ ) did not have an effect on the swimming performance of fish acclimated to 8ppt salinity (P-value $<0.05$ ). Therefore, no depuration period was given to the fish to recover. 


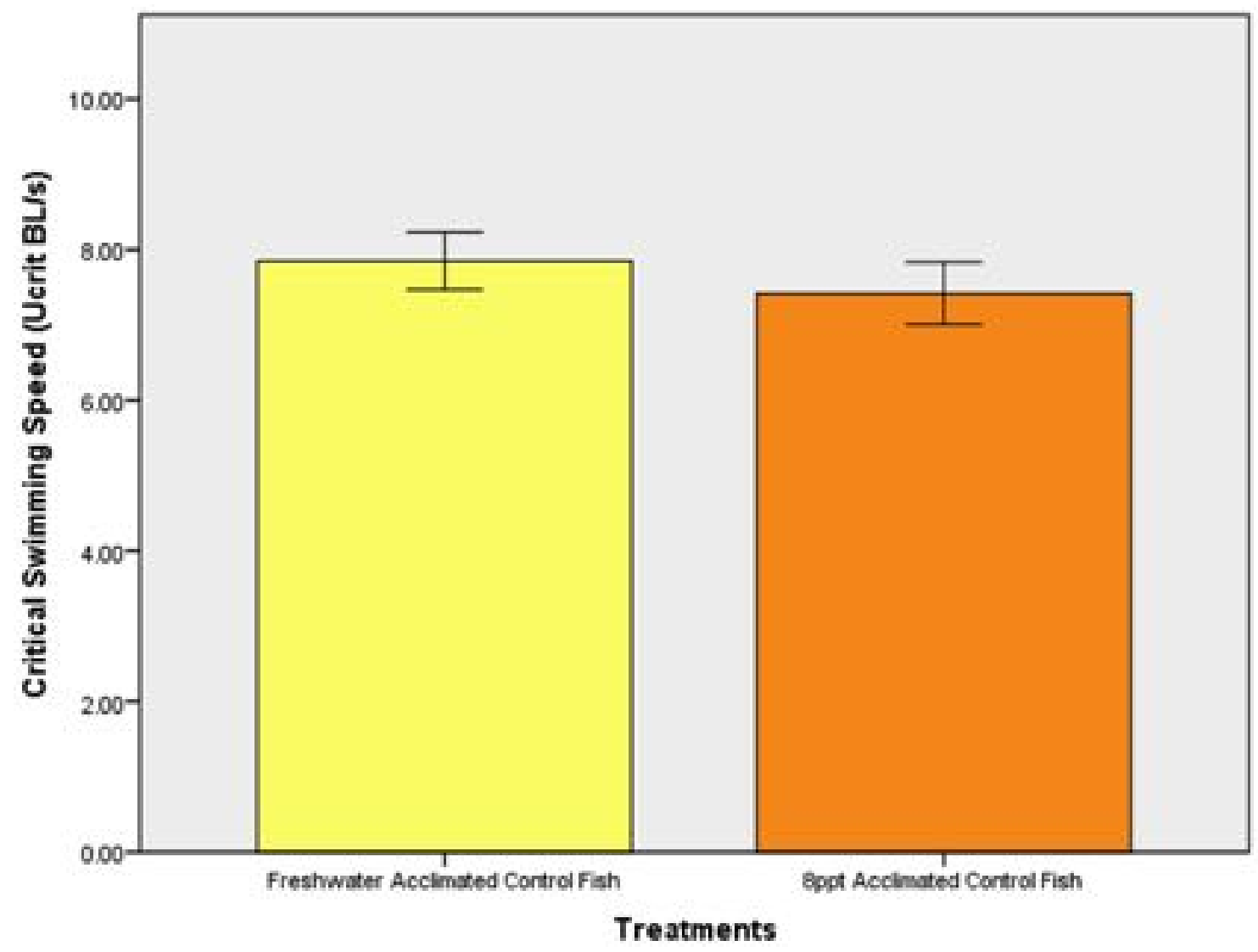

Error Bars: $95 \% \mathrm{Cl}$

Figure 15. Swimming Performance of Control Fish. There was not a significant difference between the swimming performance of fish that were acclimated to FW or 8ppt salinity. 


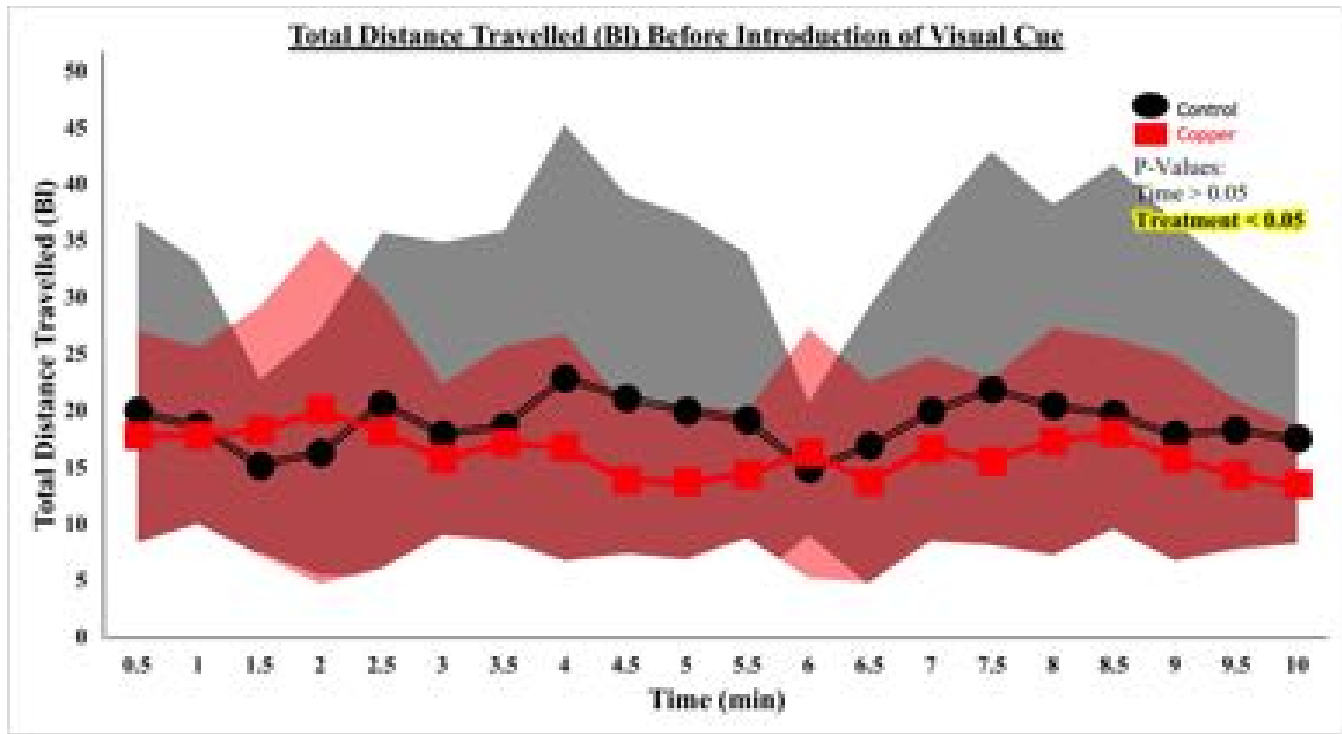

Figure 16A. Total Distance Travelled (BI) Before Introduction of Visual Cue. Before the introduction of the visual cue (predator model) both groups were left to acclimate for 10 minutes. During these 10 minutes, every 30 seconds data points were recorded. Every point in this graph represents the average of 10 individual fish and their total distance travelled at that specific time. The total distance per fish was normalized to body length in $\mathrm{cm}$ to control for differences in fish size. This graph shows that copper contaminated fish moved overall less distance than control fish before the introduction of the visual cue. Treatment was significant $(\mathrm{F}=4.45 ; \mathrm{DF}=1 ; \mathrm{P}<0.05)$ and time was not $(\mathrm{F}=0.46 ; \mathrm{DF}=1 ; \mathrm{P}>0.05)$. The shaded areas represent the standard deviation of the data. 


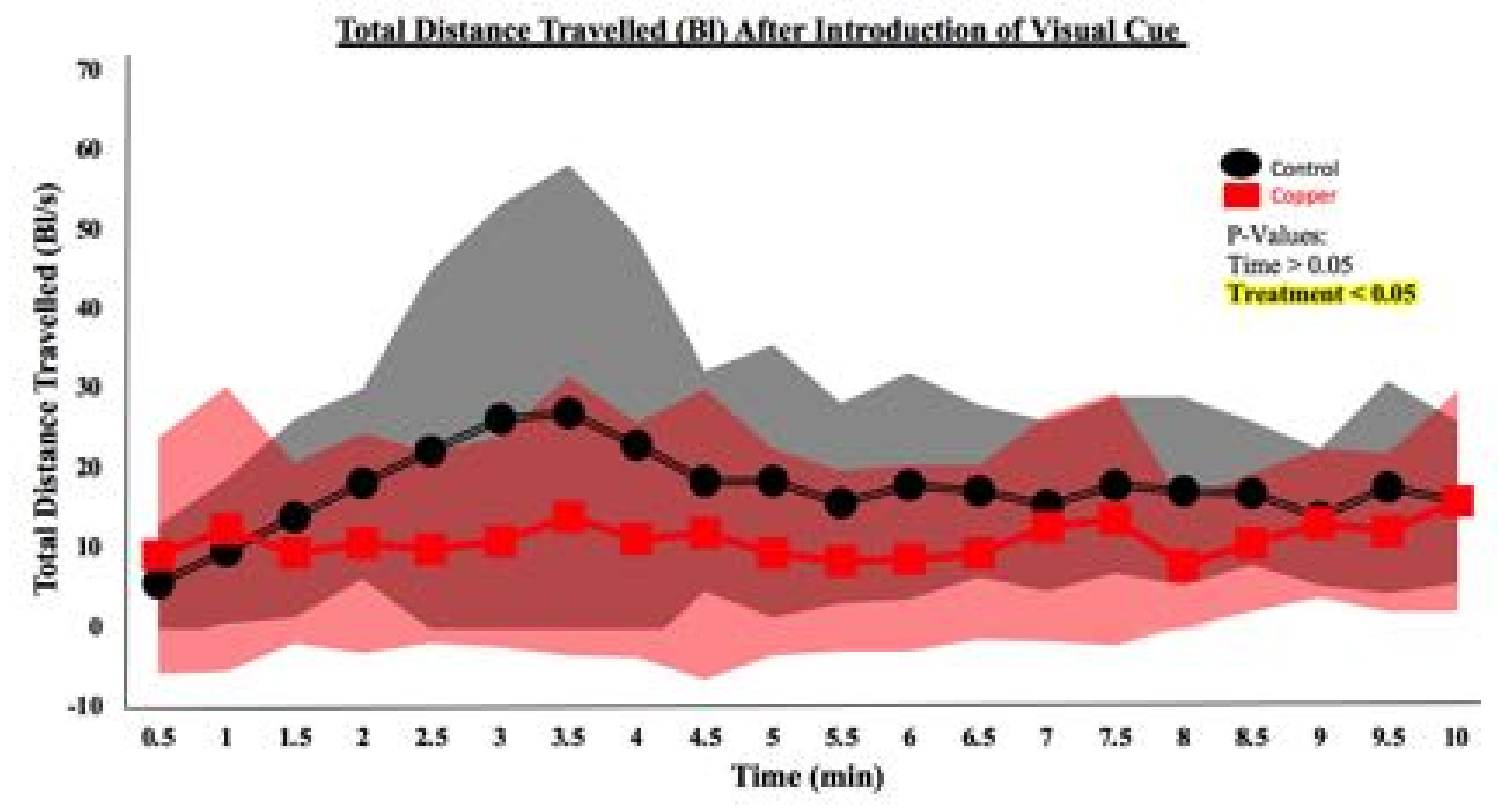

Figure 16B. Total Distance Travelled (BI) After Introduction of Visual Cue. After the introduction of the visual cue (predator model) data was recorded for 10 minutes. During these 10 minutes, every 30 seconds data points were recorded. Every point in this graph represents the average of 10 individual fish and their total distance travelled at that specific time. The total distance per fish was normalized to body length in $\mathrm{cm}$ to control for differences in fish size. This graph shows that copper contaminated fish moved overall less distance than control fish after the introduction of the visual cue. Treatment was significant $(\mathrm{F}=19.04 ; \mathrm{DF}=1 ; \mathrm{P}<0.05)$ and time was not $(\mathrm{F}=0.467 \mathrm{DF}=1$; $\mathrm{P}>0.05)$. The shaded areas represent the standard deviation of the data. 


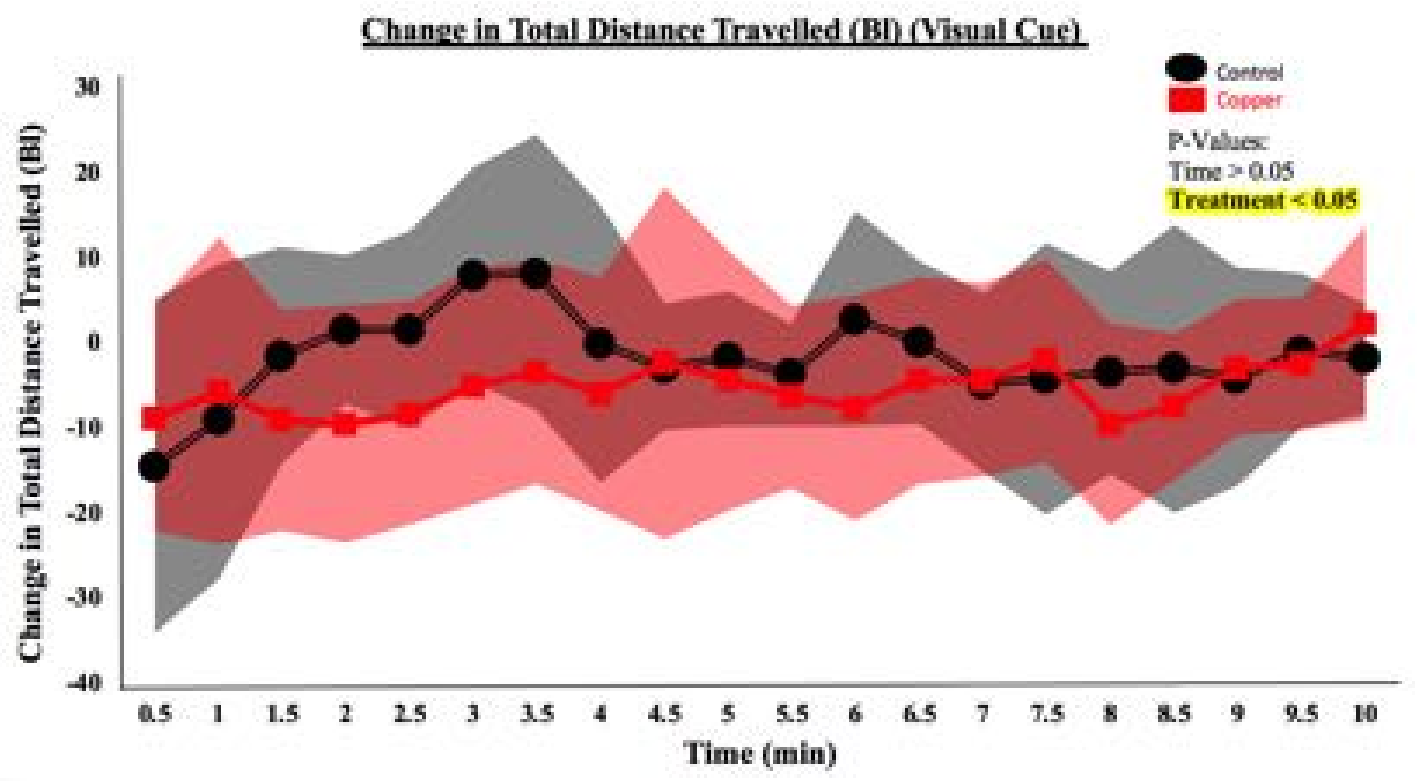

Figure 16C. Change in Total Distance Travelled (BI) (Visual Cue). After the experiment, the change in total distance travelled was calculated by subtracting the data from Trial one from the data from Trial two. Every point in this graph represents the average of 10 individual fish and their total distance travelled at that specific time. The total distance per fish was normalized to body length in $\mathrm{cm}$ to control for differences in fish size. This graph shows that copper contaminated fish moved overall less distance than control fish in response to the introduction of the visual cue. Treatment was significant $(\mathrm{F}=14.70 ; \mathrm{DF}=1 ; \mathrm{P}<0.05)$ and time was not $(\mathrm{F}=01.62 ; \mathrm{DF}=1 ; \mathrm{P}>0.05)$. The shaded areas represent the standard deviation of the data. 


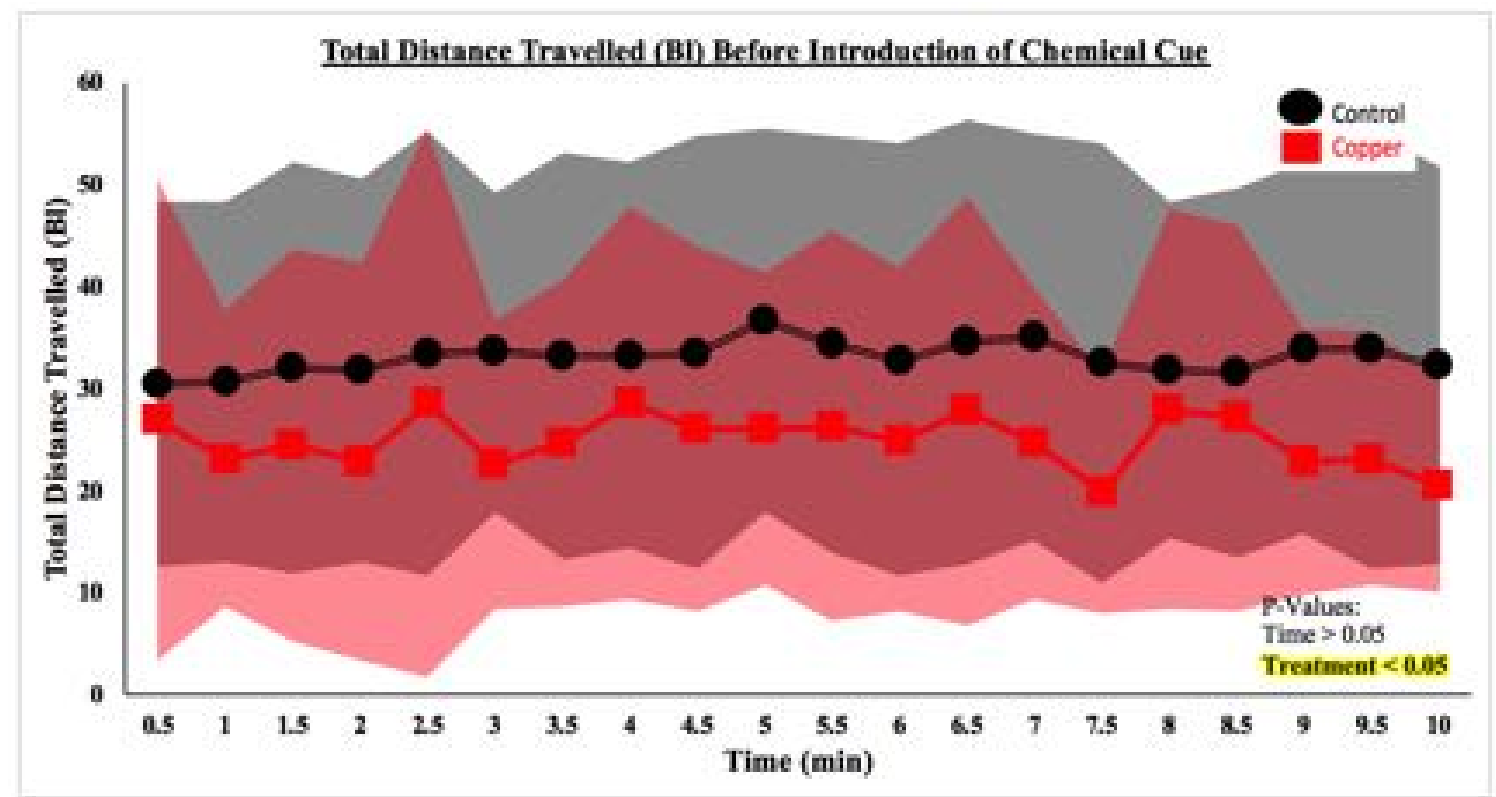

Figure 17A. Total Distance Travelled (Bl) Before Introduction of Chemical Cue. Before the introduction of the chemical cue (predator kairomones) both groups were left to acclimate for 10 minutes. During these 10 minutes, every 30 seconds data points were recorded. Every point in this graph represents the average of 10 individual fish and their total distance travelled at that specific time. The total distance per fish was normalized to body length in $\mathrm{cm}$ to control for differences in fish size. This graph shows that copper contaminated fish moved overall less distance than control fish before the introduction of the chemical cue. Treatment was significant $(\mathrm{F}=30.70 ; \mathrm{DF}=1 ; \mathrm{P}<0.05)$ and time was not $(\mathrm{F}=0.005 ; \mathrm{DF}=1 ; \mathrm{P}>0.05)$. The shaded areas represent the standard deviation of the data. 


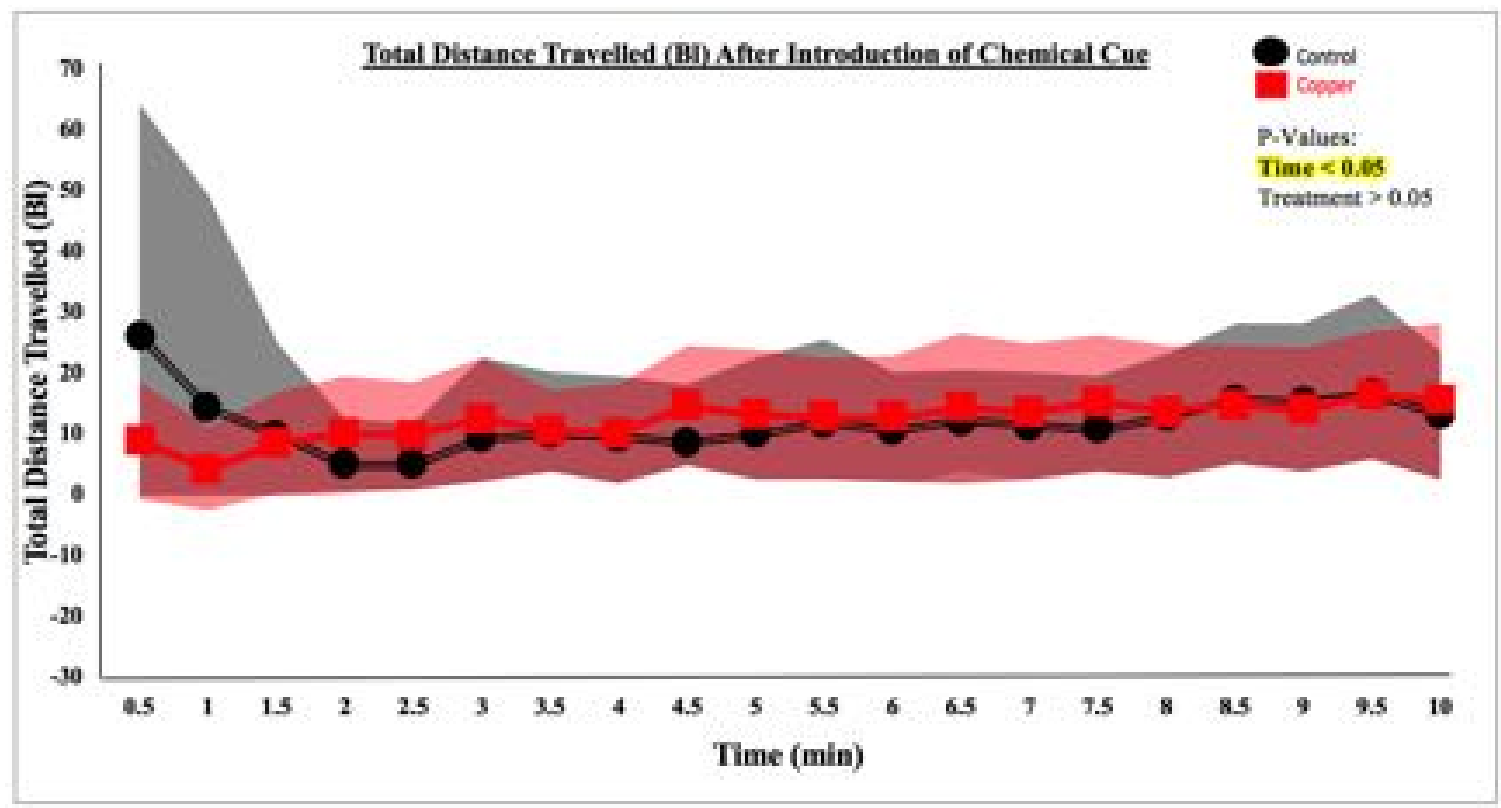

Figure 17B. Total Distance Travelled (Bl) After Introduction of Chemical Cue. After the introduction of the chemical cue (predator kairomones) data was recorded for 10 minutes. During these 10 minutes, every 30 seconds data points were recorded. Every point in this graph represents the average of 10 individual fish and their total distance travelled at that specific time. The total distance per fish was normalized to body length in $\mathrm{cm}$ to control for differences in fish size. Treatment was not significant $(\mathrm{F}=0.183$; $\mathrm{DF}=1 ; \mathrm{P}>0.05)$ but time was $(\mathrm{F}=5.89 ; \mathrm{DF}=1 ; \mathrm{P}<0.05)$. The shaded areas represent the standard deviation of the data. 


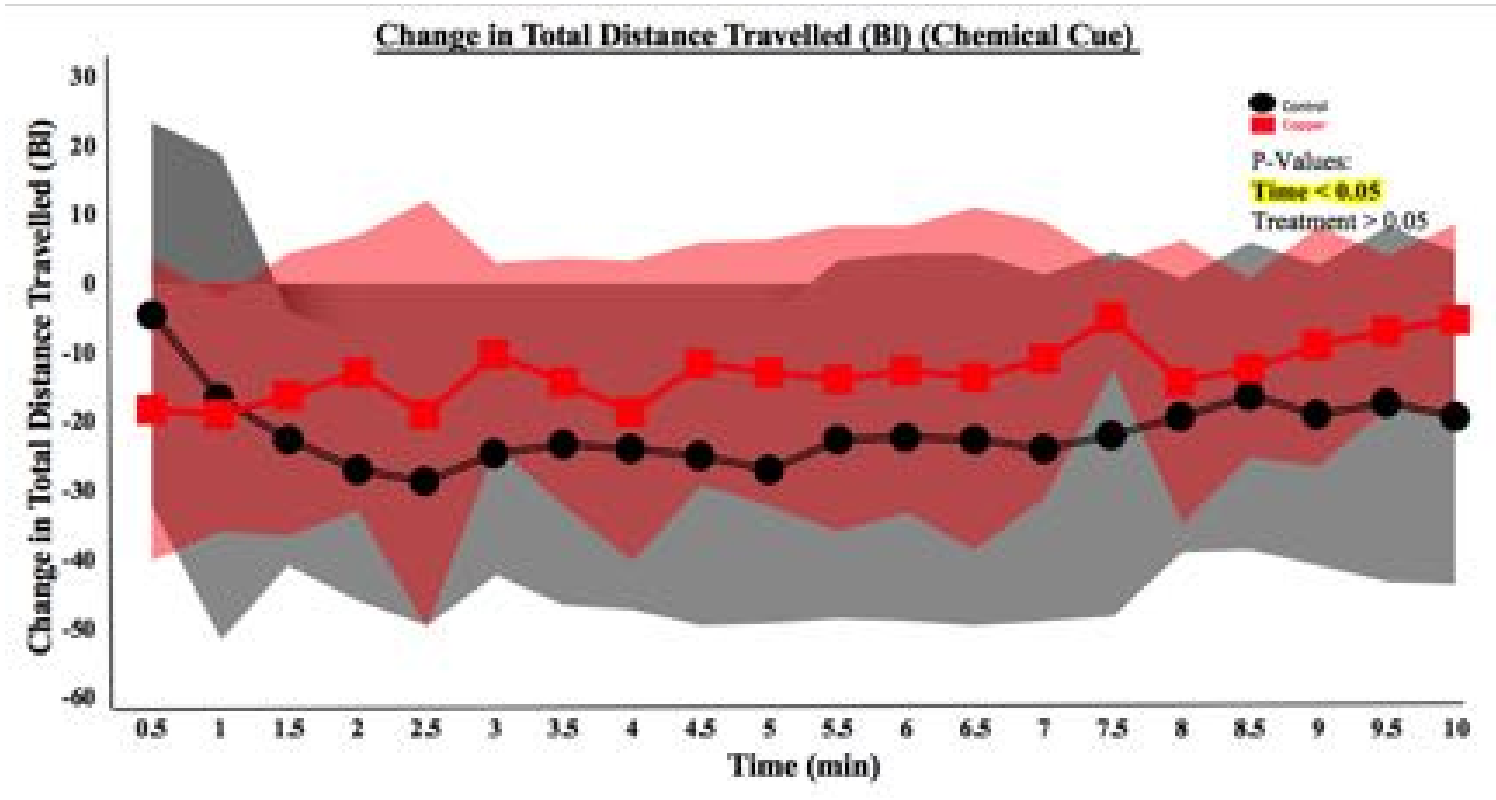

Figure 17C. Change in Total Distance Travelled (BI) (Chemical Cue). After the experiment, the change in total distance travelled was calculated by subtracting the data from Trial one from the data from Trial two. Every point in this graph represents the average of 10 individual fish and their total distance travelled at that specific time. The total distance per fish was normalized to body length in $\mathrm{cm}$ to control for differences in fish size. This graph shows that time had an effect on the change in distance travelled for both control and copper-exposed fish. Treatment was not significant $(\mathrm{F}=0.57 ; \mathrm{DF}=1$; $\mathrm{P}>0.05)$ and time was $(\mathrm{F}=6.0 ; \mathrm{DF}=1 ; \mathrm{P}<0.05)$. The shaded areas represent the standard deviation of the data. 


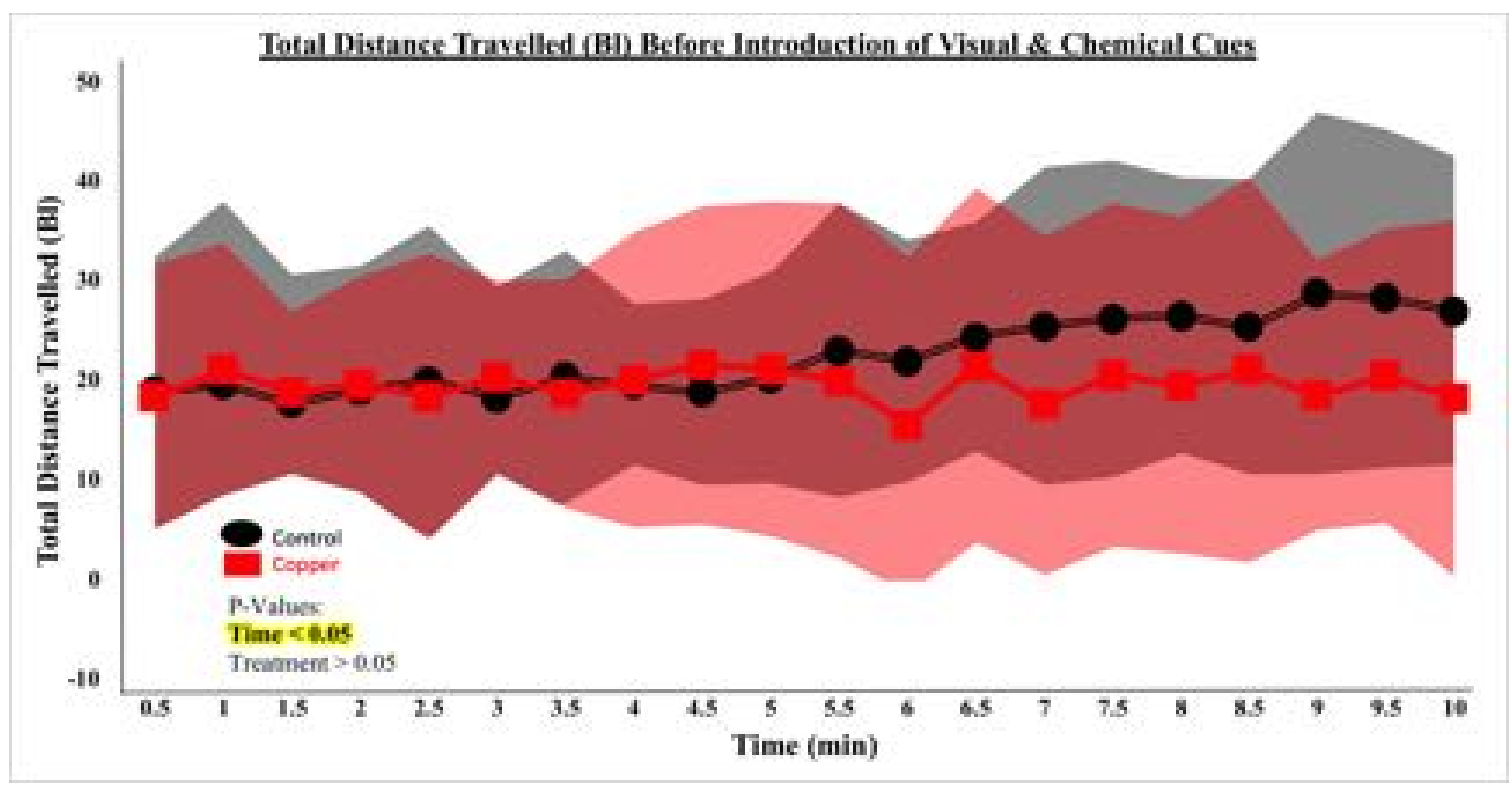

Figure 18A. Total Distance Travelled (BI) Before Introduction of Visual \& Chemical

Cue. Before the introduction of the visual \& chemical cue (predator model + predator kairomones) both groups were left to acclimate for 10 minutes. During these 10 minutes, every 30 seconds data points were recorded. Every point in this graph represents the average of 10 individual fish and their total distance travelled at that specific time. The total distance per fish was normalized to body length in $\mathrm{cm}$ to control for differences in fish size. This graph shows that time had an effect on the total distance travelled by both groups (copper \& control) before the introduction of both cues. Treatment was not significant $(\mathrm{F}=3.52 ; \mathrm{DF}=1 ; \mathrm{P}>0.06)$ but time was $(\mathrm{F}=4.50 ; \mathrm{DF}=1 ; \mathrm{P}<0.05)$. The shaded areas represent the standard deviation of the data. 


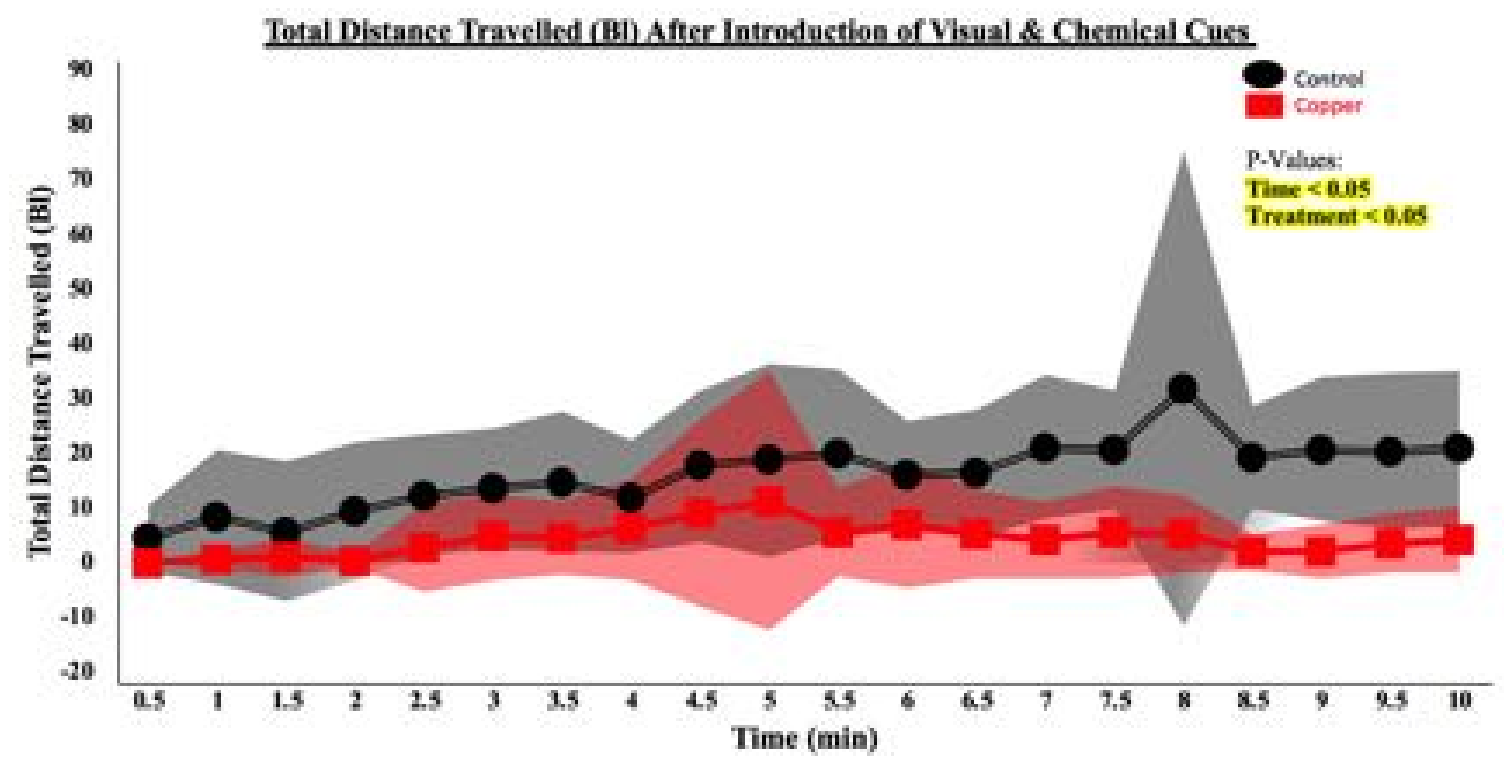

Figure 18B. Total Distance Travelled (BI) After Introduction of Visual \& Chemical Cue. After the introduction of the visual \& chemical cue (predator model + predator kairomones) data was recorded for 10 minutes. During these 10 minutes, every 30 seconds data points were recorded. Every point in this graph represents the average of 10 individual fish and their total distance travelled at that specific time. The total distance per fish was normalized to body length in $\mathrm{cm}$ to control for differences in fish size. This graph shows that individually, treatment and time had an effect in the total distance travelled by both groups (copper \& control) after the introduction of cues. Treatment was significant $(\mathrm{F}=72.52 ; \mathrm{DF}=1 ; \mathrm{P}<0.05)$ as well as time $(\mathrm{F}=16.11 ; \mathrm{DF}=1 ; \mathrm{P}<0.05)$. The shaded areas represent the standard deviation of the data. 


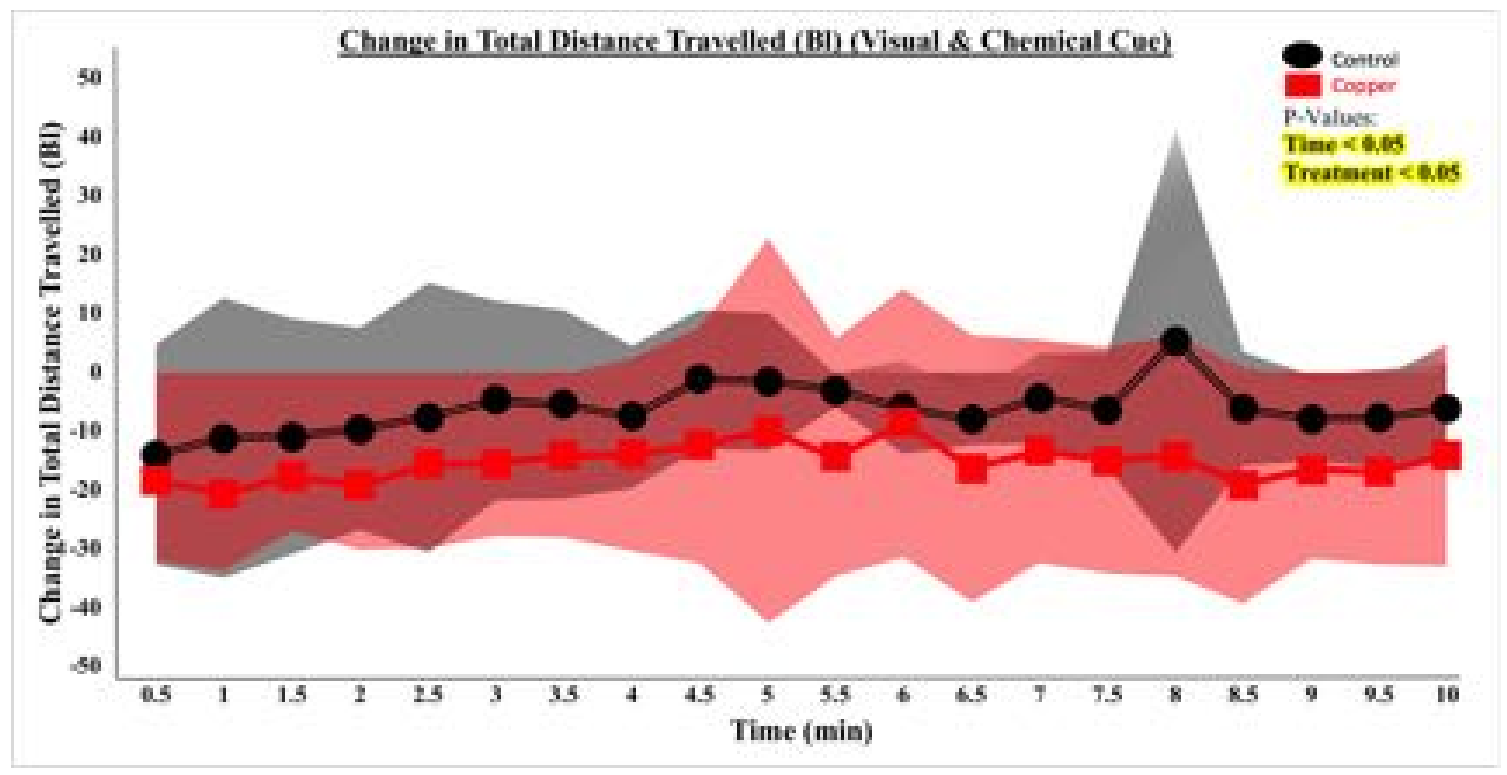

Figure 18C. Change in Total Distance Travelled (BI) (Visual \& Chemical Cue). After the experiment, the change in total distance travelled was calculated by subtracting the data from trial one from the data from trial two. Every point in this graph represents the average of 10 individual fish and their total distance travelled at that specific time. The total distance per fish was normalized to body length in $\mathrm{cm}$ to control for differences in fish size. This graph shows that Individually, treatment and time had an effect in the total distance travelled by both groups (copper \& control) after the introduction of cues.

Overall, this graph shows that copper contaminated fish moved less distance than control when introduced to visual \& chemical cues simultaneously. Treatment was significant $(\mathrm{F}=68.25 ; \mathrm{DF}=1 ; \mathrm{P}<0.05)$ as well as time $(\mathrm{F}=12.73 ; \mathrm{DF}=1 ; \mathrm{P}<0.05)$. The shaded areas represent the standard deviation of the data. 


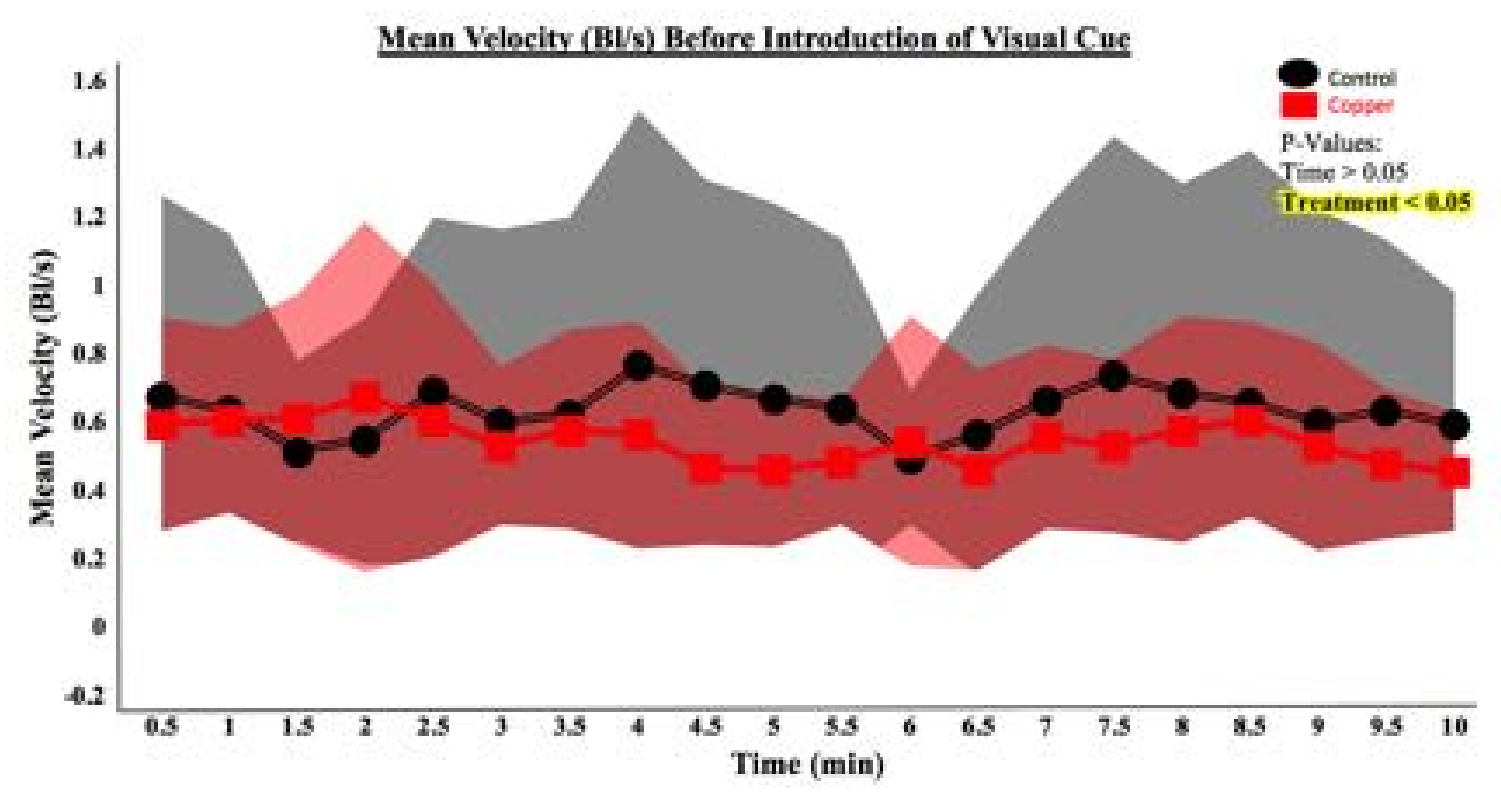

Figure 19A. Mean Velocity ( $\mathrm{Bl} / \mathrm{s})$ Before Introduction of Visual Cue. Before the introduction of the visual cue (predator model) both groups were left to acclimate for 10 minutes. During these 10 minutes, every 30 seconds data points were recorded. Every point in this graph represents the average of 10 individual fish and their mean velocity at that specific time. The mean velocity per fish was normalized to body length per second to control for differences in fish size. This graph shows that copper contaminated fish had a lower mean velocity than control fish before the introduction of the visual cue. Treatment was significant $(\mathrm{F}=4.46 ; \mathrm{DF}=1 ; \mathrm{P}<0.05)$ but time was not $(\mathrm{F}=0.445 ; \mathrm{DF}=1$; $\mathrm{P}>0.05)$. The shaded areas represent the standard deviation of the data. 


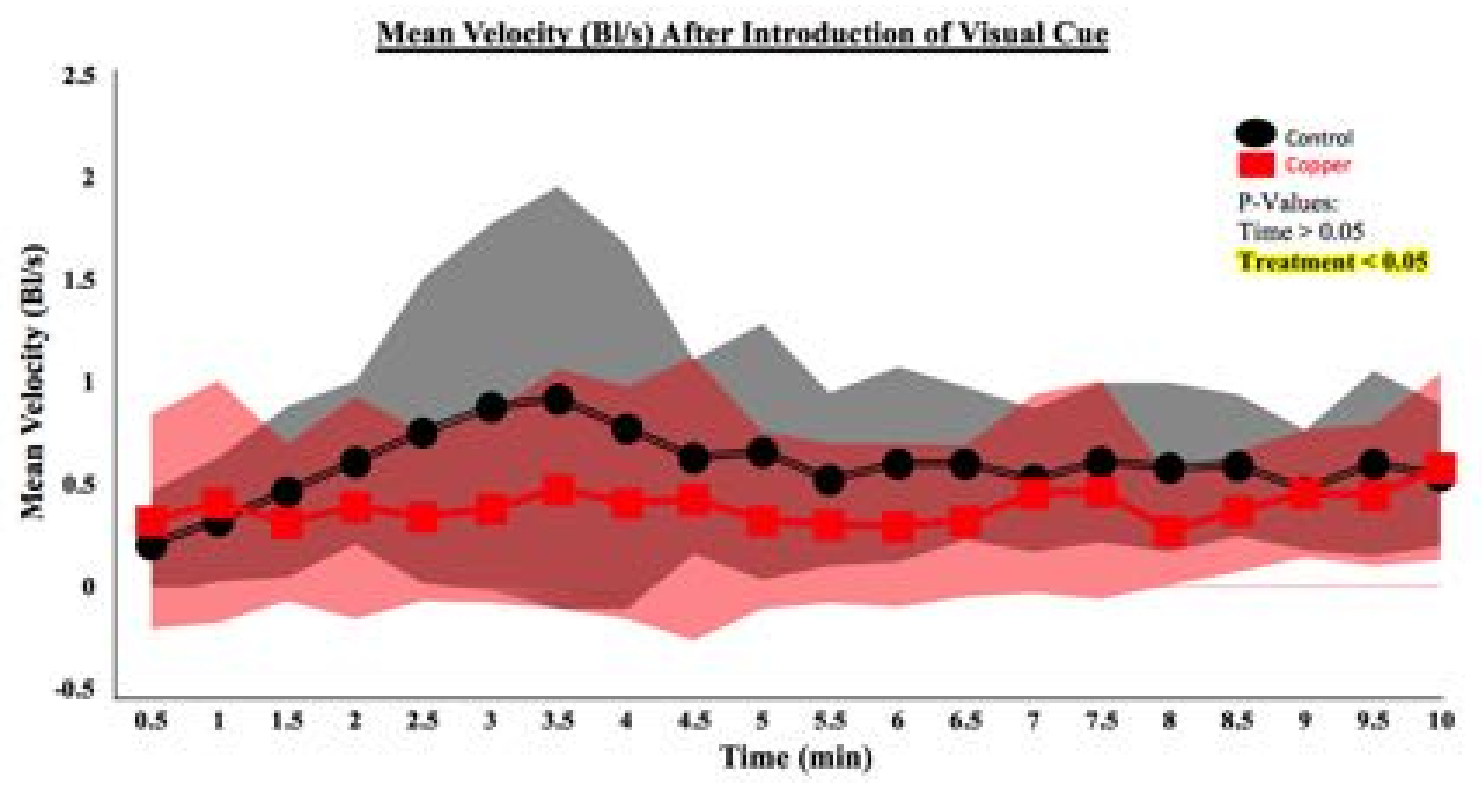

Figure 19B. Mean Velocity (Bl/s) After Introduction of Visual Cue. After the introduction of the visual cue (predator model) data was recorded for 10 minutes. During these 10 minutes, every 30 seconds data points were recorded. Every point in this graph represents the average of 10 individual fish and their mean velocity at that specific time. The mean velocity per fish was normalized to body length per second to control for differences in fish size. This graph shows that copper contaminated fish had a lower mean velocity than control fish after the introduction of the visual cue. Treatment was significant $(\mathrm{F}=17.18 ; \mathrm{DF}=1 ; \mathrm{P}<0.05)$ but time was not $(\mathrm{F}=0.65 \mathrm{DF}=1 ; \mathrm{P}>0.05)$. The shaded areas represent the standard deviation of the data. 


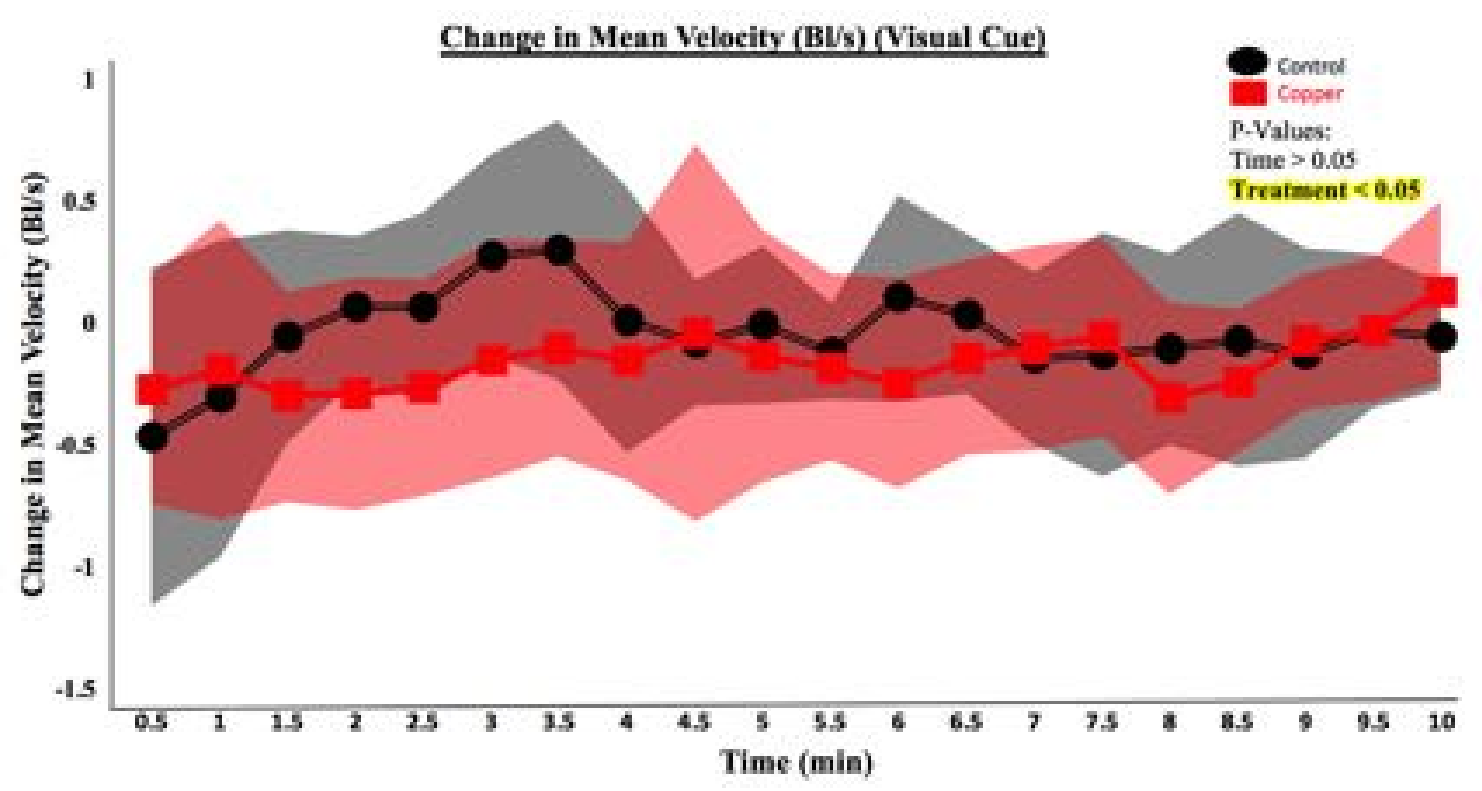

Figure 19C. Change in Mean Velocity (Bl/s) (Visual Cue). After the experiment, the change in mean velocity was calculated by subtracting the data from Trial one from the data from Trial two. Every point in this graph represents the average of 10 individual fish and their mean velocity at that specific time. The mean velocity per fish was normalized to body length per second to control for differences in fish size. This graph shows that copper-exposed fish experienced a decrease in their mean velocity when compared to control fish in response to the predator model. Treatment was significant $(\mathrm{F}=12.80$; $\mathrm{DF}=1 ; \mathrm{P}<0.05)$ but time was not $(\mathrm{F}=01.61 ; \mathrm{DF}=1 ; \mathrm{P}>0.05)$. The shaded areas represent the standard deviation of the data. 


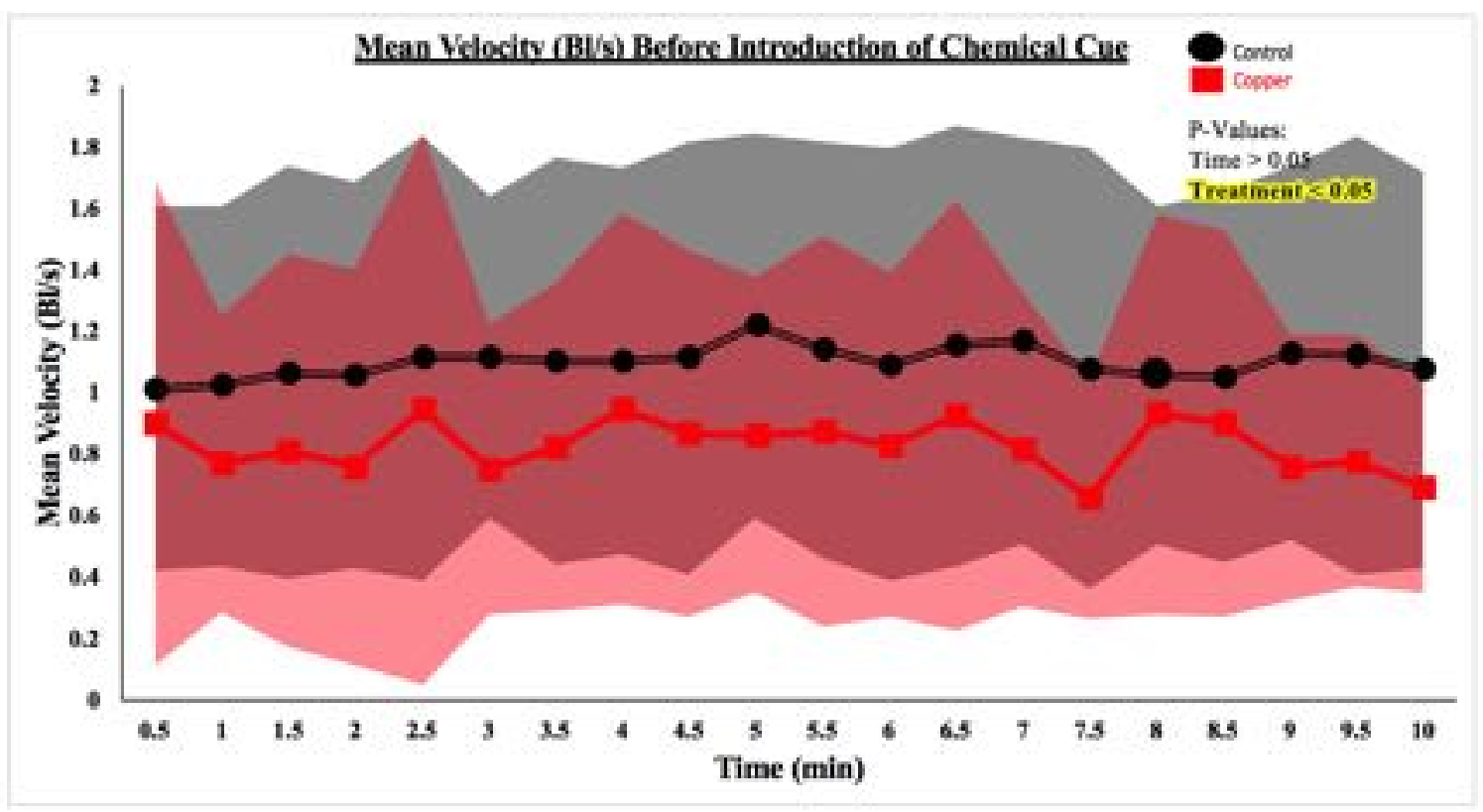

Figure 20A. Mean Velocity (BI/s) Before Introduction of Chemical Cue. Before the introduction of the chemical cue (predator kairomones) both groups were left to acclimate for 10 minutes. During these 10 minutes, every 30 seconds data points were recorded. Every point in this graph represents the average of 10 individual fish and their mean velocity at that specific time. The mean velocity per fish was normalized to body length per second to control for differences in fish size. This graph shows that copper contaminated fish had a lower mean velocity than control fish before the introduction of the chemical cue. Treatment was significant $(\mathrm{F}=20.63$; $\mathrm{DF}=1 ; \mathrm{P}<0.05)$ but time was not $(\mathrm{F}=0.003 ; \mathrm{DF}=1 ; \mathrm{P}>0.05)$. The shaded areas represent the standard deviation of the data. 


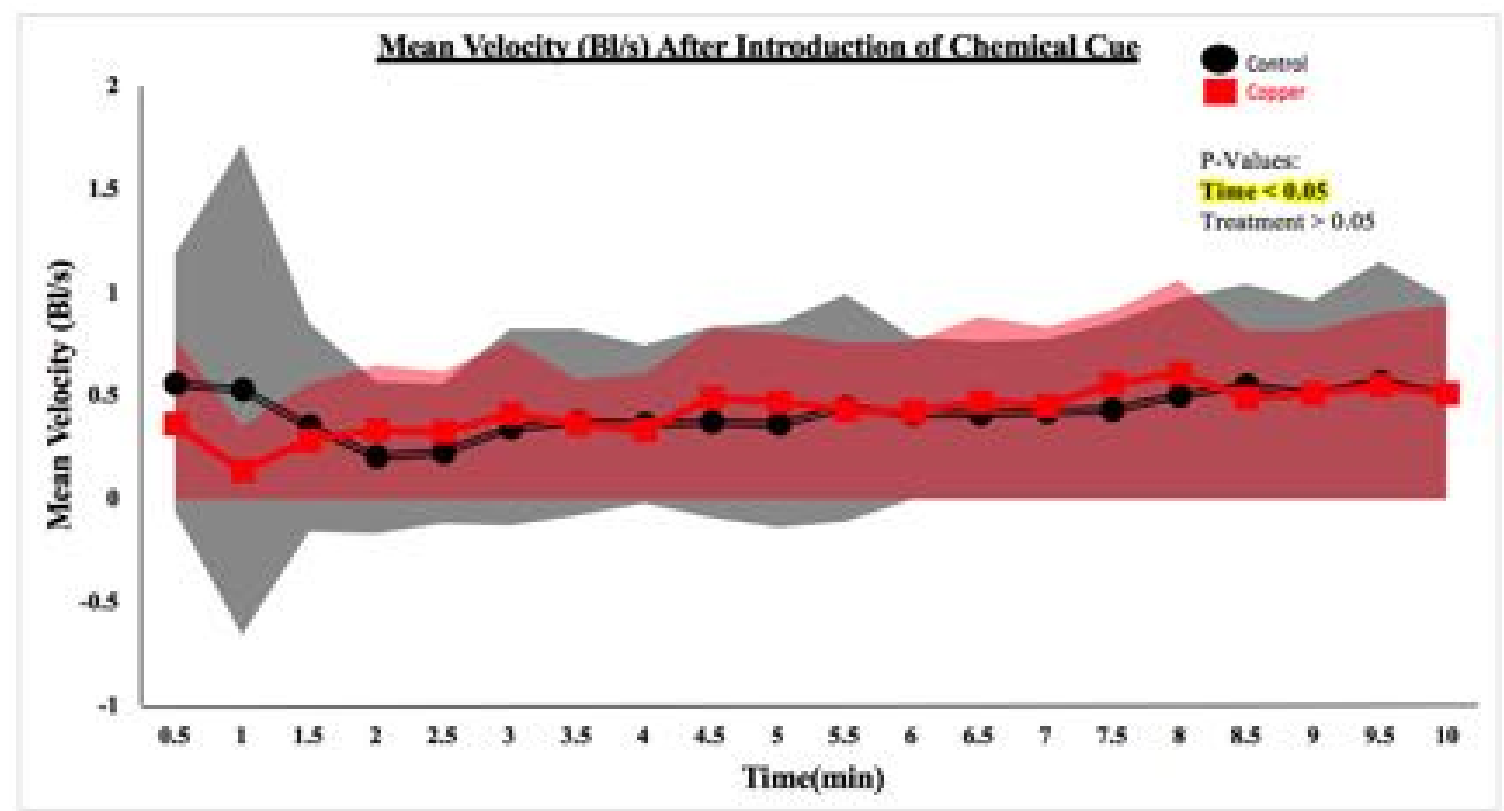

Figure 20B. Mean Velocity (Bl/s) After Introduction of Chemical Cue. After the introduction of the chemical cue (predator kairomones) data was recorded for 10 minutes. During these 10 minutes, every 30 seconds data points were recorded. Every point in this graph represents the average of 10 individual fish and their mean velocity at that specific time. The mean velocity per fish was normalized to body length per second to control for differences in fish size. Treatment was not significant $(\mathrm{F}=0.04 ; \mathrm{DF}=1 ; \mathrm{P}>0.05)$ but time was $(\mathrm{F}=10.96 ; \mathrm{DF}=1 ; \mathrm{P}<0.05)$. The shaded areas represent the standard deviation of the data. 


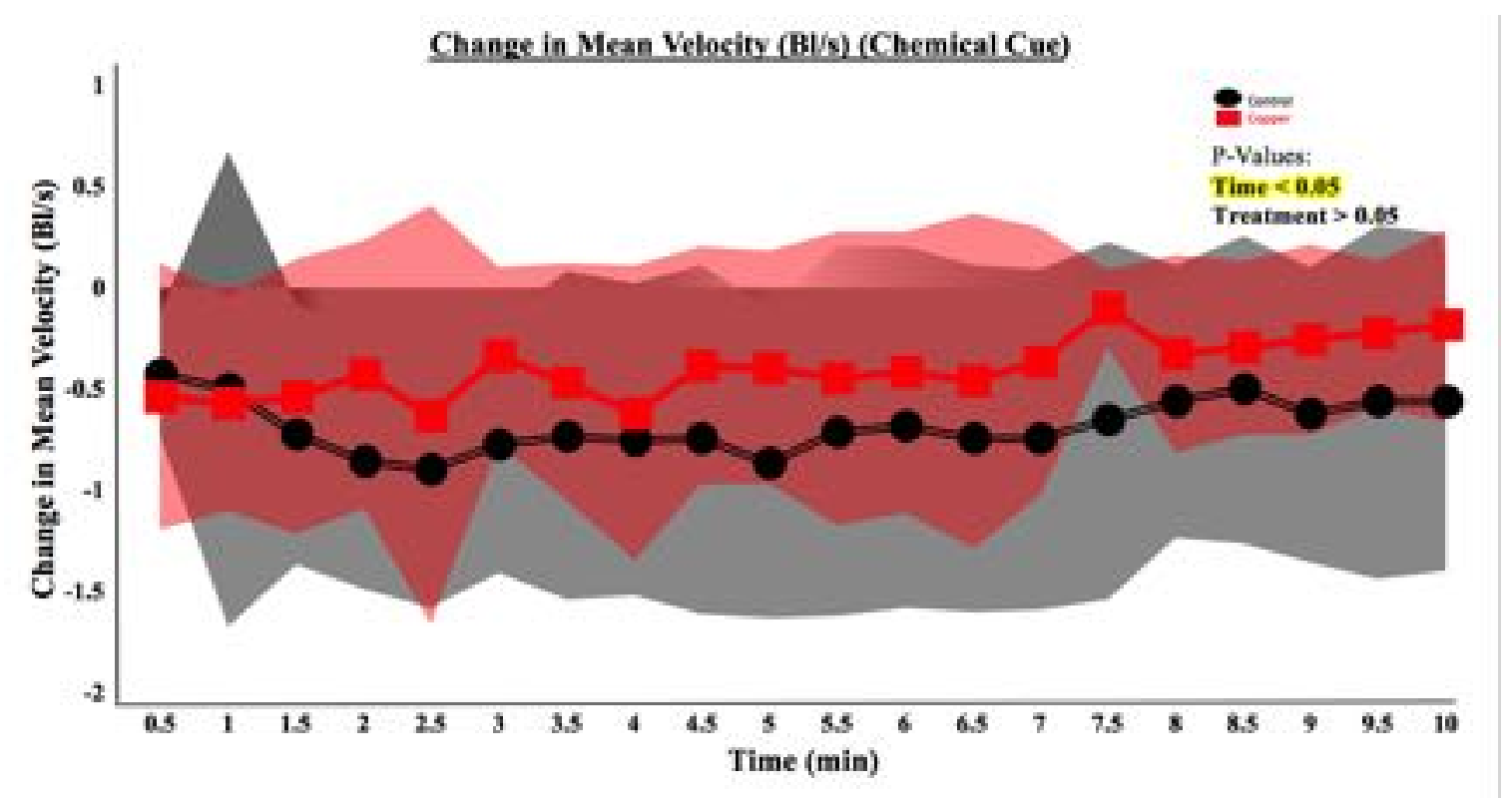

Figure 20C. Change in Mean Velocity (Bl/s) (Chemical Cue). After the experiment, the change in mean velocity was calculated by subtracting the data from Trial one from the data from Trial two. Every point in this graph represents the average of 10 individual fish and their mean velocity at that specific time. The mean velocity per fish was normalized to body length per second to control for differences in fish size. This graph shows that copper contaminated fish had overall a higher mean velocity than control fish when introduced to the chemical cue. Time had an effect on the change of the mean velocity travelled by both groups (copper \& control). Treatment was not significant $(\mathrm{F}=0.49 ; \mathrm{DF}=1 ; \mathrm{P}>0.05)$ but time was significant $(\mathrm{F}=11.13 ; \mathrm{DF}=1 ; \mathrm{P}<0.05)$. The shaded areas represent the standard deviation of the data. 


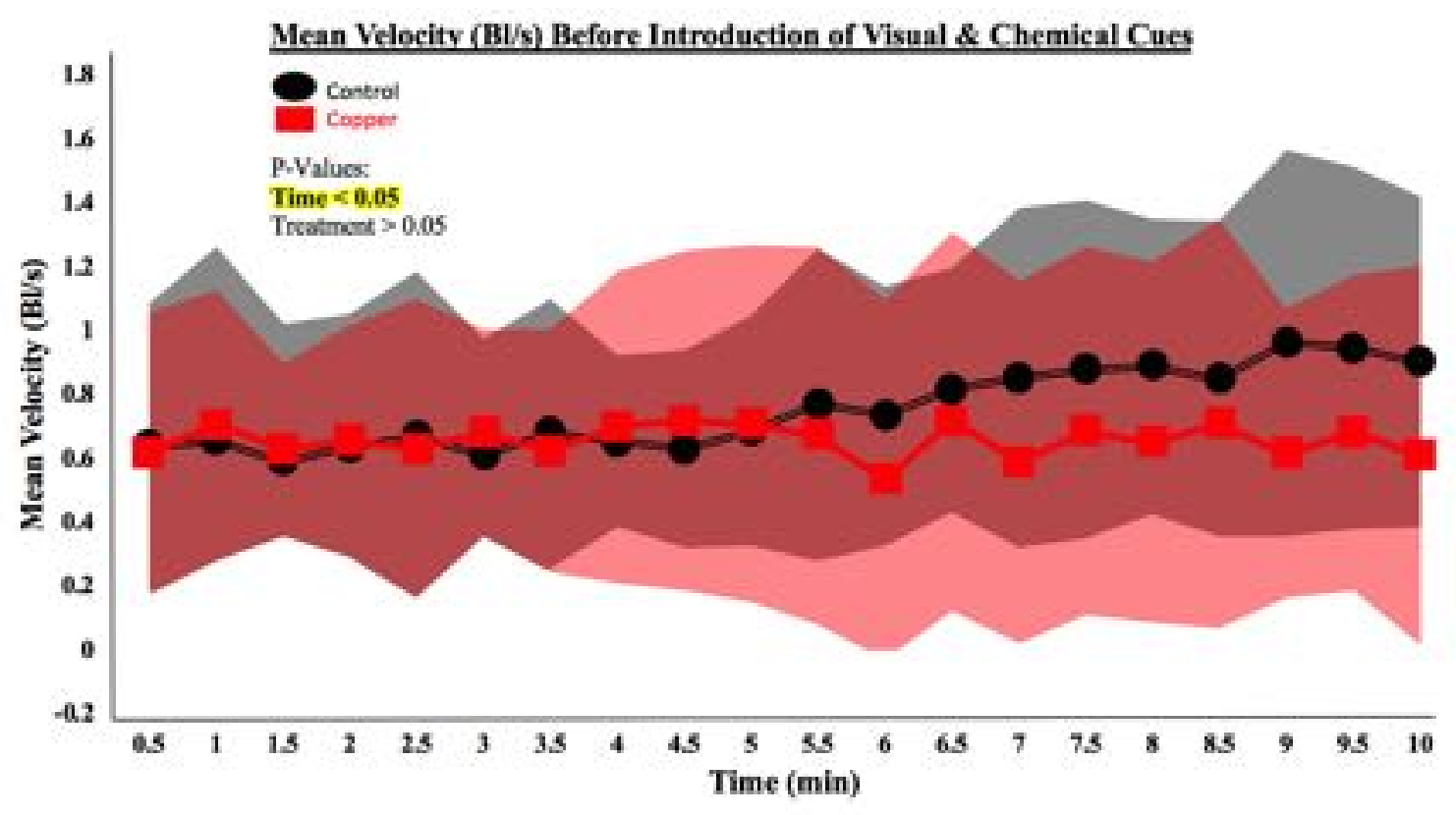

Figure 21A. Mean Velocity (BI/s) Before Introduction of Visual \& Chemical Cue. Before the introduction of the visual cue \& chemical cues (predator model+ kairomones) both groups were left to acclimate for 10 minutes. During these 10 minutes, every 30 seconds data points were recorded. Every point in this graph represents the average of 10 individual fish and their mean velocity at that specific time. The mean velocity per fish was normalized to body length per second to control for differences in fish size. This graph shows that time had an effect on the mean velocity swam by both groups (copper \& control) before the introduction of both cues. Treatment was not significant ( $\mathrm{F}=3.44$; $\mathrm{DF}=1 ; \mathrm{P}>0.05)$ but time was $(\mathrm{F}=4.43 ; \mathrm{DF}=1 ; \mathrm{P}<0.05)$. The shaded areas represent the standard deviation of the data. 


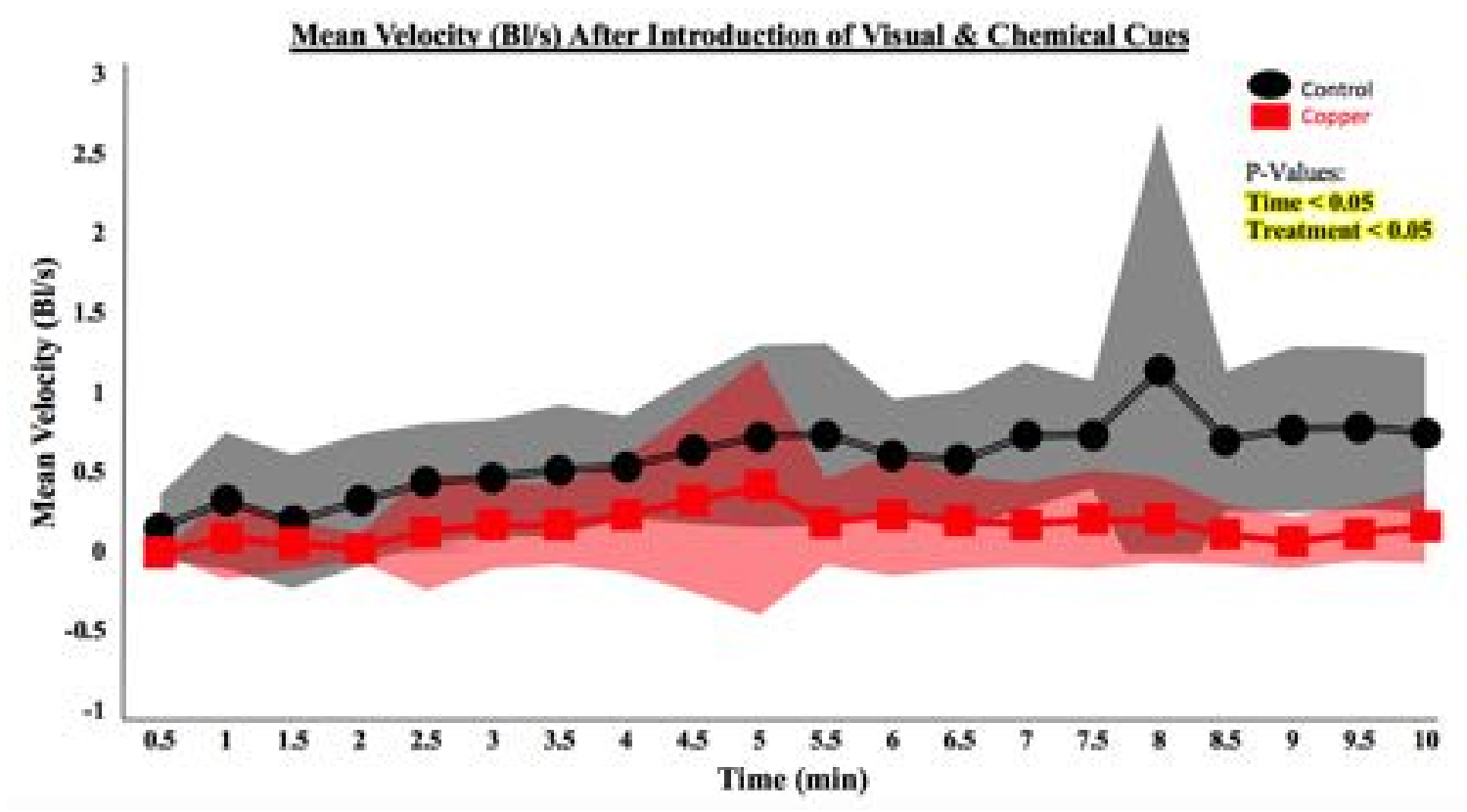

Figure 21B. Mean Velocity (BI/s) After Introduction of Visual \& Chemical Cue.

After the introduction of the visual \& chemical cue (predator model + kairomones) data was recorded for 10 minutes. Every point in this graph represents the average of 10 individual fish and their mean velocity at that specific time. The mean velocity per fish was normalized to body length per second to control for differences in fish size. Independently, time and treatment had an effect on the mean velocity swam by both groups (copper \& control) after the introduction of cues. Treatment was significant $(\mathrm{F}=74.02 ; \mathrm{DF}=1, \mathrm{P}<0.05)$ but time was not $(\mathrm{F}=15.74 ; \mathrm{DF}=1 ; \mathrm{P}<0.05)$. The shaded areas represent the standard deviation of the data. 


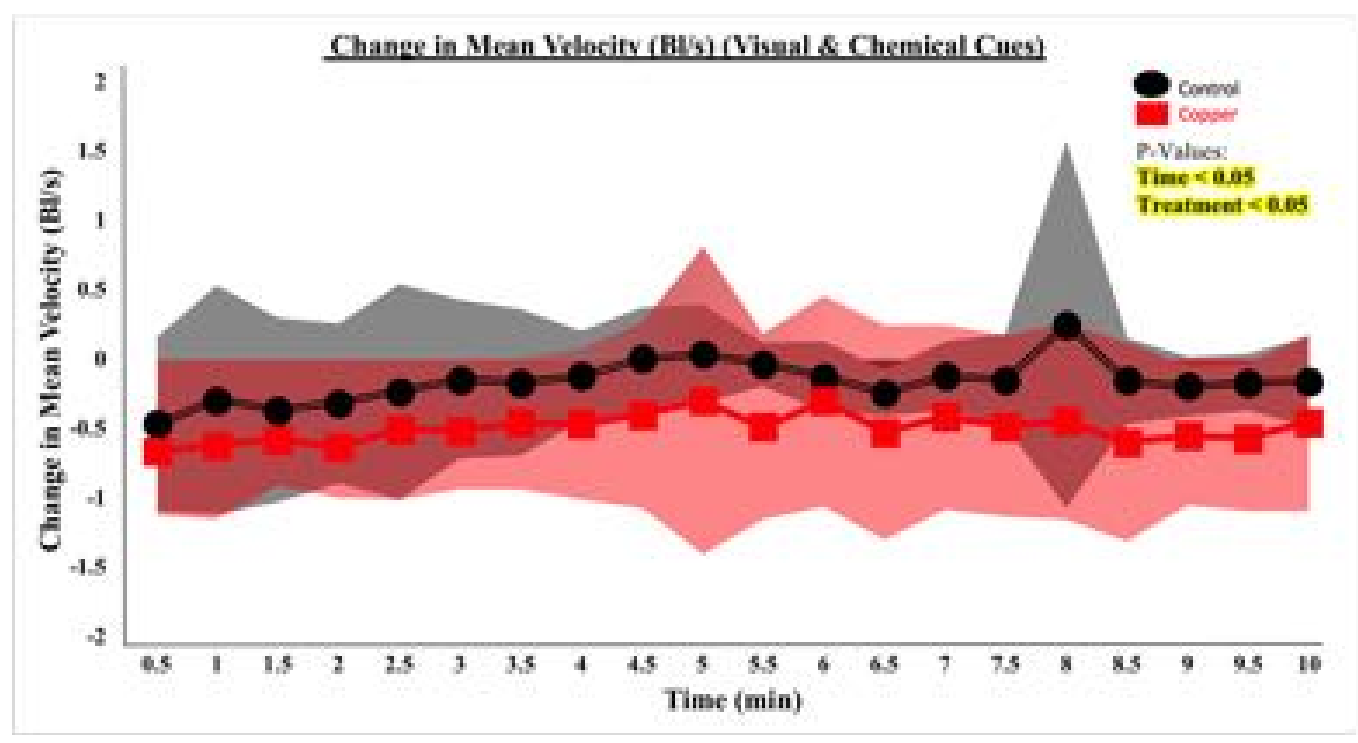

Figure 21C. Change in Mean Velocity (Bl/s) (Visual \& Chemical Cue). After the experiment, the change in mean velocity was calculated by subtracting the data from trial one from the data from trial two. Every point in this graph represents the average of 10 individual fish and their mean velocity at that specific time. The mean velocity per fish was normalized to body length per second to control for differences in fish size. This graph shows that copper-exposed fish experienced a decrease in their mean velocity when compared to control fish in response to the predator model and kairomones. Both treatment $(\mathrm{F}=70.33 ; \mathrm{DF}=1, \mathrm{P}<0.05)$ and time $(\mathrm{F}=12.37$; $\mathrm{DF}=1, \mathrm{P}<0.05)$ were significantly different. The shaded areas represent the standard deviation of the data. 


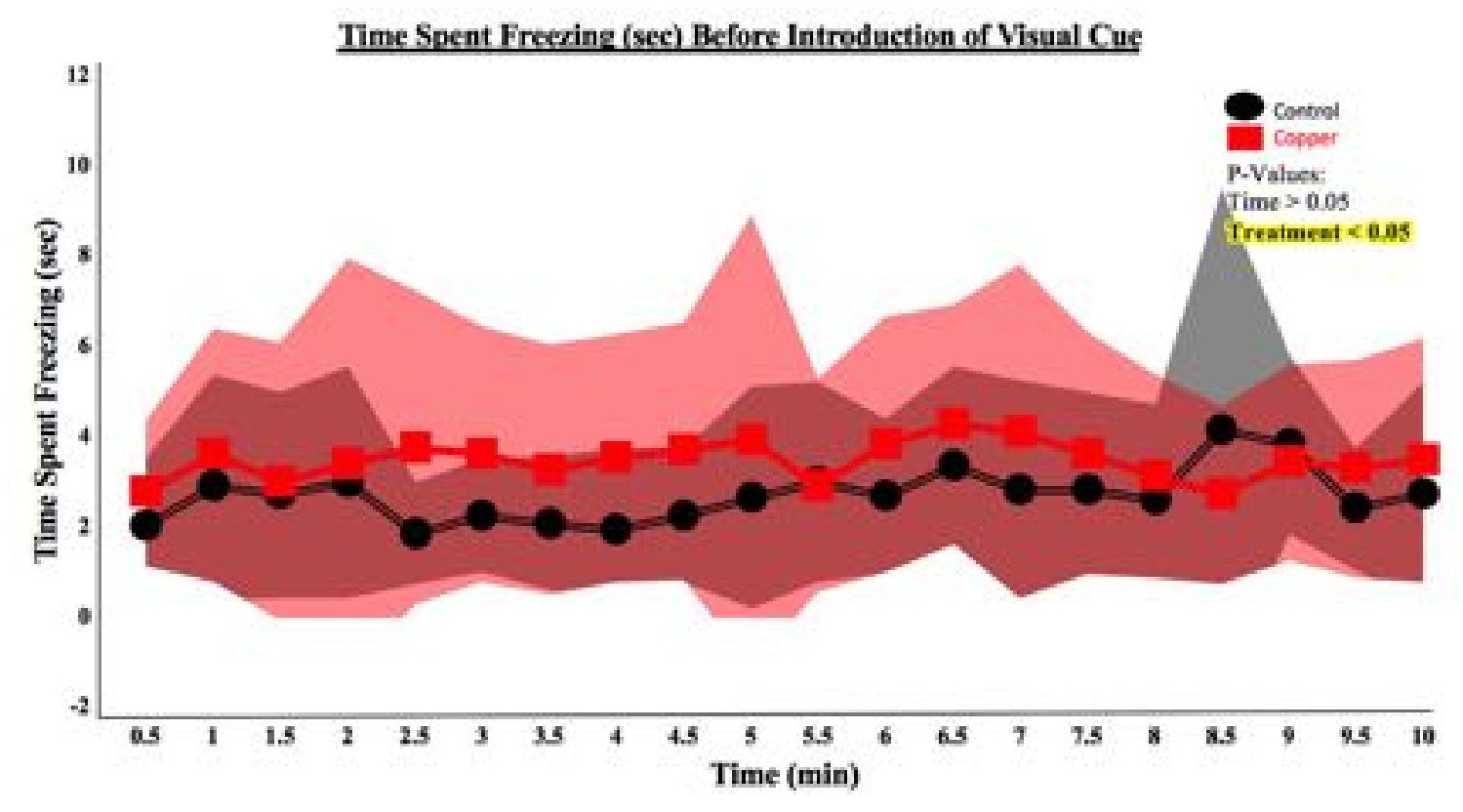

Figure 22A. Time Spent Freezing (sec) Before Introduction of Visual Cue. Before the introduction of the visual cue (predator model) both groups (control \& copper) were left to acclimate for 10 minutes. During these 10 minutes, every 30 seconds data points were recorded. Every point in this graph represents the average of 10 individual fish and their total time spent freezing in seconds at that specific time. This graph shows that copper contaminated fish spent more time freezing before the introduction of the visual cue. Treatment was significant $(\mathrm{F}=8.88 ; \mathrm{DF}=1, \mathrm{P}<0.05)$ but time was not $(\mathrm{F}=1.47 ; \mathrm{DF}=1$; $\mathrm{P}>0.05)$. The shaded areas represent the standard deviation of the data. 




Figure 22B. Time Spent Freezing (sec) After Introduction of Visual Cue. After the introduction of the visual cue (predator model) data was recorded for 10 minutes every 30 seconds. Every point in this graph represents the average of 10 individual fish and their total time spent freezing in seconds at that specific time. This graph shows that copper contaminated fish spent more time freezing after the introduction of the visual cue. Both treatment $(\mathrm{F}=44.41 ; \mathrm{DF}=1, \mathrm{P}<0.05)$ and time were significant $(\mathrm{F}=17.51 ; \mathrm{DF}=1$, $\mathrm{P}<0.05) \quad$ The shaded areas represent the standard deviation of the data. 


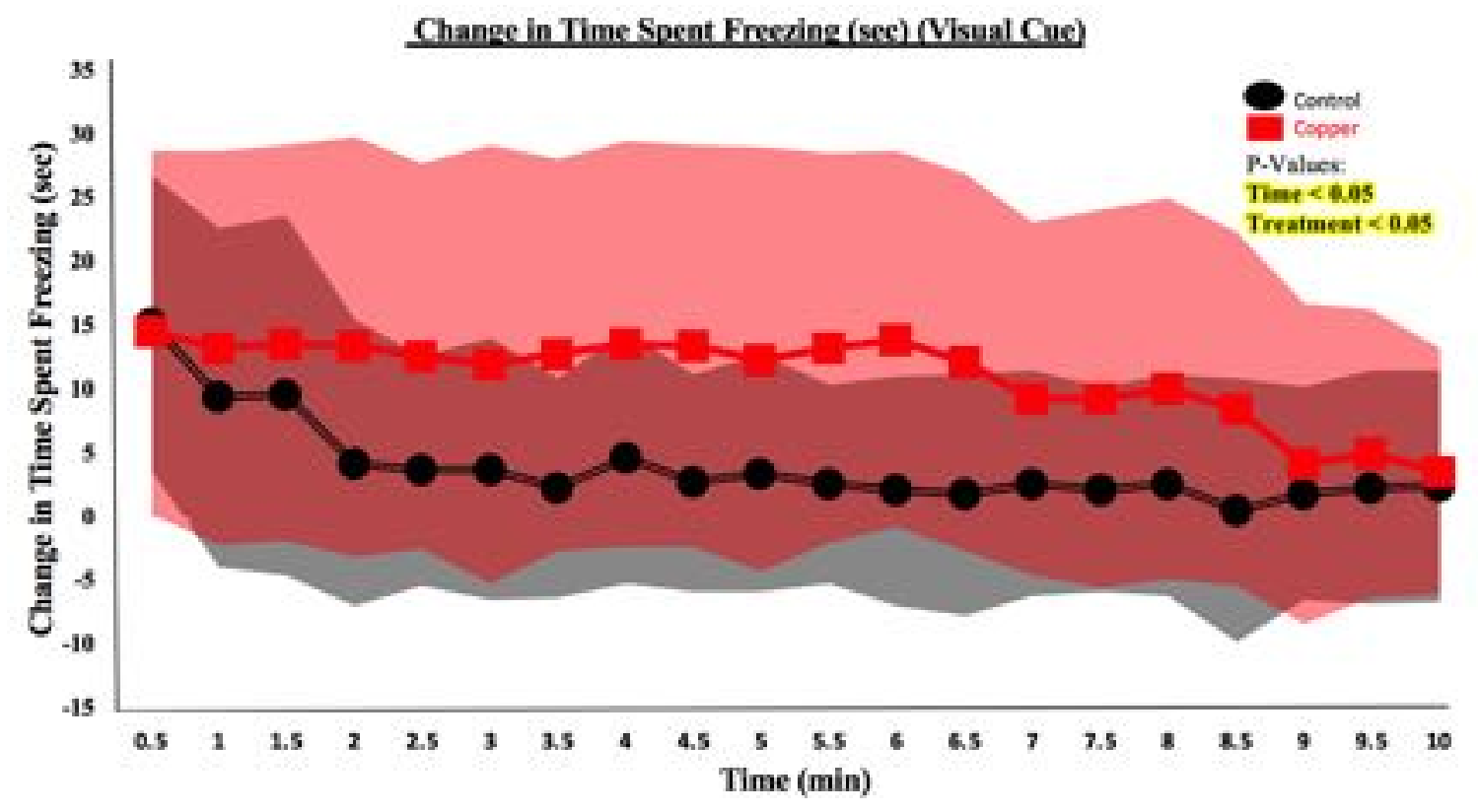

Figure 22C. Change Time Spent Freezing (sec) (Visual Cue). After the experiment, the change in time spent freezing was calculated by subtracting the data from trial one from the data from trial two. Every point in this graph represents the average of 10 individual fish and their total time spent freezing in seconds at that specific time. This graph shows that copper contaminated fish overall spent more time freezing. Both treatment $(\mathrm{F}=45.72 ; \mathrm{DF}=1, \mathrm{P}<0.05)$ and time were significant $(\mathrm{F}=16.87 ; \mathrm{DF}=1, \mathrm{P}<0.05)$. The shaded areas represent the standard deviation of the data. 


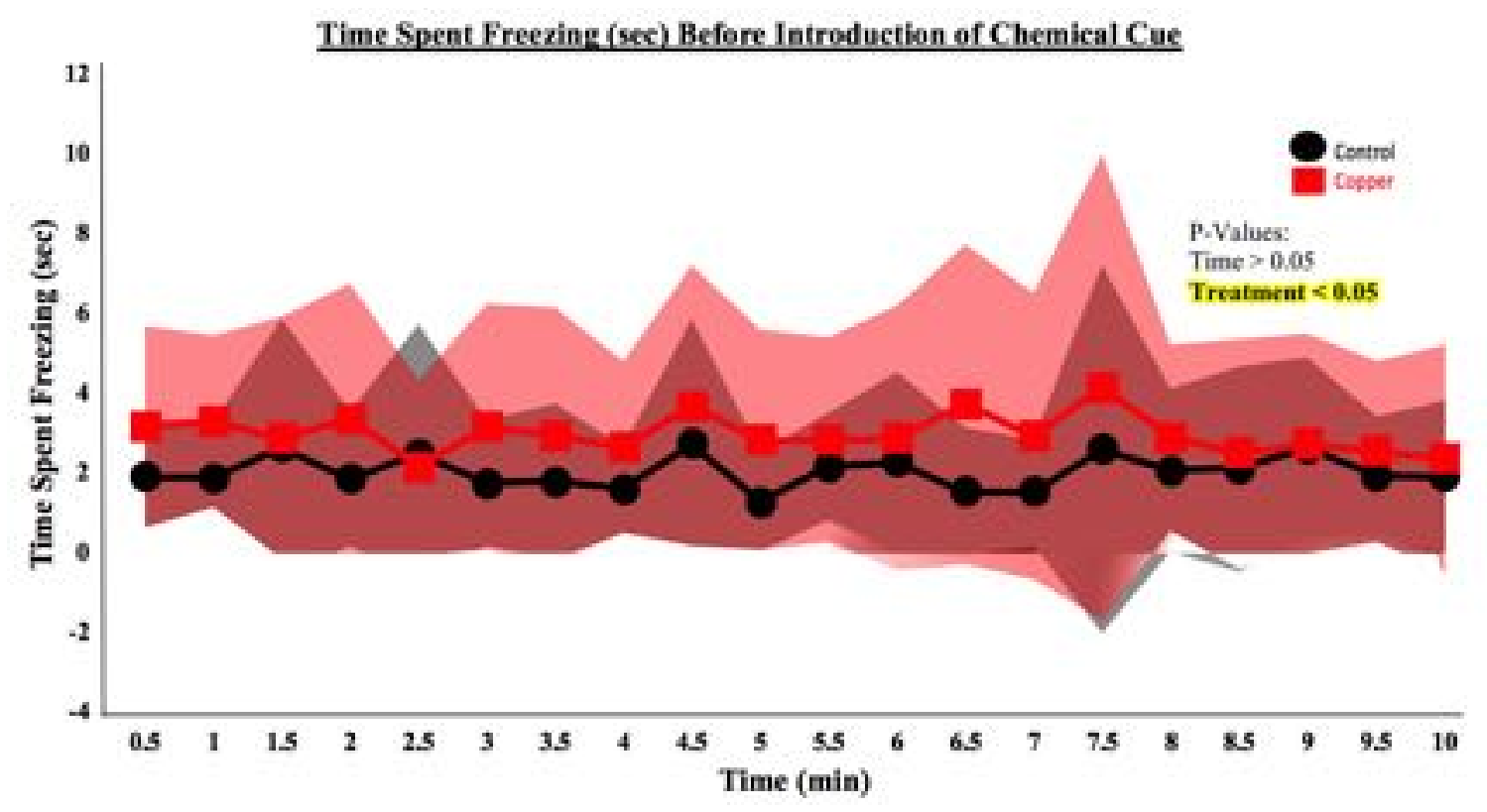

Figure 23A. Time Spent Freezing (sec) Before Introduction of Chemical Cue.

Before the introduction of the chemical cue (predator kairomones) both groups were left to acclimate for 10 minutes. During these 10 minutes, every 30 seconds data points were recorded. Every point in this graph represents the average of 10 individual fish and their total time spent freezing in seconds at that specific time. This graph shows that copper contaminated fish spent more time freezing before the introduction of the chemical cue. Treatment was significant $(\mathrm{F}=13.05 ; \mathrm{DF}=1, \mathrm{P}<0.05)$ but time was not $(\mathrm{F}=0.08 ; \mathrm{DF}=1$; $\mathrm{P}>0.05)$. The shaded areas represent the standard deviation of the data. 


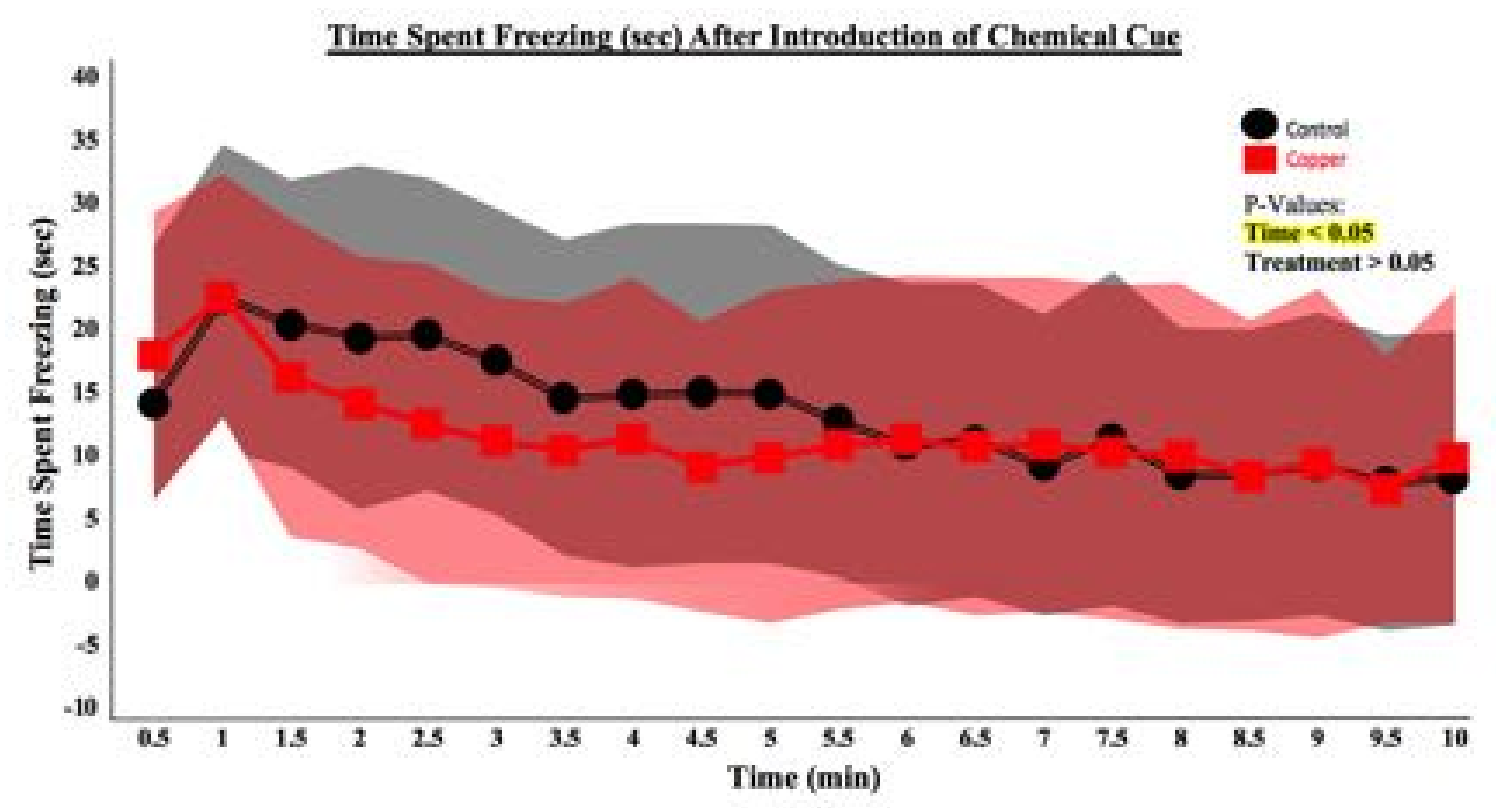

Figure 23B. Time Spent Freezing (sec) After Introduction of Chemical Cue. After the introduction of the chemical cue (kairomones) data was recorded for 10 minutes every 30 seconds. Every point in this graph represents the average of 10 individual fish and their total time spent freezing in seconds at that specific time. Both control and copper-exposed fish reduced their time spent freezing towards the end of the trial. Treatment was not significant $(\mathrm{F}=2.376 ; \mathrm{DF}=1, \mathrm{P}<0.05)$ but time was significant $(\mathrm{F}=30.03 ; \mathrm{DF}=1, \mathrm{P}<0.05)$. The shaded areas represent the standard deviation of the data. 




Figure 23C. Change Time Spent Freezing (sec) (Chemical Cue). After the experiment, the change in time spent freezing was calculated by subtracting the data from trial one from the data from trial two. Every point in this graph represents the average of 10 individual fish and their total time spent freezing in seconds at that specific time. This graph shows that copper contaminated fish spent less time freezing in response to the introduction of the chemical cue when compared to the control fish. Both groups reduced their time spent freezing towards the end of the trial. Both treatment $(\mathrm{F}=4.64 ; \mathrm{DF}=1$, $\mathrm{P}<0.05)$ and time were significant $(\mathrm{F}=30.41 ; \mathrm{DF}=1, \mathrm{P}<0.05)$. The shaded areas represent the standard deviation of the data. 


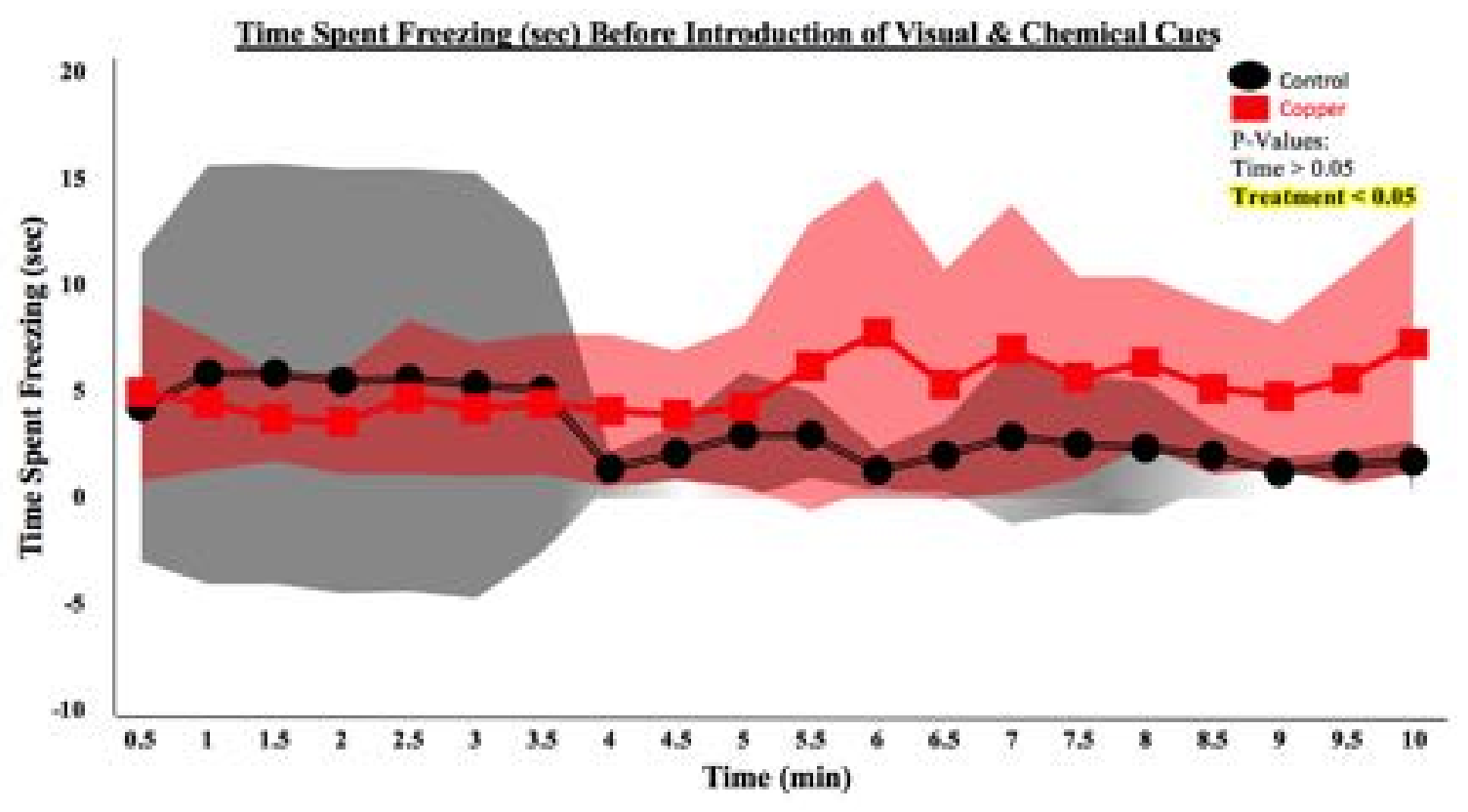

Figure 24A. Time Spent Freezing (sec) Before Introduction of Visual \& Chemical Cue. Before the introduction of the visual cue \& chemical cues (predator model+ kairomones) both groups were left to acclimate for 10 minutes. During these 10 minutes, every 30 seconds data points were recorded. Every point in this graph represents the average of 10 individual fish and their time spent freezing in seconds at that specific time. This graph shows that treatment had an effect on the time spent freezing before the introduction of both cues. Treatment was significant $(\mathrm{F}=11.98 ; \mathrm{DF}=1, \mathrm{P}<0.05)$ but time was not $(\mathrm{F}=1.22 ; \mathrm{DF}=1 ; \mathrm{P}>0.05)$. The shaded areas represent the standard deviation of the data. 


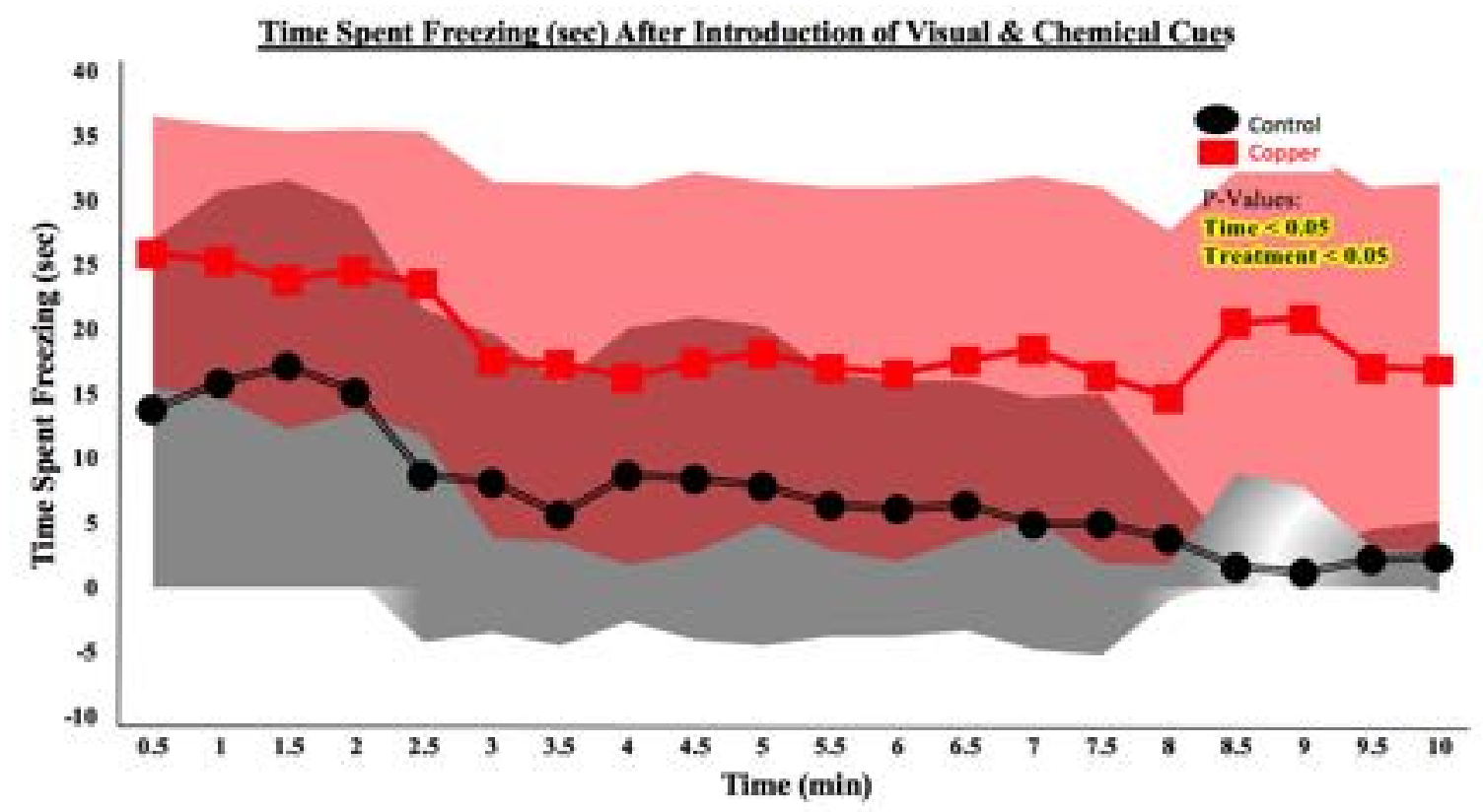

Figure 24B. Time Spent Freezing (sec) After Introduction of Visual \& Chemical Cue. After the introduction of the visual \& chemical cue (predator model + kairomones) data was recorded every 30 seconds for 10 minutes. Every point in this graph represents the average of 10 individual fish and their time spent freezing in seconds at that specific time. This graph shows that copper contaminated fish spent much more time freezing after the introduction of both cues when compared to control fish. Both treatment $(\mathrm{F}=85.88 ; \mathrm{DF}=1, \mathrm{P}<0.05)$ and time were significant $(\mathrm{F}=25.22 ; \mathrm{DF}=1, \mathrm{P}<0.05)$. The shaded areas represent the standard deviation of the data. 


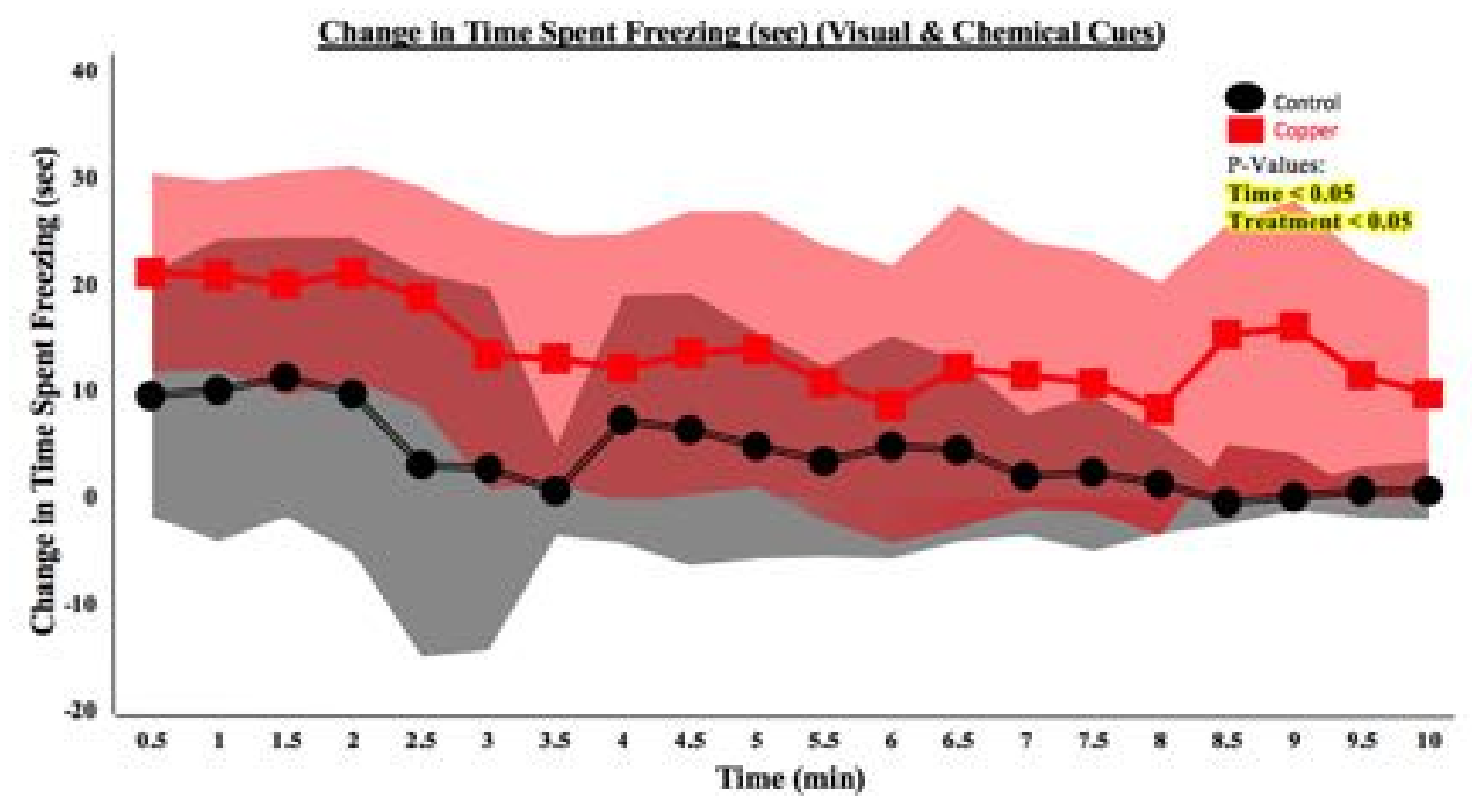

Figure 24C. Change Time Spent Freezing (sec) (Visual \& Chemical Cue). After the experiment, the changes in time spent freezing was calculated by subtracting the data from trial one from the data from trial two. Every point in this graph represents the average of 10 individual fish and their time spent freezing at that specific time. This graph shows that copper-exposed fish spent overall more time freezing in response to the introduction of both cues in comparison to the control group. Both treatment $(\mathrm{F}=71$; $\mathrm{DF}=1, \mathrm{P}<0.05)$ and time $(\mathrm{F}=24.42 ; \mathrm{DF}=1, \mathrm{P}<0.05)$ were significantly different. The shaded areas represent the standard deviation of the data. 


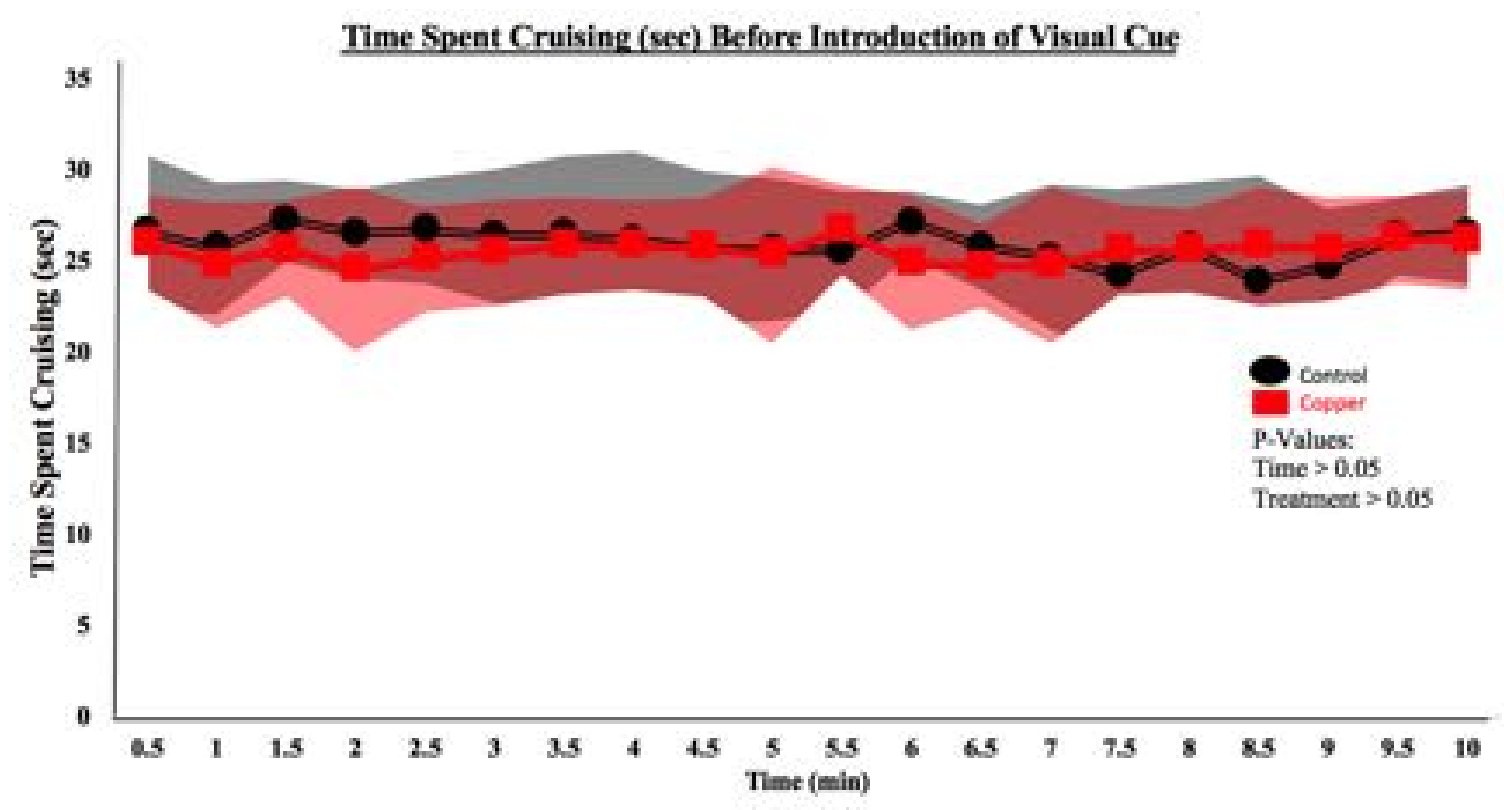

Figure 25A. Time Spent Cruising (sec) Before Introduction of Visual Cue. Before the introduction of the visual cue (predator model) both groups were left to acclimate for 10 minutes. During these 10 minutes, every 30 seconds data points were recorded. Every point in this graph represents the average of 10 individual fish and their total time spent cruising in seconds at that specific time. This graph shows that there was no difference in time spent cruising before the introduction of the visual cue. Treatment $(\mathrm{F}=1.27 ; \mathrm{DF}=1$, $\mathrm{P}>0.05)$ and time were not significant $(\mathrm{F}=0.68 ; \mathrm{DF}=1 ; \mathrm{P}>0.05)$. The shaded areas represent the standard deviation of the data. 


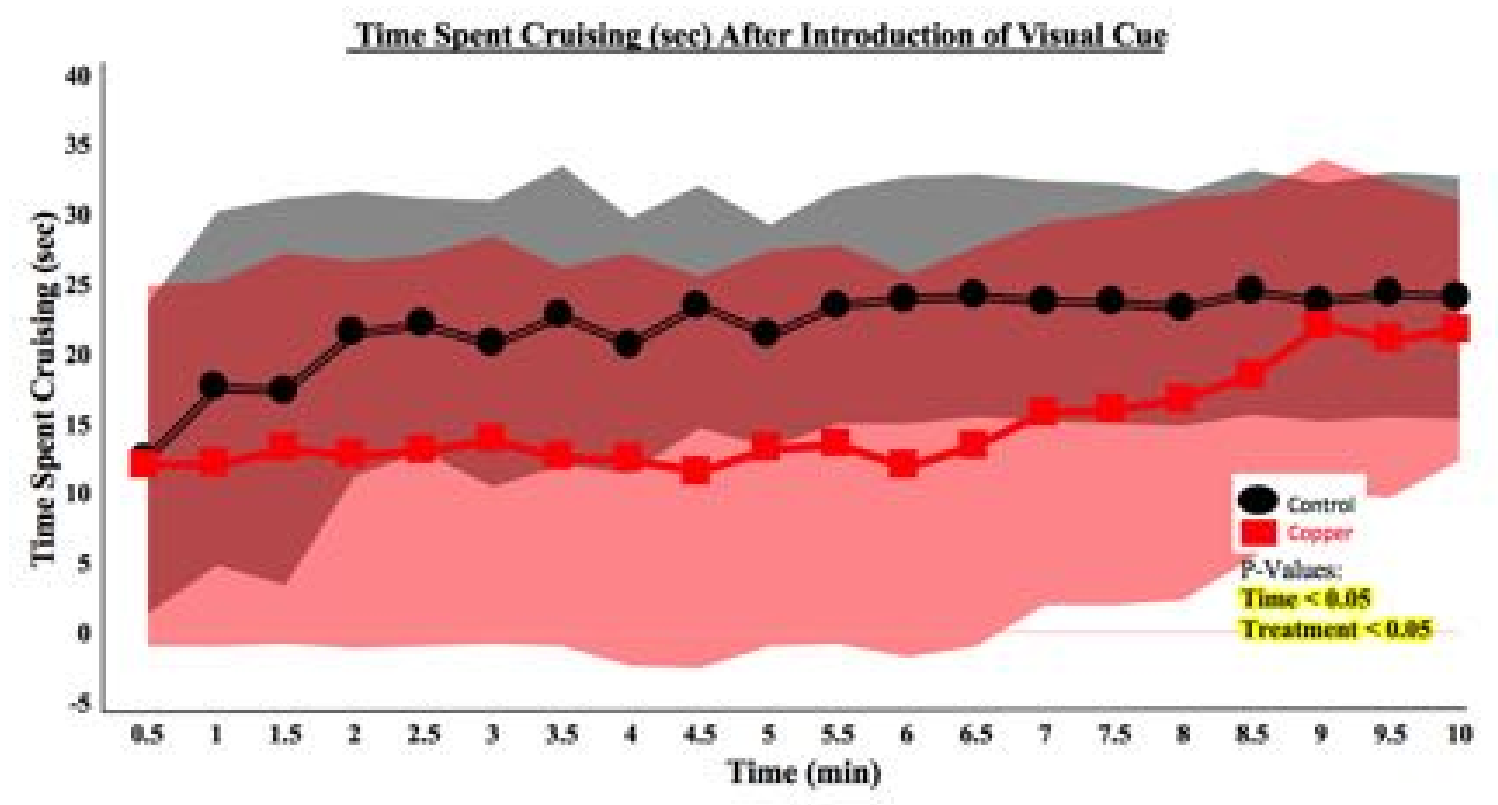

Figure 25B. Time Spent Cruising (sec) After Introduction of Visual Cue. After the introduction of the visual cue (predator model) data was recorded for 10 minutes every 30 seconds. Every point in this graph represents the average of 10 individual fish and their total time spent cruising in seconds at that specific time. This graph shows that copper contaminated fish spent less time cruising after the introduction of the visual cue. Both treatment $(\mathrm{F}=38.58 ; \mathrm{DF}=1, \mathrm{P}<0.05)$ and time were significant $(\mathrm{F}=20.01 ; \mathrm{DF}=1, \mathrm{P}<0.05)$ The shaded areas represent the standard deviation of the data. 


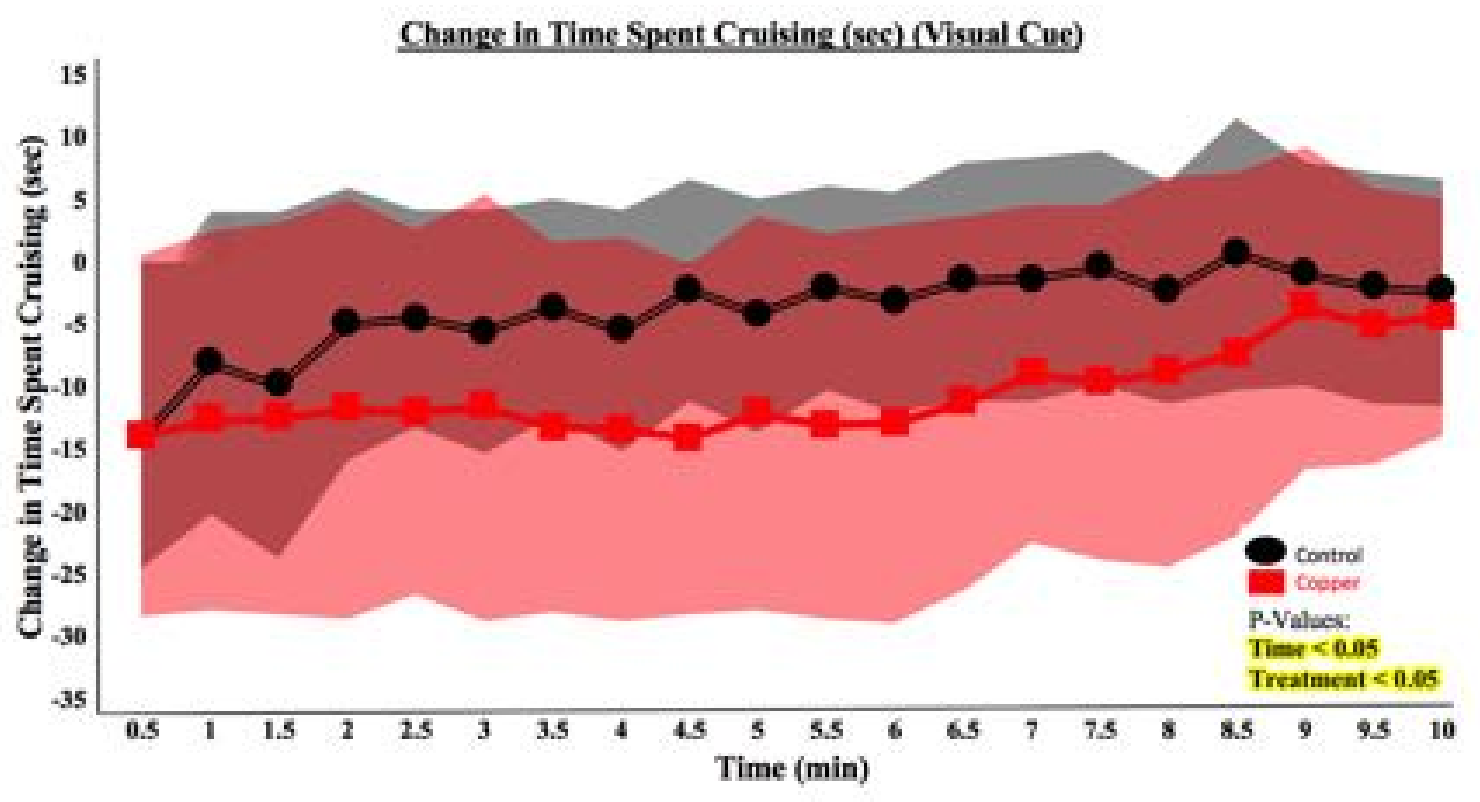

Figure 25C. Change Time Spent Cruising (sec) (Visual Cue). After the experiment, the change in time spent cruising was calculated by subtracting the data from trial one from the data from trial two. Every point in this graph represents the average of 10 individual fish and their total time spent cruising in seconds at that specific time. This graph shows that copper contaminated fish overall spent less time cruising in response to the introduction of the visual cue. Time also had an effect on how these groups too responded to the introduction of the cue. Both treatment $(\mathrm{F}=39.62 ; \mathrm{DF}=1, \mathrm{P}<0.05)$ and time were significant $(\mathrm{F}=19.50 \mathrm{DF}=1, \mathrm{P}<0.05)$. The shaded areas represent the standard deviation of the data. 


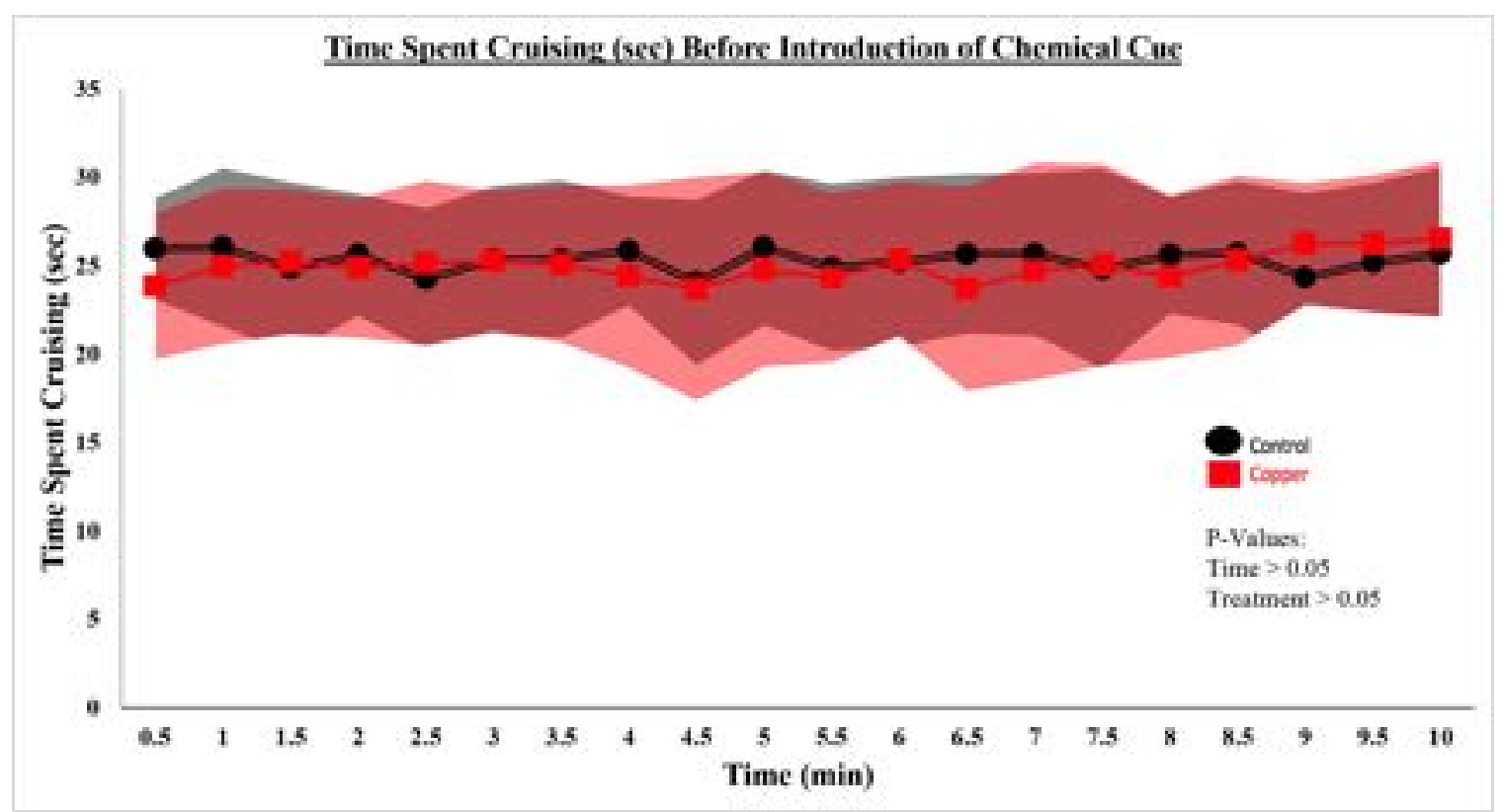

Figure 26A. Time Spent Cruising (sec) Before Introduction of Chemical Cue. Before the introduction of the chemical cue (predator kairomones) both groups were left to acclimate for 10 minutes. During these 10 minutes, every 30 seconds data points were recorded. Every point in this graph represents the average of 10 individual fish and their total time spent cruising in seconds at that specific time. This graph shows that there was no difference between the control and copper groups before the introduction of the chemical cue. Treatment was not significant $(\mathrm{F}=0.62 ; \mathrm{DF}=1, \mathrm{P}>0.05)$ and time was also not significant $(\mathrm{F}=0.46 ; \mathrm{DF}=1 ; \mathrm{P}>0.05)$. The shaded areas represent the standard deviation of the data. 


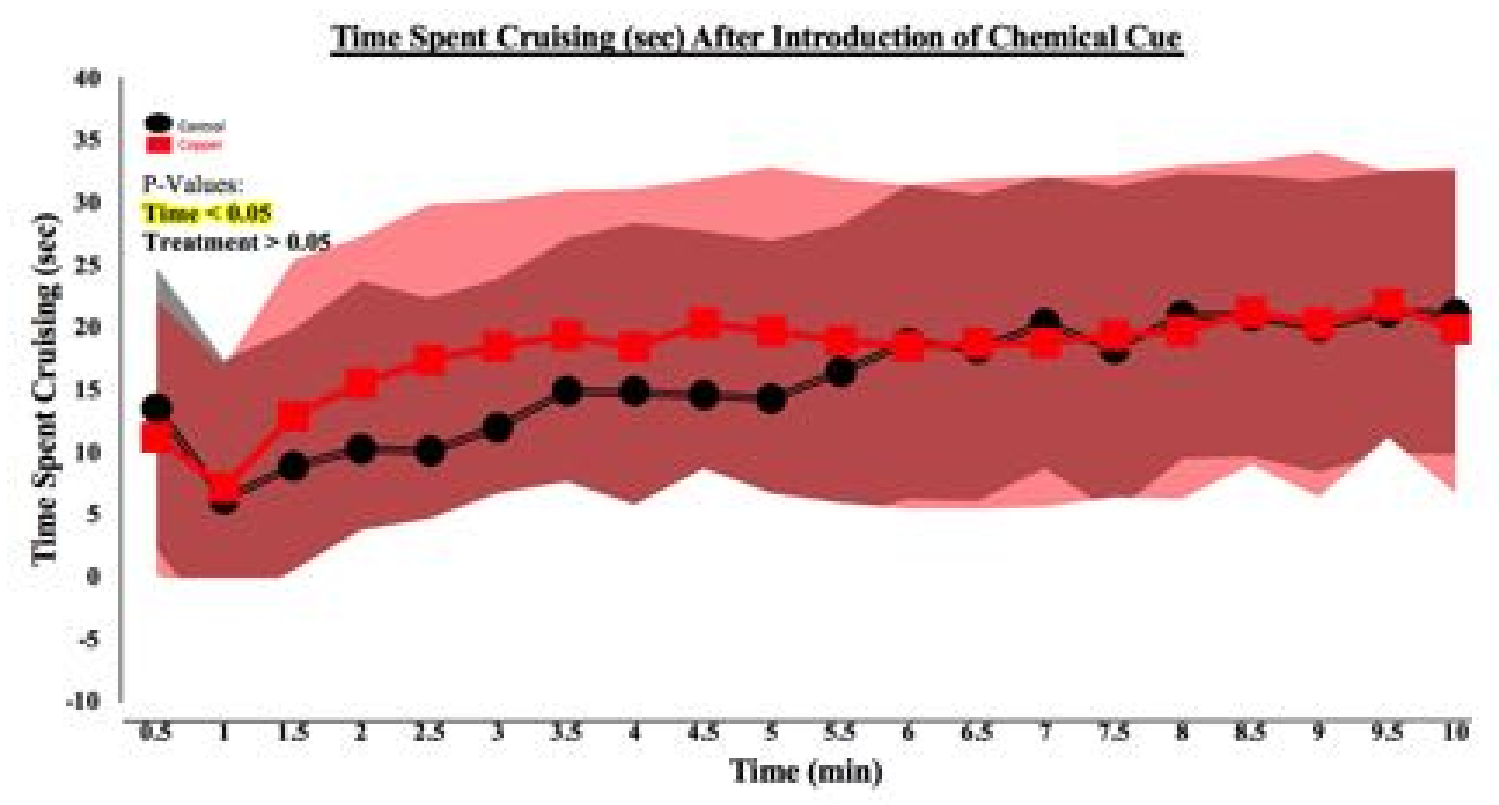

Figure 26B. Time Spent Cruising (sec) After Introduction of Chemical Cue. After the introduction of the chemical cue (kairomones) data was recorded for 10 minutes every 30 seconds. Every point in this graph represents the average of 10 individual fish and their total time spent cruising in seconds at that specific time. Time had an effect on the time spent cruising by both groups. Treatment was not significant $(\mathrm{F}=3.14 ; \mathrm{DF}=1, \mathrm{P}>0.05)$ but time was significant $(\mathrm{F}=32.50 ; \mathrm{DF}=1, \mathrm{P}<0.05) \quad$ The shaded areas represent the standard deviation of the data. 


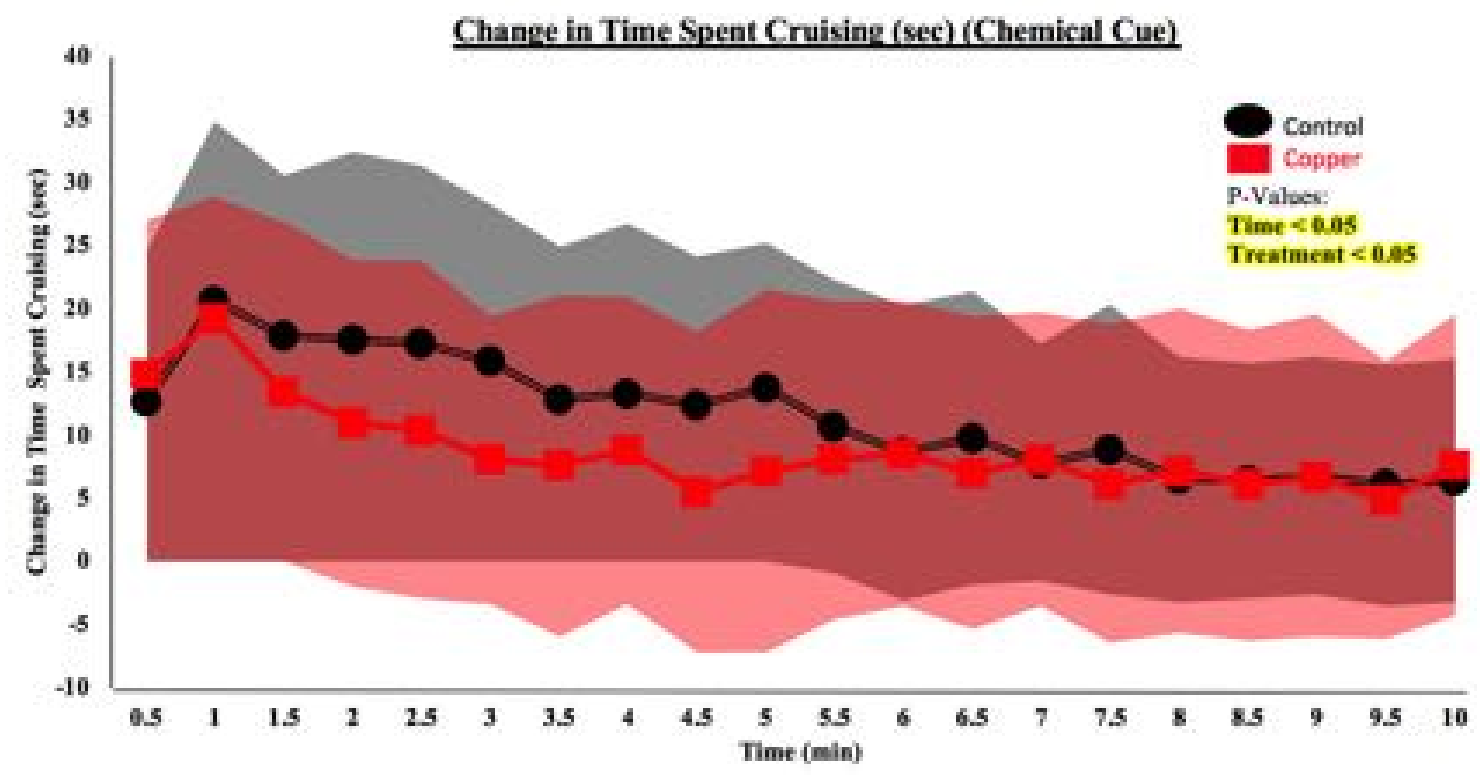

Figure 26C. Change Time Spent Cruising (sec) (Chemical Cue). After the experiment the change in time spent cruising was calculated by subtracting the data from trial one from the data from trial two. Every point in this graph represents the average of 10 individual fish and their total time spent cruising in seconds at that specific time. This graph shows that at the beginning of the trial copper contaminated fish spent less time cruising in respond to the introduction of the chemical cue when compared to the control fish. At the end of the trial, both groups decreased their time spent. Both treatment $(\mathrm{F}=5.16 ; \mathrm{DF}=1, \mathrm{P}<0.05)$ and time were significant $(\mathrm{F}=34.70 ; \mathrm{DF}=1, \mathrm{P}<0.05)$. The shaded areas represent the standard deviation of the data 




Figure 27A. Time Spent Cruising (sec) Before Introduction of Visual \& Chemical

Cue. Before the introduction of the visual cue \& chemical cues (predator model+ kairomones) both groups were left to acclimate for 10 minutes. During these 10 minutes, every 30 seconds data points were recorded. Every point in this graph represents the average of 10 individual fish and their time spent cruising in seconds at that specific time. This graph shows that towards the end of the trial copper contaminated fish spent less time cruising before the introduction of both cues. Treatment was significant $(\mathrm{F}=8.66$; $\mathrm{DF}=1, \mathrm{P}<0.05)$ but time was not $(\mathrm{F}=0.30 ; \mathrm{DF}=1 ; \mathrm{P}>0.05)$. The shaded areas represent the standard deviation of the data. 


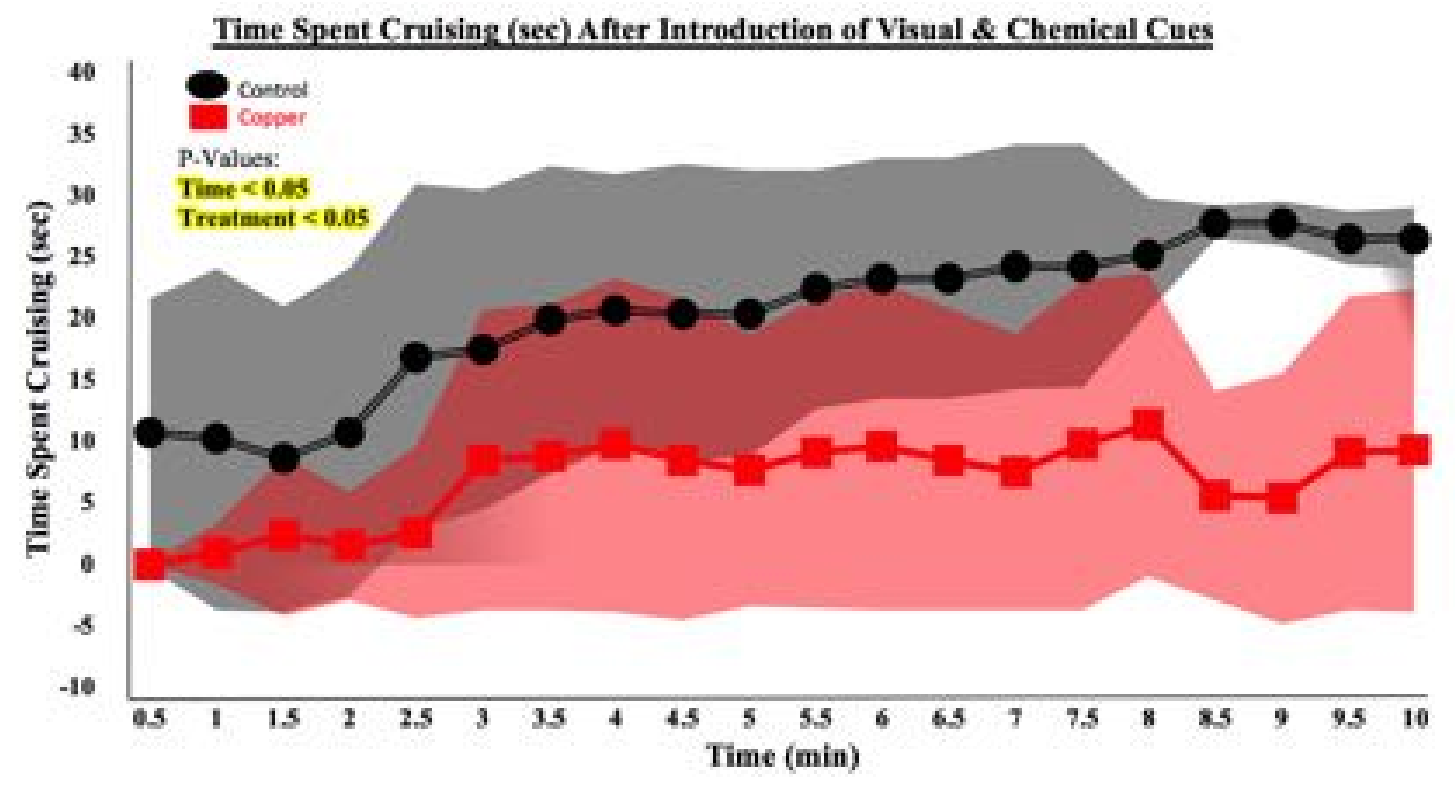

Figure 27B. Time Spent Cruising (sec) After Introduction of Visual \& Chemical

Cue. After the introduction of the visual \& chemical cue (predator model + kairomones) data was recorded every 30 seconds for 10 minutes. Every point in this graph represents the average of 10 individual fish and their time spent cruising in seconds at that specific time. This graph shows that copper contaminated fish spent less time cruising after the introduction of both cues when compared to control fish. Both treatment $(\mathrm{F}=138.21$; $\mathrm{DF}=1, \mathrm{P}<0.05)$ and time were significant $(\mathrm{F}=46.01 ; \mathrm{DF}=1, \mathrm{P}<0.05)$. The shaded areas represent the standard deviation of the data. 


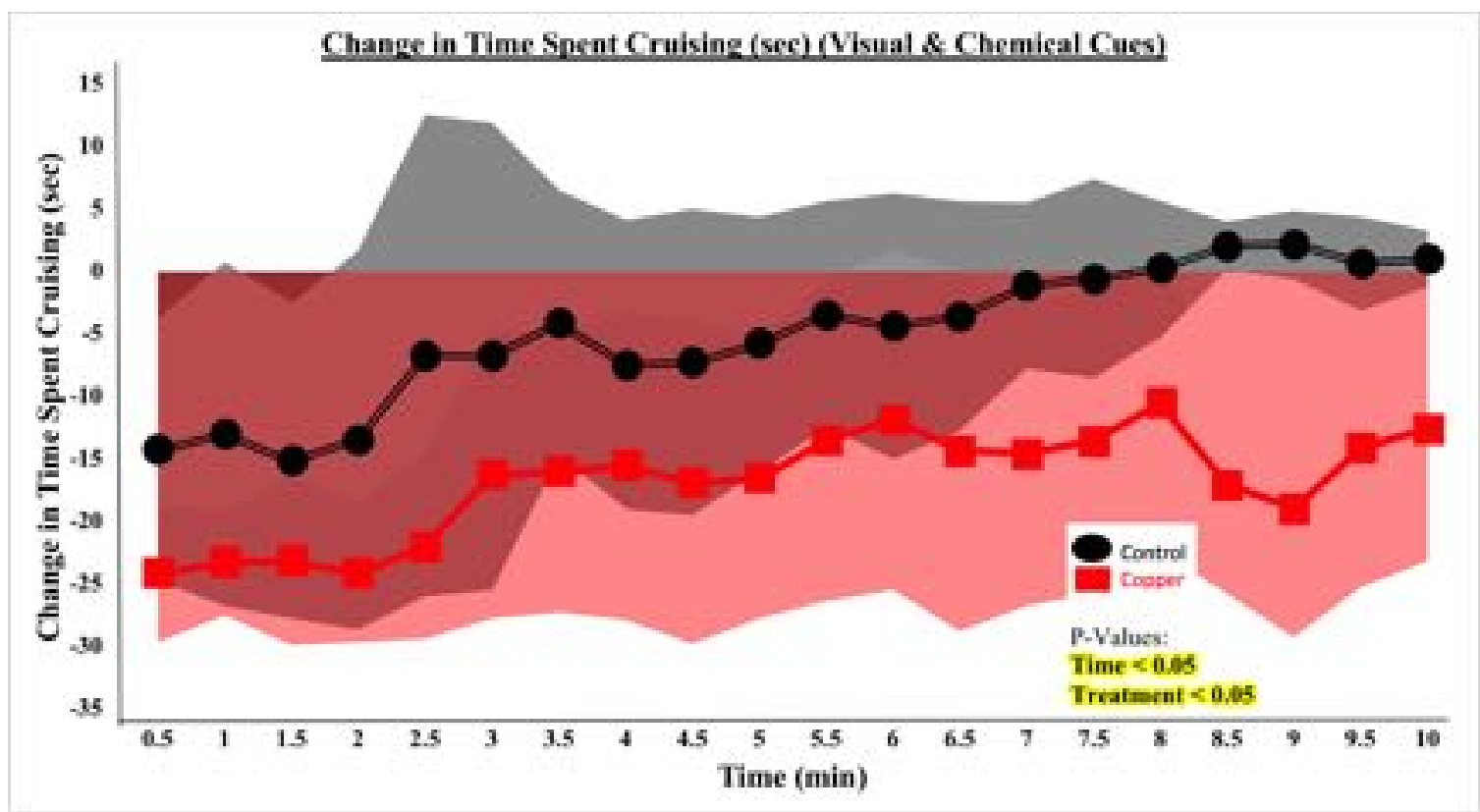

Figure 27C. Change Time Spent Cruising (sec) (Visual \& Chemical Cue). After the experiment, the change in time spent cruising was calculated by subtracting the data from trial one from the data from trial two. Every point in this graph represents the average of 10 individual fish and their total time spent cruising at that specific time. This graph shows that copper-exposed fish spent less time cruising as a response to the introduction of both cues in comparison to the control group. Both treatment $(\mathrm{F}=125.82 ; \mathrm{DF}=1$, $\mathrm{P}<0.05)$ and time $(\mathrm{F}=50.02 ; \mathrm{DF}=1, \mathrm{P}<0.05)$ were significantly different. The shaded areas represent the standard deviation of the data. 


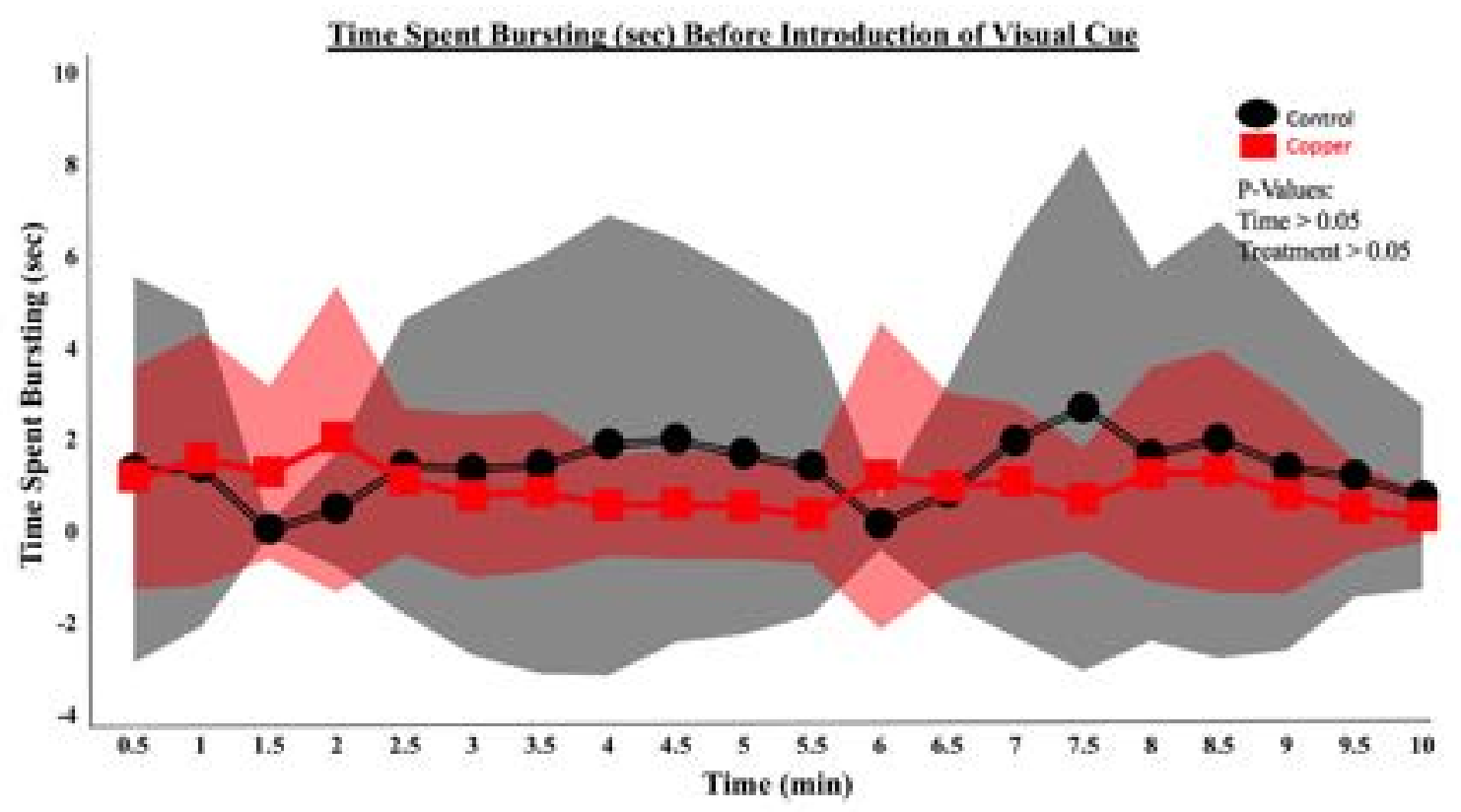

Figure 28A. Time Spent Bursting (sec) Before Introduction of Visual Cue. Before the introduction of the visual cue (predator model) both groups were left to acclimate for 10 minutes. During these 10 minutes, every 30 seconds data points were recorded. Every point in this graph represents the average of 10 individual fish and their total time spent bursting in seconds at that specific time. Treatment $(\mathrm{F}=16.91 ; \mathrm{DF}=1, \mathrm{P}>0.05)$ and time were not significant $(\mathrm{F}=0.41 ; \mathrm{DF}=1 ; \mathrm{P}>0.05)$. The shaded areas represent the standard deviation of the data. 


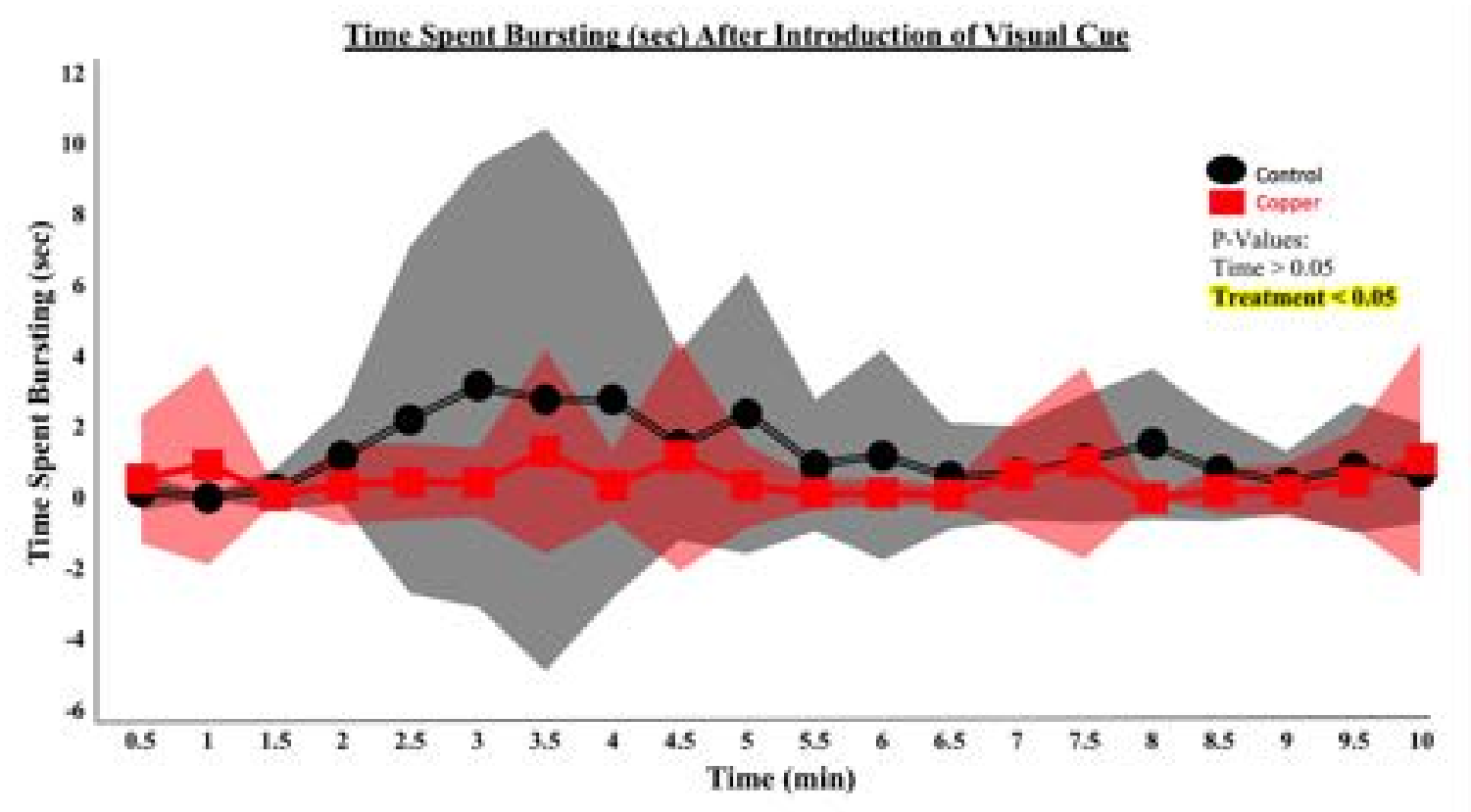

Figure 28B. Time Spent Bursting (sec) After Introduction of Visual Cue. After the introduction of the visual cue (predator model) data was recorded for 10 minutes every 30 seconds. Every point in this graph represents the average of 10 individual fish and their total time spent bursting in seconds at that specific time. This graph shows that copper contaminated fish spent less time bursting after the introduction of the visual cue. Treatment was significant $(\mathrm{F}=8.77 ; \mathrm{DF}=1, \mathrm{P}<0.05)$ but time was not $(\mathrm{F}=0.40 ; \mathrm{DF}=1$, $\mathrm{P}>0.05) \quad$ The shaded areas represent the standard deviation of the data. 


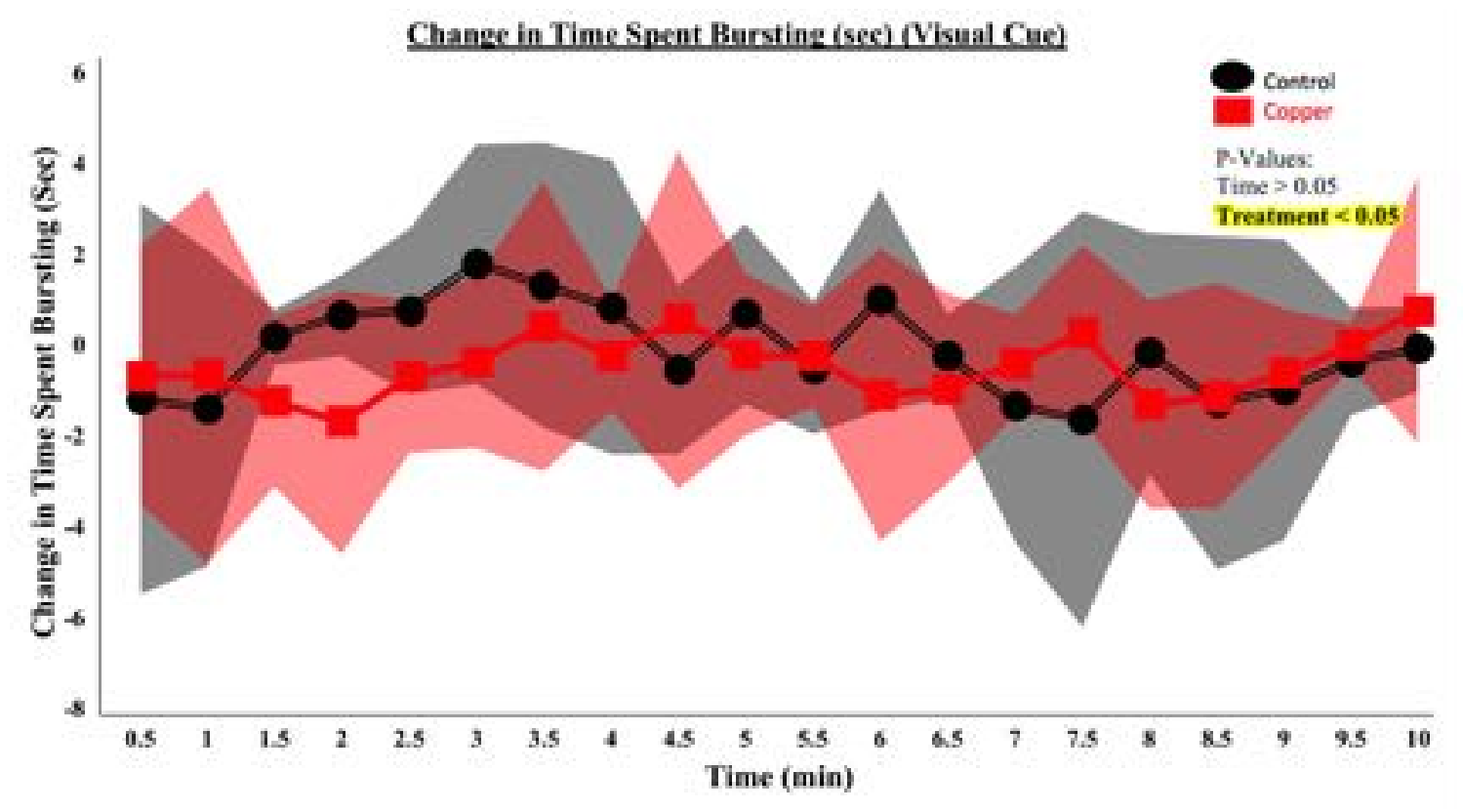

Figure 28C. Change Time Spent Bursting (sec) (Visual Cue). After the experiment, the change in time spent bursting was calculated by subtracting the data from trial one from the data from trial two. Every point in this graph represents the average of 10 individual fish and their total time spent bursting in seconds at that specific time. This graph shows that overall copper-exposed fish reduced their time spent bursting when compared to control fish in response to the visual cue. Treatment was significant $(\mathrm{F}=6.91$; $\mathrm{DF}=1, \mathrm{P}<0.05)$ but time was not $(\mathrm{F}=0.41 \mathrm{DF}=1, \mathrm{P}>0.05)$. The shaded areas represent the standard deviation of the data. 


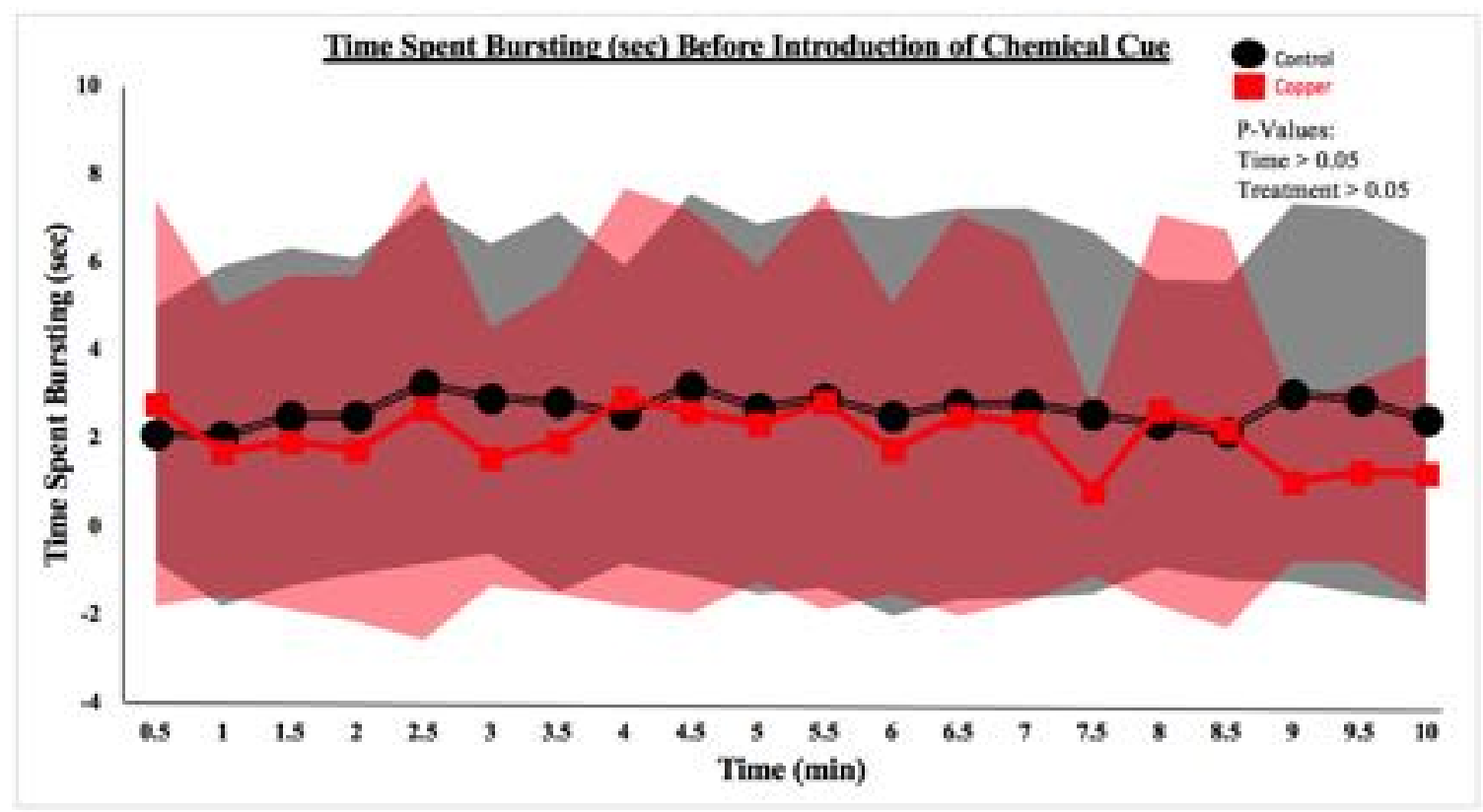

Figure 29A. Time Spent Bursting (sec) Before Introduction of Chemical Cue. Before the introduction of the chemical cue (predator kairomones) both groups were left to acclimate for 10 minutes. During these 10 minutes, every 30 seconds data points were recorded. Every point in this graph represents the average of 10 individual fish and their total time spent bursting in seconds at that specific time. This graph shows that there was no difference between the control and copper groups before the introduction of the chemical cue. Treatment $(\mathrm{F}=0.56 ; \mathrm{DF}=1, \mathrm{P}>0.05)$ and time were not significant $(\mathrm{F}=0.28$; $\mathrm{DF}=1 ; \mathrm{P}>0.05)$. The shaded areas represent the standard deviation of the data. 


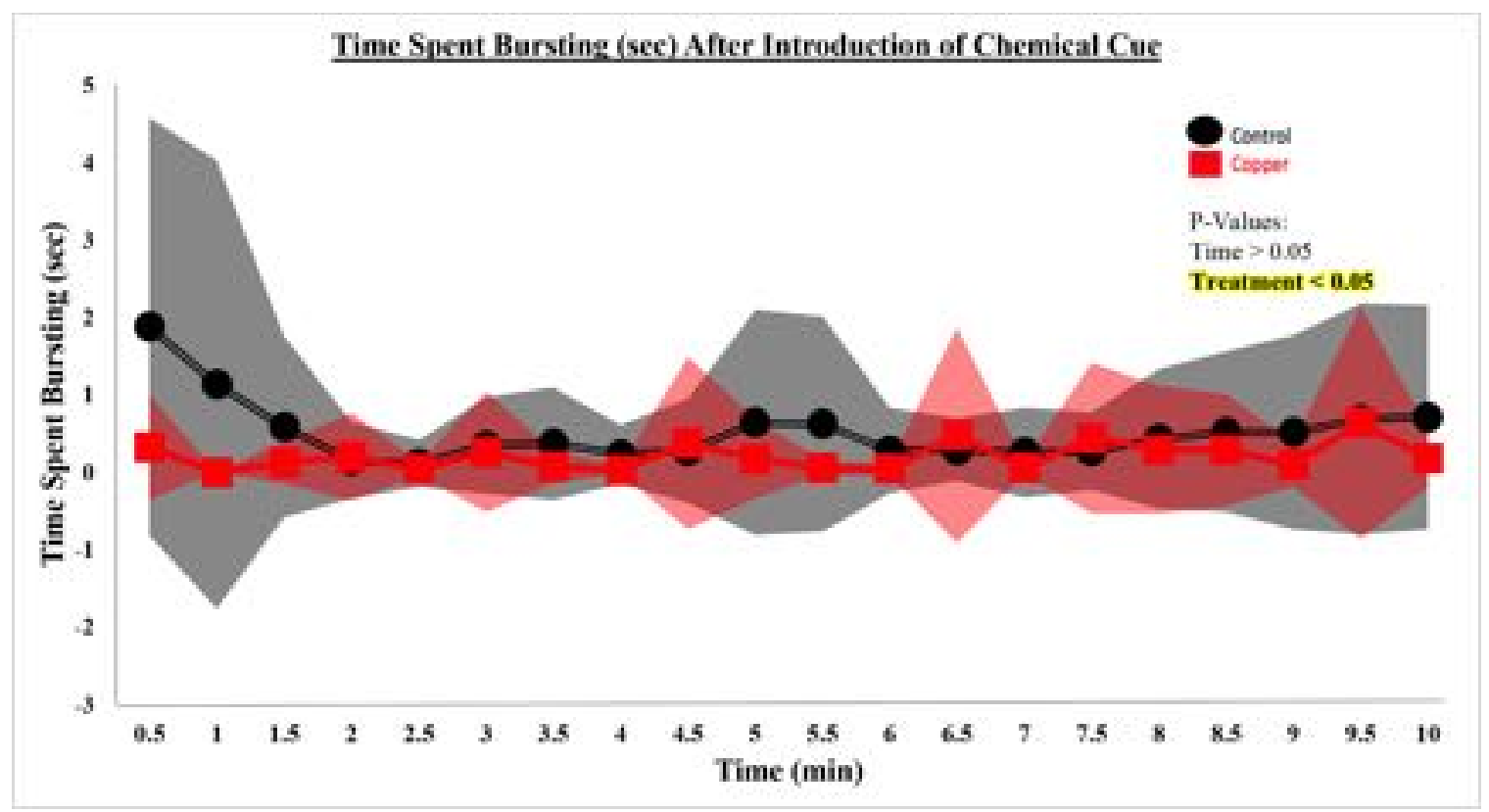

Figure 29B. Time Spent Bursting (sec) After Introduction of Chemical Cue. After the introduction of the chemical cue (kairomones) data was recorded for 10 minutes every 30 seconds. Every point in this graph represents the average of 10 individual fish and their total time spent bursting in seconds at that specific time. This graph shows that copper contaminated fish spent less time bursting after the introduction of the chemical cue when compared to the control. Treatment was significant $(\mathrm{F}=8.85 ; \mathrm{DF}=1, \mathrm{P}<0.05)$ but time was not $(\mathrm{F}=0.10 ; \mathrm{DF}=1, \mathrm{P}>0.05)$. The shaded areas represent the standard deviation of the data. 


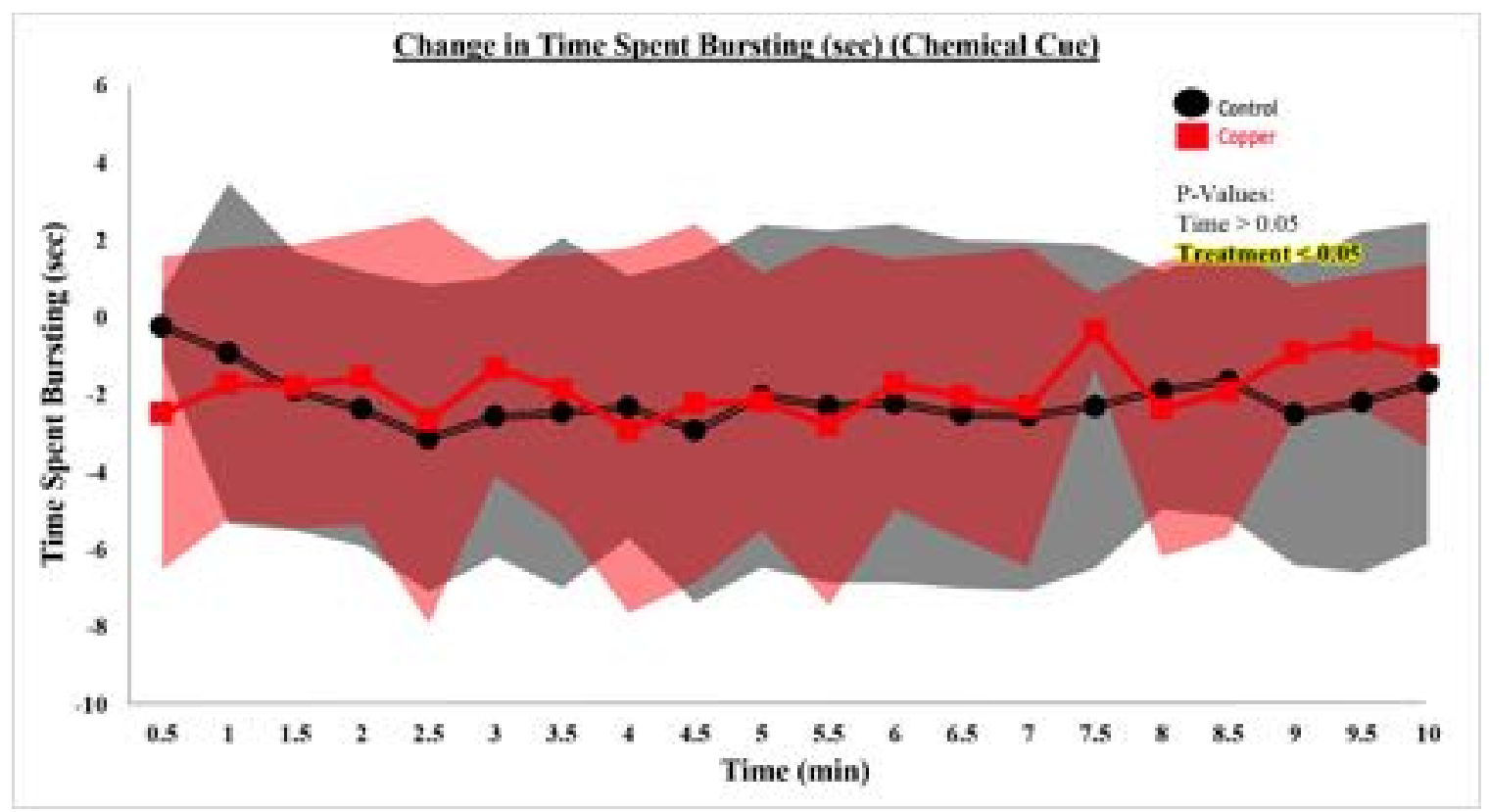

Figure 29C. Change Time Spent Bursting (sec) (Chemical Cue). After the experiment, the change in time spent bursting was calculated by subtracting the data from trial one from the data from trial two. Every point in this graph represents the average of 10 individual fish and their total time spent bursting in seconds at that specific time. This graph shows that copper-exposed fish increased their time spent bursting when compared to control fish in response to the chemical cue. Treatment was significant $(\mathrm{F}=7.13 ; \mathrm{DF}=1$, $\mathrm{P}<0.05)$ but time was not $(\mathrm{F}=0.03 \mathrm{DF}=1, \mathrm{P}>0.05)$. The shaded areas represent the standard deviation of the data. 


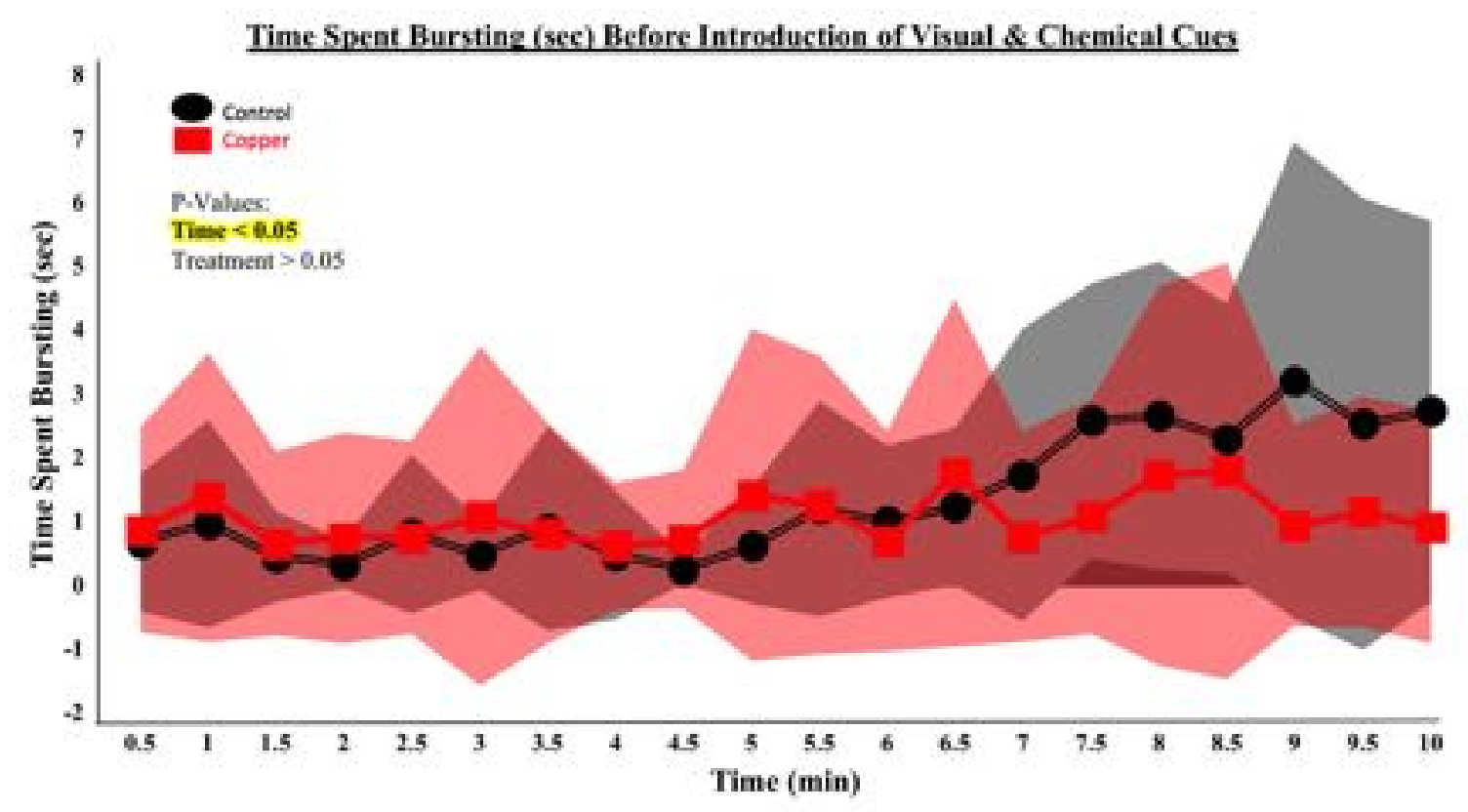

Figure 30A. Time Spent Bursting (sec) Before Introduction of Visual \& Chemical Cue. Before the introduction of the visual cue $\&$ chemical cues (predator model + kairomones) both groups were left to acclimate for 10 minutes. During these 10 minutes, every 30 seconds data points were recorded. Every point in this graph represents the average of 10 individual fish and their time spent bursting in seconds at that specific time. This graph shows that time had an effect on the time spent bursting by both groups. Treatment was not significant $(\mathrm{F}=1.95 ; \mathrm{DF}=1, \mathrm{P}>0.05)$ but time was significant $(\mathrm{F}=18.55 ; \mathrm{DF}=1 ; \mathrm{P}<0.05)$. The shaded areas represent the standard deviation of the data. 


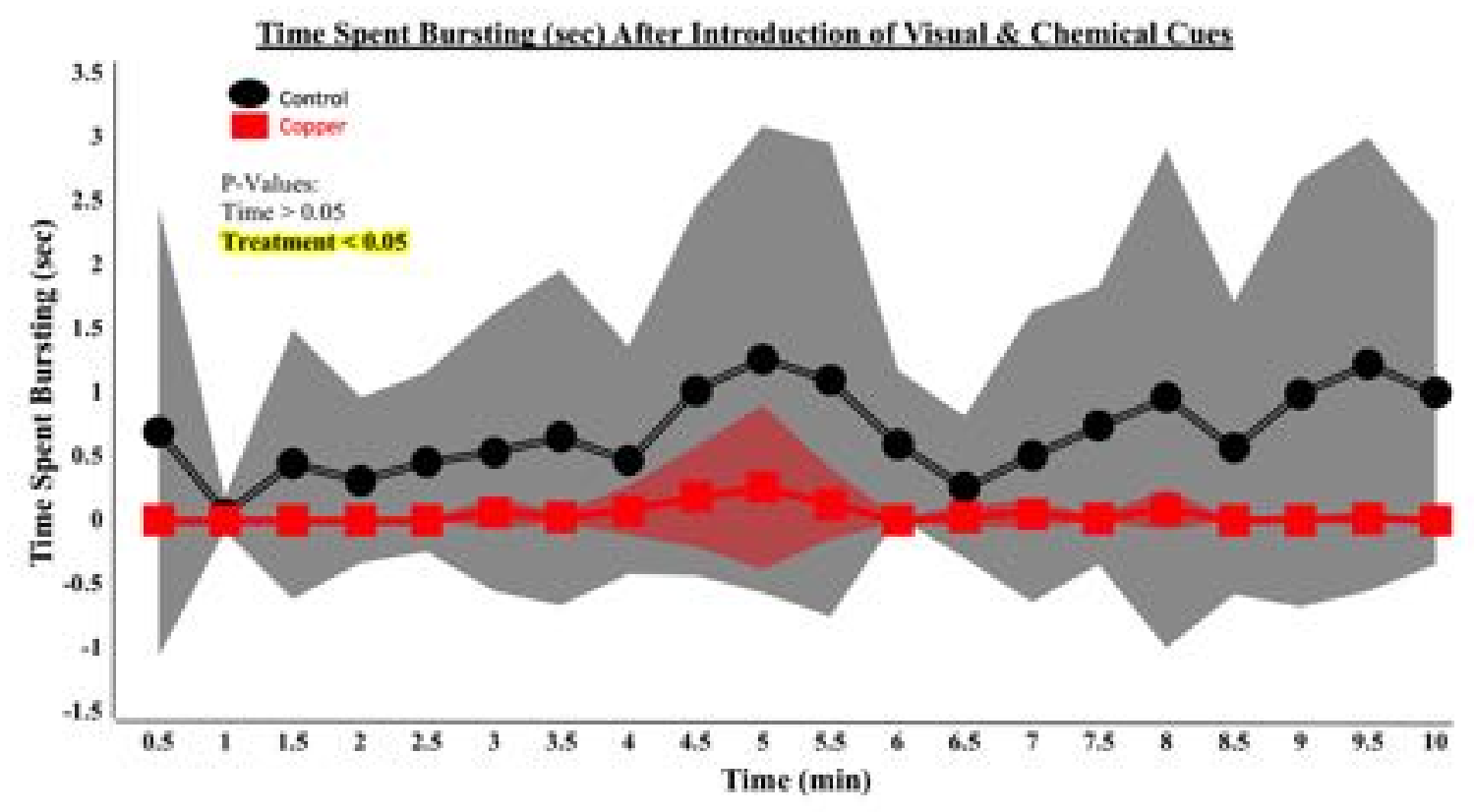

Figure 30B. Time Spent Bursting (sec) After Introduction of Visual \& Chemical Cue. After the introduction of the visual \& chemical cue (predator model + kairomones) data was recorded every 30 seconds for 10 minutes. Every point in this graph represents the average of 10 individual fish and their time spent bursting in seconds at that specific time. This graph shows that copper contaminated fish spent less time bursting after the introduction of both cues when compared to control fish. Treatment was significant $(\mathrm{F}=41.22 ; \mathrm{DF}=1, \mathrm{P}<0.05)$ but time was not $(\mathrm{F}=3.18 ; \mathrm{DF}=1, \mathrm{P}>0.05)$. The shaded areas represent the standard deviation of the data. 


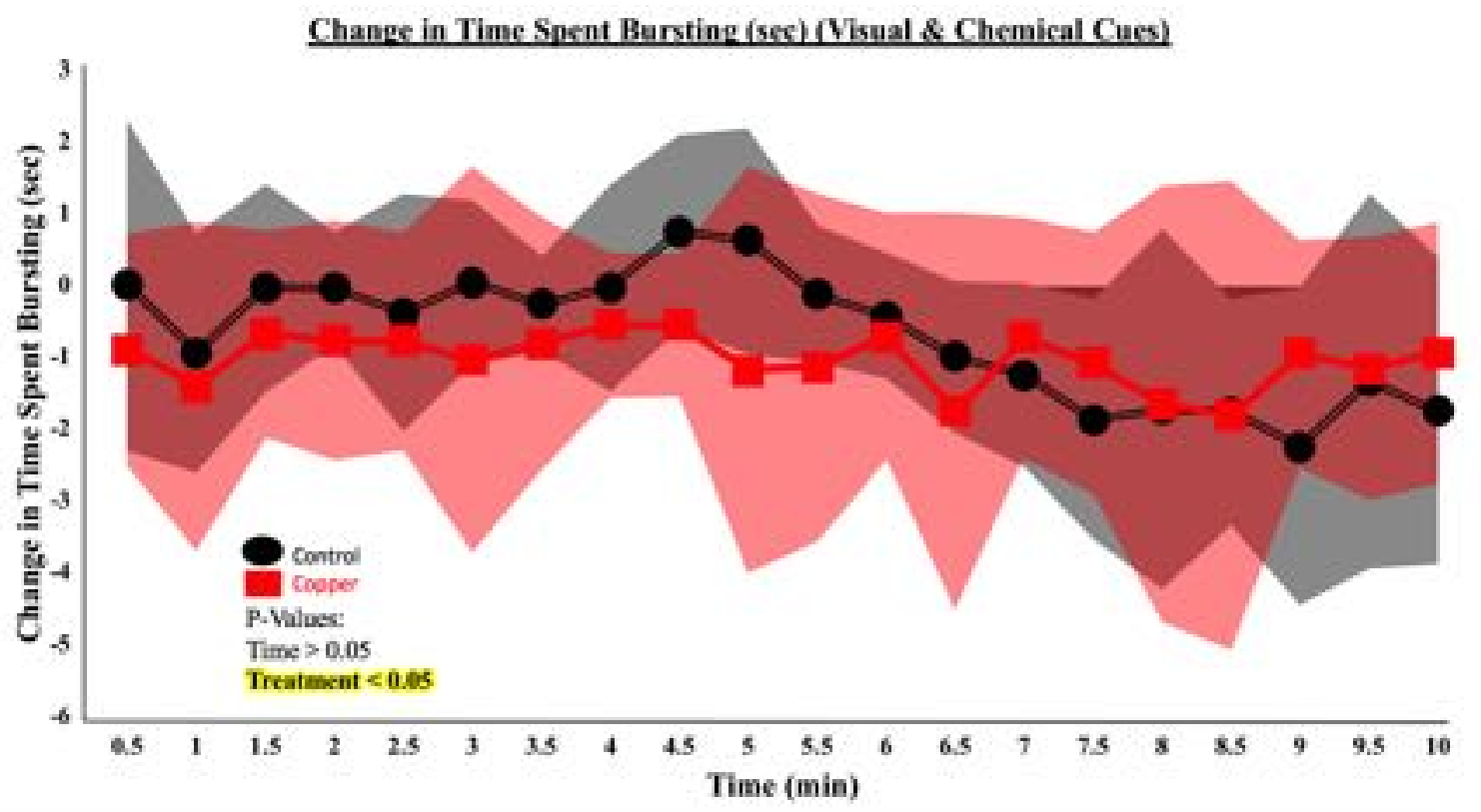

Figure 30C. Change Time Spent Bursting (sec) (Visual \& Chemical Cue). After the experiment, the change in time spent bursting was calculated by subtracting the data from trial one from the data from trial two. Every point in this graph represents the average of 10 individual fish and their time spent bursting at that specific time. This graph shows that copper-exposed fish spent overall less time bursting in response to the introduction of both cues in comparison to the control group. Treatment was significant $(\mathrm{F}=39.50$; $\mathrm{DF}=1, \mathrm{P}<0.05)$ but time was not $(\mathrm{F}=0.13 ; \mathrm{DF}=1, \mathrm{P}>0.05)$. The shaded areas represent the standard deviation of the data. 


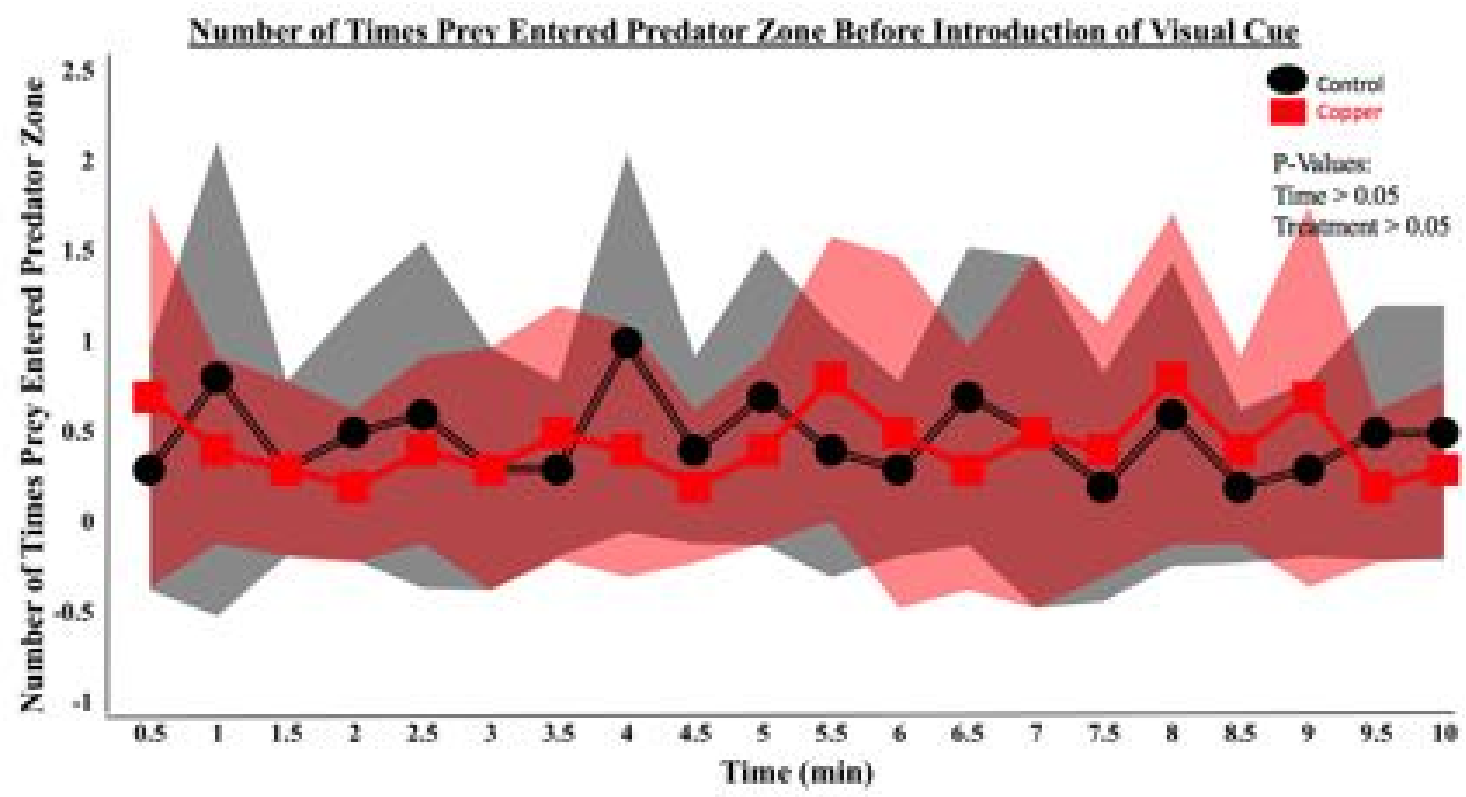

Figure 31A. Number of Times Prey Entered Predator Zone Before Introduction of Visual Cue. Before the introduction of the visual cue (predator model) both groups were left to acclimate for 10 minutes. During these 10 minutes, every 30 seconds data points were recorded. Every point in this graph represents the average of 10 individual fish and the amount of times the prey entered the predator zone at that specific time. This graph shows that there was no difference in amount of times each group entered the predator zone before the introduction of the visual cue. Treatment $(\mathrm{F}=0.23 ; \mathrm{DF}=1, \mathrm{P}>0.05)$ and time were not significant $(\mathrm{F}=0.03 ; \mathrm{DF}=1 ; \mathrm{P}>0.05)$. The shaded areas represent the standard deviation of the data. 




Figure 31B. Number of Times Prey Entered Predator Zone After Introduction of Visual Cue. After the introduction of the visual cue (predator model) data was recorded for 10 minutes every 30 seconds. Every point in this graph represents the average of 10 individual fish and the amount of times the prey entered the predator zone at that specific time. This graph shows that copper contaminated fish entered the predator zone more times than the control after the introduction of the visual cue. Time also had an effect on the number of times both groups entered the predator zone. Both, treatment $(\mathrm{F}=4.04$; $\mathrm{DF}=1, \mathrm{P}<0.05)$ and time were significant $(\mathrm{F}=5.89 ; \mathrm{DF}=1, \mathrm{P}<0.05)$. The shaded areas represent the standard deviation of the data. 


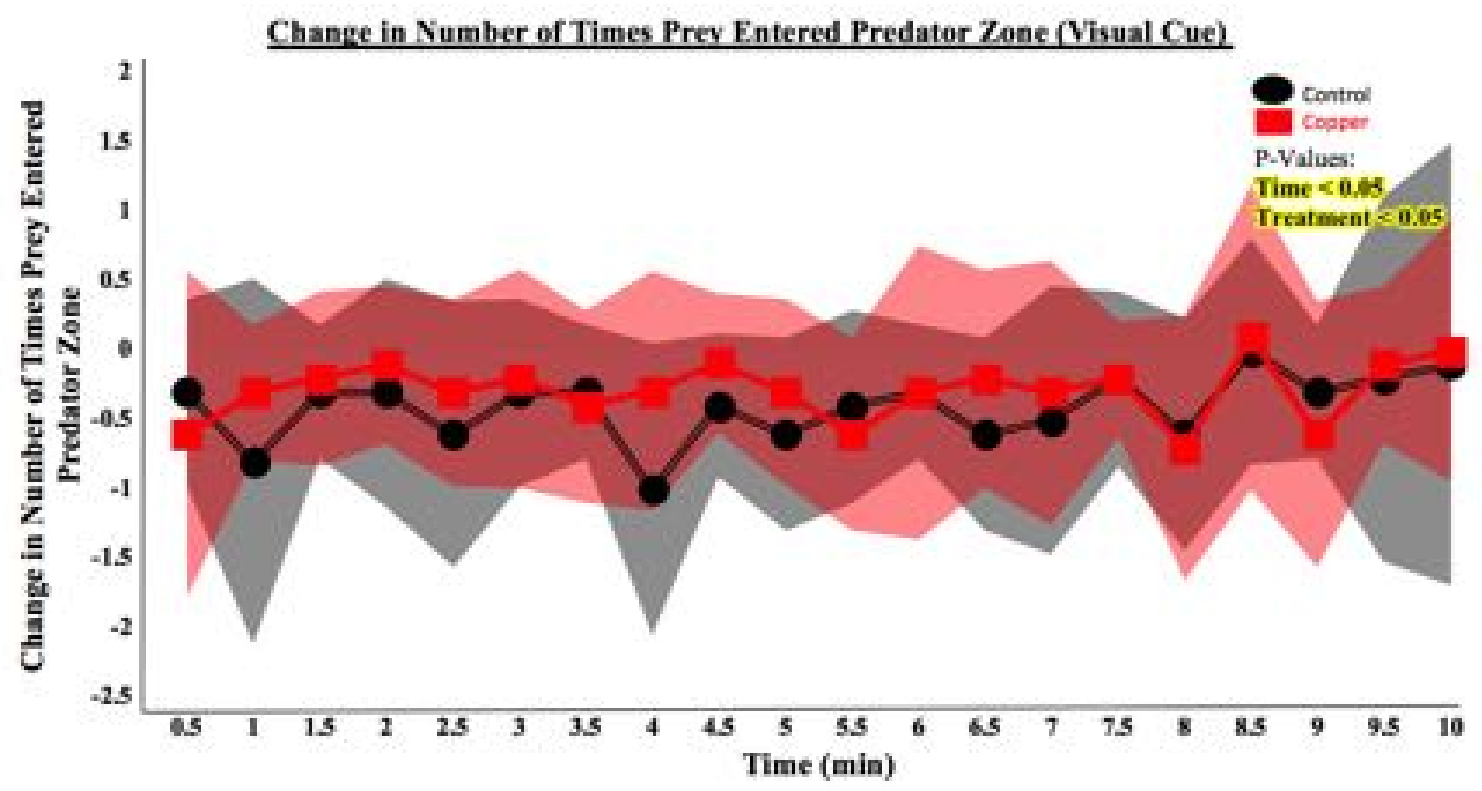

Figure 31C. Change in Number of Times Prey Entered Predator Zone (Visual Cue). After the experiment, the change in the amount of times the predator zone was calculated by subtracting the data from trial one from the data from trial two. Every point in this graph represents the average of 10 individual fish and the amount of times the predator zone was entered at that specific time. This graph shows that time and treatment had an effect on the number of times both groups entered the predator zone in response to the introduction of the visual cue. Both treatment $(\mathrm{F}=4.13 ; \mathrm{DF}=1, \mathrm{P}<0.05)$ and time were significant $(\mathrm{F}=5.93 ; \mathrm{DF}=1, \mathrm{P}<0.05)$. The shaded areas represent the standard deviation of the data. 


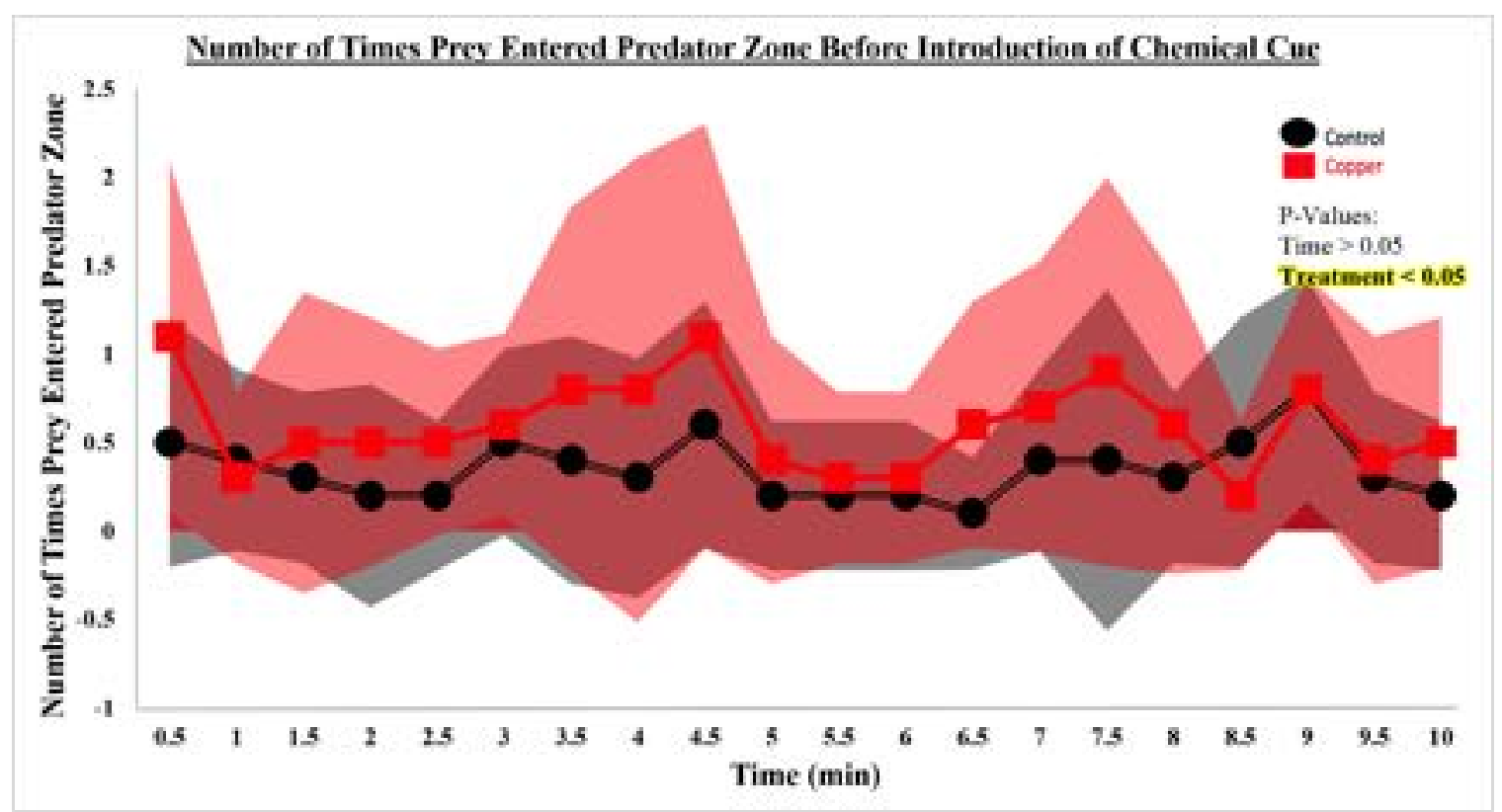

Figure 32A. Number of Times Prey Entered Predator Zone Before Introduction of Chemical Cue. Before the introduction of the chemical cue (predator kairomones) both groups were left to acclimate for 10 minutes. During these 10 minutes, every 30 seconds data points were recorded. Every point in this graph represents the average of 10 individual fish and the amount of times the prey entered the predator zone at that specific time. This graph shows that the copper-contaminated fish entered the predator zone more times than the control before the introduction of the visual cue. Treatment was significant $(\mathrm{F}=12.31 ; \mathrm{DF}=1, \mathrm{P}<0.05)$ but time was not $(\mathrm{F}=0.22 ; \mathrm{DF}=1 ; \mathrm{P}>0.05)$. The shaded areas represent the standard deviation of the data. 


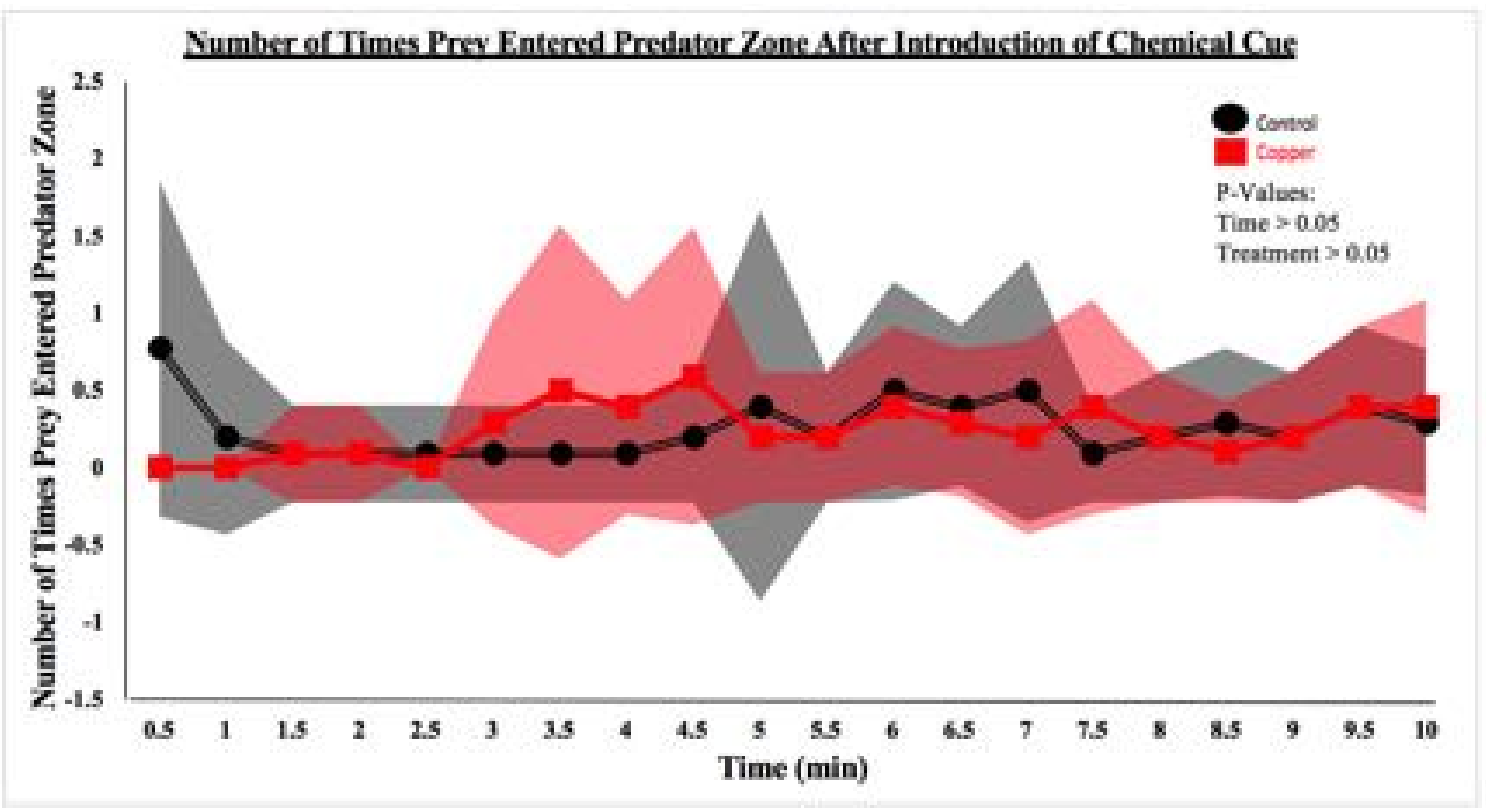

Figure 32B. Number of Times Prey Entered Predator Zone After Introduction of Chemical Cue. After the introduction of the chemical cue (predator kairomones) data was recorded for 10 minutes every 30 seconds. Every point in this graph represents the average of 10 individual fish and the amount of times the prey entered the predator zone at that specific time. This graph shows that there was no statistical difference between the amount of times copper-contaminated fish entered the predator zone and the number of times control fish entered predator zone after the introduction of the cue. Treatment $(\mathrm{F}=0.02 ; \mathrm{DF}=1, \mathrm{P}>0.05)$ and time were not significant $(\mathrm{F}=2.66 ; \mathrm{DF}=1, \mathrm{P}<0.05)$. The shaded areas represent the standard deviation of the data. 


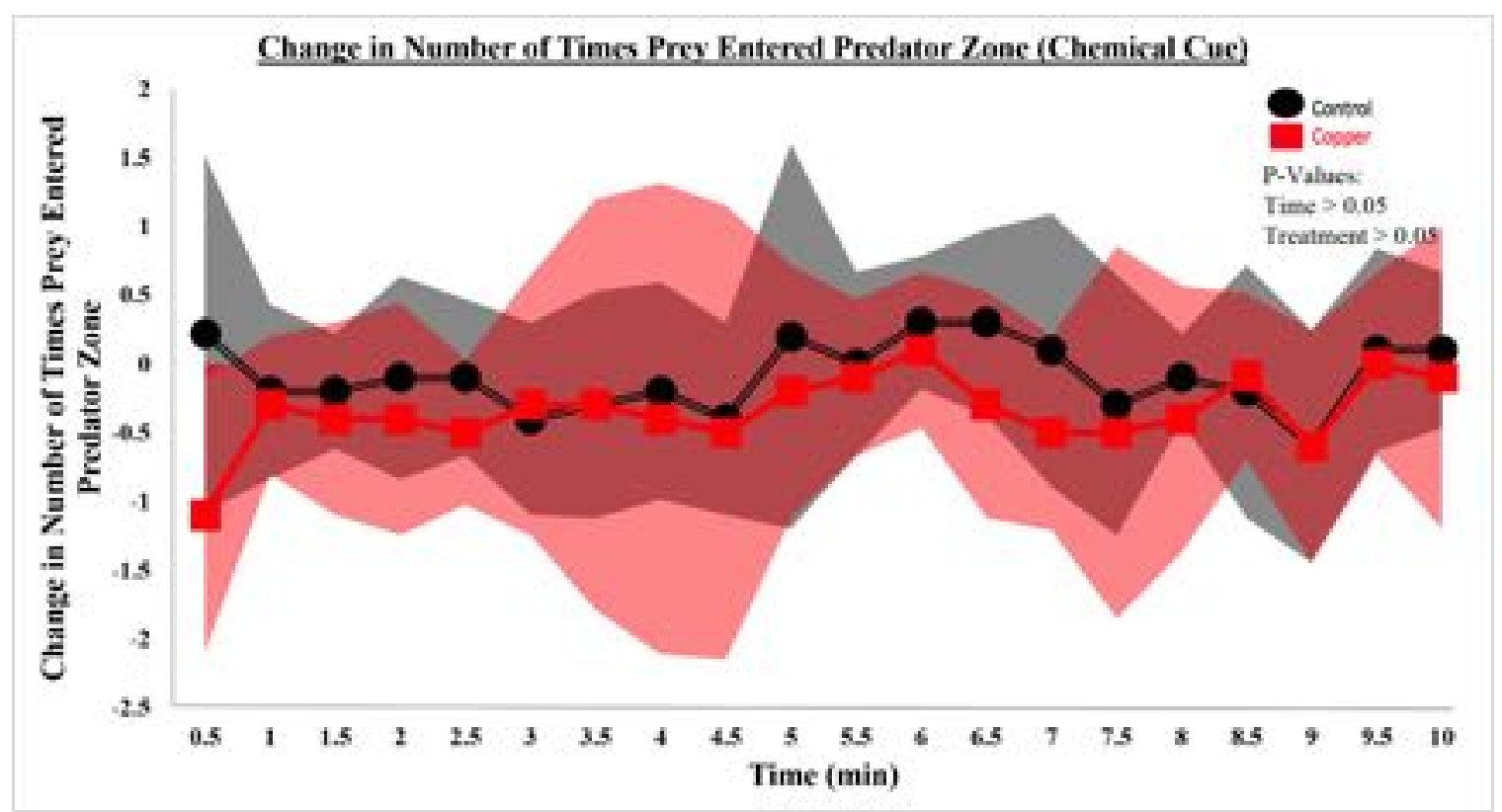

Figure 32C. Change in Number of Times Prey Entered Predator Zone (Chemical Cue). After the experiment, the change in the amount of times the predator zone was calculated by subtracting the data from trial one from the data from trial two. Every point in this graph represents the average of 10 individual fish and the amount of times the predator zone was entered at that specific time. This graph shows that there was no statistically significant difference between the amount of times copper-contaminated fish entered the predator zone and the number of times control fish entered predator zone. Treatment $(\mathrm{F}=0.05 ; \mathrm{DF}=1, \mathrm{P}>0.05)$ and time were not significant $(\mathrm{F}=2: 69 ; \mathrm{DF}=1$, $\mathrm{P}>0.05)$. The shaded areas represent the standard deviation of the data. 


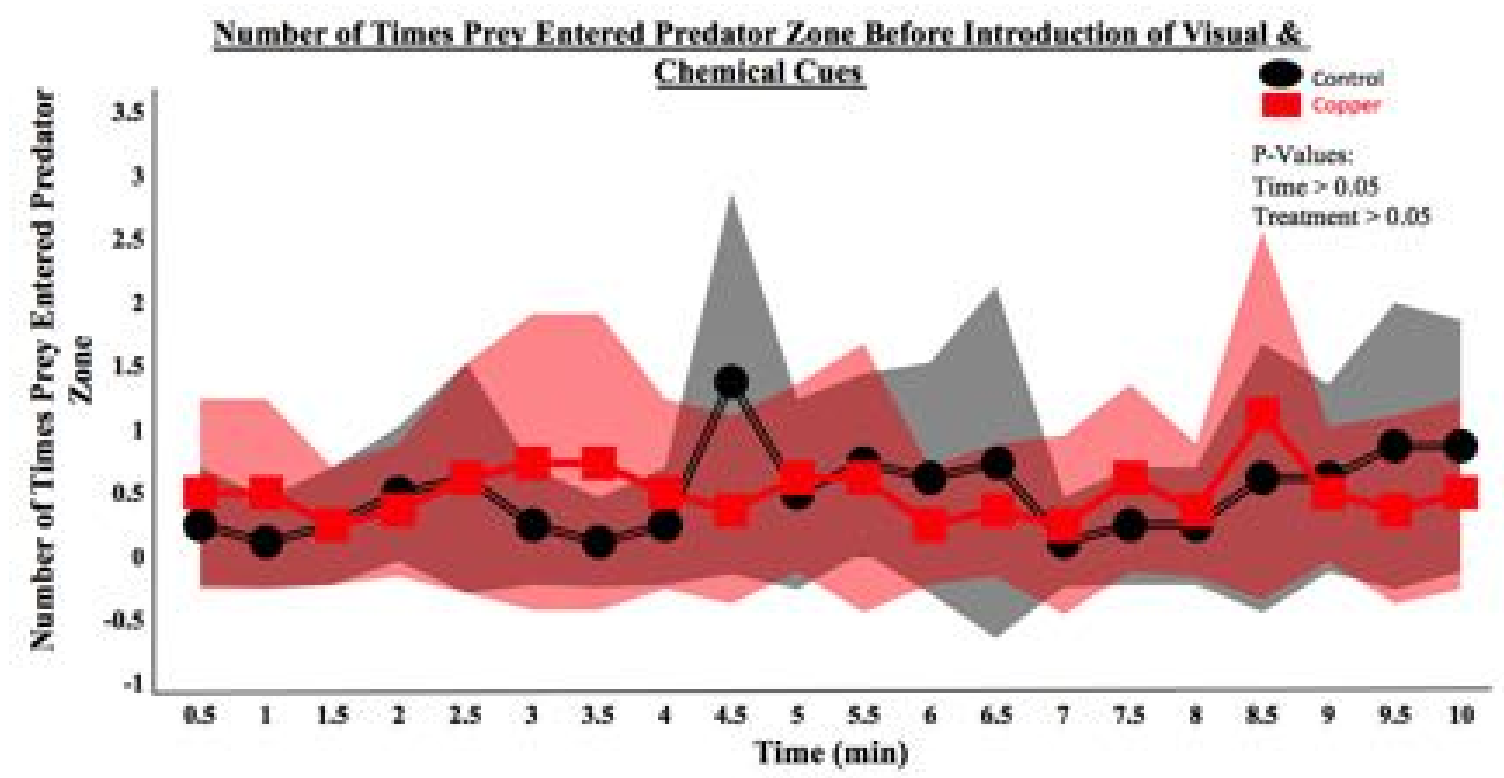

Figure 33A. Number of Times Prey Entered Predator Zone Before Introduction of Visual \& Chemical Cue. Before the introduction of the visual \& chemical cue (predator model + predator kairomones) both groups were left to acclimate for 10 minutes. During these 10 minutes, every 30 seconds data points were recorded. Every point in this graph represents the average of 10 individual fish and the amount of times the prey entered the predator zone at that specific time. This graph shows that there was no statistically significant difference between the amount of times copper-contaminated fish entered the predator zone and the number of times control fish entered predator zone. Treatment $(\mathrm{F}=0.02 ; \mathrm{DF}=1 ; \mathrm{P}>0.05)$ and time were not significant $(\mathrm{F}=2.28 ; \mathrm{DF}=1 ; \mathrm{P}>0.05)$. The shaded areas represent the standard deviation of the data. 


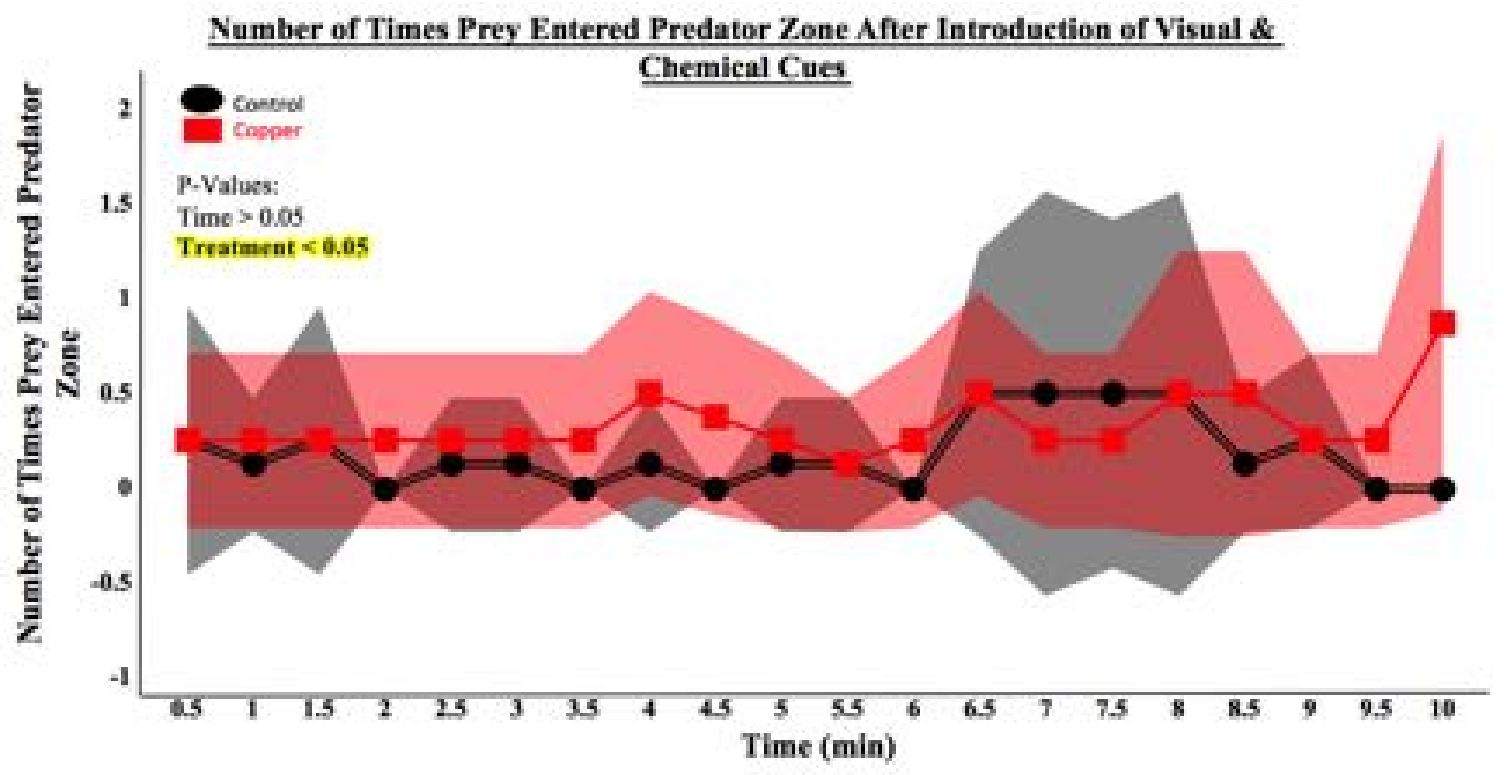

Figure 33B. Number of Times Prey Entered Predator Zone After Introduction of Visual \& Chemical Cue. After the introduction of the visual \& chemical cue (predator model + predator kairomones) data was recorded for 10 minutes every 30 seconds. Every point in this graph represents the average of 10 individual fish and the amount of times the prey entered the predator zone at that specific time. This graph shows that treatment had an effect on the number of times both groups (copper \& control) entered the predator zone after the introduction of cues. Treatment was significant $(\mathrm{F}=6.32 ; \mathrm{DF}=1, \mathrm{P}<0.05)$ but time was not $(\mathrm{F}=3.30 ; \mathrm{DF}=1, \mathrm{P}>0.05)$. The shaded areas represent the standard deviation of the data. 


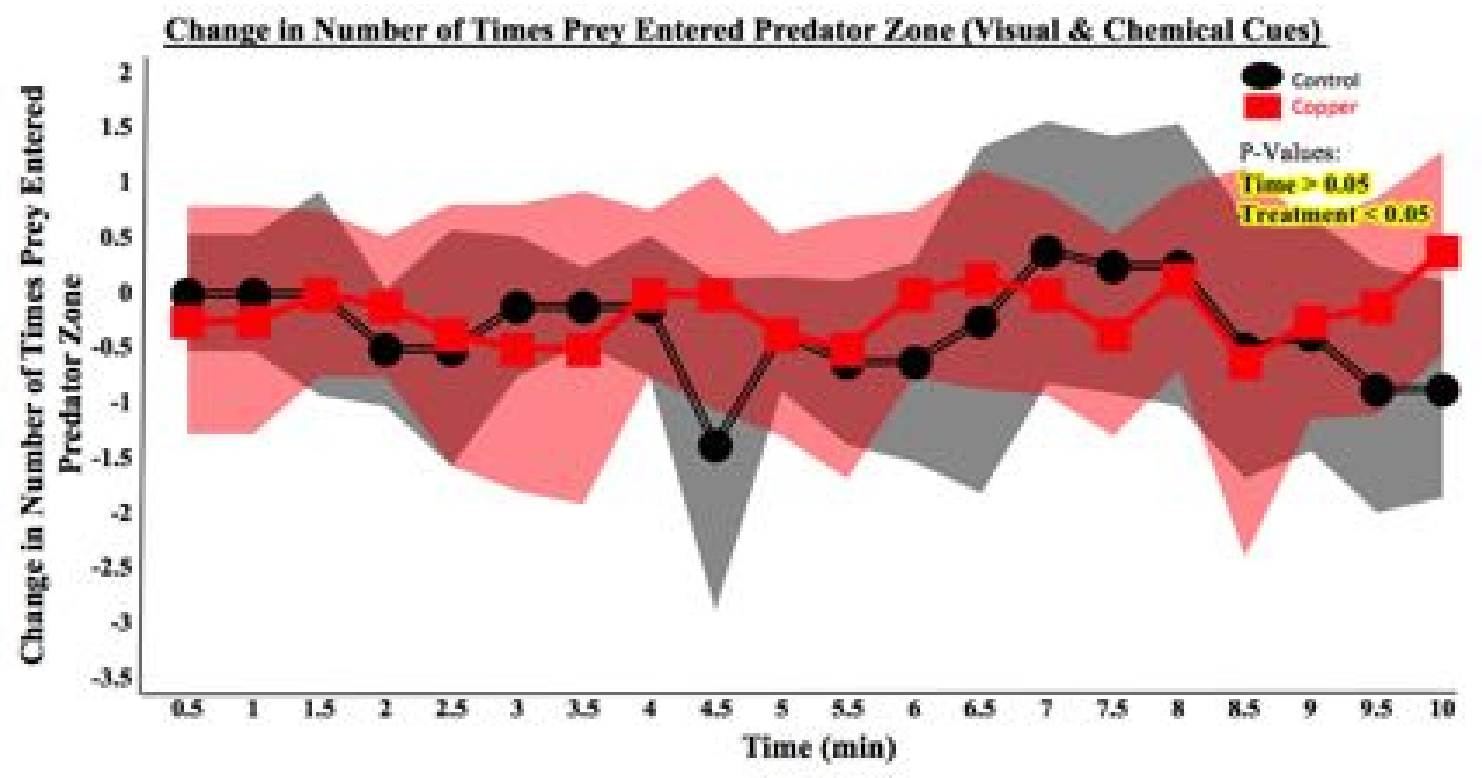

Figure 33C. Change in Number of Times Prey Entered Predator Zone (Visual \& Chemical Cue). After the experiment the change in the amount of times the predator zone was entered was calculated by subtracting the data from trial one from the data from trial two. Every point in this graph represents the average of 10 individual fish and the amount of times the predator zone was entered at that specific time. This graph shows that independently, treatment and time had an effect on the change of number of times both groups (copper \& control) entered the predator zone. Treatment $(\mathrm{F}=0.05 ; \mathrm{DF}=1$, $\mathrm{P}<0.05)$ and time were significant $(\mathrm{F}=2: 69 ; \mathrm{DF}=1, \mathrm{P}<0.05)$. The shaded areas represent the standard deviation of the data. 


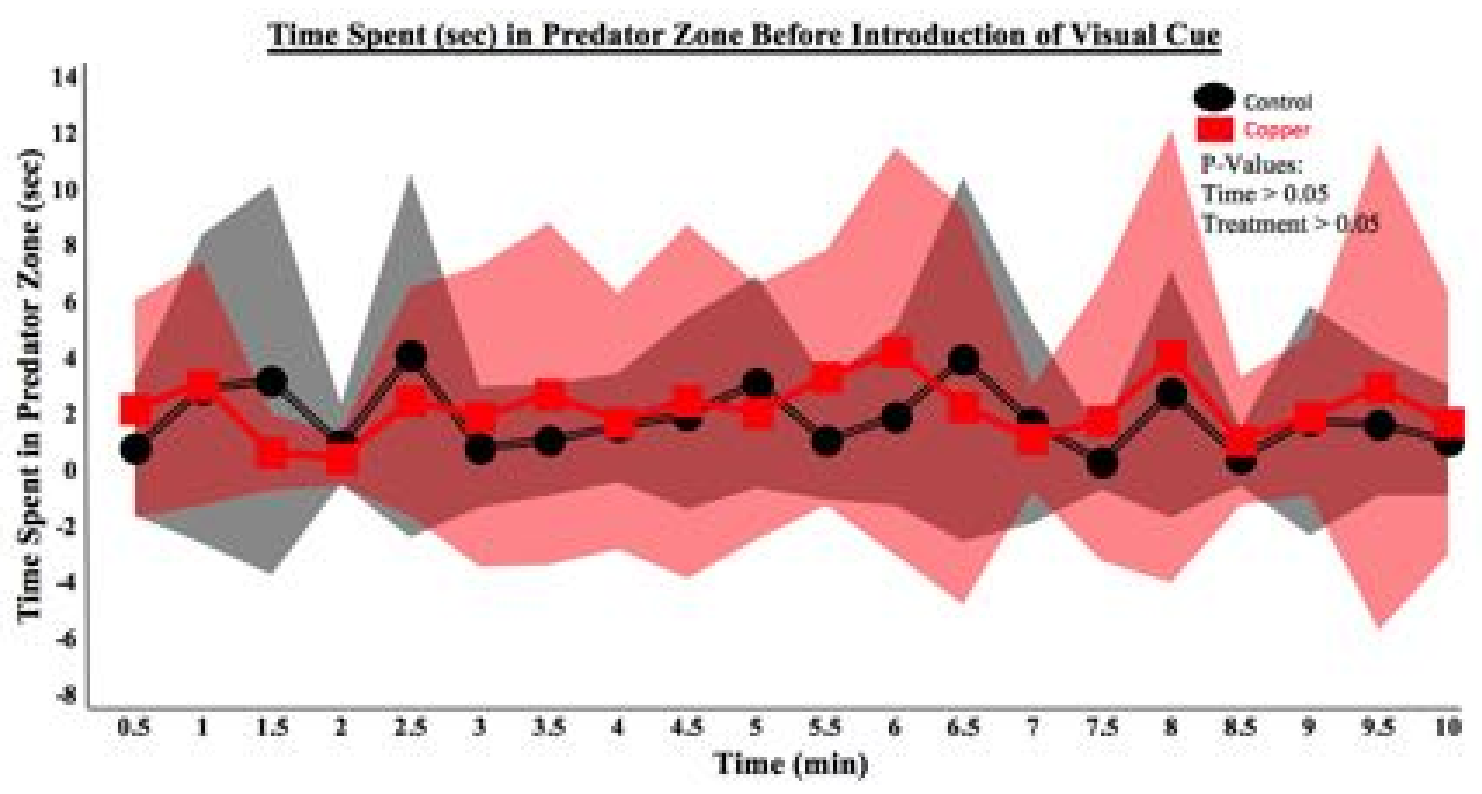

Figure 34A. Time Spent (Sec) in Predator Zone Before Introduction of Visual Cue. Before the introduction of the visual cue (predator model) both groups were left to acclimate for 10 minutes. During these 10 minutes, every 30 seconds data points were recorded. Every point in this graph represents the average of 10 individual fish and the total amount of time in seconds they spent in the predator zone at that specific time. This graph shows that there was no difference in the total amount of time spent in the predator zone before the introduction of the visual cue. Treatment $(\mathrm{F}=0.64 ; \mathrm{DF}=1, \mathrm{P}>0.05)$ and time were not significant $(\mathrm{F}=0.04 ; \mathrm{DF}=1 ; \mathrm{P}>0.05)$. The shaded areas represent the standard deviation of the data. 


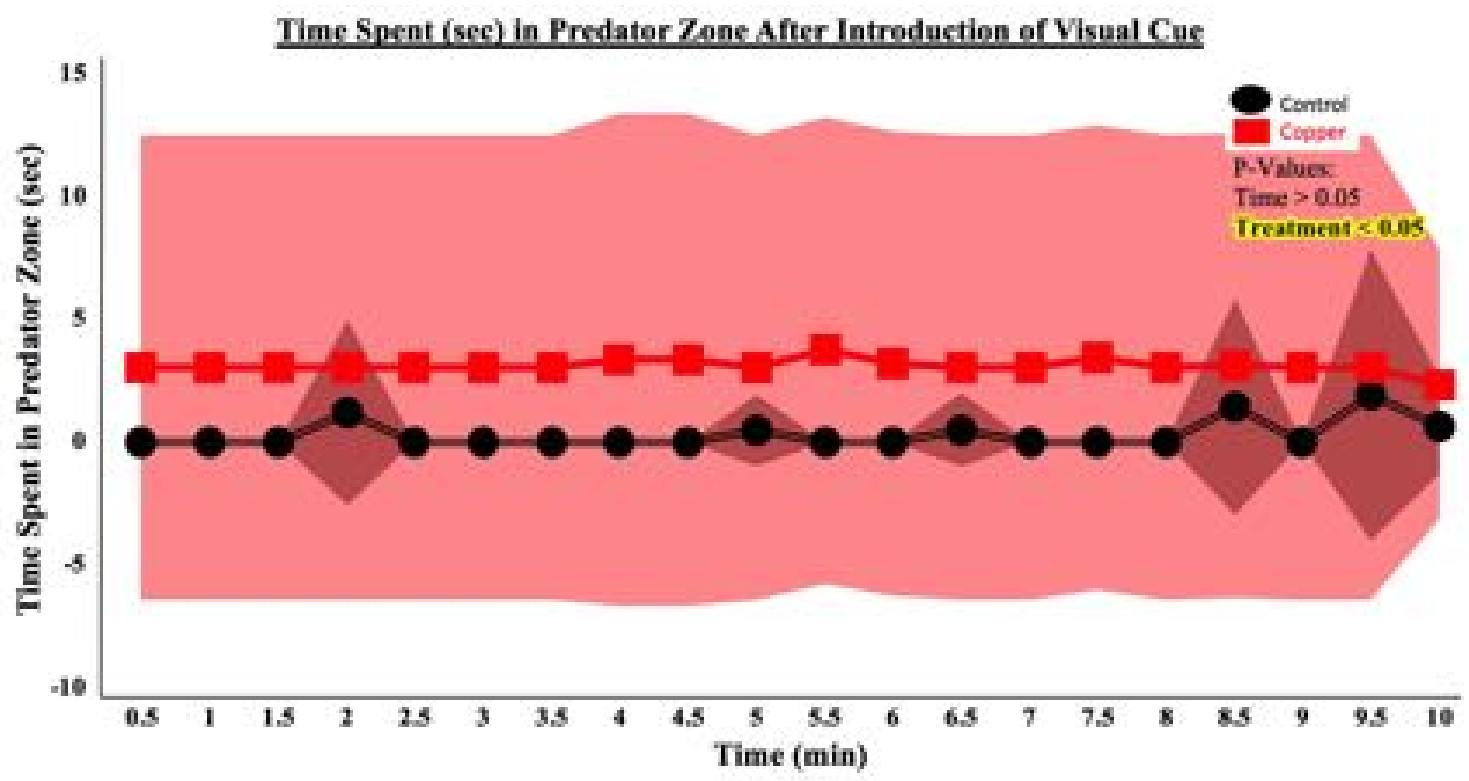

Figure 34B. Time Spent (Sec) in Predator Zone After Introduction of Visual Cue. After the introduction of the visual cue (predator model) data was recorded for 10 minutes every 30 seconds. Every point in this graph represents the average of 10 individual fish and the total amount of time in seconds spent in the predator zone at that specific time. This graph shows that copper contaminated fish spent more time in the predator zone than the control after the introduction of the visual cue. Treatment was significant $(\mathrm{F}=18.32 ; \mathrm{DF}=1, \mathrm{P}<0.05)$ but time was not $(\mathrm{F}=0.07 ; \mathrm{DF}=1, \mathrm{P}<0.05)$. The shaded areas represent the standard deviation of the data. 


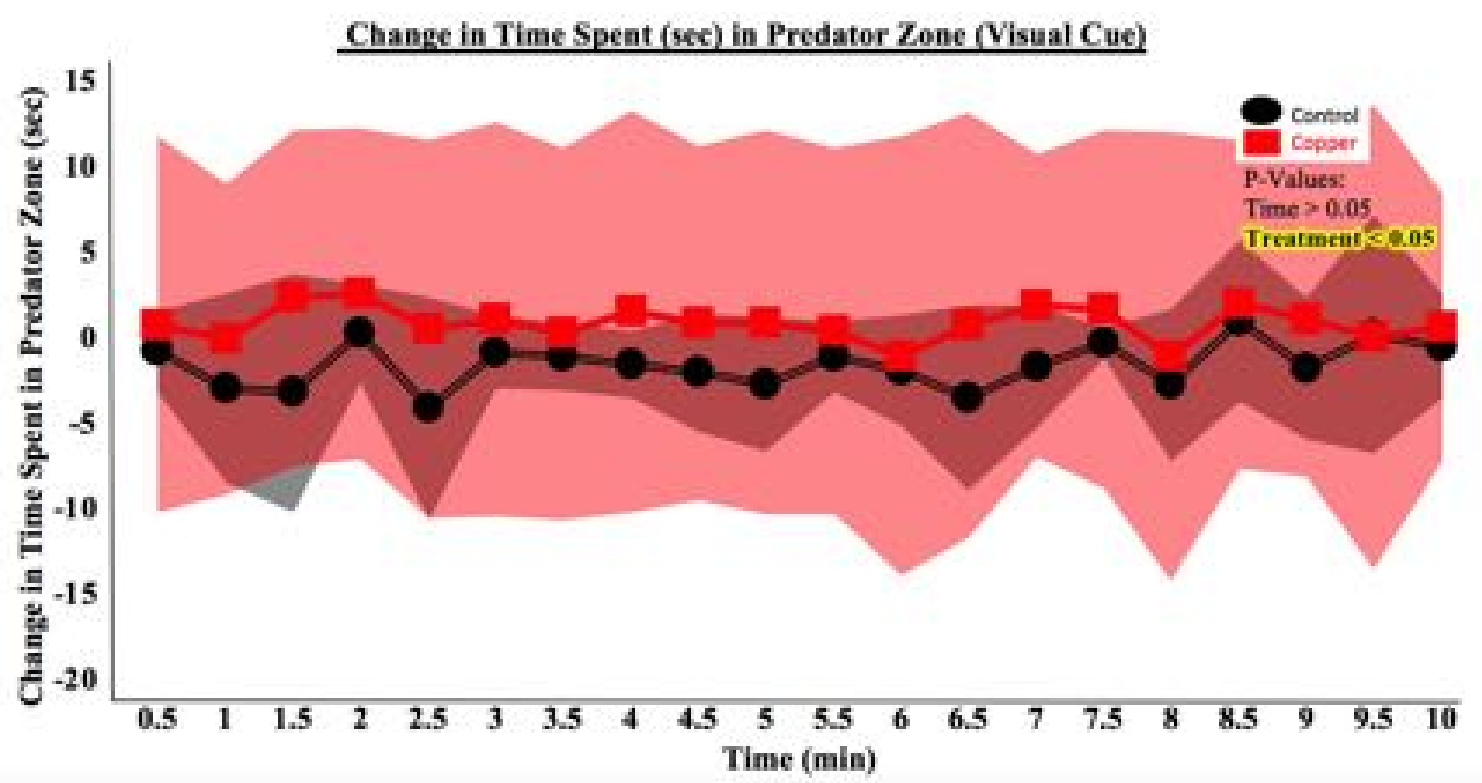

Figure 34C. Change in Time Spent (Sec) in Predator Zone (Visual Cue). After the experiment, the change in the time spent in the predator zone was calculated by subtracting the data from trial one from the data from trial two. Every point in this graph represents the average of 10 individual fish and the total amount of time the fish spent in the predator zone at that specific time. This graph shows that copper contaminated fish spent more time in the predator zone than the control in response to the introduction of the visual cue. Treatment was significant $(\mathrm{F}=18.47$; $\mathrm{DF}=1, \mathrm{P}<0.05)$ but time was not $(\mathrm{F}=0.07 ; \mathrm{DF}=1, \mathrm{P}>0.05)$. The shaded areas represent the standard deviation of the data. 


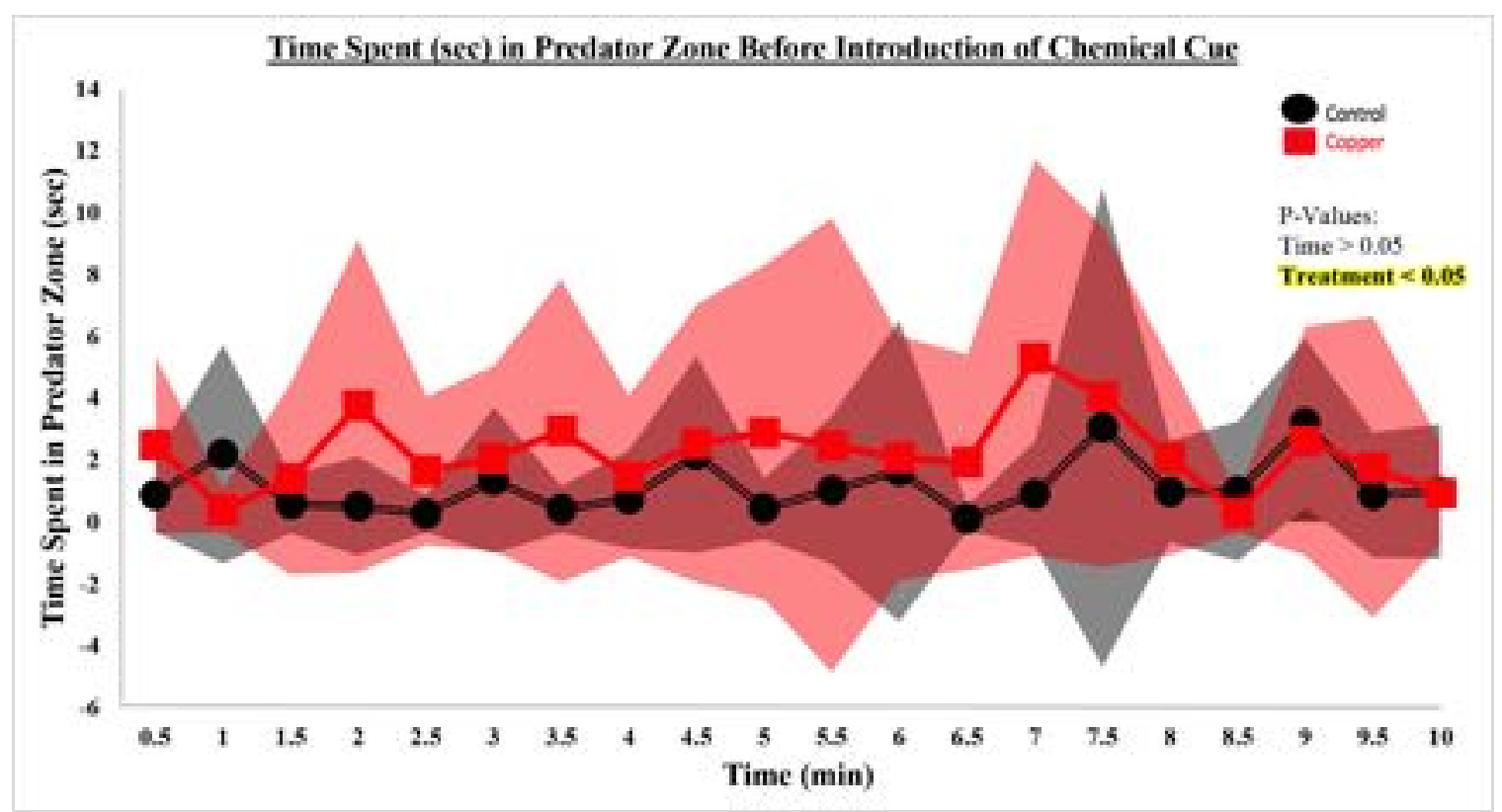

Figure 35A. Time Spent (Sec) in Predator Zone Before Introduction of Chemical

Cue. Before the introduction of the chemical cue (predator kairomones) both groups were left to acclimate for 10 minutes. During these 10 minutes, every 30 seconds data points were recorded. Every point in this graph represents the average of 10 individual fish and the total amount of time in seconds they spent in the predator zone at that specific time. This graph shows that copper-contaminated fish spent more time in the predator zone than the control before the introduction of the chemical cue. Treatment was significant $(\mathrm{F}=9.55 ; \mathrm{DF}=1, \mathrm{P}<0.05)$ but time was not $(\mathrm{F}=0.45 ; \mathrm{DF}=1 ; \mathrm{P}>0.05)$. The shaded areas represent the standard deviation of the data. 


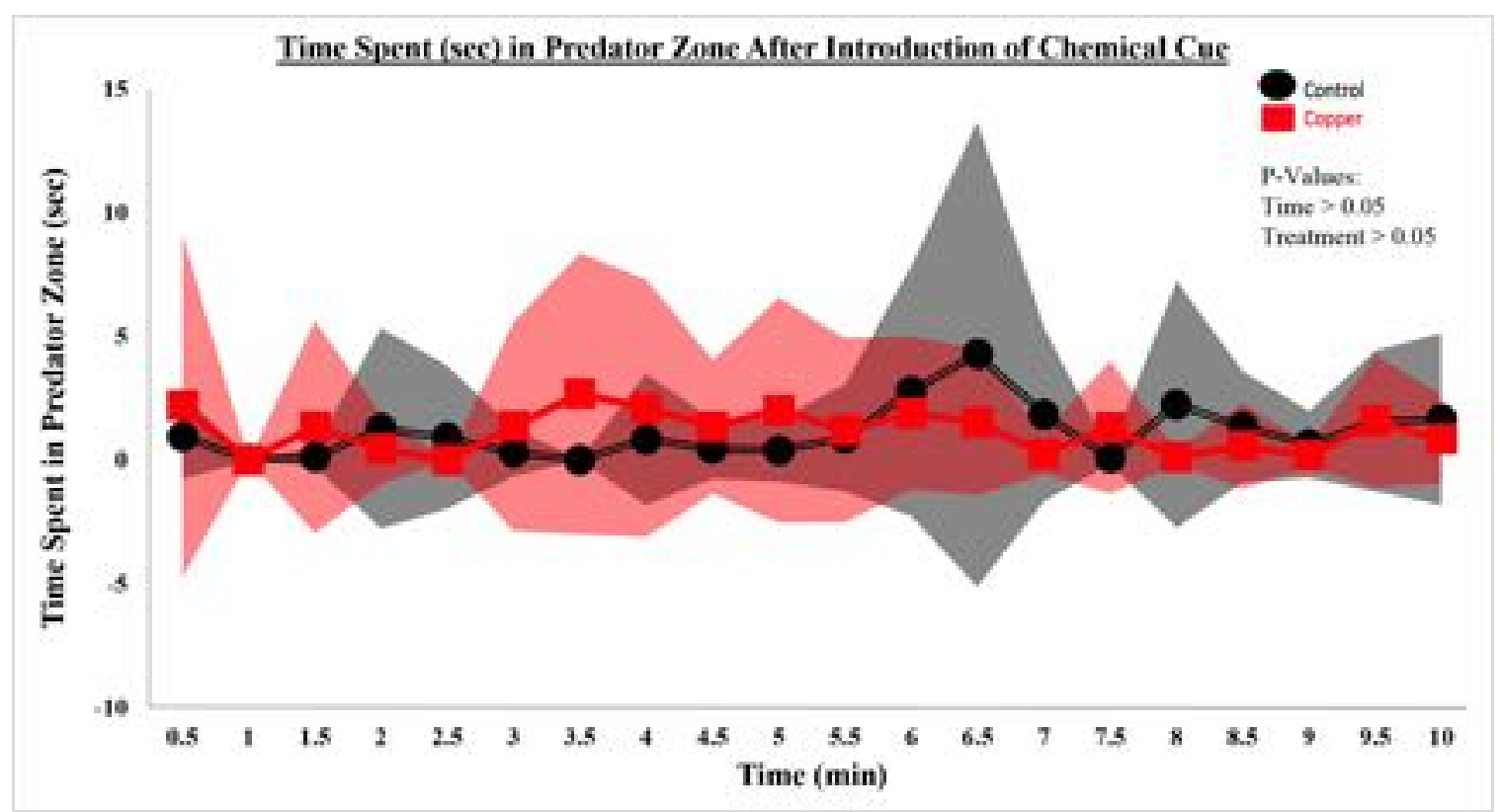

Figure 35B. Time Spent (Sec) in Predator Zone After Introduction of Chemical Cue. After the introduction of the chemical cue (predator kairomones) data was recorded for 10 minutes every 30 seconds. Every point in this graph represents the average of 10 individual fish and the total amount of time in seconds spent in the predator zone at that specific time. This graph shows that there was no statistical difference between the time spent by the copper-contaminated fish in the predator zone and the time spent by the control fish in the predator zone after the introduction of the cue. Treatment $(\mathrm{F}=0.01$; $\mathrm{DF}=1, \mathrm{P}>0.05)$ and time were not significant $(\mathrm{F}=0.70 ; \mathrm{DF}=1, \mathrm{P}>0.05)$. The shaded areas represent the standard deviation of the data. 


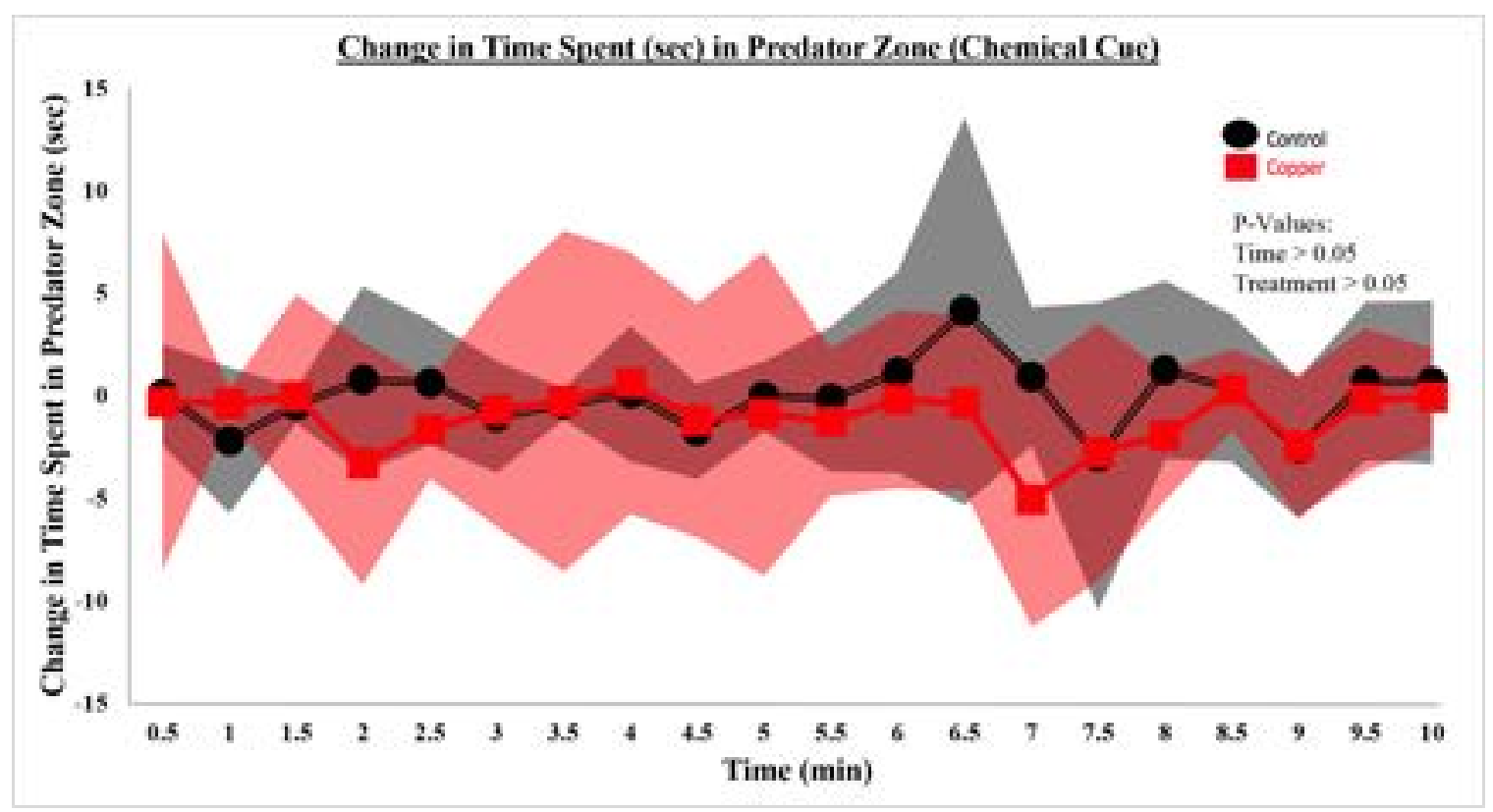

Figure 35C. Change in Time Spent (Sec) in Predator Zone (Chemical Cue). After the experiment the change in the amount of time spent in the predator zone was calculated by subtracting the data from trial one from the data from trial two. Every point in this graph represents the average of 10 individual fish and the total amount of time the fish spent in the predator zone at that specific time. This graph shows that there was no statistically significant difference between the time spent by copper-contaminated fish in the predator zone and the time spent by the control fish in the predator zone in response to the introduction of the chemical cue. Treatment $(\mathrm{F}=0.0003 ; \mathrm{DF}=1, \mathrm{P}<0.05)$ and time were not significant $(\mathrm{F}=0.66 ; \mathrm{DF}=1, \mathrm{P}>0.05)$. The shaded areas represent the standard deviation of the data. 


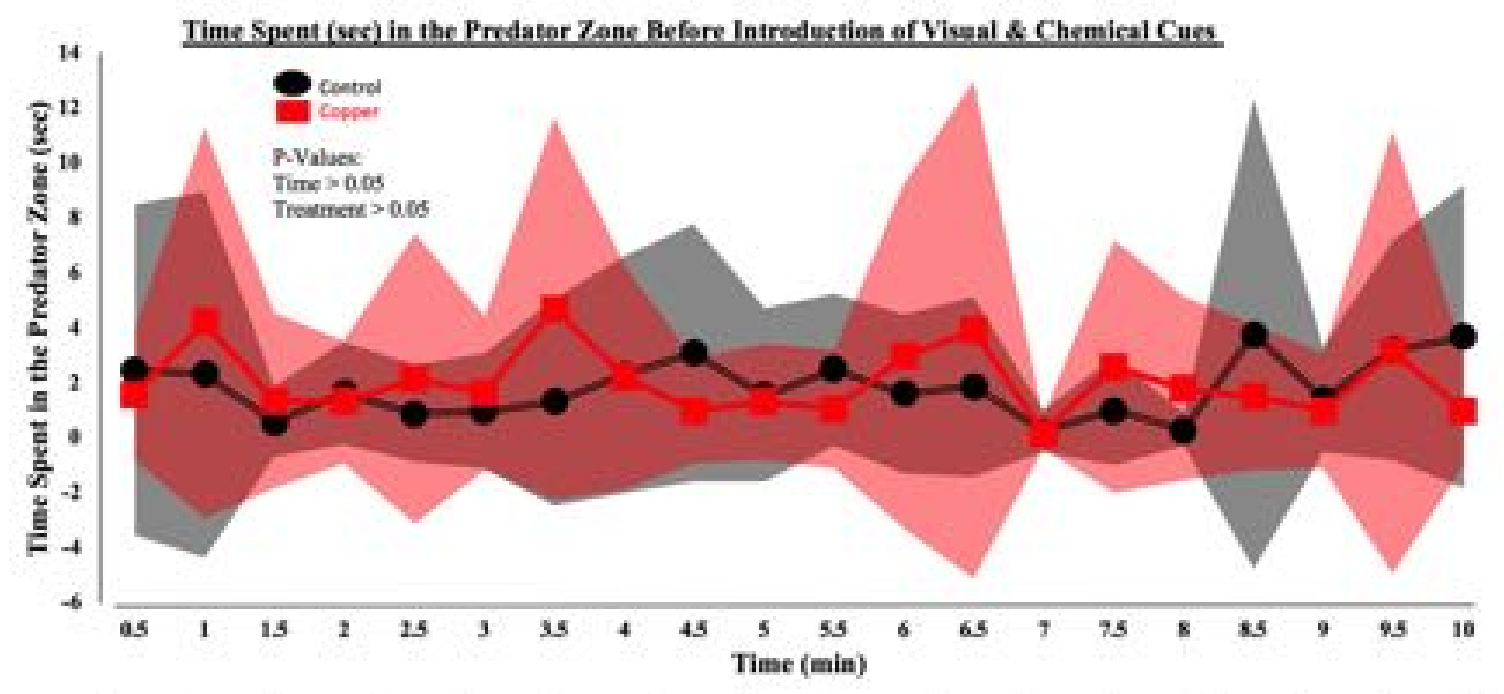

Figure 36A. Time Spent (Sec) in Predator Zone Before Introduction of Visual \&

Chemical Cue. Before the introduction of the visual \& chemical cue (predator model + predator kairomones) both groups were left to acclimate for 10 minutes. During these 10 minutes, every 30 seconds data points were recorded. Every point in this graph represents the average of 10 individual fish and the total amount of time in seconds they spent in the predator zone at that specific time. This graph shows that there was no statistically significant difference between the time spent by copper-contaminated fish in the predator zone and the time spent by the control fish in the predator zone after the introduction of the cues. Treatment $(\mathrm{F}=0.18 ; \mathrm{DF}=1, \mathrm{P}<0.05)$ and time were not significant $(\mathrm{F}=0.02$; $\mathrm{DF}=1 ; \mathrm{P}>0.05)$. The shaded areas represent the standard deviation of the data. 


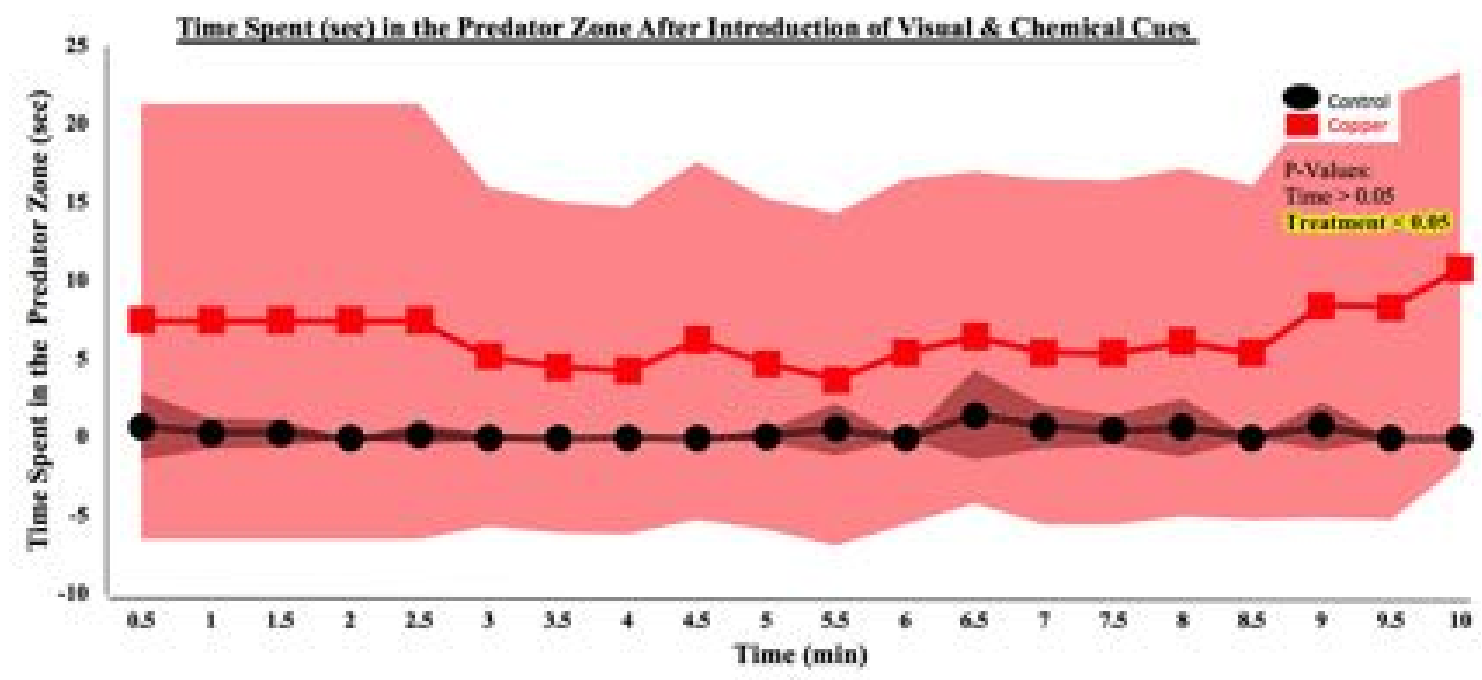

Figure 36B. Time Spent (Sec) in Predator Zone After Introduction of Visual \&

Chemical Cue. After the introduction of the visual \& chemical cue (predator model + predator kairomones) data was recorded for 10 minutes every 30 seconds. Every point in this graph represents the average of 10 individual fish and the total amount of time in seconds spent in the predator zone at that specific time. This graph shows that coppercontaminated fish spent more time in the predator zone than the control after the introduction of the cues. Treatment was significant $(\mathrm{F}=45.04 ; \mathrm{DF}=1, \mathrm{P}<0.05)$ but time was not $(\mathrm{F}=0.13 ; \mathrm{DF}=1, \mathrm{P}>0.05)$. The shaded areas represent the standard deviation of the data. 


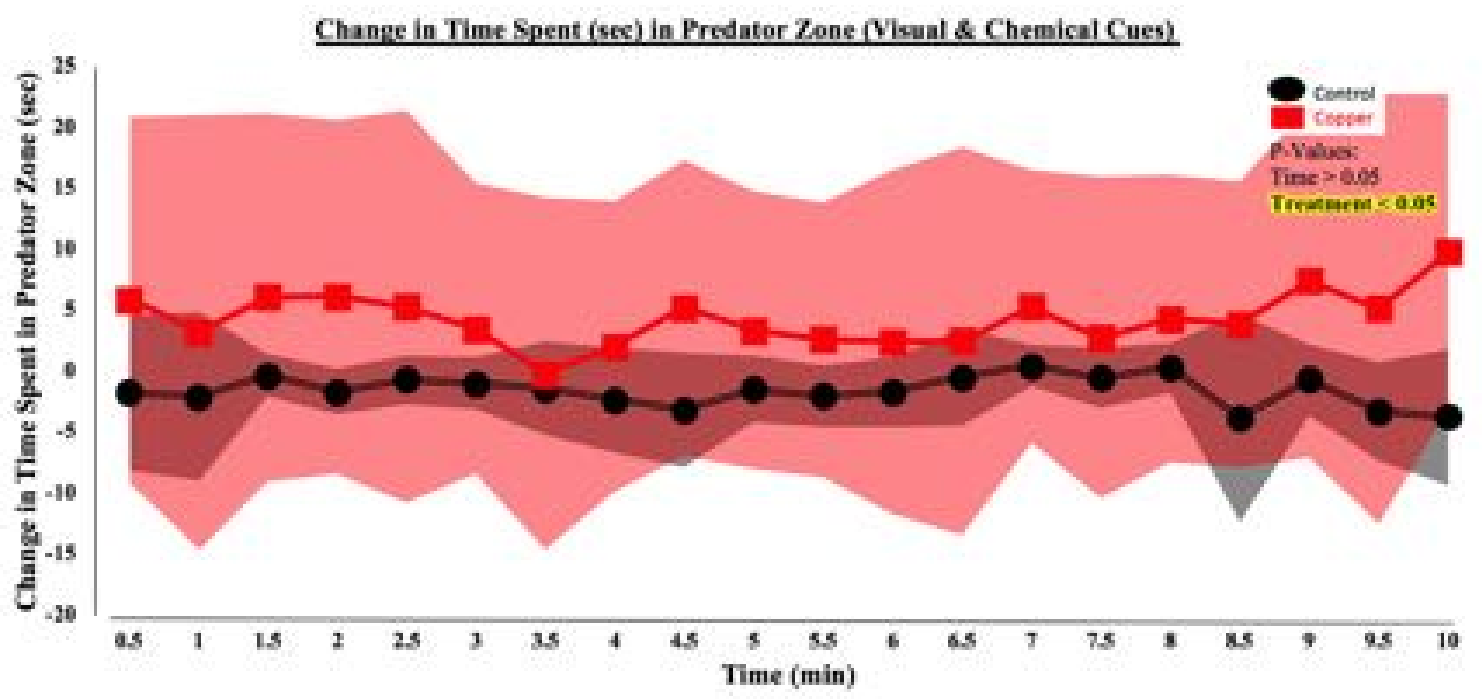

Figure 36C. Change in Time Spent (Sec) in Predator Zone (Visual \& Chemical Cue). After the experiment, the change in the amount of time spent in the predator zone was calculated by subtracting the data from trial one from the data from trial two. Every point in this graph represents the average of 10 individual fish and the total amount of time the fish spent in the predator zone at that specific time. This graph shows that copper contaminated fish spent more time in the predator zone than the control after the introduction of the cues. Treatment was significant $(\mathrm{F}=47.37 ; \mathrm{DF}=1, \mathrm{P}<0.05)$ but time was not $(\mathrm{F}=0.15 ; \mathrm{DF}=1, \mathrm{P}>0.05)$. The shaded areas represent the standard deviation of the data. 


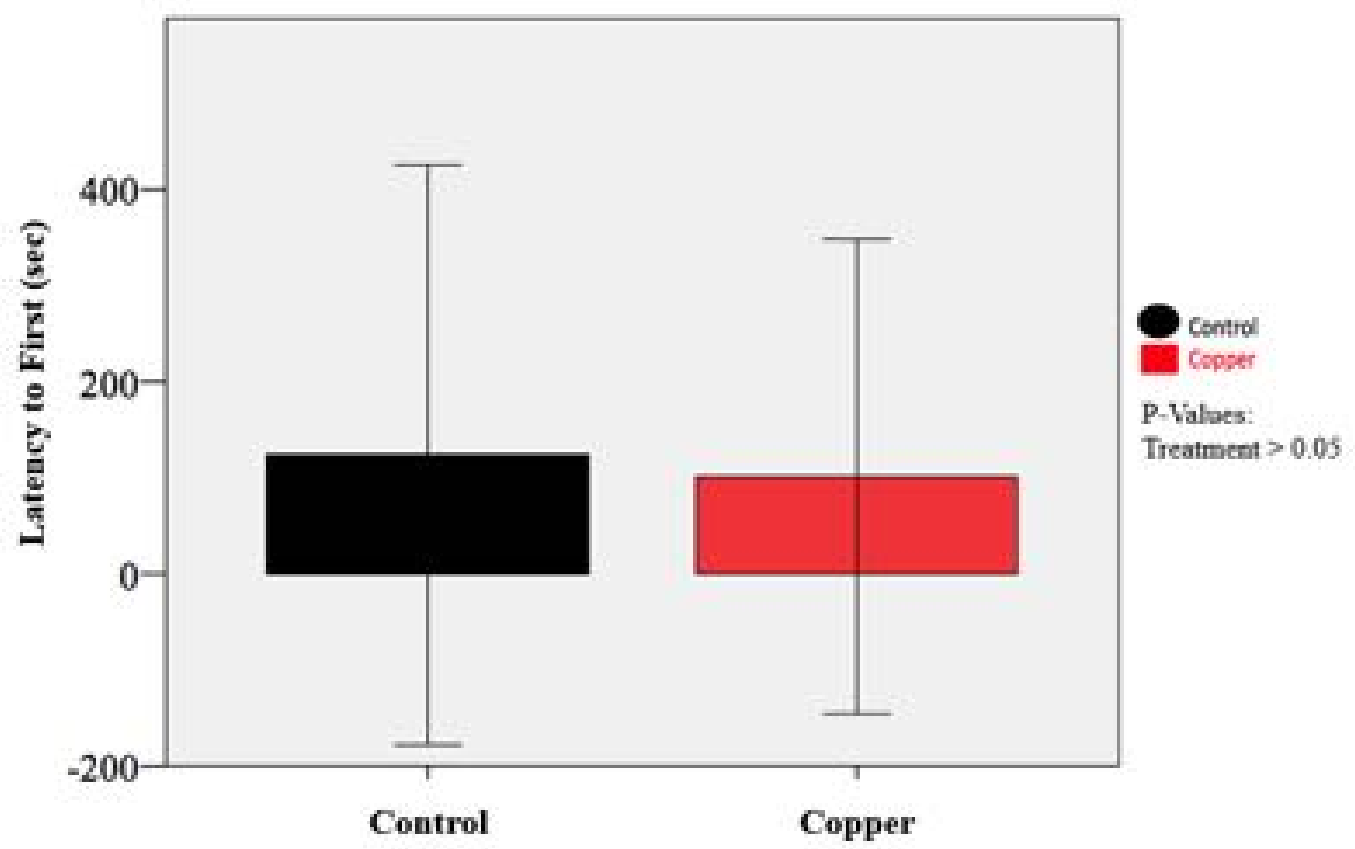

Figure 37A. Latency to First (sec) Before Introduction of Visual Cue. Before the introduction of the visual cue (predator model) both groups were left to acclimate for 10 minutes. During these 10 minutes, every 30 seconds data points were recorded. This graph represents the average of 10 individual fish (control \& copper) and how long it took them to first enter the predator zone in seconds at that specific time. This graph shows there was no statistically significant difference between the time it took the copper-contaminated fish to first enter the predator zone and the time it took the control fish to first enter the predator zone before the introduction to the cue. Treatment was not significant $(\mathrm{F}=2.32 ; \mathrm{DF}=1 ; \mathrm{P}>0.05)$. 


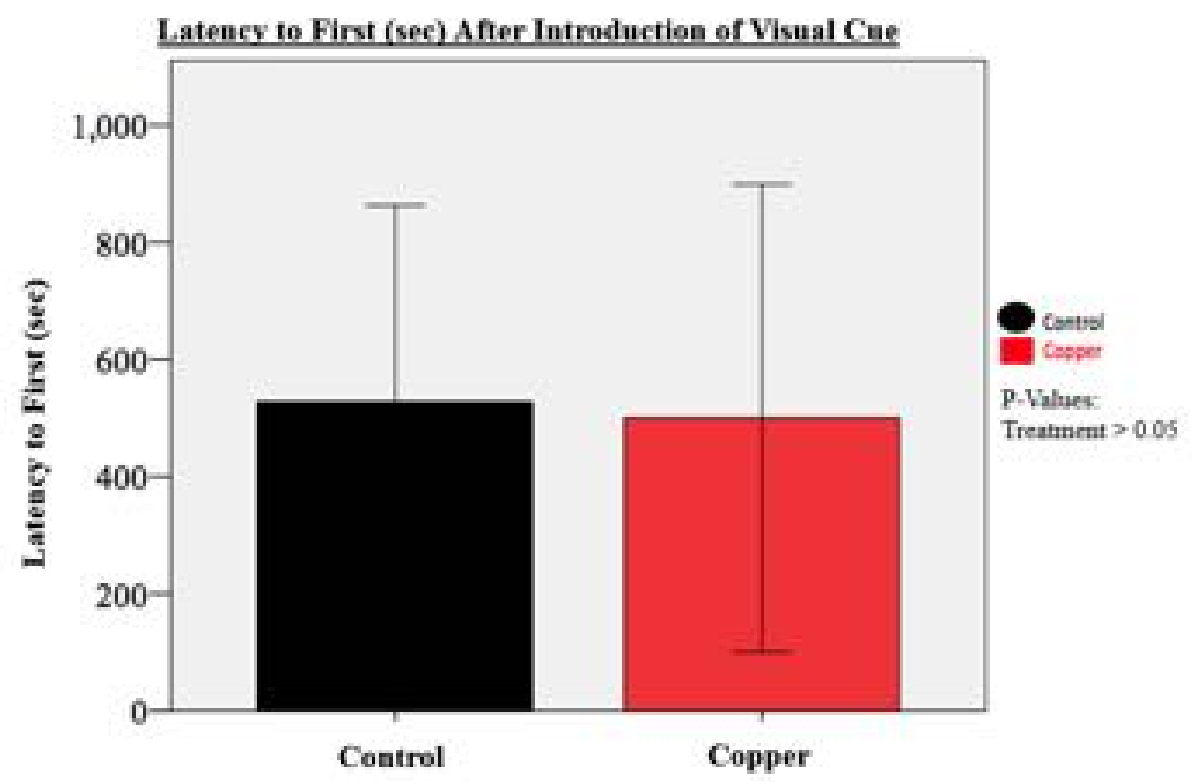

Figure 37B. Latency to First (sec) After Introduction of Visual Cue. After the introduction of the visual cue (predator model) data was recorded every 30 seconds for 10 minutes. This graph represents the average of 10 individual fish (control \& copper) and how long it took them to first enter the predator zone in seconds at that specific time. This graph shows there was no statistically significant difference between the time it took the copper-contaminated fish to first enter the predator zone and the time it took the control fish to first enter the predator zone before the introduction to the cue. Treatment was not significant $(\mathrm{F}=0.72 ; \mathrm{DF}=1 ; \mathrm{P}>0.05)$. 


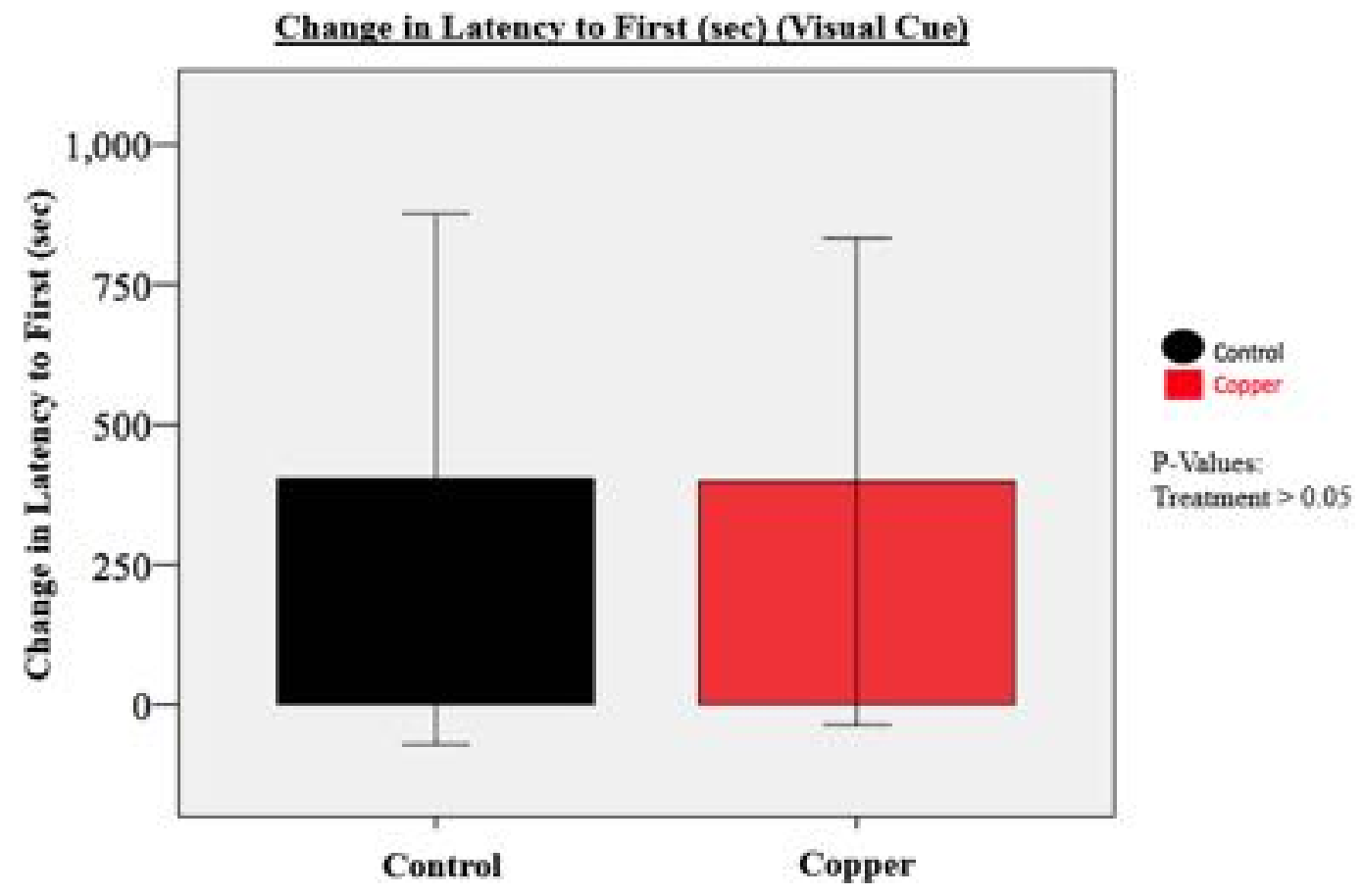

Figure 37C. Change in Latency to First (sec) (Visual Cue). After the experiment, the change in latency was calculated by subtracting the data from trial one from the data from trial two. Every point in this graph represents the average of 10 individual fish and how long it took them to first enter the predator zone in seconds at that specific time. This graph shows there was no statistically significant difference between the time it took the copper-contaminated fish to first enter the predator zone and the time it took the control fish to first enter the predator zone before the introduction to the cue. Treatment was not significant $(\mathrm{F}=2.16 ; \mathrm{DF}=1 ; \mathrm{P}>0.05)$. 


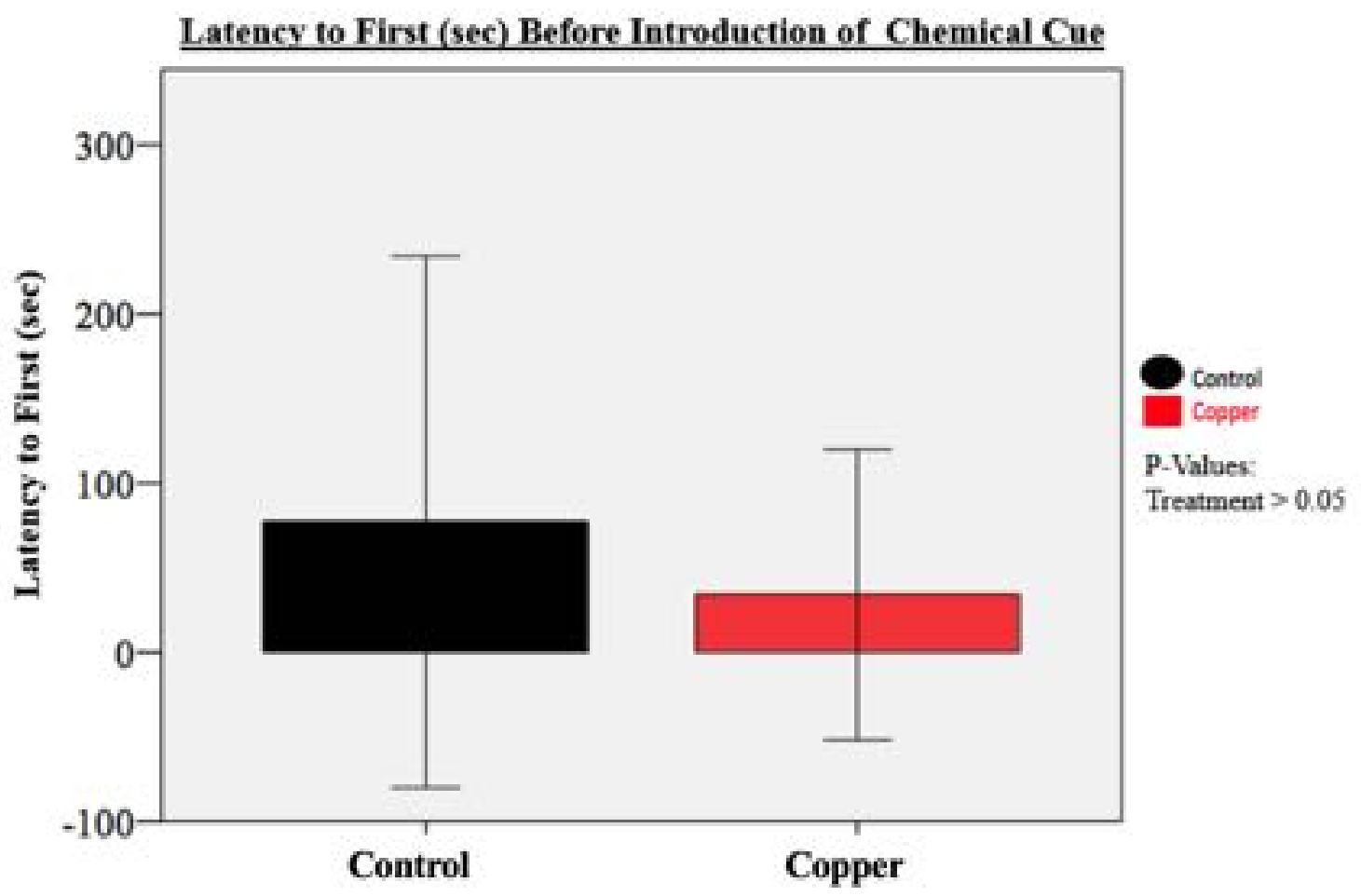

Figure 38A. Latency to First (sec) Before Introduction of Chemical Cue. Before the introduction of the chemical cue (predator kairomones) both groups were left to acclimate for 10 minutes. During these 10 minutes, every 30 seconds data points were recorded. This graph represents the average of 10 individual fish (control \& copper) and how long it took them to first enter the predator zone in seconds at that specific time. This graph shows there was no statistically significant difference between the time it took the copper-contaminated fish to first enter the predator zone and the time it took the control fish to first enter the predator zone before the introduction to the cue. Treatment was not significant $(\mathrm{F}=2.32 ; \mathrm{DF}=1 ; \mathrm{P}>0.05)$. 




Figure 38B. Latency to First (sec) After Introduction of Chemical Cue. After the introduction of the chemical cue (predator kairomones) data was recorded every 30 seconds for 10 minutes. This graph shows there was no statistically significant difference between the time it took the copper-contaminated fish to first enter the predator zone and the time it took the control fish to first enter the predator zone before the introduction to the cue. Treatment was not significant $(\mathrm{F}=3.15 ; \mathrm{DF}=1 ; \mathrm{P}>0.05)$. 


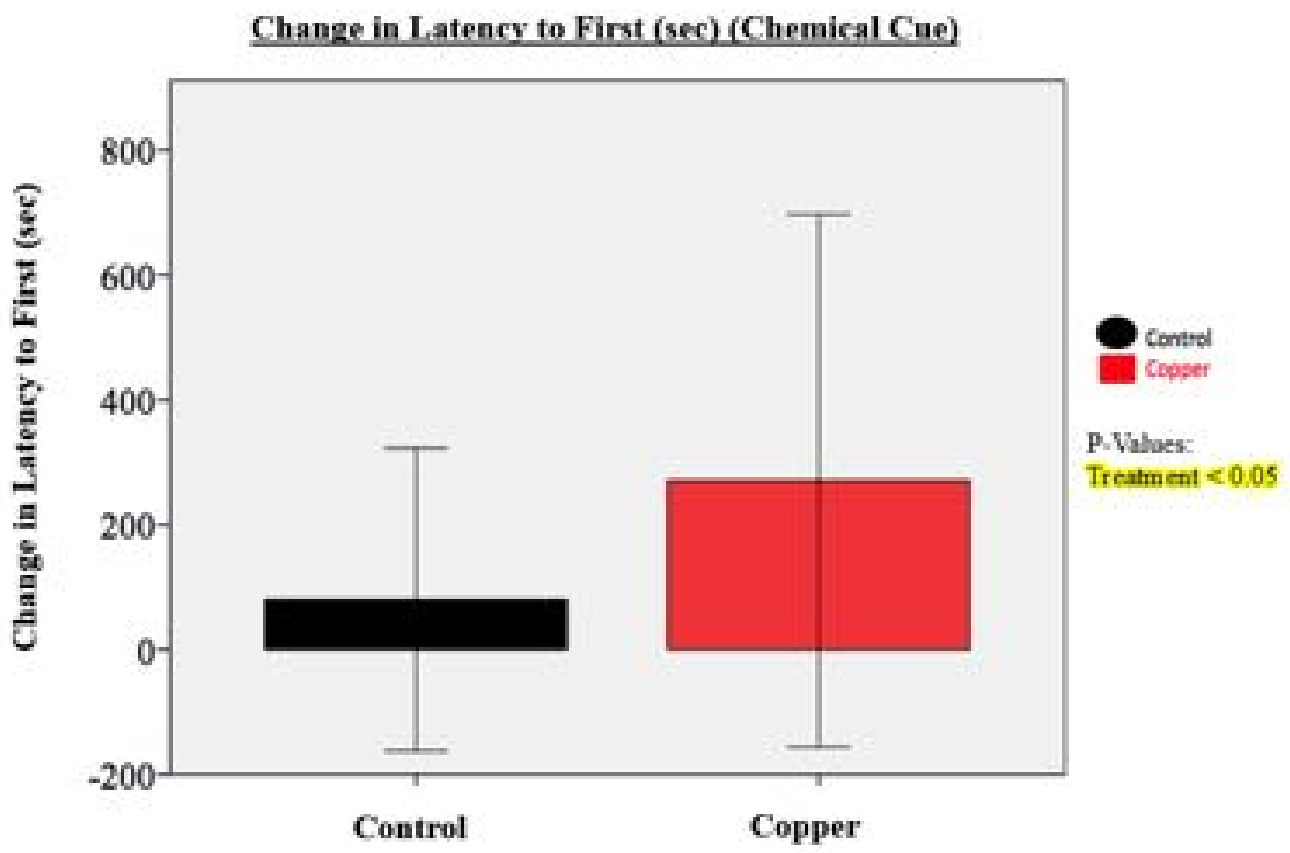

Figure 38C. Change in Latency to First (sec) (Chemical Cue). After the experiment, the change in latency was calculated by subtracting the data from trial one from the data from trial two. This graph represents the average of 10 individual fish (control \& copper) and how long it took them to enter the predator zone in seconds at that specific time. This graph shows copper-contaminated fish took more time to first enter the predator zone than control after the introduction of the chemical cue. Treatment was significant $(\mathrm{F}=6.03 ; \mathrm{DF}=1 ; \mathrm{P}<0.05)$. 


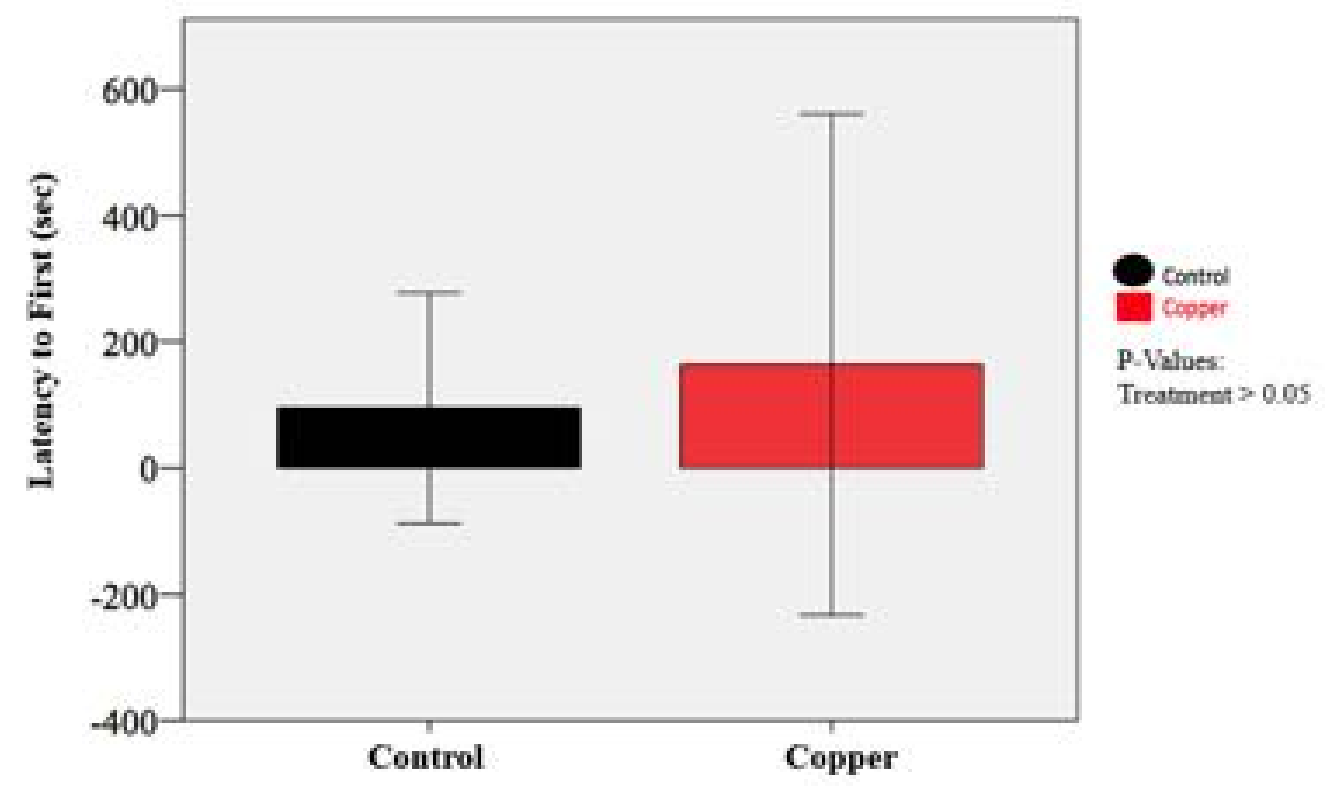

Figure 39A. Latency to First (sec) Before Introduction of Visual \& Chemical Cue. Before the introduction of the visual cue and chemical cues (predator model + predator kairomones) both groups were left to acclimate for 10 minutes. This graph represents the average of 10 individual fish (control \& copper) and how long it took them to first enter the predator zone in seconds at that specific time. This graph shows there was no statistically significant difference between the time it took the copper-contaminated fish to first enter the predator zone and the time it took the control fish to first enter the predator zone before the introduction to the cue. Treatment was not significant $(\mathrm{F}=0.80$; $\mathrm{DF}=1 ; \mathrm{P}>0.05)$. 


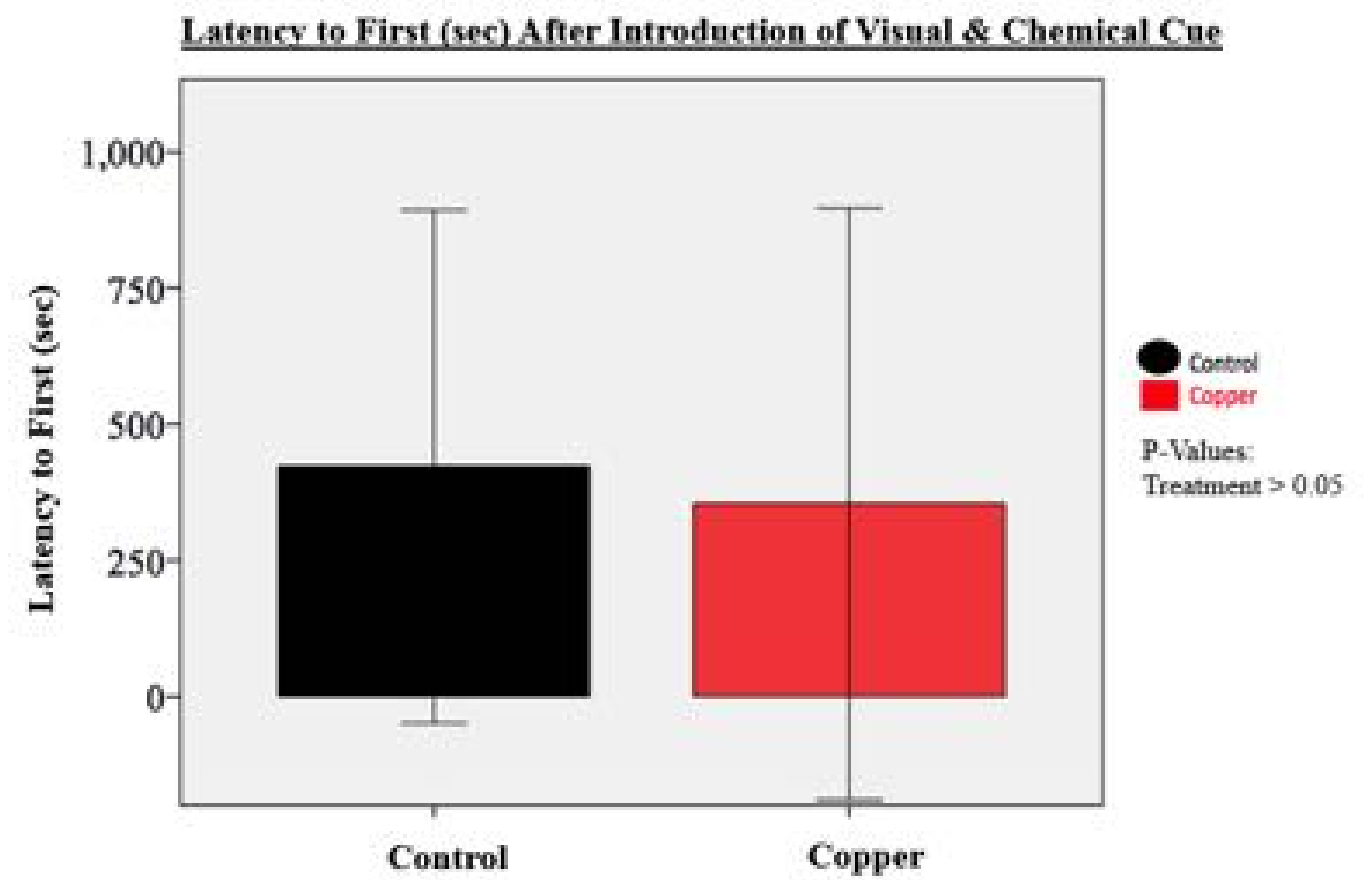

Figure 39B. Latency to First (sec) After Introduction of Visual \& Chemical Cue. After the introduction of the visual \& chemical cue (predator model+ predator kairomones) data was recorded every 30 seconds for 10 minutes. This graph represents the average of 10 individual fish (control \& copper) and how long it took them to first enter the predator zone in seconds at that specific time. This graph shows there was no statistically significant difference between the time it took the copper-contaminated fish to first enter the predator zone and the time it took the control fish to first enter the predator zone after the introduction to the cue. Treatment was not significant $(F=0.29$; $\mathrm{DF}=1 ; \mathrm{P}>0.05)$. 


\section{Change in Latency to First (sec) (Visual \& Chemical Cue)}

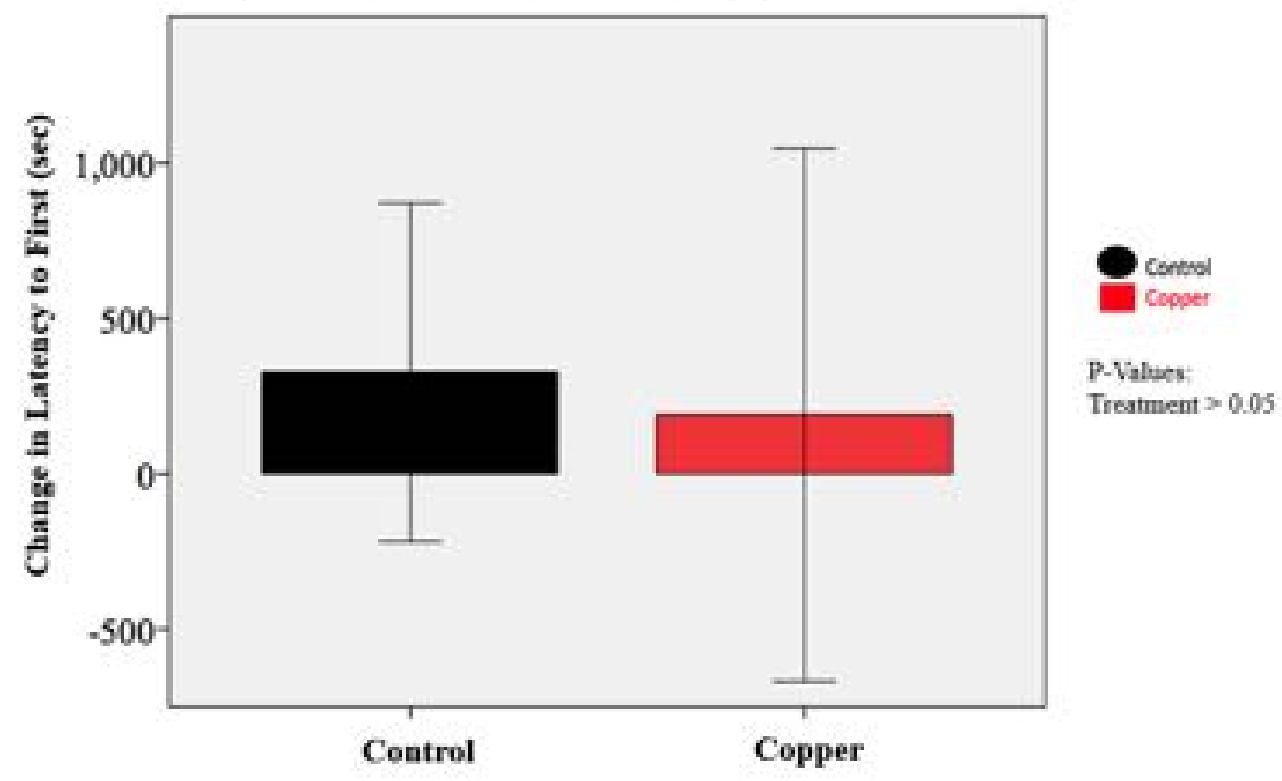

Figure 39C. Change in Latency to First (sec) (Visual \& Chemical Cue. After the experiment, the change in latency was calculated by subtracting the data from trial one from the data from trial two. This graph represents the average of 10 individual fish (control \& copper) and how long it took them to first enter the predator zone in seconds at that specific time. This graph shows there was no statistically significant difference between the time it took the copper-contaminated fish to first enter the predator zone and the time it took the control fish to first enter the predator zone in response to the introduction to the cue. Treatment was not significant $(\mathrm{F}=0.01 ; \mathrm{DF}=1 ; \mathrm{P}>0.05)$. 


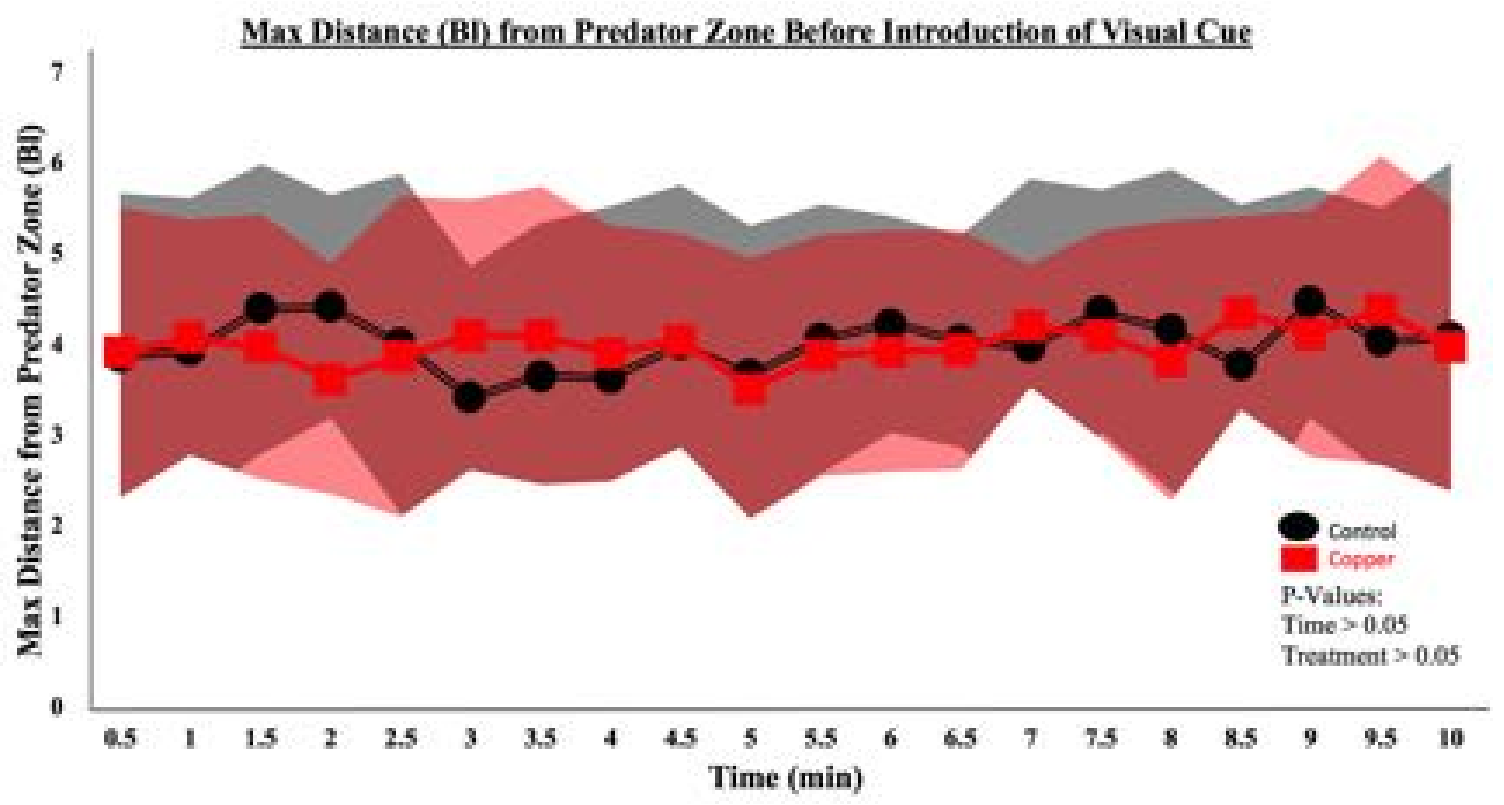

Figure 40A. Max Distance (Bl) from Predator Zone Before Introduction of Visual

Cue. Before the introduction of the visual cue (predator model) both groups were left to acclimate for 10 minutes. During these 10 minutes, every 30 seconds data points were recorded. Every point in this graph represents the average of 10 individual fish and their max distance from the predator zone at that specific time. The max distance per fish was normalized to body length in $\mathrm{cm}$ to control for differences in fish size. This graph shows that there was no statistically significant difference between the maximum distance from the copper-contaminated fish to the predator zone and the maximum distance from the control fish to the predator zone. Treatment $(\mathrm{F}=0.02 ; \mathrm{DF}=1 ; \mathrm{P}>0.05)$ and time were not significant $(\mathrm{F}=0.92 ; \mathrm{DF}=1 ; \mathrm{P}>0.05)$. The shaded areas represent the standard deviation of the data. 


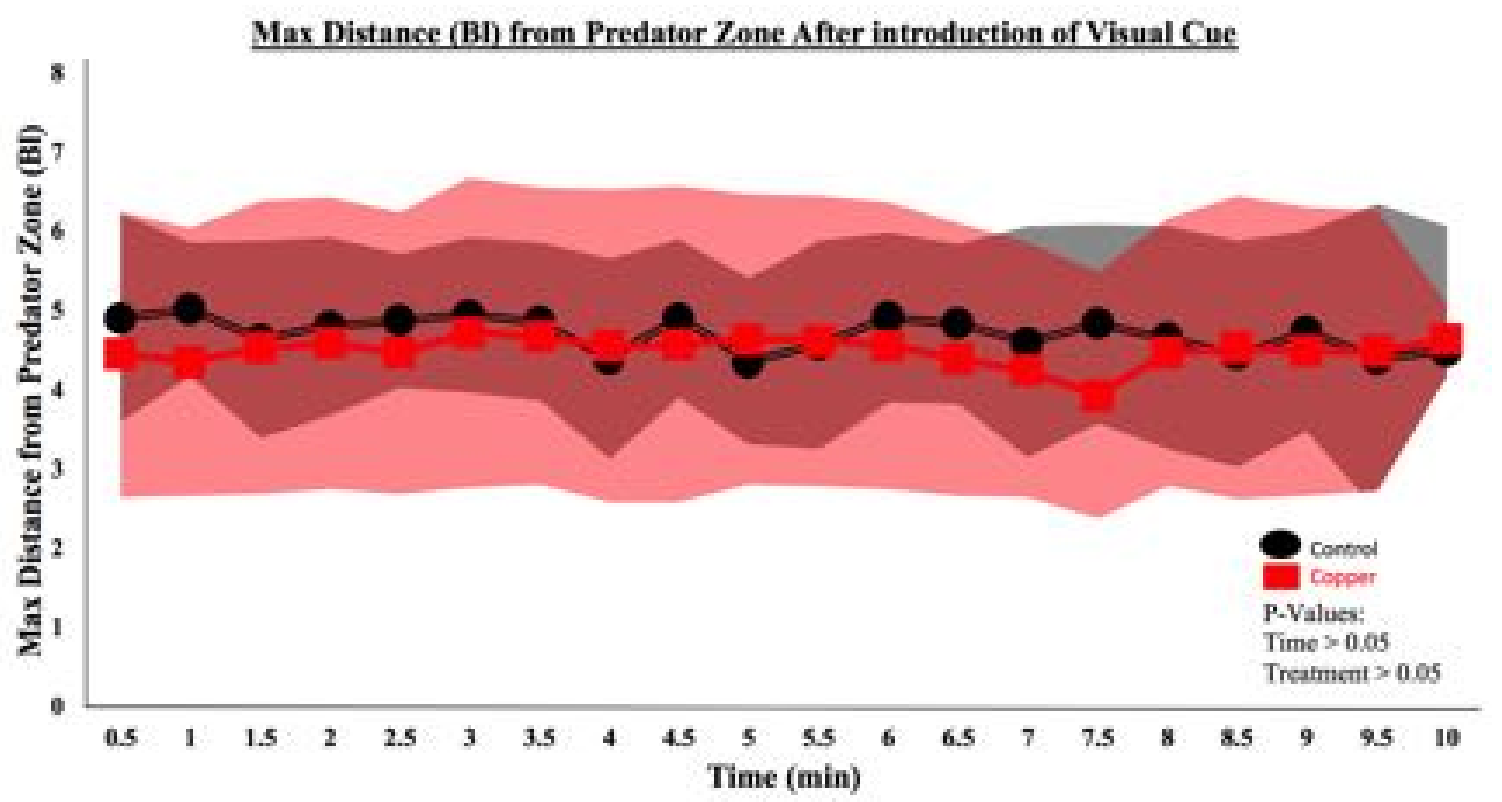

Figure 40B. Max Distance (B) from Predator Zone After Introduction of Visual

Cue. After the introduction of the visual cue (predator model) data was recorded every 30 seconds for 10 minutes. Every point in this graph represents the average of 10 individual fish and their max distance from the predator zone at that specific time. The max distance per fish was normalized to body length in $\mathrm{cm}$ to control for differences in fish size. This graph shows that there was no statistically significant difference between the maximum distance from the copper-contaminated fish to the predator zone and the maximum distance from the control fish to the predator zone. Treatment $(\mathrm{F}=2.14 ; \mathrm{DF}=1 ; \mathrm{P}>0.05)$ and time were not significant $(\mathrm{F}=0.83 ; \mathrm{DF}=1 ; \mathrm{P}>0.05)$. The shaded areas represent the standard deviation of the data. 


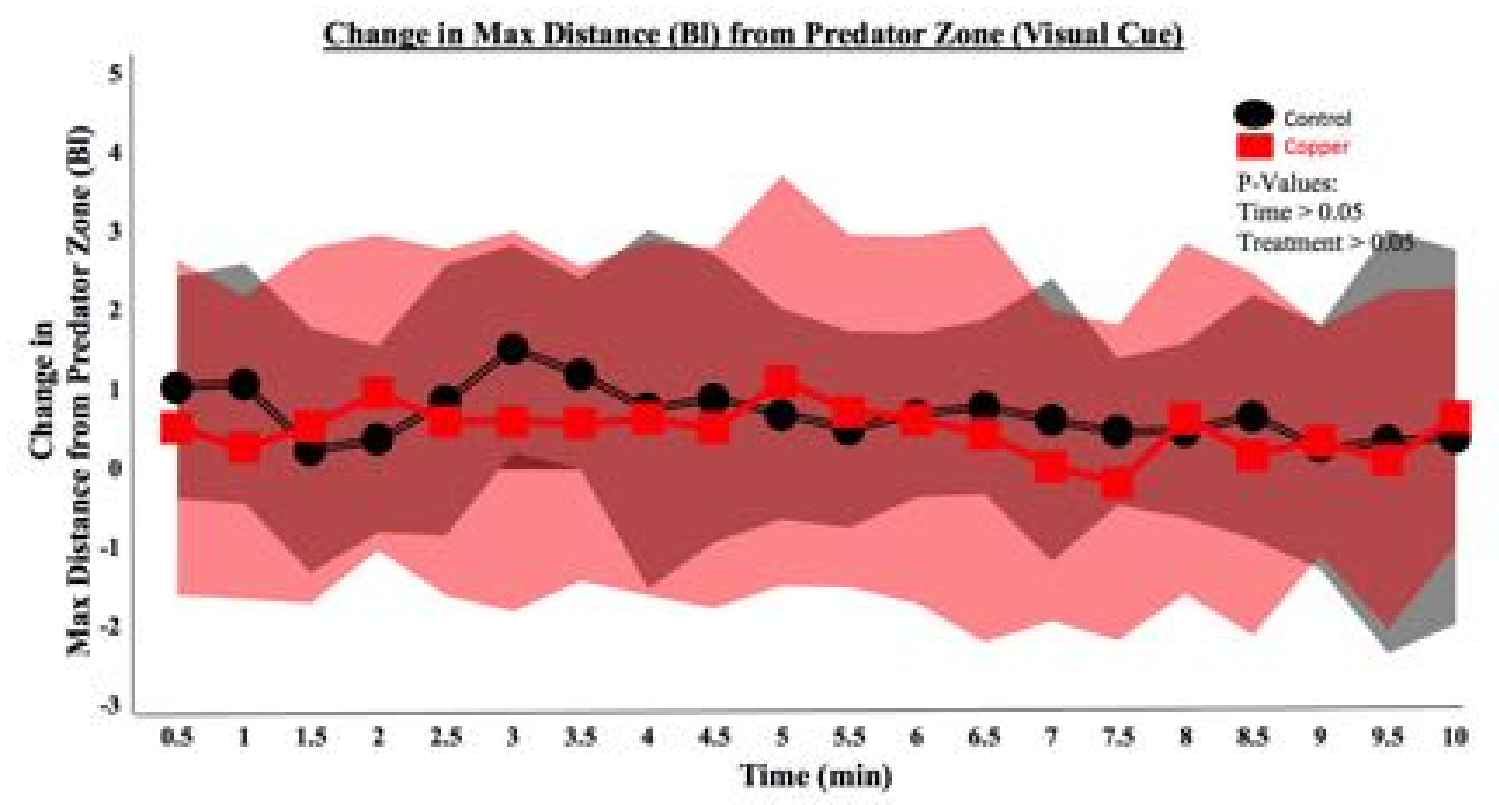

Figure 40C. Change in Max Distance (BI) from Predator Zone (Visual Cue). After the experiment, the change in max distance was calculated by subtracting the data from trial one from the data in trial two. Every point in this graph represents the average of 10 individual fish and their max distance from the predator zone at that specific time. The max distance per fish was normalized to body length in $\mathrm{cm}$ to control for differences in fish size. This graph shows that there was no statistically significant difference between the maximum distance from the copper-contaminated fish to the predator zone and the maximum distance from the control fish to the predator zone. Treatment $(\mathrm{F}=2.16 ; \mathrm{DF}=1$; $\mathrm{P}>0.05)$ and time were not significant $(\mathrm{F}=1.30 ; \mathrm{DF}=1 ; \mathrm{P}>0.05)$. The shaded areas represent the standard deviation of the data. 


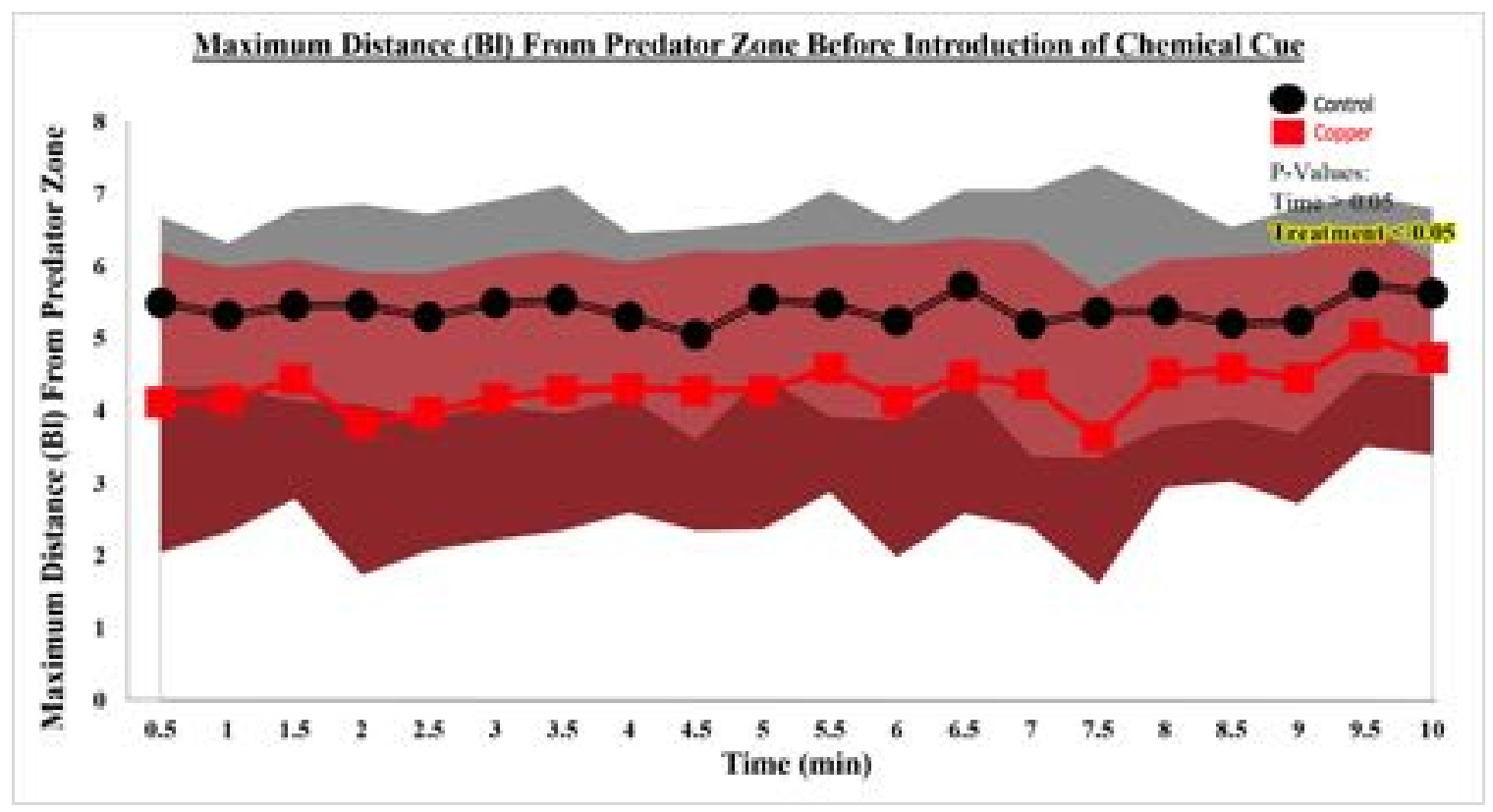

Figure 41A. Max Distance (BI) from Predator Zone Before Introduction of

Chemical Cue. Before the introduction of the chemical cue (predator kairomones) both groups were left to acclimate for 10 minutes. During these 10 minutes, every 30 seconds data points were recorded. Every point in this graph represents the average of 10 individual fish and their max distance from the predator zone at that specific time. The max distance per fish was normalized to body length in $\mathrm{cm}$ to control for differences in fish size. This graph shows copper-contaminated fish were at a shorter distance than the control from the predator zone before the introduction of the chemical cue. Treatment $(\mathrm{F}=47.32 ; \mathrm{DF}=1 ; \mathrm{P}<0.05)$ and time were not significant $(\mathrm{F}=1.36 ; \mathrm{DF}=1 ; \mathrm{P}>0.05)$. The shaded areas represent the standard deviation of the data. 


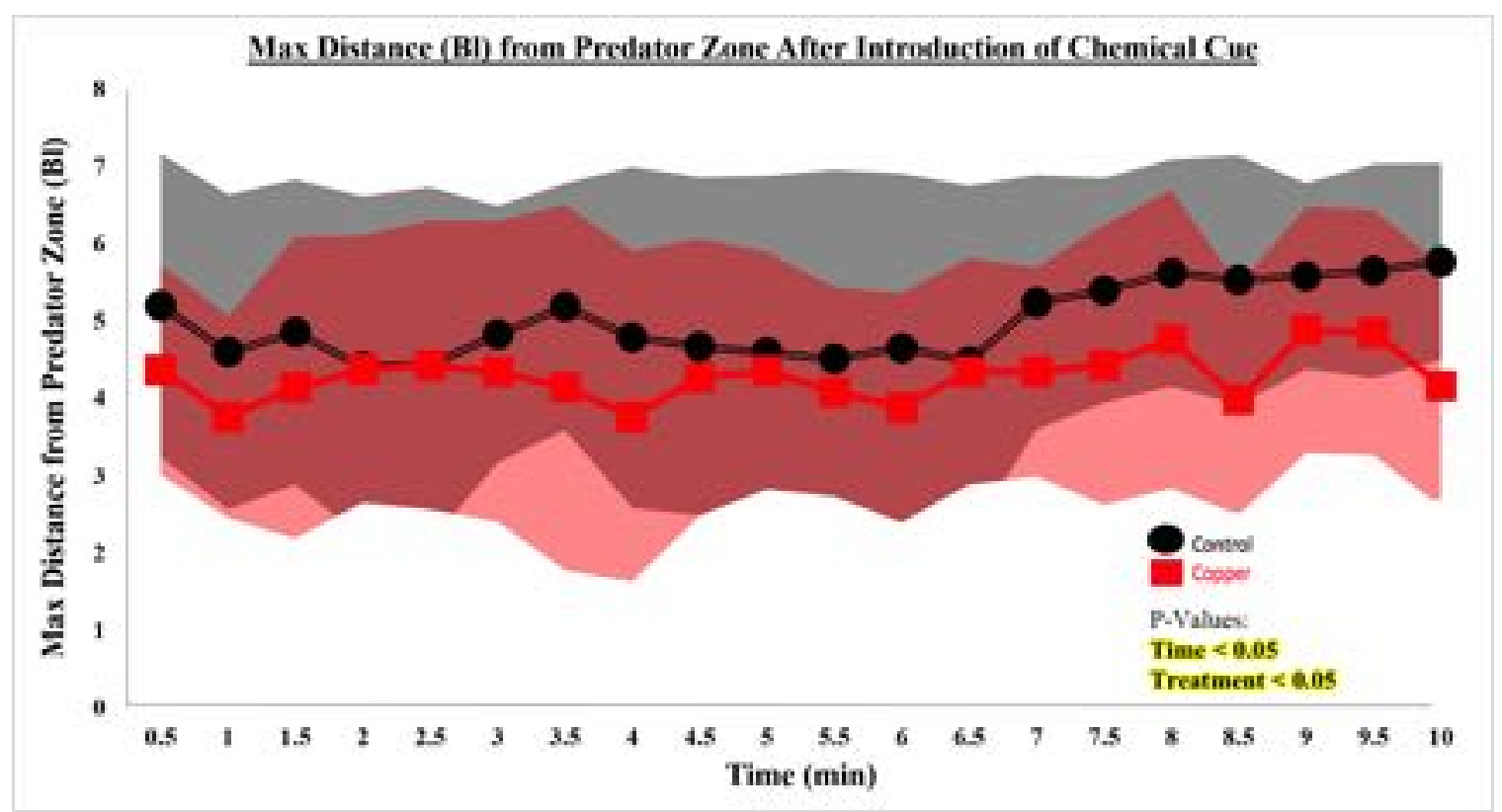

Figure 41B. Max Distance (BI) from Predator Zone After Introduction of Chemical Cue. After the introduction of the chemical cue (predator kairomones) data was recorded every 30 seconds for 10 minutes. Every point in this graph represents the average of 10 individual fish and their max distance from the predator zone at that specific time. The max distance per fish was normalized to body length in $\mathrm{cm}$ to control for differences in fish size. This graph shows copper-contaminated fish were at a shorter distance than the control from the predator zone before the introduction of the chemical cue. Treatment $(\mathrm{F}=16.22 ; \mathrm{DF}=1 ; \mathrm{P}<0.05)$ and time were not significant $(\mathrm{F}=5.93 ; \mathrm{DF}=1 ; \mathrm{P}<0.05)$. The shaded areas represent the standard deviation of the data. 


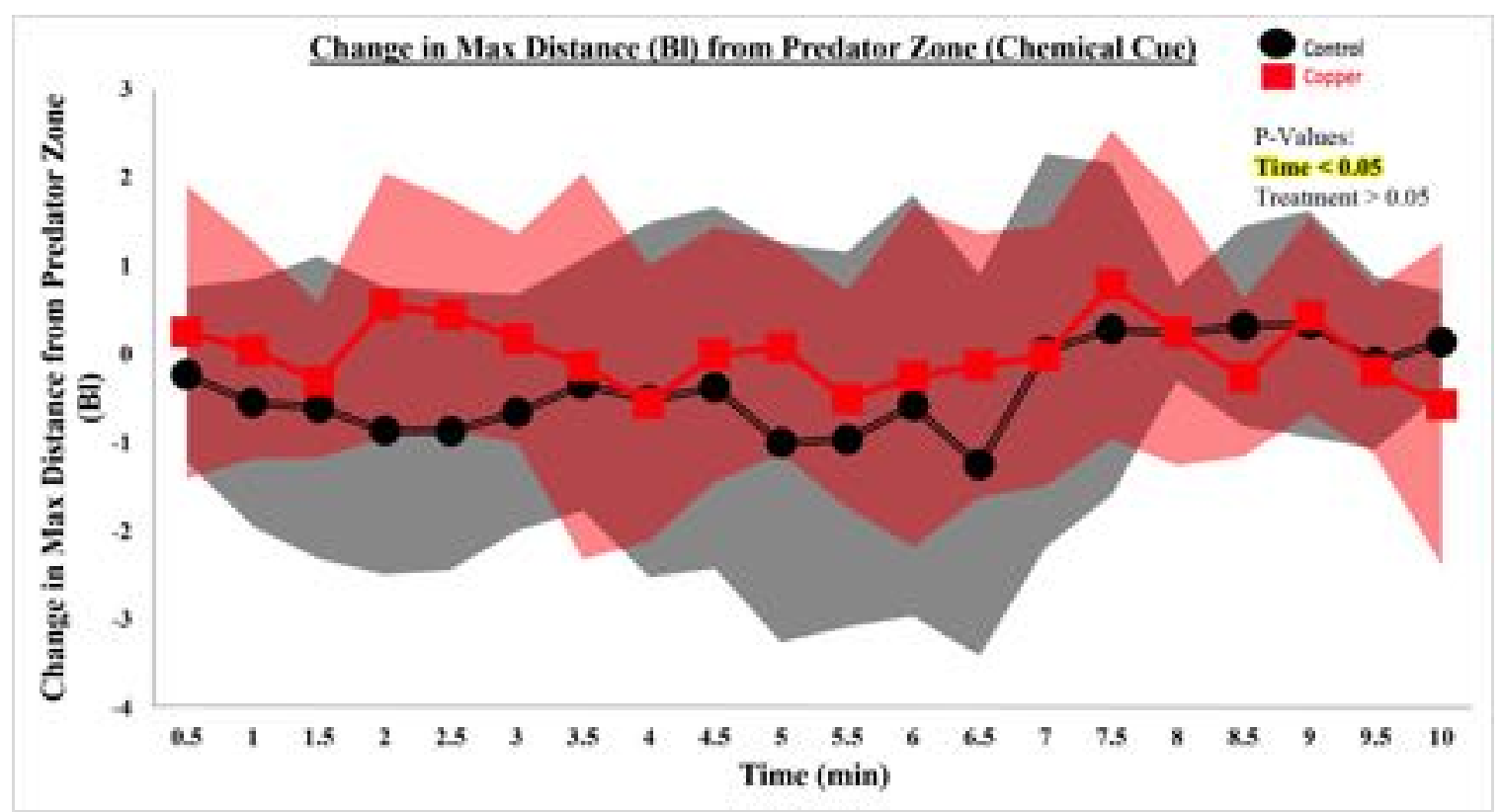

Figure 41C. Change in Max Distance (BI) from Predator Zone (Chemical Cue). After the experiment, the change in max distance from predator zone was calculated by subtracting the data from trial one from the data in trial two. Every point in this graph represents the average of 10 individual fish and their max distance from the predator zone at that specific time. The max distance per fish was normalized to body length in $\mathrm{cm}$ to control for differences in fish size. This graph shows that there was no statistically significant difference between the maximum distance from the copper-contaminated fish to the predator zone and the maximum distance from the control fish to the predator zone. Treatment was not significant $(\mathrm{F}=0.01 ; \mathrm{DF}=1 ; \mathrm{P}>0.05)$ but time was $(\mathrm{F}=4.06 \mathrm{DF}=1$; $\mathrm{P}>0.05)$. The shaded areas represent the standard deviation of the data. 


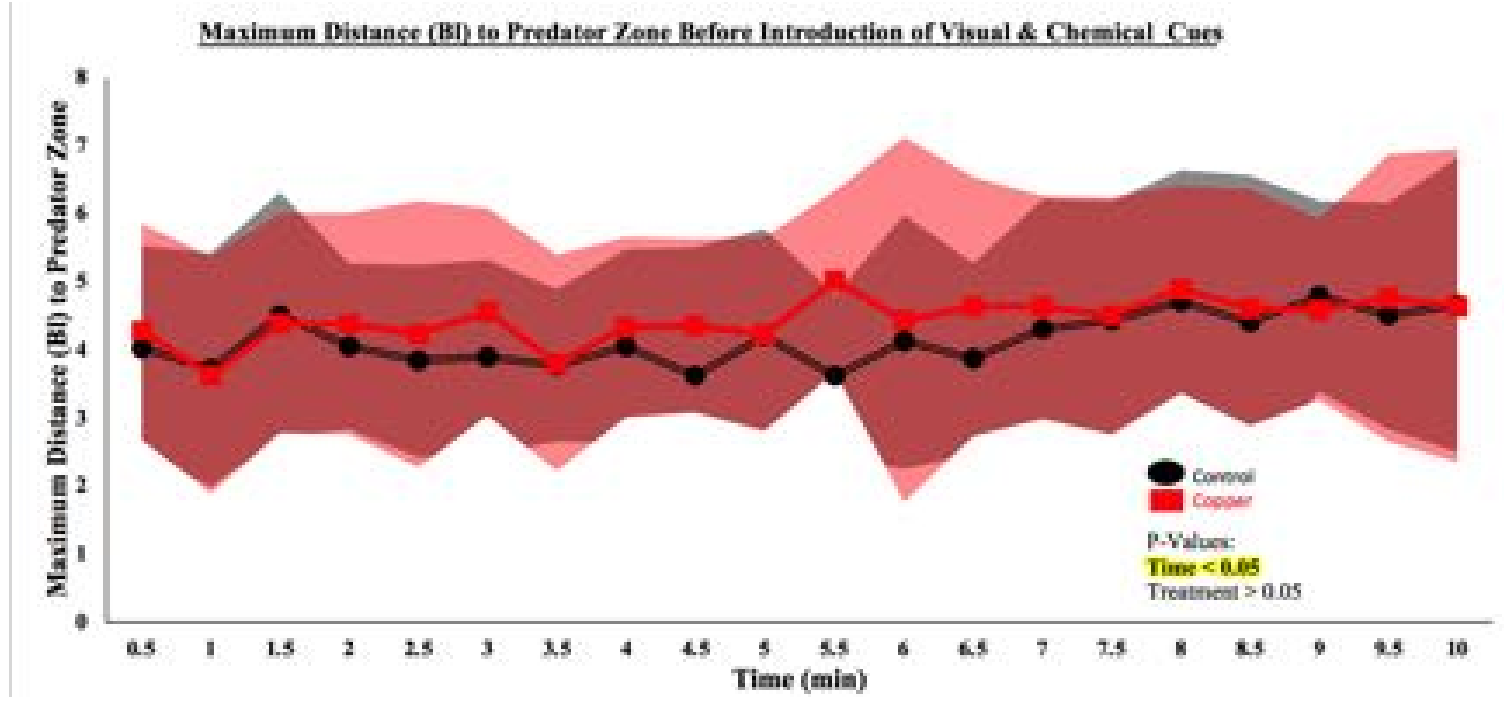

Figure 42A. Max Distance (Bl) from Predator Zone Before Introduction of Visual \& Chemical Cue. Before the introduction of the cues (predator model \& predator kairomones) both groups were left to acclimate for 10 minutes. During these 10 minutes, every 30 seconds data points were recorded. Every point in this graph represents the average of 10 individual fish and their max distance from the predator zone at that specific time. The max distance per fish was normalized to body length in $\mathrm{cm}$ to control for differences in fish size. This graph shows time had an effect on the maximum distance fish were from the predator zone before the introduction of cues. Treatment $(\mathrm{F}=2.58$; $\mathrm{DF}=1 ; \mathrm{P}>0.05)$ and time were not significant $(\mathrm{F}=5.81 ; \mathrm{DF}=1 ; \mathrm{P}<0.05)$. The shaded areas represent the standard deviation of the data. 


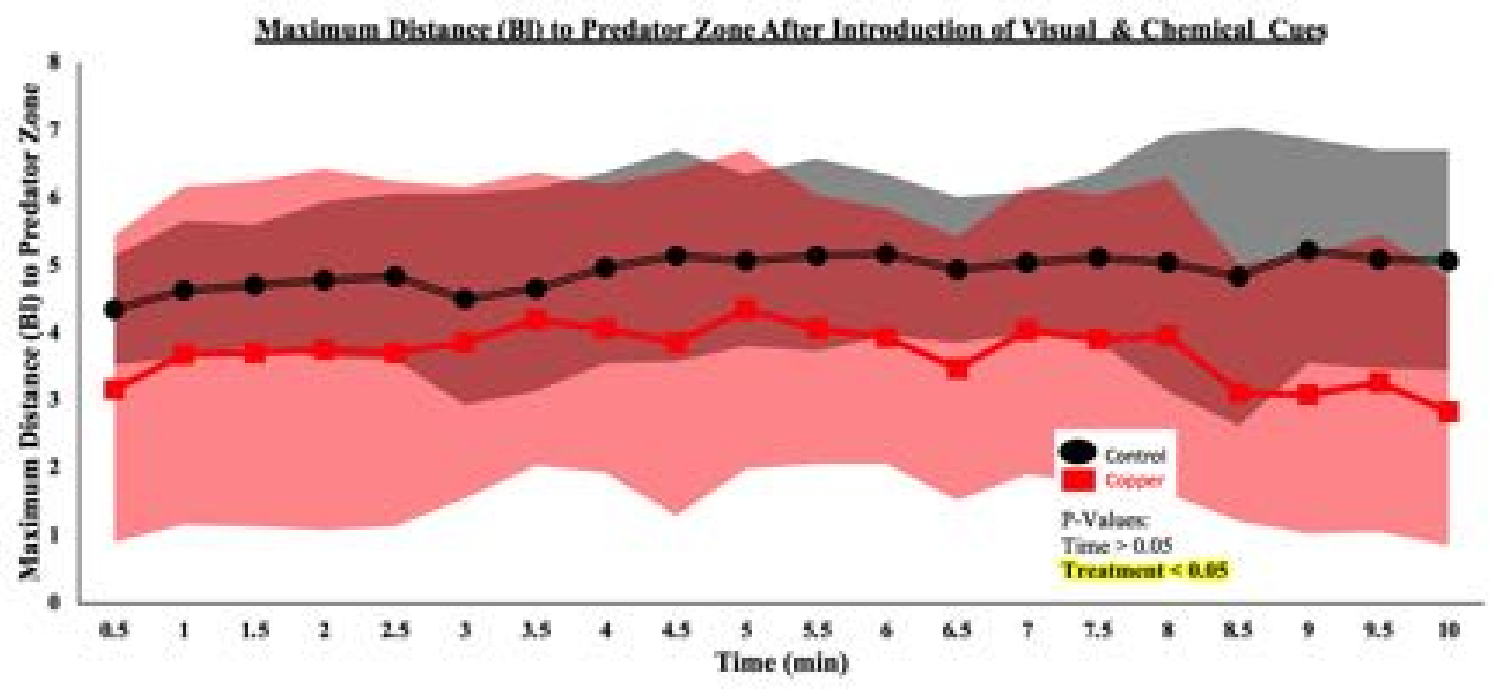

Figure 42B. Max Distance (BI) from Predator Zone After Introduction of Visual \&

Chemical Cue. After the introduction of the cues (predator model \& predator

kairomones). Data was recorded for 10 minutes. During these 10 minutes, every 30

seconds data points were recorded. Every point in this graph represents the average of 10 individual fish and their max distance from the predator zone at that specific time. The max distance per fish was normalized to body length in $\mathrm{cm}$ to control for differences in fish size. This graph shows copper-contaminated fish were at a shorter distance than the control from the predator zone after the introduction of the cues. Treatment $(\mathrm{F}=35.84$; $\mathrm{DF}=1 ; \mathrm{P}<0.05)$ and time were not significant $(\mathrm{F}=0.18 ; \mathrm{DF}=1 ; \mathrm{P}>0.05)$. The shaded areas represent the standard deviation of the data. 


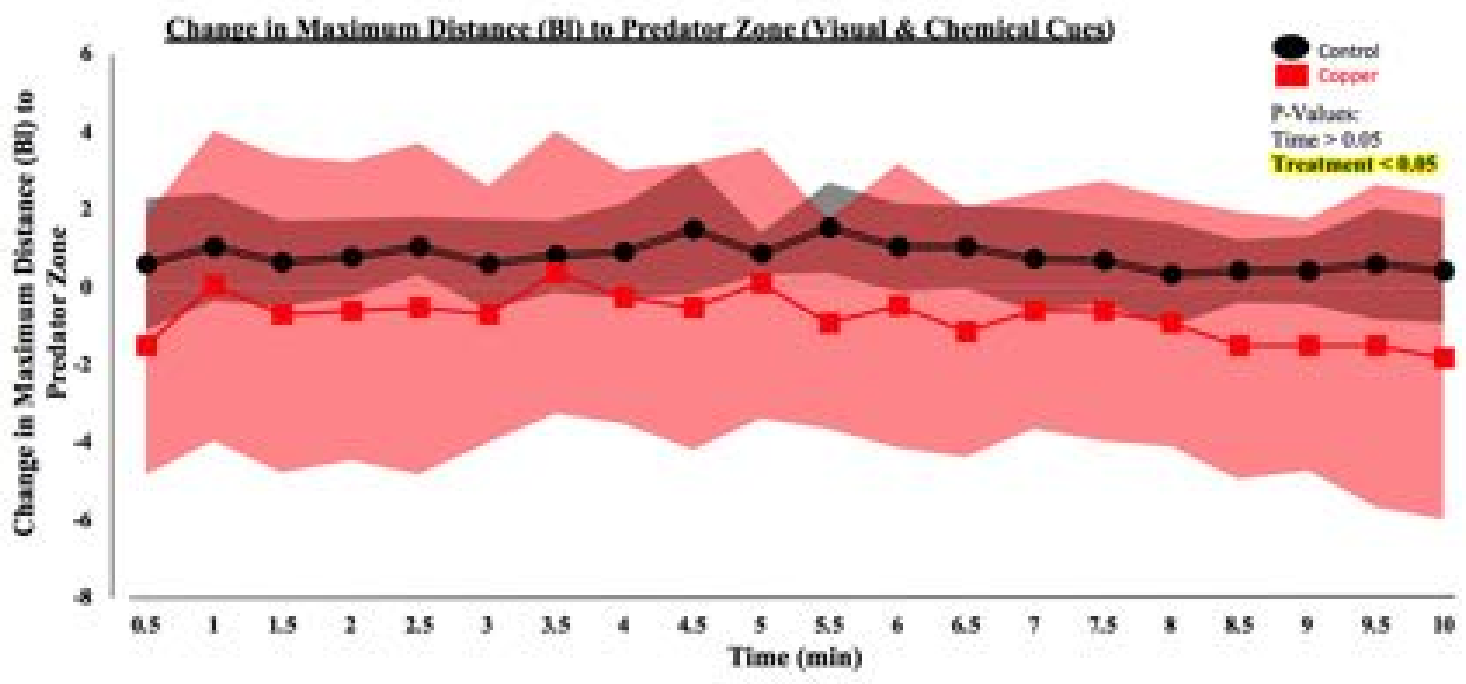

Figure 42C. Change in Max Distance (BI) from Predator Zone (Visual \& Chemical Cue). After the experiment, the change in maximum distance from the predator zone was calculated by subtracting the data from trial one from the data in trial two. Every point in this graph represents the average of 10 individual fish and their max distance from the predator zone at that specific time. The max distance per fish was normalized to body length in $\mathrm{cm}$ to control for differences in fish size. This graph shows coppercontaminated fish were at a shorter distance than the control from the predator zone before the introduction of the cues. Treatment was significant $(\mathrm{F}=33.06 ; \mathrm{DF}=1 ; \mathrm{P}<0.05)$ but time was not $(\mathrm{F}=0.18 ; \mathrm{DF}=1 ; \mathrm{P}>0.05)$. The shaded areas represent the standard deviation of the data. 




Figure 43A. Mean Distance (BI) from Predator Zone Before Introduction of Visual Cue. Before the introduction of the visual cue (predator model) both groups were left to acclimate for 10 minutes. During these 10 minutes, every 30 seconds data points were recorded. Every point in this graph represents the average of 10 individual fish and their mean distance from the predator zone at that specific time. The mean distance per fish was normalized to body length in $\mathrm{cm}$ to control for differences in fish size. This graph shows that there was no statistically significant difference between the mean distance from the copper-contaminated fish to the predator zone and the maximum distance from the control fish to the predator zone. Treatment $(\mathrm{F}=0.08 ; \mathrm{DF}=1 ; \mathrm{P}>0.05)$ and time were not significant $(\mathrm{F}=3.16 ; \mathrm{DF}=1 ; \mathrm{P}<0.05)$. The shaded areas represent the standard deviation of the data. 


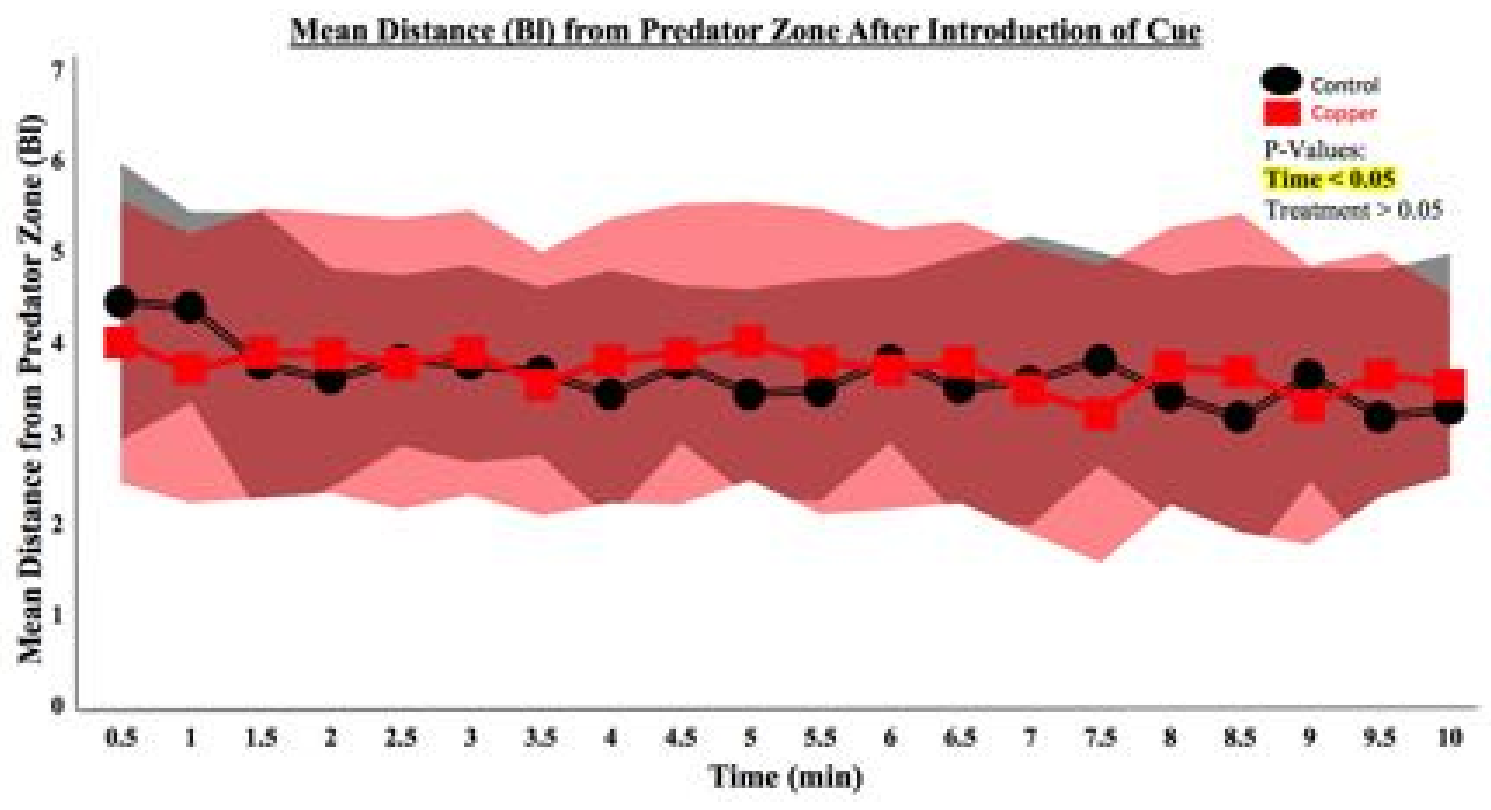

Figure 43B. Mean Distance (BI) from Predator Zone After Introduction of Visual

Cue. After the introduction of the visual cue (predator model) data was recorded every 30 seconds for 10 minutes. Every point in this graph represents the average of 10 individual fish and their mean distance from the predator zone at that specific time. The mean distance per fish was normalized to body length in $\mathrm{cm}$ to control for differences in fish size. This graph shows that there was no statistically significant difference between the mean distance from the copper-contaminated fish to the predator zone and the maximum distance from the control fish to the predator zone. Time had an effect on the mean distance fish were from the predator zone after the introduction of cues. Treatment was not significant $(\mathrm{F}=0.12 ; \mathrm{DF}=1 ; \mathrm{P}=0.74)$ but time was significant $(\mathrm{F}=6.57 ; \mathrm{DF}=1$; $\mathrm{P}=0.01)$. The shaded areas represent the standard deviation of the data. 


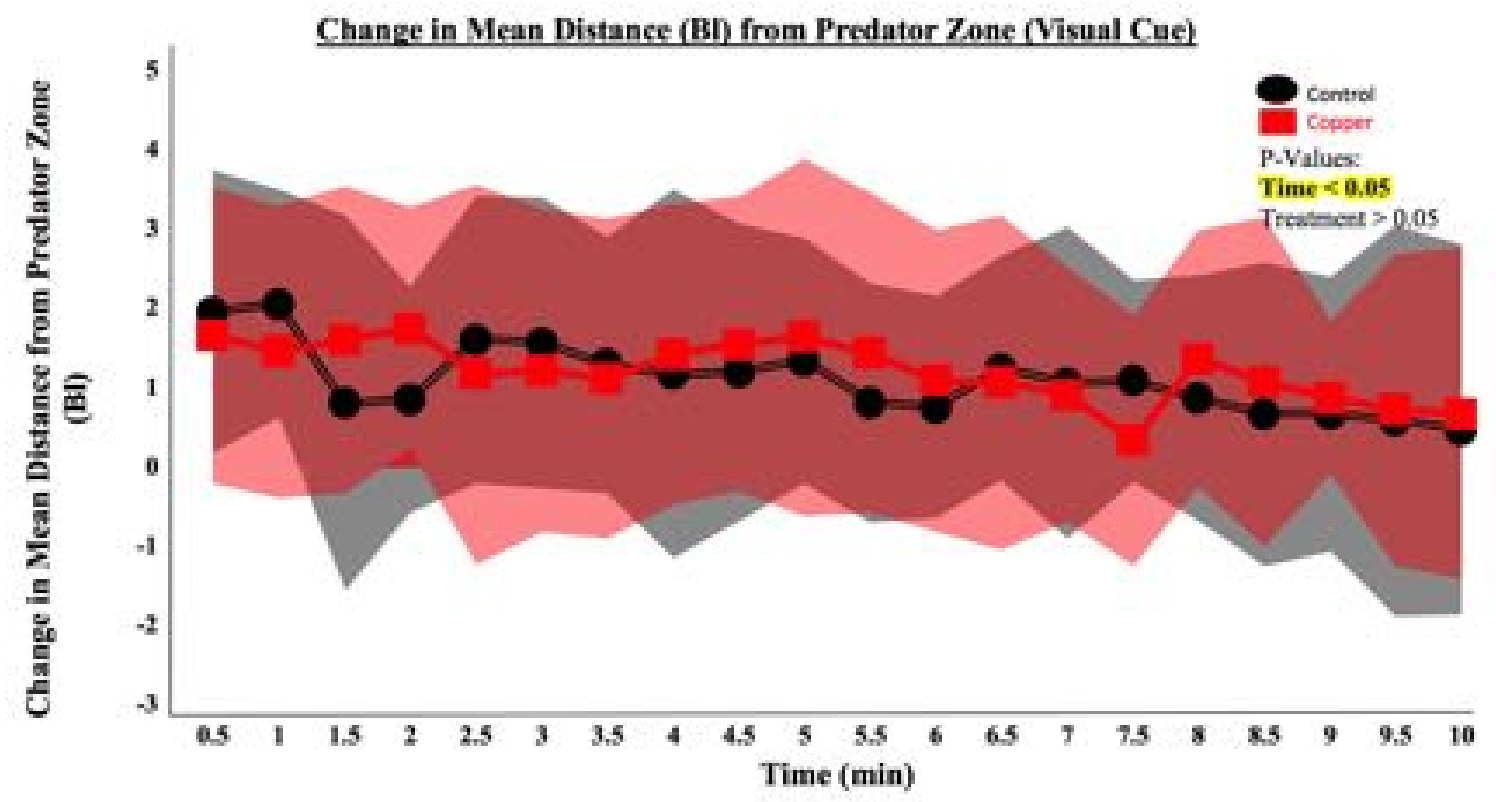

Figure 43C. Change in Mean Distance (Bl) from Predator Zone (Visual Cue). After the experiment, the change in mean distance was calculated by subtracting the data from trial one from the data from trial two. Every point in this graph represents the average of 10 individual fish and their mean distance from the predator zone at that specific time. The mean distance per fish was normalized to body length in $\mathrm{cm}$ to control for differences in fish size. This graph shows that there was no statistically significant difference between the mean distance from the copper-contaminated fish to the predator zone and the maximum distance from the control fish to the predator zone. Time had an effect on the mean distance fish were from the predator zone after the introduction of cues. Treatment $(\mathrm{F}=0.25 ; \mathrm{DF}=1 ; \mathrm{P}>0.05)$ and time were not significant $(\mathrm{F}=1.30 ; \mathrm{DF}=1$; $\mathrm{P}<0.05)$. The shaded areas represent the standard deviation of the data. 


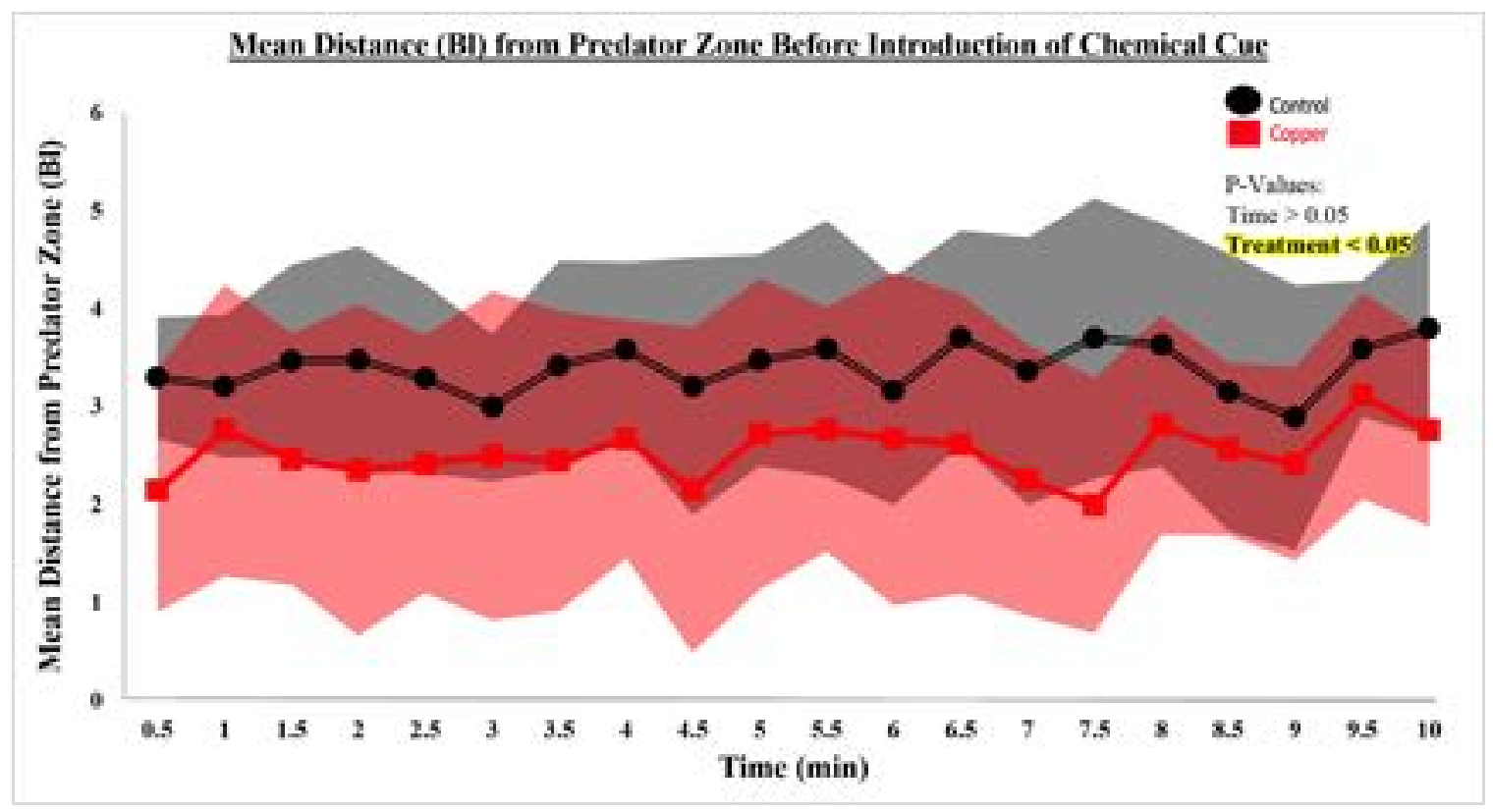

Figure 44A. Mean Distance (BI) from Predator Zone Before Introduction of

Chemical Cue. Before the introduction of the chemical cue (predator kairomones) both groups were left to acclimate for 10 minutes. During these 10 minutes, every 30 seconds data points were recorded. Every point in this graph represents the average of 10 individual fish and their mean distance from the predator zone at that specific time. The mean distance per fish was normalized to body length in $\mathrm{cm}$ to control for differences in fish size. This graph shows copper-contaminated fish were at a shorter distance than the control from the predator zone before the introduction of the chemical cue. Treatment was significant $(\mathrm{F}=51.64 ; \mathrm{DF}=1 ; \mathrm{P}<0.05)$ but time was not $(\mathrm{F}=1.38 ; \mathrm{DF}=1 ; \mathrm{P}>0.05)$. The shaded areas represent the standard deviation of the data. 


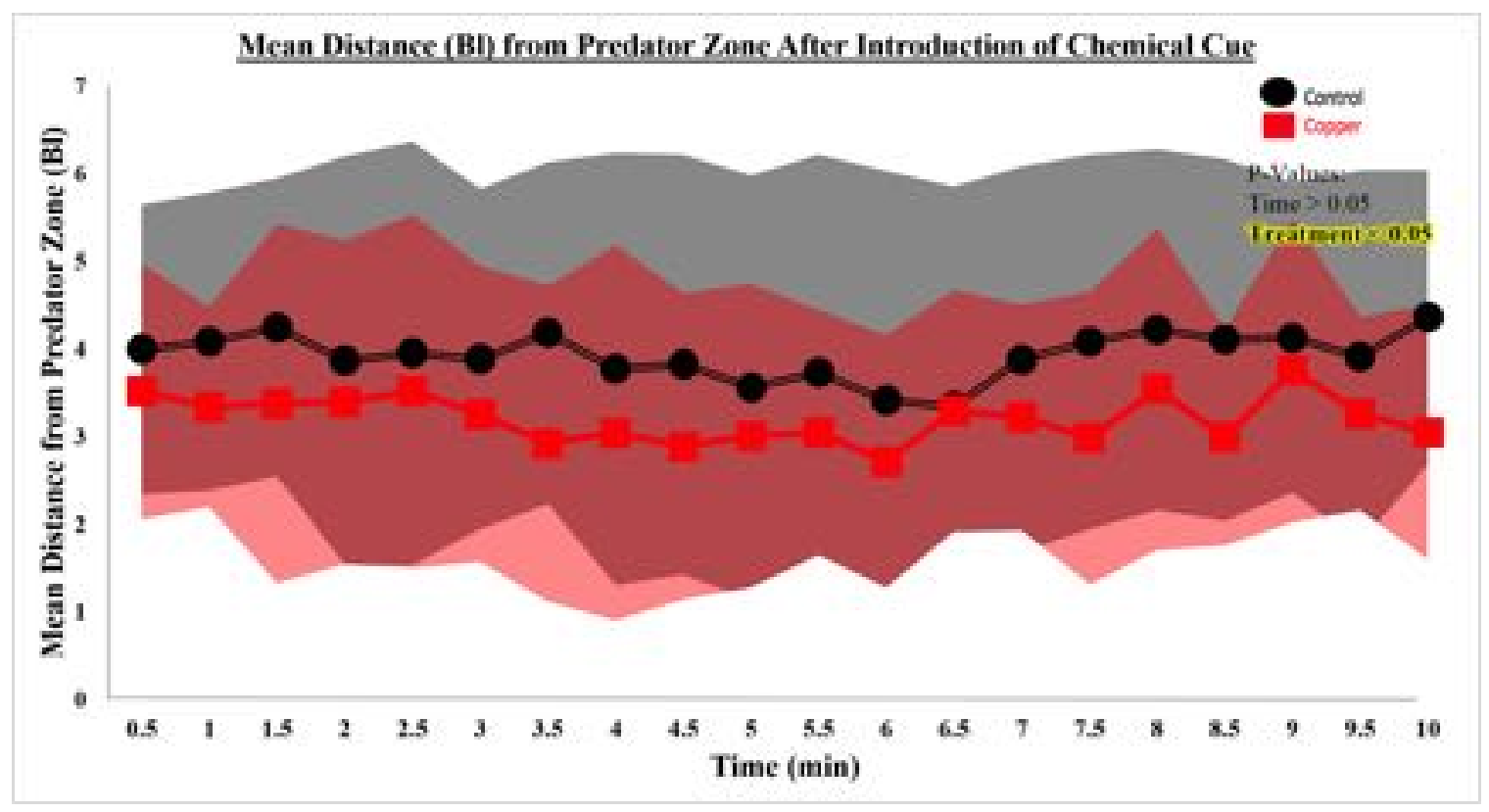

Figure 44B. Mean Distance (BI) from Predator Zone After Introduction of Chemical Cue. After the introduction of the chemical cue (predator kairomones) data was recorded every 30 seconds for 10 minutes. Every point in this graph represents the average of 10 individual fish and their mean distance from the predator zone at that specific time. The mean distance per fish was normalized to body length in $\mathrm{cm}$ to control for differences in fish size. This graph shows that copper-contaminated fish were at a shorter distance than the control from the predator zone after the introduction of the chemical cue. Treatment was significant $(\mathrm{F}=15.17 ; \mathrm{DF}=1 ; \mathrm{P}<0.05)$ but time was not $(\mathrm{F}=0.01 ; \mathrm{DF}=1 ; \mathrm{P}>0.05)$. The shaded areas represent the standard deviation of the data. 


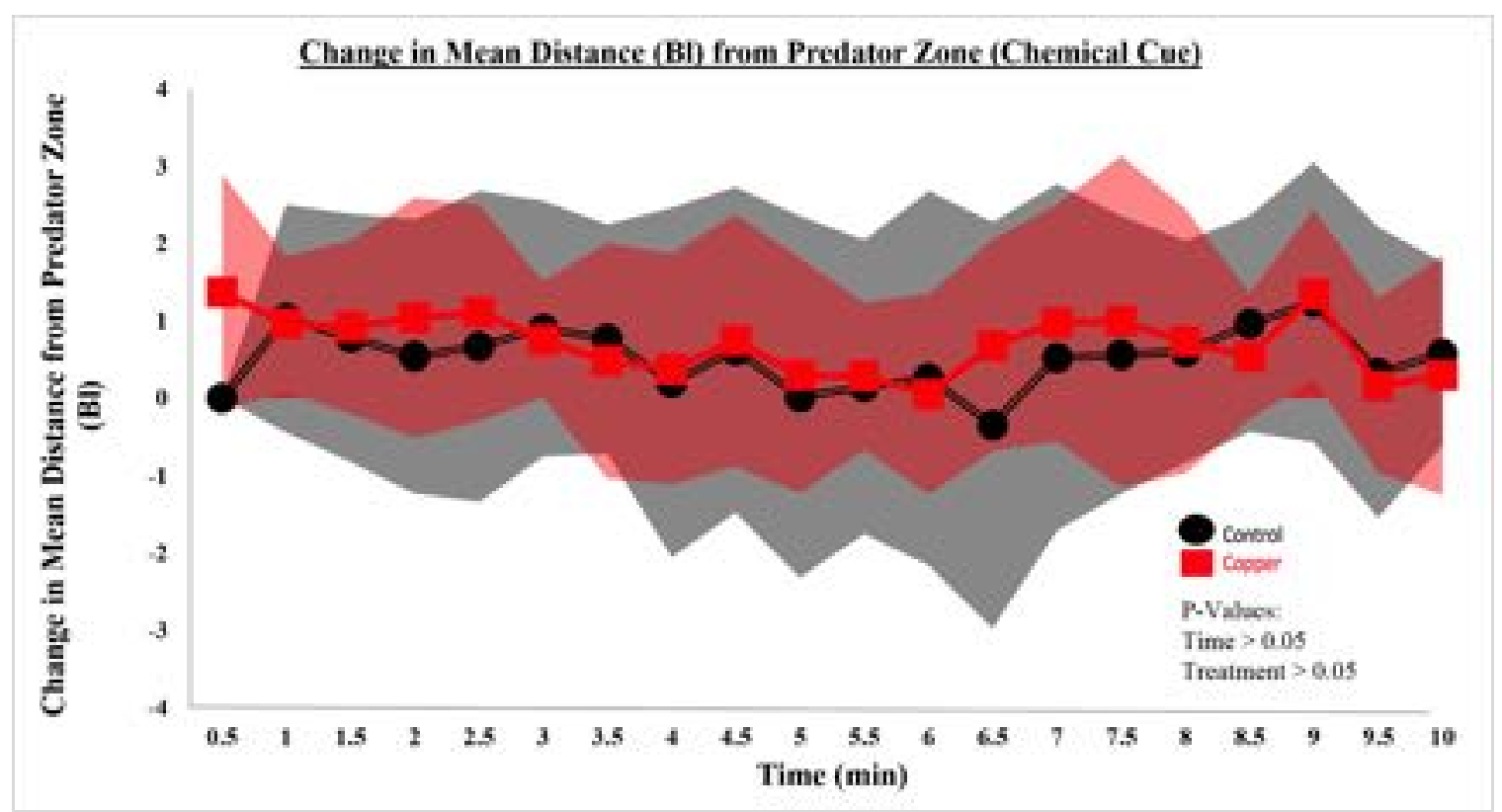

Figure 44C. Change in Mean Distance (BI) from Predator Zone (Chemical Cue). After the experiment, the change in mean distance was calculated by subtracting the data from trial one from the data from trial two. Every point in this graph represents the average of 10 individual fish and their mean distance from the predator zone at that specific time. The mean distance per fish was normalized to body length in $\mathrm{cm}$ to control for differences in fish size. This graph shows that there was no statistically significant difference between the mean distance from the copper-contaminated fish to the predator zone and the mean distance from the control fish to the predator zone. Treatment $(\mathrm{F}=0.11 ; \mathrm{DF}=1 ; \mathrm{P}>0.05)$ and time were not significant $(\mathrm{F}=0.95 ; \mathrm{DF}=1 ; \mathrm{P}>0.05)$. The shaded areas represent the standard deviation of the data. 


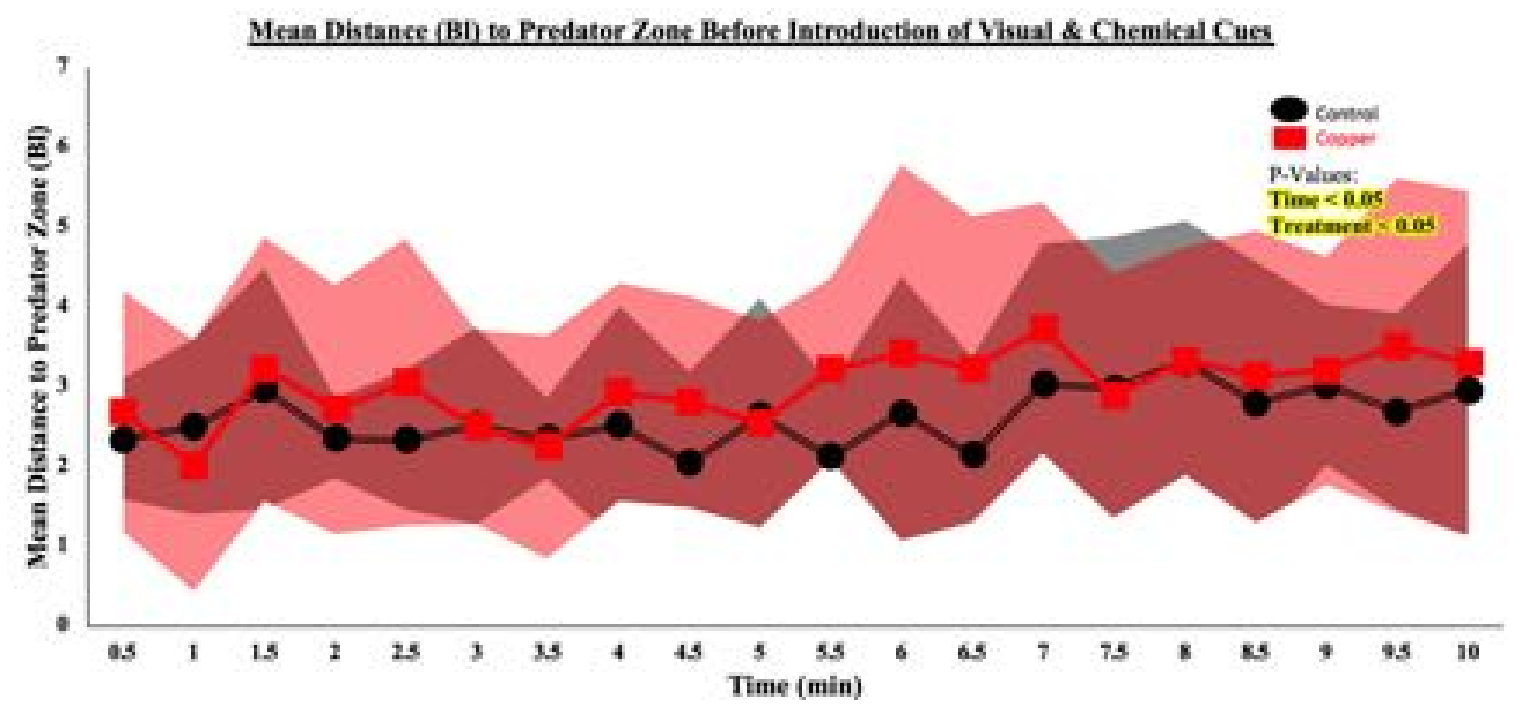

Figure 45A. Mean Distance (BI) from Predator Zone Before Introduction of Visual

\& Chemical Cue. Before the introduction of the visual \& chemical cue (predator model + predator kairomones) both groups were left to acclimate for 10 minutes. During these 10 minutes, every 30 seconds data points were recorded. Every point in this graph represents the average of 10 individual fish and their mean distance from the predator zone at that specific time. The mean distance per fish was normalized to body length in $\mathrm{cm}$ to control for differences in fish size. This graph shows that independently, treatment and time had an effect on the mean distance fish were from the predator zone. Treatment $(\mathrm{F}=5.20 ; \mathrm{DF}=1 ; \mathrm{P}<0.05)$ and time were significant $(\mathrm{F}=7.72 ; \mathrm{DF}=1 ; \mathrm{P}<0.05)$. The shaded areas represent the standard deviation of the data. 


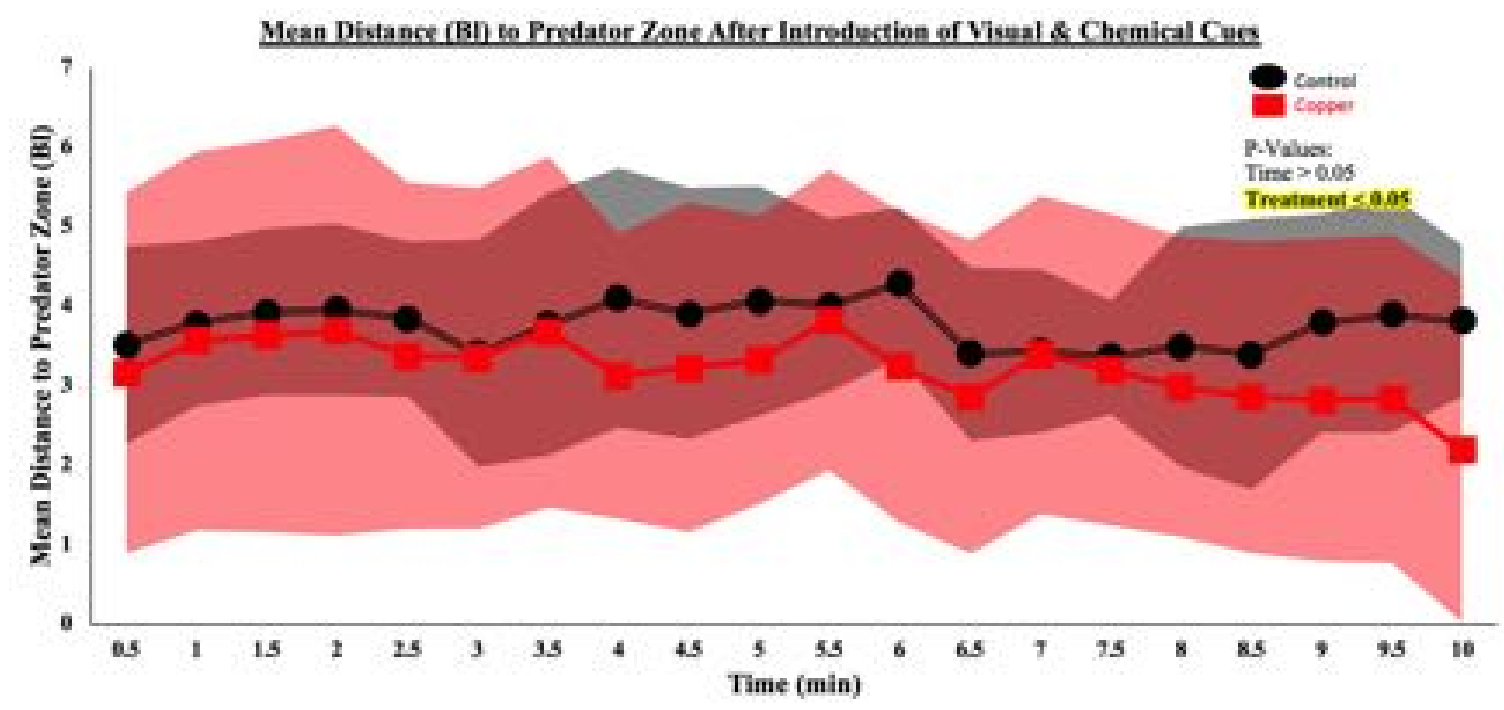

Figure 45B. Mean Distance (BI) from Predator Zone After Introduction of Visual \& Chemical Cue. After the introduction of the visual \& chemical cues (predator model + predator model) data was recorded every 30 seconds for 10 minutes. Every point in this graph represents the average of 10 individual fish and their mean distance from the predator zone at that specific time. The mean distance per fish was normalized to body length in $\mathrm{cm}$ to control for differences in fish size. This graph shows that coppercontaminated fish were closer to the predator zone than the control after introduction of the cues. Treatment was significant $(\mathrm{F}=8.68 ; \mathrm{DF}=1 ; \mathrm{P}<0.05)$ but time was not $(\mathrm{F}=3.30$; $\mathrm{DF}=1 ; \mathrm{P}>0.05)$. The shaded areas represent the standard deviation of the data. 


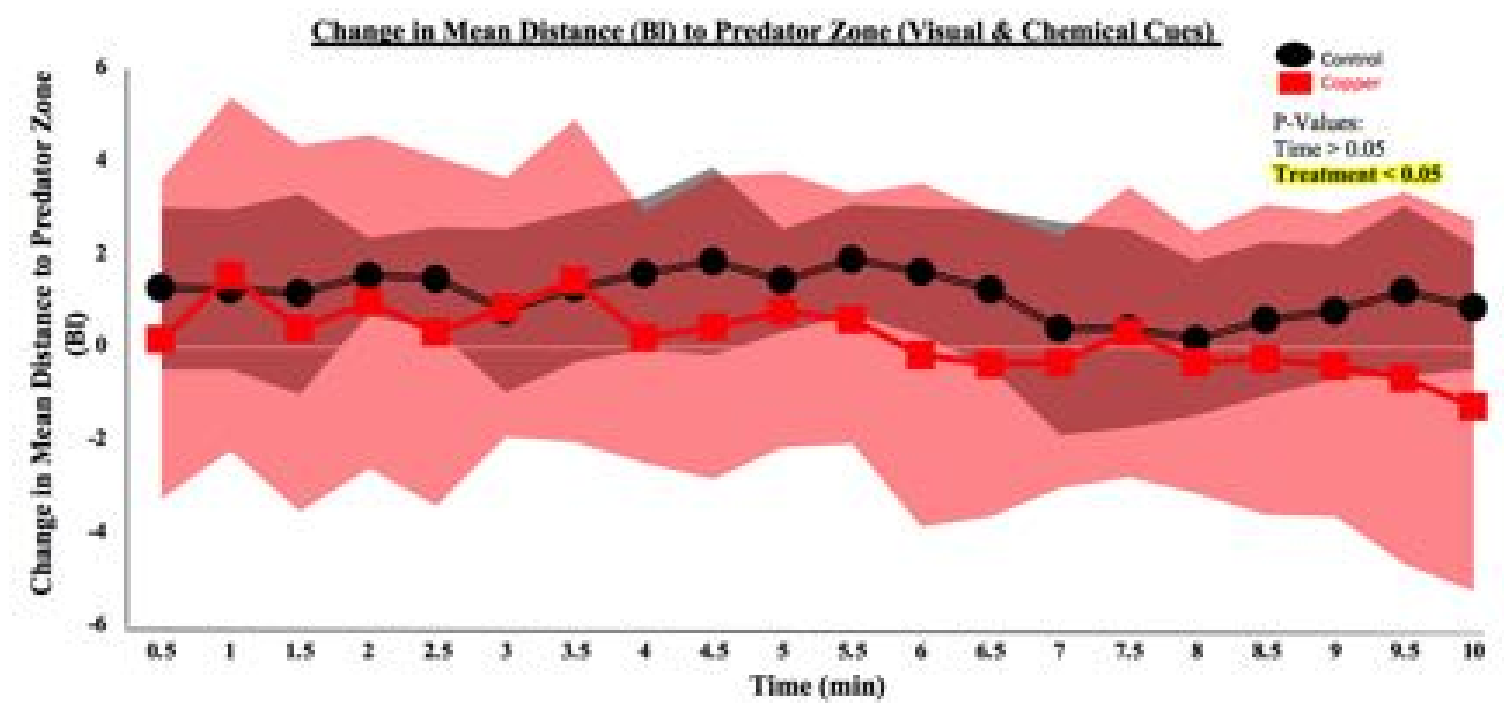

Figure 45C. Change in Mean Distance (Bl) from Predator Zone (Visual \& Chemical

Cue). After the experiment, the changes in mean distance was calculated by subtracting the data from trial one from the data from trial two. Every point in this graph represents the average of 10 individual fish and their mean distance from the predator zone at that specific time. The mean distance per fish was normalized to body length in $\mathrm{cm}$ to control for differences in fish size. This graph shows that copper contaminated fish were closer to the predator zone than control fish in response to the introduction of the cues. Treatment was significant $(\mathrm{F}=5.21 ; \mathrm{DF}=1 ; \mathrm{P}<0.05)$ but time was not $(\mathrm{F}=0.97 ; \mathrm{DF}=1 ; \mathrm{P}>0.05)$. The shaded areas represent the standard deviation of the data. 